Peter Faulstich

\title{
Aufklärung, Wissenschaft und lebensentfaltende Bildung
}

Geschichte und Gegenwart einer großen Hoffnung der Moderne 
Peter Faulstich

Aufklärung, Wissenschaft und lebensentfaltende Bildung

Theorie Bilden | Band 25 


\section{Editorial}

Die Universität ist traditionell der hervorragende Ort für Theoriebildung. Ohne diese können weder Forschung noch Lehre ihre Funktionen und die in sie gesetzten gesellschaftlichen Erwartungen erfüllen. Zwischen Theorie, wissenschaftlicher Forschung und universitärer Bildung besteht ein unlösbares Band. Auf diesen Zusammenhang soll die Schriftenreihe Theorie Bilden wieder aufmerksam machen in einer Zeit, in der Effizienz- und Verwertungsimperative wissenschaftliche Bildung auf ein Bescheidwissen zu reduzieren drohen und in der theoretisch ausgerichtete Erkenntnis- und Forschungsinteressen durch praktische oder technische Nützlichkeitsforderungen zunehmend delegitimiert werden. Der Zusammenhang von Theorie und Bildung ist in besonderem Maße für die Erziehungswissenschaft von Bedeutung, da Bildung nicht nur einer ihrer zentralen theoretischen Gegenstände, sondern zugleich auch eine ihrer praktischen Aufgaben ist. In ihr verbindet sich daher die Bildung von Theorien mit der Aufgabe, die Studierenden zur Theoriebildung zu befähigen.

Die Reihe Theorie Bilden ist ein Forum für theoretisch ausgerichtete Ergebnisse aus Forschung und Lehre, die das Profil des Faches Erziehungswissenschaft, seine bildungstheoretische Besonderheit im Schnittfeld zu den Fachdidaktiken, aber auch transdisziplinäre Ansätze dokumentieren.

Die Reihe wird herausgegeben von Hannelore Faulstich-Wieland, HansChristoph Koller, Karl-Josef Pazzini und Michael Wimmer, im Auftrag des Fachbereichs Erziehungswissenschaft der Universität Hamburg. 
Peter Faulstich

\section{Aufklärung, Wissenschaft und lebensentfaltende Bildung}

Geschichte und Gegenwart einer großen Hoffnung der Moderne 
Gefördert von der Deutschen Gesellschaft für wissenschaftliche Weiterbildung und Fernstudium (DGWF).

Die freie Verfügbarkeit der E-Book-Ausgabe dieser Publikation wurde ermöglicht durch das Bundesinstitut für Berufsbildung (BIBB), Stabsstelle »Publikationen und wissenschaftliche Informationsdienste

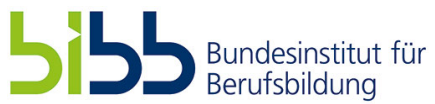

\section{Bibliografische Information der Deutschen Nationalbibliothek}

Die Deutsche Nationalbibliothek verzeichnet diese Publikation in der Deutschen Nationalbibliografie; detaillierte bibliografische Daten sind im Internet über http://dnb.d-nb.de abrufbar.

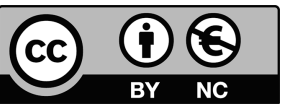

Dieses Werk ist lizenziert unter der Creative Commons Attribution-Non-Commercial 4.० Lizenz (BY-NC). Diese Lizenz erlaubt unter Voraussetzung der Namensnennung des Urhebers die Bearbeitung, Vervielfältigung und Verbreitung des Materials in jedem Format oder Medium ausschliesslich für nicht-kommerzielle Zwecke. (Lizenztext: https://creativecommons.org/licenses/by-nc/4.o/deed.de)

Um Genehmigungen für die Wiederverwendung zu kommerziellen Zwecken einzuholen, wenden Sie sich bitte an rights@transcript-verlag.de

Die Bedingungen der Creative-Commons-Lizenz gelten nur für Originalmaterial. Die Wiederverwendung von Material aus anderen Quellen (gekennzeichnet mit Quellenangabe) wie z.B. Schaubilder, Abbildungen, Fotos und Textauszüge erfordert ggf. weitere Nutzungsgenehmigungen durch den jeweiligen Rechteinhaber.

\section{(C) 2011 transcript Verlag, Bielefeld}

Umschlagkonzept: Kordula Röckenhaus, Bielefeld

Lektorat: Peter Faulstich

Satz: Justine Haida, Bielefeld

Druck: Majuskel Medienproduktion GmbH, Wetzlar

Print-ISBN 978-3-8376-1816-7

PDF-ISBN 978-3-8394-1816-1

https://doi.org/10.14361/9783839418161

Gedruckt auf alterungsbeständigem Papier mit chlorfrei gebleichtem Zellstoff. Besuchen Sie uns im Internet: https://www.transcript-verlag.de Unsere aktuelle Vorschau finden Sie unter www.transcript-verlag.de/vorschaudownload 


\section{Inhalt}

\section{Vorwort | 7}

\section{Vorbemerkung | 9}

\section{Aufklärung als Epoche $\mid 15$}

1.1 Fragen an die »Aufklärung « $\mid 16$

1.2 Wissenschaft und Aufklärung | 19

1.3 Gesellschaftsordnung und Volksaufklärung |30

1.4 Träger der Aufklärung | 34

1.5 Aufklärung als Reform | 41

1.6 Aufklärung als Horizont | 44

1.7 Aufklärung als Fiktion | 50

1.8 Probleme mit der Aufklärung | 54

1.9 Weiterwirkende Tendenzen | 57

2. Prinzipien der Aufklärung | $6_{1}$

2.1 Vernunft und Herrschaft $\mid 6_{3}$

2.2 Öffentlichkeit und Wissenschaft $\mid 82$

2.3 Wissen der Welt $\mid 88$

2.4 Wissen und Glauben $\mid 97$

2.5 Schauspiel der Freiheit $\mid 107$

2.6 Völker der Welt | 112

2.7 Volksaufklärung ohne Volk | 124

2.8 Verbreitung der Aufklärung | 129

2.9 Aufklärung und Bildung | 143

3. Perspektiven der Aufklärung | 151

3.1 Aufklärung und Wissenschaft | 151

3.2 Aufklärung und Erwachsenenbildung | 157

3.3 Tendenzen und Perspektiven $\mid 168$ 
4. Personenindex $\mid 177$

5. Abbildungsverzeichnis $\mid 181$

6. Literaturverzeichnis $\mid 185$ 


\section{Vorwort}

Aufklärung durch Wissenschaft war und ist die große Hoffnung der Moderne. Historisch verdankt diese Idee ihren Ursprung dem Wissenschaftsenthusiasmus des 17. und 18. Jahrhunderts. Wissenschaftshistorische Symbolgestalt ist Isaak Newton, der mit seiner Grundlegung der Mechanik die Erwartung beflügelte, dass durch wissenschaftliche Forschung langfristig der Weg zur umfassenden Erkenntnis der Welt gebahnt sei. Wissenschaft soll die Irrtümer, die Täuschungen und den Aberglauben durchschauen und auflösen, durch die der Blick auf die Welt verstellt und verzerrt ist.

Allerdings wurden die Rahmenbedingungen dafür, dass Wissen Macht sei, wenig geklärt. Weder wurde der Begriff des Wissens in der Herrschaftsdimension hinreichend differenziert und problematisiert, noch die gesellschaftlichen Machtkonstellationen und -strukturen aufgedeckt, die ein Umschlagen von Aufklärung in Verdummung und Unterwerfung möglich machen.

So konnte es geschehen, dass sich die dunkle Seite der Aufklärung ausbreitete - davon spricht auch die »Dialektik der Aufklärung«. Ein verkürzter Rationalismus erzeugte gleichzeitig vielfältige Irrationalitäten. Der grelle Schein des Lichtes einer szientifischen Wissenschaft trieb die Gespenster, Hexen und Zauberer in die Dunkelheit. Dort aber beharrten sie auf ihrem Reich und betreiben immer wieder Ausfälle, die die nur scheinbar sicheren Grenzen wissenschaftlicher Erkenntnis gefährden.

Insofern können wir heute nicht mehr ungebrochen am Fortschrittsglauben früher Aufklärung festhalten. Wir haben gelernt, wie voraussetzungsvoll und heikel der Verlauf der Aufklärung sich fortsetzt. Auch wenn man der Diagnose eines Scheitern und des Umschlags nicht folgt, ist zumindest eine sich immer wieder erneuernde Vorläufigkeit des Prozesses der Aufklärung zu konstatieren. Es geht nicht einfach um eine Ausbreitung der Vernunft, sondern um eine Entwicklung der Urteilskraft, die die Resultate wissenschaftlicher Forschung im menschlichen Lebenszusammenhang beachtet - allen Irrationalitäten zum Trotz, die sich immer wieder einnisten.

Genau hier kann wissenschaftliche Weiterbildung ansetzen. Sicherlich geht es immer auch um die Vermittlung instrumenteller Kompetenzen und deren 
Anwendbarkeit. Aber eine reflektierte Strategie wissenschaftlicher Weiterbildung fördert auch reflexive Kompetenzen und Zusammenhangsdenken. Wenn man sich der Dichotomie von Wissenschaftseuphorie und Wissenschaftsskepsis entziehen will, braucht man Einsicht über Chancen und Limits wissenschaftlichen Denkens und in die Unverfügbarkeit menschlichen Lebens, das sich nie im Begriff auflöst.

Dieser Gedanke ist in den Debatten um »public understanding of research « - teils modernistisch gefasst - aufgenommen worden. Es geht dabei darum, wissenschaftliches Wissen nicht als fixierte Resultate hinzunehmen, sondern ihre Methoden und ihr - auch historisches - Vorgehen zu durchschauen, um die Folgen beurteilen zu können. Sicherlich ist dies eine anspruchsvolle Aufgabe. Aber in einer Gesellschaft, die für sich den Entwurf der Demokratie beansprucht, ist es zugleich eine unverzichtbare Aufgabe.

Die »Deutsche Gesellschaft für wissenschaftliche Weiterbildung und Fernstudium « (DGWF) hat selbst ihre Wurzeln in Bemühungen um eine »Öffnung der Hochschule«. Es soll die Möglichkeit geschaffen werden, gesellschaftlichen Gruppen, die nicht »normale Studierende« sind, den Zugang zur Wissenschaft zu erschließen. Dies erfordert zum einen neue Formate von Weiterbildungsangeboten bereitzustellen, die eine öffentliche Diskussion über wissenschaftliche Themen ermöglichen,

Zum andern und weitergehend muss die Diskussion um wissenschaftliche Weiterbildung sich ihrer theoretischen und historischen Fundamente vergewissern. Dies haben wir begonnen mit den beiden Texten zur »Öffentlichen Wissenschaft« und über die »Vermittler wissenschaftlichen Wissens«.

Der vorliegende Text greift das Verhältnis von Aufklärung, Bildung und Wissenschaft grundlegender auf und kontrastiert die Epochenprobleme der Aufklärung mit gegenwärtigen Debatten. Es zeigt sich ein Fortwirken der Fragen - in veränderter Form - bis heute. Insofern ist der Rückbezug zur Aufklärung berechtigt, als Aufgreifen unabgeschlossener, uneingelöster und unabgegoltener Hoffnungen auf eine Wissenschaft, die das Zusammenleben der Menschen befördert und zu entwickeln hilft.

Dr. Martin Beyersdorf

Vorsitzender der DGWF 


\section{Vorbemerkung}

Die Frage nach dem Stellenwert, der Bedeutsamkeit und den Perspektiven von Bildung - bzw. von Lernen besonders in der Erwachsenenbildung - im Verhältnis zur Wissenschaft und zur Aufklärung ist ein naheliegendes und ebenso ein schwieriges Thema. Obwohl es selbstverständlich erscheint, Lernen, Wissen und Aufklären dicht aneinanderzurücken, ist es auf den ersten Blick erstaunlich, dass Aufklärung in der Diskussion um lebensentfaltende Bildung keineswegs den unbezweifelten, hohen Stellenwert hat, der zu vermuten oder vielleicht zu erhoffen wäre.

Die etablierte Wissenschaft sperrt sich gegen »Popularisierung«, gegen Verständlichkeit und Zugänglichkeit für den »gemeinen Mann«, das »einfache Volk«, die »niederen Schichten«. Sie scheint der Exegese durch ihre Priester zu bedürfen und erhält dadurch erst Akzeptanz bei den Laien. Bei genauerem Hinsehen handelt es sich also um ein intensives, aber auch, wie oft bei Gemeinsamkeiten, um ein problematisches, gebrochenes und verschleiertes Dreiecksverhältnis. Die Ménage à trois ist von allen Seiten gefährdet durch die brüchigen Zweierbeziehungen von Aufklärung und Wissenschaft, von Wissenschaft und Bildung und auch von Aufklärung und Bildung.

Zu schnell wurde der Aufklärung kalte und flache Vernünftelei und Vergessenheit für tiefe Gefühle unterstellt. Hintergrund war ein Zurückschrecken vor einer angeblichen Unmenschlichkeit nur verstandesmäßigen, »kalten« Denkens. Schon der »Sturm und Drang« zeigte in Schillers Drama den Übergang von den »Libertinern« zu den »Räubern« als Angst vor unbeherrschbaren Folgen und in Goethes Werther zerbrach das Gefühl an der Starre der Verhältnisse. Die Romantiker suchten die »Blaue Blume«, nicht die Wahrheit. Der Vernunft wurde halbierte Instrumentalität unterstellt, Wissenschaft in szientifischen Engpässen gesehen; der Terror der Revolution wurde der Aufklärung angelastet. Romantik flüchtete in Innerlichkeit.

$\mathrm{Zu}$ schnell wurde der Popularisierung der Wissenschaften eine Absage erteilt. Nach dem kurzen Zwischenspiel der Popularphilosophie bei Thomasius, Garve u.a. zog sich der Wissenschaftsbetrieb wieder zurück in die Exklusivität der Experten. Schon Kants Äußerungen zum Popularitätsproblem sind zwie- 
spältig und seinen Anhängern war die Vorstellung einer verständlichen Einführung oder gar Übersetzung der »Kritik der reinen Vernunft« ein Gräuel.

Erstaunlicherweise bedient sich aber sogar hochgradig elaborierte Wissenschaftskritik einfacher, einprägsamer Bilder. Das Bild des »Elfenbeinturms « ist eines der schönsten - aber es war als vermeintlicher Ort der Abgeschiedenheit und Reinheit, von Einsamkeit und Freiheit immer schon schief: Eine absolute Autonomie von Wissenschaft hat es nie gegeben. Die Idee einer »öffentlichen Wissenschaft« wird erst gegenwärtig als Gegenstrom wieder stärker angesichts der Konsequenzen wild wuchernder ungebremster Forschungsaktivitäten.

Zu schnell hat sich Volksbildung nach dem Schock des Sturms auf die Bastille von »bloßer« »verstandesmäßiger « Kenntnisvermittlung abgewendet, wurde konservativ pazifiziert, liberal integriert und ist spätestens mit der »Neuen Richtung« vor, während und nach der Weimarer Republik auf die Suche nach dem »Eigentlichen« gegangen«. »Verbreitung der Volksbildung« wurde diffamiert und als »alte« mit der »Neuen Richtung « konfrontiert. Wilhelm Flitners »Laienbildung « steht für eine lebensphilosophisch intendierte, wissenschaftsskeptische Tendenz, die die hegemoniale Sicht auch in den ersten Jahren nach 1945 in Westdeutschland fortwirkend bestimmte.

Entsprechend finden sich offensive Bezüge zu den Ideen der Aufklärung selten. Man muss, um die Grundlagen des Aufklärungsgedankens in der Erwachsenenbildung zu rekonstruieren, zurückgreifen bis auf Traditionen der Arbeiterbildung und auf einige wenige Exponenten während der Weimarer Republik wie z.B. besonders Hermann Heller (1891-1933), als Exponenten der »Leibziger Richtung « der Erwachsenenbildung, und in den $1950 e r$ und $1960 e r$ Jahren wie z.B. Willy Strzelewicz (1905-1986) und Kurt Meissner (1925-2003), als zwei sehr unterschiedliche Personen, die Aufklärung und Erwachsenenbildung zusammengebracht haben: In den Resten der Arbeiterbildung schwellt der Funke weiter, der durch das Licht der kritischen Vernunft entzündet worden ist.

Immer noch gilt Aufklärung aber im dominanten Diskurs als platt und Popularität als niveaulos. Demgegenüber sollte verwiesen und erinnert werden an Immanuel Kants Idee »in weltbürgerlicher Absicht«: Aufklärung sei trotz »unterlaufendem Wahne und Grillen« ein großes Gut.

Die Ursprünge der »Aufklärung« finden sich in einem Epochenbegriff, der das 18. Jahrhundert umfasst, an dessen Anfang er überhaupt erst im Anschluss an Leibniz als Selbstbezeichnung einer geistigen Bewegung verbreitet wurde. Damals wurden die Grundlagen der Entwicklung der Moderne erweitert und mit dem Aufstieg der Vernunft gegen Irrglauben und Adelsherrschaft, gegen Kirche und Hof aufgedeckt. Ihren immer wieder zitierten Höhepunkt findet die Frage, was denn Aufklärung sei, dann fast schon am Ende des Jahrhunderts mit Kants Antwort von 1784.

Im historischen Prozess wurde »Aufklärung « dann zu einem Prinzipienbegriff, der die gesellschaftliche Bedeutung wissenschaftlicher Vernunft, poli- 
tischer Öffentlichkeit, sowie politischer, kultureller und zuletzt auch ökonomischer Partizipation stark macht. Damit waren auch die Beschränktheiten des Aufklärungsbegriffs auf »halbierte« Vernunft, begrenzte und medial verkehrte Öffentlichkeit unter Ausschluss des »Volkes« und auf politisches Wahlverhalten reduzierte Teilhabe neu zu diskutieren.

Es ist jedoch von Anfang an ein schädliches Missverständnis und eine böswillige Anklage, Aufklärung habe aus vollem Halse ein Loblied der nackten Vernunft angestimmt. Vielmehr war und ist die Abstraktion »Vernunft« immer schon für diese selbst problematisch, wenn sie nicht angemessen, d.h. kritisch durchdacht und verwendet wird. Und Emanzipation verkommt zur Worthülse, wenn sie nicht als unabschließbarer Prozess der Entdeckung des Möglichen im Bestehenden betrieben und Mündigkeit als »Leitziel« formalisiert und pädagogisiert wird.

Von den Anfängen der Aufklärung an gibt es eine subtile, gelegentlich sogar radikal skeptische Selbstkritik der Vernunft. Es haftet ihr die Diagnose des Vorläufigen, des Verdrehten, des Gescheiterten an. Zwar unterliefen immer auch szientifische Wissenschafts- und positivistische Wahrheitsbegriffe. Aber erst eine Kritik der »reinen Vernunft« und der »Urteilskraft« ist der von Anfang an angelegten »Dialektik der Aufklärung« entsprechend. Erst die Selbstkritik der Vernunftidee und pragmatistische Konzepte ermöglichen einen Ausweg aus dem Münchhausen Trilemma der Letztbegründungen - infiniter Regress, permanenter Zirkel, rigides Dogma - sich am eignen Schopf aus dem Sumpf zu ziehen. Sie hebt die Zentralprobleme der Aufklärung auf die Metaebene reflexiven Denkens. Keine Rede kann davon sein, dass die Aufklärung des 18. Jahrhunderts insgesamt einem abstrakten Verstandeskult oder einem fortschrittsfanatischen Rationalitätsglauben gehuldigt habe. Engführungen, Querschläger und Ausrutscher allerdings sind nicht zu leugnen.

Aufklärung bedeutete eine grundlegende Wandlung des Bewusstseins und des Verhaltens, welche unterschiedliche gesellschaftliche Gruppen im Laufe des 18. Jahrhunderts ergriff. Über die Vielfalt einzelner Impulse hinaus war es eine Veränderung des sozio-kulturellen Klimas und dessen Struktur, welche alle gesellschaftlichen Bereiche von der Technik der Dampf- und Werkzeugmaschinen Maudslays bis zur Musik Mozarts umfasste.

Aufklärung ist zuallererst ein Vorhaben der Kritik des unhinterfragt Üblichen und Verfestigten. Es geht darum, traditionelle Strukturen, realisiert im absolutistischen Staat, auf ihre Richtigkeit, Gültigkeit und Wahrheit oder sogar Schönheit zu befragen. Damit erfolgt auch eine Beurteilung bestehender Verhältnisse hinsichtlich ihrer Vernünftigkeit und zugleich ihrer Menschlichkeit. Kritik entsteht aus der Krise und treibt zugleich die Krise voran (Koselleck 1973). Dies gilt zunächst für das 18. Jahrhundert und die Krise von Ökonomie, Politik und Religion. Und es setzt sich fort bis ins 21. Jahrhundert. Rationale Kritik deckt die Krise auf und spitzt sie zu. 
Eine angemessene Diskussion beschränkt sich also nicht auf die Interpretation der Vergangenheit. Sie spürt die Wurzeln der Gegenwart auf und entwirft die möglichen Verzweigungen der Äste in der Zukunft. Deshalb müssen sowohl die historischen Konstellationen der Aufklärung betrachtet (Teil 1) als auch ihre systematischen Prinzipien (Teil 2) und weiterwirkenden Ansätze und perspektivischen Chancen (Teil 3) geklärt werden.

Dabei ist spätestens seit Ernst Blochs »Geist der Utopie« (1918) und seinem »Prinzip Hoffnung « (1954-1959) deutlich, dass Fortschritt keineswegs nur ein Weg zum immer Besseren sein muss, sondern dass ständig auch Stillstand und Rückfall möglich sind und stattfinden. Nichtsdestoweniger ist eine Erneuerung der Aufklärung gerade für eine wissenschaftsbezogene Weiterbildung unverzichtbar, die nicht nur Spielball je neuer Wendewellen bleiben will, sondern den Kurs in eine menschlichere Zukunft mit verfolgen will.

Angesichts des Spektrums der Probleme ist ein Scheitern des Projektes Aufklärung - und seiner Darstellung - immer möglich. Aber auch Schiffsbrüche öffnen - für die Überlebenden - neue Seestraßen. In Deutschland wird seit dreihundert Jahren über Aufklärung diskutiert, seit mehr als zweihundert Jahren über Volksbildung, seit mehr als hundert Jahren über wissenschaftliche Weiterbildung. Diese Debatte gilt es fortzusetzen, ihre Erfahrungen aufzuarbeiten und ihren Kurs immer wieder neu zu bestimmen. Es geht darum, auf hoher See, nachdem der sichere Hafen verlassen und das Schiff gesunken ist, aus den empor schießenden Planken und Trümmern ein Floß zusammenzuzimmern, das weiter trägt. Bildung, Aufklärung und Wissenschaft sind für die Weiterfahrt die wichtigsten Antriebe. Für die Diskussion um die Ausweitung des Lernens auf alle Lebensalter und über vielfältige Lernorte bleibt das Prinzip der Aufklärung unverzichtbar mit der Intention lebensentfaltender Bildung verknüpft.

Die Suche nach einem Kurs zur Beseitigung von Ausbeutung und Unterdrückung wird oft einerseits als Gefahr, anderseits als Halbheit diffamiert. Eine Verteidigung der Aufklärung muss eine Zweifrontenabwehr sichern: Zum einen gegen den immer schon selbstgewissen Konservativismus, der ihr alle Missstände anlastet, die seit Beginn des Kapitalismus über die Welt gekommen sind; zum andern gegen einen Progressismus, der ihre Rückbindung an bestehende Herrschaftsverhältnisse kritizistisch aufdeckt.

Es mag sein, dass man beim Versuch einer Rehabilitierung der Aufklärung in ein unserer »coolen « und oft zynischen Zeit unangemessenes Pathos verfällt. Dazu zu stehen, ist sicherlich auch Ausdruck eigenen Engagements. Und indem dies so formuliert wird, kann es sein, dass dies auch wieder pathetisch wirkt. Die Flucht in die Formel gilt es mit Ironie zu tragen.

Eine Hauptschwierigkeit einer angemessenen Darstellung ist die Selektion aus der Überfülle des Materials über Aufklärung. Das gilt auch, wenn der Fokus auf Deutschland liegt und damit nur ein Ausschnitt einer europäischen Bewegung betrachtet wird. Die Präsentation soll deshalb dicht an dem roten Faden 
bleiben: Lebensentfaltende Bildung und der Stellenwert der Wissenschaft. Dies ist ein Problem, dessen Grundzüge schon in der Periode der Aufklärung gezeichnet wurden. Hier hat sich eine gesellschaftliche Struktur herausgebildet, die das Feld moderner Wissenschaft aufspannte. Der Übergang von Schriftdeutung zu Erfahrungsbezug war wesentliche Voraussetzung für den Siegeszug des technologisch orientierten Wissenschaftsbetriebs, der gegenwärtige Lebensverhältnisse vom Fernrohr bis zum Mikroskop, vom Automobil bis zum Kühlschrank bis ins Detail fixiert.

Der Transfer wissenschaftlicher Resultate in technische Systeme hat zahlreiche intermediäre Institutionen entstehen lassen, die ihre Funktion in der Vermittlung zwischen wissenschaftlichem Forschen und technischem Anwenden finden. Um zu verhindern, dass sich dieser Wissenschaftstransfer in bloßer Instrumentalität erschöpft, kommt es auf die Reflexion seiner Aktivitäten an, die bis zu den im 17. und 18. Jahrhundert als Transferinstitutionen entstandenen Akademien zurück zu verfolgen und über die Innovationsberatungsstellen voran zu treiben ist. Die Perspektiven der Kontakt-, Zentral- und Transferstellen für Wissenschaft und Weiterbildung sind nur verständlich, wenn man sie auf ihre lange Tradition zurückführt und so erst ihre Strukturen und auch Instabilitäten $\mathrm{zu}$ begreifen lernt. Damit ist auch die Hoffnung verbunden, ihre Leistungen aus instrumenteller Enge herauszuführen und wissenschaftliches Wissen zu prüfen hinsichtlich seines Beitrags zu identitätsbegründender, lebensorientierter Bildung. 



\section{Aufklärung als Epoche}

Die Fragen, die sich heute an die »Aufklärung « stellen (1.1), werden nicht durch ein nur historisches Interesse angestoßen. Sie richten sich auf Tendenzen aus einer Vergangenheit, die in Zukunft weiter wirkt. Zweifellos liefert die Vielfalt geschichtlicher Konstellationen, die das 18. Jahrhundert rahmten, spannende, sogar aufregende Impulse zur Klärung eigener Positionen. Neue Begriffe von Wissenschaft und Herrschaft, von Wissen und Macht können sich hier rückversichern. Aber um weiter von Emanzipation und Demokratie zu reden, braucht man auch eine neue Basis, die nach dreihundert Jahren weiter trägt.

Betrachtet wird im Verhältnis von Wissenschaft und lebensentfaltender Bildung ein Handlungsfeld, das nach verbreiteter Ansicht immer wichtiger werden wird: Es geht um die gesellschaftliche Produktion von Wissen und dessen individuelle Aneignung (1.2). Wissenschaft und Aufklärung sind dabei untrennbar verbunden. Wissenschaftstransfer wurde - unter anderem Namen - bereits zur Grundlage kameralistischer Wirtschaftpolitik. Der praktische Gebrauch der Vernunft, den schon die Frühaufklärer betrieben, stieß neue Impulse der Technologie an, wurde aber zugleich bei ihren besten Vertretern kritisch reflektiert.

Strittig ist, wie weit Aufklärung gehen kann und soll und wen sie erreicht. Schon bei den ersten Debatten um Volksaufklärung und Bildung (1.3) wurde gewarnt vor dem gebildeten Bauer, der sich über das Buch beugt, während sein Korn verfault. Solche offensichtlich den Interessen von Herrschaft geschuldeten Polemiken und Pamphlete wurden ergänzt durch die Frage, ob es denn überhaupt möglich sei, allen alles zugänglich zu machen.

Und: Welche Medien, Personen und Organisationen sind geeignet und berechtig als Träger der Aufklärung aufzutreten? Hat nicht Aufklärung unausweichlich patrimonale Implikationen? Wen erreichten die Volksschriften? Und welche Ideologien verbreiteten die Prediger, Publizisten und Gelehrten? (1.4).

Wenn Aufklärung Kritik bestehender, bisher unhinterfragter Zustände betreibt, enthält sie auch immer schon gesellschaftsverändernde Ideen. Aufklärung als Reform (1.5) scheut oft selbst zurück vor der Reichweite des Umbruchs. Die Horizonte werden deshalb eingeengt, um nicht von aktuellen Problemen eingeholt und überrollt zu werden (1.6). Die Französische Revolution 1789 trieb das 
Bürgertum wieder zurück in die Obhut der Obrigkeiten. Das Leiden an bestehenden Zuständen verführt in die bessere Welt der Fiktion und in Individualismus (1.7). Die Weltflucht der Romantik ist in der Aufklärung ebenfalls schon angelegt, wenn sie der Enge instrumenteller Vernunft unterworfen und Menschlichkeit abstrakten, manchmal noch nachwirkenden religiösen Prinzipien geopfert wird.

So bestehen von Anfang an Probleme mit der Aufklärung (1.8), die sich fortsetzten. Weiterwirkende Tendenzen (1.9) beunruhigen bis heute. Kant-von dem öfters die Rede sein wird - warnt in den »Ideen« vor einem »arkadischen Schäferleben, bei vollkommener Eintracht, Genügsamkeit und Wechselliebe« (Kant 1969, XI, 38).

Solche Widersprüche erzeugen die Dynamik der Gesellschaftsentwicklung. Wir arbeiten an den Spannungsverhältnissen (2.) von Vernunft und Herrschaft, von Wissen und Welt, von Wissen und Glauben, von Realität und Fiktion inszeniert als Schauspiel der Freiheit, von Universalismus und Partikularismus zwischen den Kulturen, von Selektivität und Elite und von Aufklärung und Bildung.

Das alles fließt zusammen im Dreieckverhältnis populärer Wissenschaft, reflektierter Aufklärung und lebensentfaltender Bildung. Auch diese immer auch emotional hoch aufgeladene Beziehung kann aufgeklärt werden - zumindest hinsichtlich Intentionen und Selbstverständnis (1.1), Themen und Wissenschaftsbezug (1.2), der Sozialstrukturen (1.3) und Konstellation der Akteure (1.4) sowie ihrer Intensität und Reichweite (1.5). Macht begrenzt die Horizonte (1.6) und setzt sich fort als Zwang individueller Biographie (1.7). Es werden allerdings immer auch neue Probleme und dunkle Seiten auftauchen (1.8), weil die Perspektiven und Entwicklungen (1.9 und 3.) unsicher und unklar bleiben müssen.

\subsection{Fragen AN die "AUfKLÄrUng"}

Die Frage danach, was unter Aufklärung zu verstehen sei, steht schon am Anfang der Debatte. Sie konkretisiert sich in den Problemen ihrer Themen, ihrer Adressaten, ihrer Institutionen, ihrer Grenzen und ihrer Weiterwirkung. Die Frage »Was ist Aufklärung?«, die 1783 in den »Berlinischen Monatsschriften« gestellt wurde, ist eine zutiefst aufklärerische, indem sie kritische Reflexion auf sich selbst richtet.

Zunächst geht es um Kritik. Bestehende Herrschafts- und Wissensordnungen werden in Frage gestellt. Das kritische Prinzip lässt nichts unbefragt und selbstverständlich gelten. Alte Machtverhältnisse und Glaubensbekenntnisse brechen auf. Die Vernunft erzeugt eine neue Wissenschaft, die an die Stelle scholastischer Exegese logische Stringenz und empirische Analyse setzt. Zunächst der Rationalismus und in der nächsten Welle der Empirismus untergruben die Gültigkeit einer immer wieder erneuerten Auslegung der Schriften. Sie fragen radikal nach Begründung und nach Erfahrung.

Ursprünglich ging es um die Aufklärung der »Gebildeten« und später erst um das »Volk«. Die Begriffe haben sich verschoben. »Volksaufklärung« war zunächst 
der älteste Begriff, wenn es darum ging, Wissen nicht nur den »gebildeten Schichten«, sondern auch dem »gemeinen Mann« verfügbar zu machen. Die Terminologie hat dann gewechselt über Volksbildung, Arbeiterbildung, Erwachsenenbildung, Weiterbildung bis zum »Lebenslangen Lernen« bzw. - um den Zwangsweg der »Immer-weiter-Bildung « zu verlassen, zu lebensentfaltender Bildung.

Auch der Gegenstand der Aufklärung selbst ist in seinen Bedeutungsgehalten verwandelt. Fragt man heute, was denn Aufklärung sei, denken die meisten wohl nicht an Kant und seinen zitierfreundlichen Aufklärungsimperativ »Habe den Mut Dich Deines eigenen Verstandes zu bedienen!«, sondern an Sexualität. Beim Zugriff auf Google erhält man etwa 6.000.000 Ergebnisse für »Aufklärung« (Zugriff 01.02.2011). Diese umfassen philosophische, gesundheitliche, sexuelle, politische und militärische Aufklärung. Insofern ist es notwendig, sich vorab der Begriffsinhalte zu vergewissern.

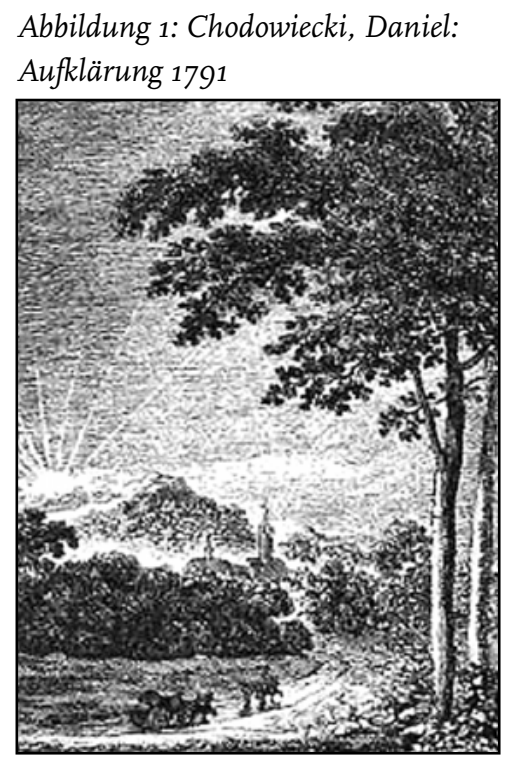

Aufklärung war zunächst ein Kampfbegriff, der sich gegen Aberglauben, Vorurteile und Schwärmerei richtete. Die erklärte Absicht war, nichts für wahr zu halten, als das, was der Prüfung durch Vernunft und Erfahrung standhält. Diese liefern die Gründe, Wahrheiten anzunehmen und in der öffentlichen Diskussion zu vertreten. Nur so sei ein Fortschreiten zu »wahrer« Aufklärung möglich. Wahrheit musste sich in der Abwägung und im Gespräch durchsetzten und von den Beteiligten akzeptiert werden. Wissenschaftsresultate entstehen als Konsens einer Diskursgemeinschaft.

Die Fahrt der Aufklärung wurde gezeichnet aus dem Tal der Dunkelheit zu den Höhen des Lichts - so in einer Radierung von Daniel Chodowiecki (1726-1801), 
die zahlreiche Buchdeckel schmückte. Mit der Licht-Metapher wurde schon von den Vertretern der Aufklärung selbst gespielt: Assoziationen reichen von Entfachen des Feuers durch einige Funken, vom Verglimmen einer trüben Funsel, dem Strahlen der Sonne bis zur Kerze in der Nacht und der aufsteigenden Morgenröte.

Insofern wird mit »Aufklärung « zunächst eine kritische Intention bezeichnet, die in der Periode zwischen dem Ende des 17. und dem Beginn des 19. Jahrhunderts verortbar ist. Es ging um erweiterten Zugang zum Wissen für alle, oder zumindest für viele. Insofern setzt Aufklärung Bemühungen voraus, die wesentlich früher liegen. Es gab eine sophistische, eine hellenistische, und dann eine frühbürgerliche Aufklärung in der Renaissance. Nichtsdestoweniger kumulieren die verschiedenen Stränge im 18. Jahrhundert und es lassen sich drei symbolische Daten und damit drei spezifische Tendenzen nennen (Schneiders 1997, 16): In England ist eine politische Aufklärung markant geknüpft an den Sieg der »Glorious Revolution« von 1688, in Frankreich erfolgte mit der Aufhebung des Edikts von Nantes 1685 ein Einschnitt, der religiöse Aufklärung provozierte; die Einführung der deutschen Sprache in seiner Vorlesung an der Universität Leipzig durch Thomasius 1687 hat eine weitgehende kulturelle Reform angestoßen. Während in Frankreich die Mauern der Herrschaft wortwörtlich durch Schleifung der Bastille eingerissen wurden, wurden in Deutschland die alten Festungen der Macht - errichtet durch Religion und Feudalismus gründlich gedanklich untergraben durch die Fragen nach ihrer Legitimation und Rationalität (Reed 2009, 16). Klöster und Paläste aber blieben unangetastet.

Die Daten belegen auch, dass Aufklärung die verschiedensten gesellschaftlichen Bereiche umfasst und von religiöser Befreiung bis hin zu technischen Erfindungen geht.

Abbildung 2: Einige Daten zum Umfeld der Aufklärung

\begin{tabular}{|lll|}
\hline Wissenschaft & Newton & $1643-1727$ \\
Technologie & Spinnmaschine & 1763 \\
Ökonomie & Adam Smith & $1723-1790$ \\
Medien & Monatsgespräche & 1688 \\
& The Spectator & 1711 \\
Politik & Glorious Revolution & 1688 \\
& Französische Revolution & 1789 \\
Religion & Aufhebung des Edikts & \\
& von Nantes & 1688 \\
Kunst & Voltaire & $1694-1778$ \\
& Hogarth & $1697-1764$ \\
Bildung & Chodowiecki & $1726-1801$ \\
Philosophie & Campe & $1746-1818$ \\
& Diderot & $1713-1784$ \\
& Kant & $1724-1804$ \\
\hline
\end{tabular}


In der Folge hat sich der Begriff Aufklärung (Stucke 1972) dann von historischen Epochen abgelöst und wurde zum systematischen Prinzip. Aufklärung in ihrer metaphorischen Beziehung setzt Licht gegen Dunkelheit, Klarheit gegen Nebel, Kritik gegen schlechte Faktizität. Es geht um einen Kampf gegen Unwissenheit und Unvernunft, insbesondere gegen religiös gestützten Irrglauben und Willkür des Despotismus.

In dieser Tradition hat sich Aufklärung über eine »zweite« und »dritte« Aufklärung (Meissner 1969) zum Prinzip kritischer Vernunft entwickelt. Allerdings hat der Glaube an die Vernunft auch Gegenströmungen erzeugt und die Kritik der Kritik. In der »Dialektik der Aufklärung« (Horkheimer/Adorno 1966) werden die Grenzen des Fortschrittsglaubens aufgedeckt und ihr Umschlag in Unterdrückung.

Aufklärung als entfalteter Begriff bezieht sich auf eine reflexive Wissenschaft, die sich ihrer Grenzen bewusst ist. Unverzichtbar ist dabei ein Konzept der Vernunft, das Emotionalität nicht ausschließt und sich nicht beschränkt auf Instrumentalität des Mitteleinsatzes. Unverzichtbar ist eine Idee der Wahrheit, die als Fluchtpunkt des Wissens angelegt ist. Wenn allerdings Aufklärung gerinnt zu immer und überall gültigen Prinzipien, liegt ihr Untergang nahe.

Der Experimentalphysiker und Aphoristiker Christoph Lichtenberg schrieb in seinen »Sudelbüchern«, dass die Aufklärung in allen Ständen eigentlich in richtigen Begriffen von wesentlichen Bedürfnissen bestehe (Lichtenberg 1790). Und der Weltreisende und Bibliothekar Georg Forster sieht in seinem Essay »Über lokale und allgemeine Bildung « als menschheitsgeschichtliches Ziel die uneingeschränkte Herrschaft der Vernunft bei unverminderter Reizbarkeit des Gefühls. Diese Vereinigung sei das große nicht aufgelöste Problem der Humanität. Er steigert sich bis zu hymnischen Formeln: »Vernunft, Gefühl und Phantasie vereint« (Forster 1789. In: 1971, Bd. 3, 54). Diese Einheit erst kann ihre aufklärerische, ihre humanisierende Wirkung auf das progredierende Menschengeschlecht ausüben.

Es ist also eine interessengeleitete, eben aufklärungsfeindliche Interpretation, Aufklärung sei kalt und flach und erst die Romantik habe die warmen und tiefen Gefühle wiederentdeckt. Es wird damit ein Hort der Irrationalität eingefriedet, der Geburtsstätte rückwärtsgewandter Weltflucht sein kann.

\subsection{Wissenschaft und Aufklärung}

Von entscheidender Bedeutung für das Zeitalter der Aufklärung war die Entwicklung der Wissenschaften, die die eigentliche Basis für die Fortschrittshoffnungen wurde. Wissenschaft als Verfahren der Erzeugung, Aneignung und Vermittlung gesicherten Wissens, als methodologisch entfalteter und gestützter 
Weg zur Erkenntnis und als im Ergebnis fundiertes handlungsanleitendes systematisches Wissen erhielt im Zeitalter der Aufklärung ein vorher nie gekanntes und beanspruchtes Gewicht. Moses Mendelssohn beantwortete im September 1784 als erster - noch vor Immanuel Kant, der erst im Dezember-Heft der »Berlinischen Monatsschriften« zu Wort kam - die Frage: Was heißt aufklären? Er bestimmte Aufklärung als vernünftige Erkenntnis und stellte fest: »Eine Sprache erlanget Aufklärung durch die Wissenschaften« (Mendelssohn ([1784] In: Bahr 1996, 4)

Bedeutsam war insbesondere der Aufstieg der Naturwissenschaften. Sie gaben für andere Wissenschaften ein Modell großer Attraktivität ab. Aus den Entwicklungen der Astronomie entstand ein neues Weltbild anknüpfend an die Vorläufer Kopernikus (1473-1543) und Kepler (1571-1639). Auch die Rechtswissenschaften differenzierten sich und suchten eine rationale Basis; neue Disziplinen wie die Staatswissenschaften entstanden. Die etablierten Fakultäten wie Theologie, Jurisprudenz und Medizin griffen neue Themen auf und erhielten so ein anders Profil (Vierhaus 1985, 8). Es ging nicht mehr nur um Theorie als Anschauung des Kosmos, sondern um Verwendbarkeit und Brauchbarkeit wissenschaftlichen Wissens.

Die Ablösung der Wissenschaft von Glauben, von Staat und Kirche waren für die neue Denkhaltung wichtige Voraussetzung. Der Wahnglaube der Hexerei, der in Europa fürchterlich gewütet hatte, wurde zum Symbol der Unvernunft. Deshalb wurde er auch zur Zielscheibe aufklärerischer Vernunft.

Allen voran wird Christian Thomasius (1655-1728) als einer der ersten Begründer der deutschen Aufklärung benannt. Er ist eine Schlüsselfigur des Umbruchs zwischen Tradition und Moderne. Sein Wissenschaftsverständnis ist gekennzeichnet durch Popularität in der Öffnung für die Volkssprache, Antimystizismus im Kampf gegen den Hexenglauben und Utilitarismus bezogen auf Anwendbarkeit.

Bekannt ist er heute durch den Hinweis, dass er die erste Vorlesung in Deutsch gehalten habe, angekündigt am Schwarzen Brett der Universität Leipzig 31. Oktober 1687: »Welcher Gestalt man denen Frantzosen in gemeinem Leben und Wandel nachahmen solle?« Die Übernahme der Volkssprache als symbolischer Akt der Öffnung der Wissenschaft für den »gemeinen Mann« war Kennzeichen einer Kritik an der scholastischen Universitätstradition, die sich erging in Exegese vor allem der Bibel und der Schriften des Aristoteles.

Gegen diese Tradition setzte Thomasius einen Begriff von Wahrheit, der sich nicht erschöpft in Interpretation von Texten, sondern der das Neue zulässt. Er fundierte praktische Vernunft in seiner Schrift: »Einleitung zu der VernunfftLehre, worinnen, durch eine leichte, und allen vernünfftigen Menschen, wasserley Standes oder Geschlechts sie seyen, verständige Manier der Weg gezeiget wird, ohne die Syllogistica das Wahre, Wahrscheinliche und Falsche voneinander zu entscheiden, und neue Wahrheiten zu erfassen.« (1691) 
Thomasius' Begriff von Wahrheit macht es möglich, sich der Wirklichkeit zu stellen und handelnd einzugreifen. Er skizziert einen Begriff von Wahrheit, der nicht auf Glauben, sondern auf Korrespondenz von Denken und Wirklichkeit beruhen soll:

"Denn die Wahrheit ist nichts anderes als eine Übereinstimmung der menschlichen Gedanken, und die Beschaffenheit der Dinge außer den Gedanken" (Zit. Hinske/Specht 1990, 128).

Über die Wahrheit kann die Vernunft deshalb auch entscheiden, weil »Harmonie « zwischen den äußeren Dingen und den Gedanken besteht: »Denn die Dinge sind so beschaffen, dass sie von den Menschen begriffen werden können, und der Verstand ist so beschaffen, dass er die äußerlichen Dinge begreifen kann.« (Ebd. 129)

Der Ausgang vom Menschen und die Rolle der Vernunft sind Merkmale des Denkens des Thomasius. Es geht ihm auch darum, Neues zuzulassen, wie es in den Syllogismen des Aristoteles unzugänglich bleibt. Er ironisiert die scholastische Exegese:

"Ja ich habe ganze volumina de methodo gelesen, und bin doch noch so klug als zuvor." (Ebd. 133)

Thomasius ist nicht durch ein zentrales Werk, das die Geschichte der Philosophie mitbestimmt hätte, hervorgetreten, sondern durch die Vielfalt seiner oft praktischen Schlussfolgerungen, welche vom Eherecht bis zur Hexenverfolgung reichten. Er vertritt einen Gelehrtentyp, der die Konsequenzen des eigenen Denkens mitberücksichtigt. Diese Haltung gilt für sein Wirken als Philosoph, als Jurist und als Publizist.

Der Hexenwahn war Höhepunkt des Aberglaubens der vergangenen Zeiten; die brutalen Prozesse zu bekämpfen, war wichtiger Schritt zur Aufklärung. Das Büchlein: »De crimine magiae« (Über das Verbrechen der Hexerei) erschien 1711 als Streitschrift gegen die Hexenprozesse. Formal war der Text als Dissertation bei Thomasius gekennzeichnet, tatsächlich aber von ihm vorgegeben und wohl auch selbst geschrieben. Das geschah erst, nachdem Thomasius als rangerster Professor der Hallenser Juristenfakultät Einsicht in Hexenprozessakten erlangt hatte und entscheidende Gutachten darüber verfassen konnte: Hunderttausende waren zum Tod auf dem Scheiterhaufen verurteilt worden, meistens Frauen und die meisten in deutschen Ländern.

Z.B. ließ man ausgerechnet im reichsunmittelbaren Frauenstift Quedlinburg 1589 an einem Tag hundertdreiunddreißig »Hexen « verbrennen; aus christlicher Barmherzigkeit hatte man den als Zauberinnen vom nahen Blocksberg Verleumdeten Pulversäcke an die Brüste gebunden. 
Abbildung 3: Hexenverbrennung

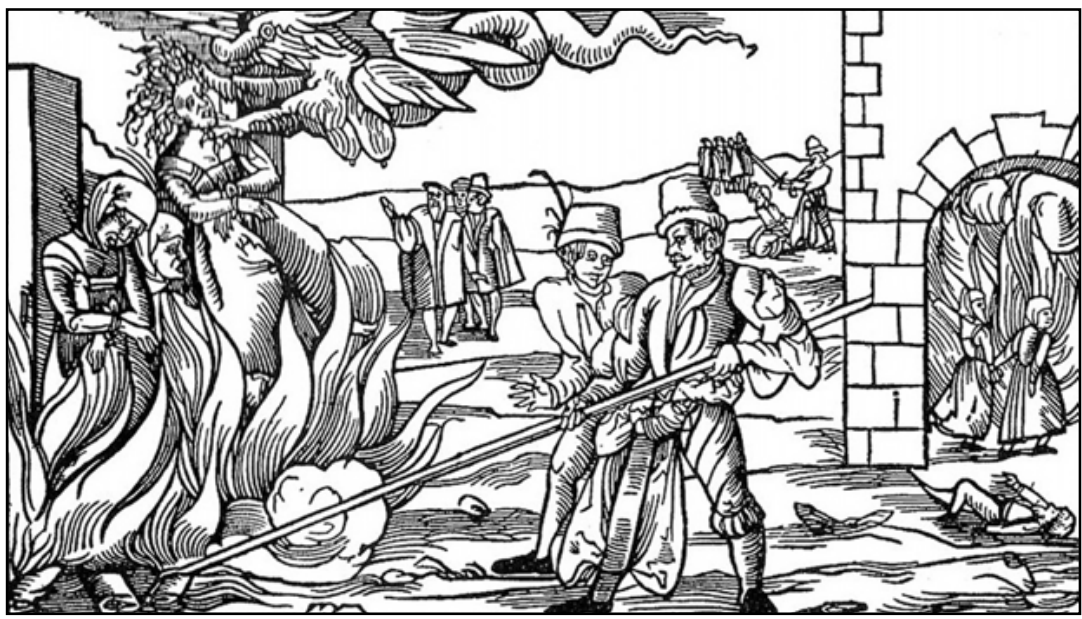

Thomasius kritisierte die Umkehrung juristischer Argumentation: bei normalen Gerichtsfällen bestimmt die Tat den Richterspruch, in Hexenprozessen bestimmt der Richter die Tat. Da beim Teufel alles möglich ist, besteht, was Buhlschaft mit dem Bösen, die Versammlungen der Hexenzunft auf dem Blocksberg angeht, kein schützendes Alibi. Die mit der Obrigkeit eng verbundene Kirche, die protestantische wie die katholische, brachte mit dem gepredigten Wahnsinn statt des Paradieses wenigstens die ihr nützliche, schreckende Hölle auf die Erde.

Thomasius lieferte das argumentative Arsenal zur Bekämpfung des ärgsten Aberglaubens, des Hexenwahns. Die Hexenprozesse ließen in Preußen, wie auch in Sachsen nach. Aufgrund der Schrift des Thomasius machte Friedrich Wilhelm I. 1714, ein Jahr nach seinem Regierungsantritt, ihnen ein Ende und verbot die Prozesse.

Thomasius aber hat nicht nur den Hexenrauch, sondern den Aberglauben jeder Art bekämpft: Geisterbanner, Kometenangst, Wunderzeichen, Amulette und die Astrologie. Ihm steht das Verdienst zu, mit »De criminae magicae « dem Hexenwahn und mit »De tortura « der Folter in Deutschland ein Ende bereitet zu haben. Insofern ist er eine herausragende Figur des Kampfes der frühen Aufklärung gegen Aberglauben und Unwissenheit. Gleichzeitig dient seine Betonung der Muttersprache der Verbreitung von Wissenschaft. Die Devise lautete:

"Je höher der Verstand in den Wissenschaften steiget, je tiefer sich zum Fall der Aberglaube neiget" (Zit. in: Behringer 2004, 383).

Diesem Leitsatz folgte auch Christian Wolff (1679-1754), Universalgelehrter, Jurist und Mathematiker. Er zählt zu den bedeutendsten Vertretern des Naturrechts und gilt als Begründer der Begriffssystematik in Philosophie und Rechts- 
wissenschaft. Er hat eine umfassende terminologische Grundlegung versucht; viele von ihm geordnete Begriffe wie »Bewusstsein«, »Bedeutung« oder »Aufmerksamkeit« wurden in den allgemeinen Sprachgebrauch übernommen. Seine weite Definition von »Aberglaube« erfasste auch Gebiete der Religion.

Von Wolfs Werk ging die erste Schulenbildung in der deutschen Philosophie aus. »Wolffianer « gab es auf fast allen Universitäten des Heiligen Römischen Reiches; ihr Einfluss in Lehre und wissenschaftlicher Forschung dominierte über Jahrzehnte. Auch außerhalb der akademischen Sphäre hatte Wolff Anhänger, darunter Adlige, so auch Friedrich II. von Preußen in seiner Kronprinzenzeit. Wolffs Philosophie ist eine systematische Ausprägung des Rationalismus, die sich aus verschiedenen Quellen, vor allem aber von Leibniz, speist. Wolff ist sowohl Verteidiger einer reziproken Ergänzung von Vernunft und Offenbarung als auch ein Anhänger des »Philosophenkönigtums« im Sinne Platos.

Wissen und Glauben wurden schon in der Frühaufklärung getrennt. Nicht mehr die Weitergabe von autoritäre und sakrosankte Geltung beanspruchenden Lehrmeinungen war Hauptaufgabe, sondern die systematische Vermehrung des Wissens, die kritische Überprüfung unter der Anforderung der Anwendung.

Wissenschaft war im Verständnis der Aufklärung durch Erfahrung gestützte Forschung und systematisch gesammeltes und geordnetes Wissen; sie war nicht zuletzt durch die Kriterien Brauchbarkeit und Nützlichkeit gekennzeichnet. Diese Sichtweise war Grundlage wissenschaftlichen Fortschritts und hat sich seitdem erhalten.

Das Zeitalter der Aufklärung wollte im Prinzip alles wissen, was menschlicher Erkenntnis zugänglich war (s.u. Teil 2.3). Diese Neugier bezog sich auf die Natur, die Geschichte, die Religion und den Menschen. Dabei waren die Grenzen zu »Wissenschaften « wie der Astrologie oder Alchemie nicht immer klar gezogen. Es gab eben keine empirisch fundierte Chemie und Biologie. So wurden diese Wissensbereiche zum Einfallstor von Skurrilitäten und Absurditäten.

Charakteristisch ist auch, dass die Unterschiedlichkeit von Geistes- und Naturwissenschaften noch nicht stark empfunden wurde. Die Fächertrennung war noch nicht durchgängig. Der Mathematiker Marquis de Condorcet (1743-1794) schrieb verfassungsrechtliche Beiträge; der Wortführer der Göttinger Akademie und Schriftleiter der »Göttinger Gelehrten Anzeigen « Albrecht von Haller (1708-1777) war zugleich berühmter Arzt, Naturwissenschaftler, Dichter und Literaturkritiker; der Experimentalphysiker Georg Christoph Lichtenberg (1742-1788) trat in seinen »Sudelbüchern" als Aphoristiker hervor; der Dichter Goethe stemmte sich als Naturforscher gegen Newtons Farbenlehre. Allerdings wird man sagen müssen, dass das Niveau dieser Wissenschaften teilweise noch wenig elaboriert war. Deutschland war um 1800 - gerade in den Naturwissenschaften - noch ein zurückgebliebenes Land.

Wissenschaft erhielt schon zu Beginn der Neuzeit, die sich in der Aufklärung fortsetzt, eine neue gesellschaftliche Stellung. Die Vorstellung von der göttlichen Schöpfungsordnung, die es durch Auslegung der Heiligen Schrift zu 
verstehen gelte, wurde im 17. Jahrhundert beiseite geschoben und durch ein vernünftiges und erfahrungsbegründetes Weltbild ersetzt. Der Kosmos wurde als Maschine aufgefasst, deren Räderwerk ewigen Gesetzen folgt, die der Mensch mit Hilfe seiner Vernunft erfassen kann.

Die bedeutendsten Naturwissenschaftler der Aufklärung und ihre Vorläufer streuten über ganz Europa:

Abbildung 4: Vorbereiter der Aufklärung in der Naturwissenschaft

Galileo Galilei (1564-1642) vertrat im Italien der Spätrenaissance ein heliozentrisches Weltbild, das in der Aufklärung durch verschiedene Wissenschaftler fortgeführt wurde.

Friedrich Johannes Kepler (1571-1630) war Naturphilosoph, evangelischer Theologe, Mathematiker, Astronom und Optiker.

Isaac Newton (1643-1727) war zugleich Mathematiker, Physiker und Astronom, dem viele bedeutende Erfindungen und die Grundlagen der klassischen Naturwissenschaften zu verdanken sind.

Carl von Linné (1707-1778) war ein schwedischer Wissenschaftler, der tausende von Pflanzen- und Tierarten beschrieb und systematisierte.

Louis Buffon (1707-1788) ordnete als Erster die Wissenschaft vom Leben, die Biologie, und die Entwicklung der Arten in sieben Stufen.

Chevalier de Lamarck (1744-1829) verneinte die Unveränderlichkeit der Tierarten, und glaubte daran dass alle Tierarten einen gemeinsamem Ursprung haben.

Georges Cuvier (1769-1832) widersprach Lamarcks Meinung in der festen Überzeugung, dass die Eigenschaften eines lebenden Organismus fest in seinen Keimen angelegt seien.

Dennis Diderot (1713-1784) war als Initiator der Enzyklopädie der entscheidende Systematiker wissenschaftlichen Wissens.

Hauptfortschritte bezogen sich auf die Entwicklung der Astronomie zum heliozentrischen Weltbild, das durch die Gesetze der Physik, besonders der Mechanik gestützt wurde (Kopernikus, Galilei, Kepler, Newton u.a.) und auf die Biologie, für die eine umfassende Systematik entwickelt wurde (Linné, Buffon, Lamark). Es ging darum die Erfahrungen in eine begriffliche Ordnung zu bringen, empirische Daten systematisch und kategorial zu fassen (Diderot und die Enzyklopädisten).

Vorläufer gab es viele: Galileo Galilei (1564 in Pisa-1642 in Arcetri bei Florenz) war Philosoph, Mathematiker, Physiker und Astronom. Er vertrat die Überzeugung, die Naturwissenschaft stehe im Buch der Natur und sei in mathematischer Sprache geschrieben. Er ist Begründer der empirisch fundierten und zugleich mathematisch formulierten Naturwissenschaften, gleichzeitig gibt er eine klare Absage an Alchemie und Astrologie. Er stand im Briefwechsel mit dem Ent- 
decker der Planetengesetze Johannes Kepler (1571-1630). Beide bezogen sich auf Nikolaus Kopernikus (1473-1543), der schon hundert Jahre vorher ein heliozentrisches Weltbild vertreten hatte. Dies wurde von ihnen gestützt durch Daten der Planetenbeobachtung.

Der englische Astronom, Physiker und Mathematiker Isaac Newton (16431727) verhalf den exakten Naturwissenschaften zum Durchbruch. Er verband empirische Erfahrung und logische Begründung. Von konkreten Einzelfällen ausgehend, erarbeitete Newton eine mathematisch formulierte Theorie der Mechanik, aus der Einzelfälle abgeleitet werden konnten, die sich überprüfen ließen. Was sich nicht im Experiment untersuchen und wiederholen ließ, was nicht exakt gemessen werden konnte und sich der mathematischen Darstellung entzog, verbannte er aus den Naturwissenschaften. Im Zentrum der Newtonschen Mechanik steht das allgemeine Gravitationsgesetz. Mit dieser Kraft erklärte Newton sowohl Galileos Fallgesetze als auch Keplers Gesetze über die Bewegung der Planeten um die Sonne. Wo allerdings die Gravitation herkommt, blieb ein Rätsel.

Der Dichter Alexander Pope (1688-1744)schrieb ein berühmtes Gedicht über Sir Isaac Newton, das an die Licht-Metapher anschließt:

"Nature and nature's laws lay hid in night;

God said 'Let Newton be! , and all was light." "Natur und der Natur Gesetze lagen in dunkler Nacht; Gott sprach: Newton sei! Und sie strahlten voll Pracht" (Zit. http://de.wikipedia.org/wiki/Alexander_Pope).

Abbildung 5: Isaak Newton bei einem Experiment mit Sonnenlicht

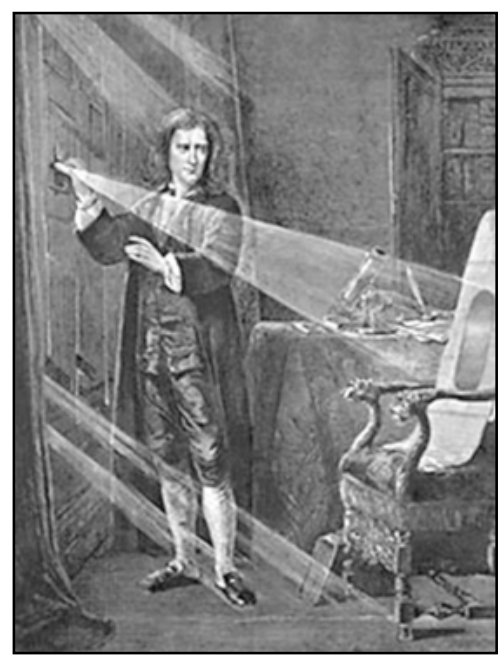


Neben das Auslegen von Texten und das Interpretieren von Begriffen, wie es die Klostergelehrtheit und die scholastische Wissenschaft des Mittelalters dominierte, tritt die Interpretation empirischer Erfahrung als wissenschaftliche Methode, welche die Resultate öffnet für neue Erkenntnisse. Vernunft erschöpft sich nicht in der formalen Logik des Verstandes, sondern öffnet sich zur Welt und der Reflexion leitender Interessen. Nicht mehr das Buch oder »die Schrift« sollen Ursprung der Erkenntnis sein, sondern das Erfahren der Welt. Grundlage war ein neues, antischolastisches Denken, das nach unhintergehbaren Begründungen durch Vernunft oder Erfahrung suchte.

Den Beginn machte der Rationalismus mit Descartes (1596-1650) und in letzter Konsequenz Leibniz (1646-1716). Im Gegenzug begann im Empirismus, besonders bei Locke (1632-1704) und Hume (1711-1776) die Suche nach empirischer Evidenz durch Wahrnehmung und Erfahrung. Der Erfolg der modernen Naturwissenschaften beruht auf der Abkehr von der Scholastik der Schriften des Aristotelismus, die die Klostergelehrtheit begründet hatte, und der Suche nach Beobachtbarkeit und Messbarkeit in der Empirie.

Die Kluft zwischen Rationalismus und Empirismus versuchte gnoseologisch schließlich Immanuel Kant 1781 in der »Kritik der reinen Vernunft« $\mathrm{zu}$ überbrücken: Vom »Ding an sich« strömt etwas Unfassbares aus. Einen Teil davon ist wahrzunehmen und erfahrbar (aposteriori - später in die Sinne gekommen) - allerdings immer nur in vorgegebenen Anschauungs- und Denkformen (apriori - nach vorher festliegenden Regeln). Kant ging also davon aus, dass alles Erkennen aus zwei Quellen gespeist wird: Die Inhalte werden sukzessiv von außen gewonnen, die Formen aber, in denen diese Erfahrungen bewusst werden, stammen aus dem überindividuellen menschlichen Geist. Raum und Zeit nannte Kant als Basis der Erkenntnis solcher Formen.

Die Verknüpfung von rationalem, moralischem und ästhetischem Denken, die bei Thomasius begann und die Kant zur höchsten Entfaltung brachte, war zugleich die Eröffnung der Anwendung »praktischer Vernunft«. Wissenschaft galt nicht nur dem Denken, sondern lieferte Begründungen für Handeln. Der Professor, der Königsberg kaum verlies, wusste vieles über die Welt.

Allerdings trifft seinen Idealismus auch der von Georg Forster am Beispiel des Streites »Über die Menschrassen« erhobene Vorwurf, »die Natur nach ihren logischen Distinktionen modeln zu wollen« (s.u. Teil 2.6).

Georg Forster (1754-1794), Freimaurer und Jakobiner, lobt den neuen Stellenwert der Erfahrung für die Wissenschaft:

"Die Erfahrungswissenschaften, diese ächten, unentbehrlichen Quellen der Erkenntniß, einst so trübe und verachtet, strömen jetzt ihre klaren, segenreichen Fluten von den äussersten Grenzen der Erde zu uns herab und in ihrem Spiegel erkennt die Vernunft ihre eigene Gestalt." (Forster 1971. Werke Bd. 3, 47) 
Er betont einen Vorrang der Empirie:

"Wer wollte nicht die wenigen Beobachtungen eines bloßen, jedoch scharfsinnigen und zuverlässigen Empirikers den vielen geschminkten eines parteiischen Systematikers vorziehen?" (Forster 1968, 6)

Spätestens seit dem 18. Jahrhundert hat sich immer wieder die Frage gestellt, ob Aufklärung durch Wissenschaft möglich oder aber trotz Wissenschaft nötig ist. Der im 17. Jahrhundert beginnende kumulative und später exponentiell wachsende wissenschaftsinterne Fortschrittsprozess ist mit zunehmendem Enthusiasmus verbunden. Die ebenso exponentiell vermehrten Möglichkeiten technischer Anwendung und Nutzung haben den - mittlerweile ins Gegenteil umgeschlagenen - Optimismus gefördert, der in den entsprechenden wissenschaftlichen Forschungen die wichtigste Quelle der Aufklärung über das sieht, was für die Menschen nützlich ist.

Denis Diderot, der führende Kopf der »Encyclopédie ou Dictionnaire raisonné des sciences, des arts et des métiers« forderte:

"Man muss diesen ganzen alten Unfug ausrotten! Die Schranken umstoßen, die nicht die Vernunft gesetzt hat! Den Wissenschaften und Künsten eine Freiheit wiedergeben, die für sie so unersetzlich ist! “ (Diderot, zit. nach http://www.abc-der-menschheit.de/ coremedia/generator/wj/de/02__ABC_20der_20Menschheit/A.html, Zugriff 24.4.11)

Erfahrung wurde so zum Kampfruf gegen die alten Glaubensbekenntnisse. Die szientifisches Wissen ansammelnde Aufklärungskonzeption ist immer wieder durch die Überlegungen der praktischen Aufklärungskonzeption relativiert worden, dass nichts für die Menschen wahrhaft nützlich sein könne, was nicht die Prüfung seiner Moral- und seiner Gemeinwohlverträglichkeit bestehen kann.

Die Aufklärung wurde nicht zuletzt durch die Fortschritte auf dem Gebiet der Mathematik und Physik in Gang gebracht, umgekehrt verlieh sie diesen weiteren Antrieb. Sie legte den Grundstein für den ungeheuren Aufschwung, den die Naturwissenschaften um die Zeit der Französischen Revolution nahmen.

Der Kreis der führenden Wissenschaftler stand großenteils miteinander in brieflichem oder persönlichem Kontakt. Allerdings führt diese Form der Weitergabe neuer Ergebnisse - sei es mündlich oder brieflich - zu einer nur mangelhaften Verständigung und oft zu Missverständnissen oder Streitigkeiten.

Ein oft zitiertes, schönes Beispiel für die neue Relevanz des Erfahrungsbezugs, besonders des Experiments, ist der Phlogiston-Oxidation-Konflikt. Gemeinsame logische Annahme ist das Gesetz der Erhaltung der Masse als Grundlage der Chemie. Es liefert den Rahmen für den wissenschaftlichen Diskurs und spannt zugleich das empirische wie interpretative Feld des Konfliktes auf.

Der Medizin-Professor in Halle Georg Ernst Stahl (1660-1734) hatte experi- 
mentell festgestellt, dass in der Regel z.B. bei Holz der Rückstand in der Asche nach Verbrennen leichter war als das Ausgangsmaterial. Daraus war geschlossen worden, dass ein Stoff - eben Phlogiston, das Verbrannte - entweicht.

Dagegen hatte Antoine Laurent de Lavoisier (1743-1794), der als Vater der modernen Chemie bezeichnet wird, festgestellt, dass Metallverbrennung zum Schwererwerden führt. Er entwickelte im Zeitraum von 1772-1785, nachdem Joseph Priestley (1733-1804) ihm bei einem Besuch in Paris von dem Gas Sauerstoff, das er »dephlogisierte Luft « nannte, erzählt hatte, die Oxidationstheorie, die (erweitert) bis heute Bestand hat.

Im Jahr 1783 verbrannte Mme. Marie Anne Pierrete Lavoisier, die gemeinsam mit ihrem Mann die chemischen Experimente durchführte und das Laborjournal schrieb, demonstrativ öffentlich die Bücher Stahls und anderer Anhänger der Phlogistontheorie. Dieser Prozess zeigt exemplarisch das Zusammenspiel von logischen Annahmen und empirischen Erfahrungen.

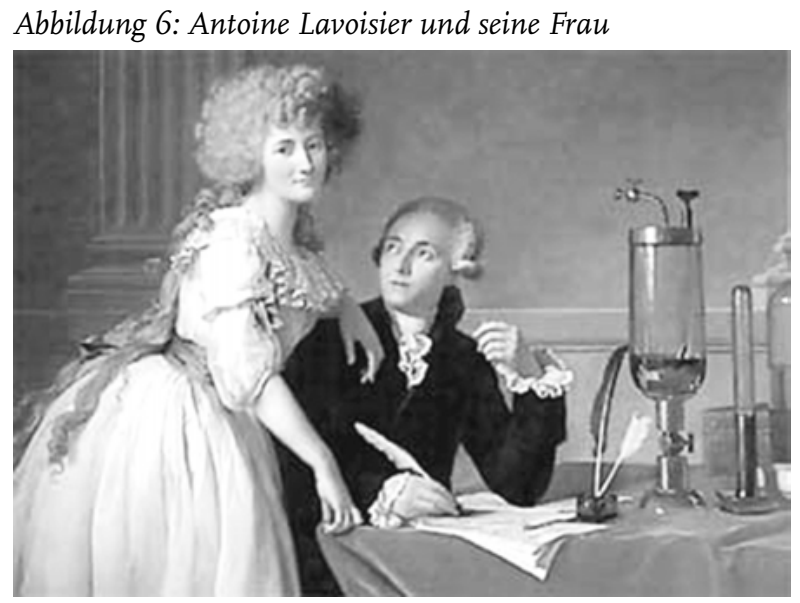

Durch den Kontakt zwischen den führenden Wissenschaftlern untereinander. entstand eine dichte Wissenschaftlergemeinschaft, die sich gegenseitig über neueste Ergebnisse informierte. Diese auf Initiative aktiver Gelehrter begonnene Organisation des Wissenschaftsbetriebs wurde von den Herrschern und den Regierungen vieler Länder besonders in den Akademien gefördert, da diese die Bedeutung der Mathematik und der Naturwissenschaften für die Wirtschaft allmählich erkannten. So entstanden die »Royal Society« (1660) und die Pariser »Académie des Sciences« (1666): später wurden Akademien auch in St. Petersburg, Berlin und anderen Orten gegründet. Mit der Gründung der Wissenschaftlichen Akademien in Berlin (1700), Göttingen (1751), München (1759), Mannheim (1760) nahm die Wissenschaft in Deutschland einen Aufschwung und eine Entwicklung, die sie wieder anschlussfähig an die europäische Diskussion machte. 
Die absolutistischen Staaten standen vor der Aufgabe, durch ein angemessenes Bildungswesen, die Qualifikationen für den Ausbau der Verwaltung, der Justiz und des Militärs zu sichern. Aber die Universitäten waren durch Territorialisierung und Konfessionalisierung geschwächt. Es waren konfessionell und dynastisch getrennte Bildungsräume entstanden (Schindling 1999, 3-48). Hinzu kam in ihrer internen Organisation Kommerzialisierung und Ritualisierung. Zahlreiche zeitgenössische Klagen beschwerten sich darüber, dass die Professoren ihren Lehrtätigkeiten aufgrund von Nebentätigkeiten kaum noch nachkämen. Sie trugen höfische Tracht und die Initiationsriten und Zeremonien wurden immer aufwendiger. Titelsucht, Bestechlichkeit und Käuflichkeit akademischer Grade brachten die Universitäten insgesamt in Verruf. Es entstanden »Familien-Universitäten «, in denen Lehrstühle in der Generationenfolge weitergegeben wurden. Die verfallenden Universitäten, z.B. Dillingen, Rinteln, Helmstedt, Duisburg oder Paderborn, erwiesen sich als reformresistent.

Der relative Anteil der Studierenden an der expandierenden Gesamtbevölkerung nahm im 18. Jahrhundert signifikant ab. Die Studentenzahl in Deutschland betrug 1701: 8807, 1751: 8346 und ging bis 1801 sogar aufgrund der politischen Verhältnisse auf 5765 zurück (Prahl 1978, 372). Die Universitäten waren bis auf ganz wenige Ausnahmen einzelner Wissenschaftlerinnen, z.B. Dorothea Christine Erxleben (vgl. Faulstich 2008, 57-76) Sozialisationsinstitutionen für junge Männer und sicherten deren Karriere (Niemeyer 1996).

Insgesamt bestanden im Alten Reich etwa 40 Universitäten, an denen zu Ende des 18. Jahrhundert schätzungsweise 800 Professoren lehrten (Müller 2002,8; zum Vergleich: Deutschland verfügte 2009 über 394 Hochschulen, davon 104 Universitäten, sechs Pädagogische Hochschulen, 14 Theologische Hochschulen, 51 Kunsthochschulen, 189 Allgemeine Fachhochschulen und 30 Verwaltungsfachhochschulen. Nach Angaben des Statistischen Bundesamtes gab es im Wintersemester 2008/2009 über 21000 Universitätsprofessuren über 1,996 Millionen Studierende, davon rund $48 \%$ Frauen).

Die Reform der alten Institutionen wurde durch neue Reformprojekte angestachelt. Die Neugründung der Universitäten Halle (1694) und Göttingen (1737) sowie Erlangen (1743) entfaltete eine Innovationsdynamik, die diese in kurzer Zeit zu den führenden in Deutschland machte. Um die Mitte des 18. Jahrhunderts gehörten diese drei Universitäten zu den berühmtesten und bestbesuchten in Deutschland. Sie konnten die bekanntesten Professoren gewinnen, in Halle z.B. Thomasius und Wolff bis zu seiner Vertreibung durch die Pietisten 1723. Es entstanden neue von »scholastischen Schulgrillen und Pedanterey« freie Universitäten (Hammerstein 1983, 74). Die Absicht der »Reformuniversitäten« war die verstaubten, rückständig und wissenschaftlich unfruchtbaren Institutionen $\mathrm{zu}$ beleben und zu verjüngen. Eine erneuerte Jurisprudenz wie in Halle prägte die Methoden aller Universitätsdisziplinen durch Öffnung zur Empirie der Sitten, Gesellschaftsgliederung und ihrer Geschichte (ebd. 76). Das machte sie 
attraktiv für die Staatsdiener also auch die Adligen, die in Göttingen bis zu $20 \%$ der Studenten ausmachten. Die Hochschulgründer argumentierten, dass ein einziger Graf mehr Geld ins Land bringe als hundert Theologen (ebd. 8o). Auch Studienorganisation, Kanon und nachweisbare Erfolge, in begehrte Positionen zu kommen aufzurücken, sicherten den hervorragenden Ruf der Anstalt. Die Wissensvermittlung konzentrierte sich nicht mehr auf Vorlesungen, sondern wurde auf die Lektüre auch anderer Autoren ausgeweitet. Dadurch wurden Verlage und Bibliotheken an den Universitäten wichtiger - in Göttingen z.B. Vandenhoeck Q Ruprecht (Vierhaus 1985, 17).

Ferner entstanden die ersten wissenschaftlichen Zeitschriften, insbesondere das »Journal des Scavans« das am 5. Januar 1665 als erste wissenschaftliche Fachzeitschrift die in Europa publiziert wurde, und 1665 (bis heute) die »Philosophical Transactions« der »Royal Society«, 1682 in Leipzig die »Acta eruditorum « als erste wissenschaftliche Zeitschrift Deutschlands (Überblick bei Habel 3007). Diese Zeitschriften veröffentlichten die neuen Ergebnisse auf dem Gebiet der Mathematik, der Naturwissenschaften, aber auch anderer Wissensgebiete.

Erstaunlicherweise verband die Aufklärung entfaltete Rationalität mit technologischen Impulsen, die den Weg zur Industrialisierung öffneten. Eine Entgegensetzung und Unvereinbarkeit von Technik und Reflexion wurde nicht gedacht. Auch Wissenschaft und Kunst vollzogen keine Abgrenzung. So umfasste die »Enzyklopädie« ein »Dictionnaire raisonné des sciences, des arts et des métiers«. Sie sammelte die Gesamtheit allen Wissens - auch das der Handwerker, Hebammen und Bauern. So entstanden in den wissenschaftlichen Akademien Frühformen des Wissenschaftstransfers. Sie umfassten vor allem angewandte Physik, besonders Mechanik, Medizin, Bergbau, Landwirtschaft u.a.

Die Umsetzung wissenschaftlicher Resultate in Anwendungszusammenhänge, der Wissenschaftstransfer, nutzte also zunächst den Geschäften der Adligen und zunehmend den Unternehmen des Bürgertums.

\subsection{Gesellschaftsordnung Und VolksaufkLÄrUng}

Wer waren eigentlich die Akteure oder Adressaten der Aufklärung? Zunächst waren es die »Gebildeten« selbst, die sich in der Diskussion bewegten. Der »ungebildete« Großteil der Bevölkerung war in diesem Prozess nicht vertreten. Das Volk nahm an der beginnenden Aufklärung noch nicht teil.

Wenn man im 18. Jahrhundert vom Volk sprach, meinte man den Landmann, den Dienstboten und Taglöhner, den Handwerkergesellen in Städten und die meisten Einwohner kleiner Dörfer (Siegert 1994, 110). Das Volk als »gemeiner Mann« umfasste in negativer Konnotation Nichtadlige. Nichtkleriker, Nichtakademiker, Nichtgebildete und Nichtreiche, während sich die »gesitteten 
Stände« von der Masse der Bevölkerung abhoben. Die Sozialstruktur wurde in einem Vier-Stände-Modell gefasst, in dem nach dem Regenten, die Adligen und Kleriker, als dritter Stand das Bürgertum gestellt wurde und Bauern, Handwerker und Bedienstete den gesamten Bau zu tragen hatten.

Abbildung 7: Stände im 18. Jahrhundert (um 1790)

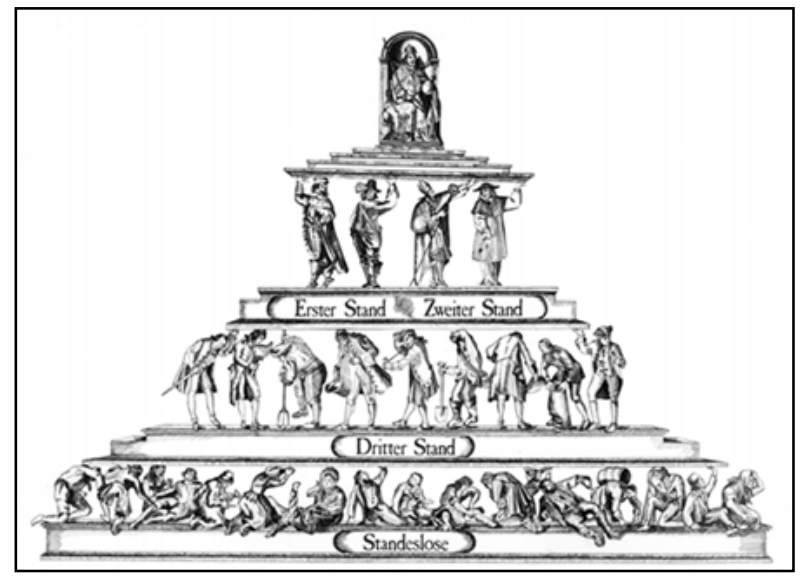

Um 1700 hatte Europa etwa 100-120 Millionen Einwohner. Diese Zahl wuchs bis 1800 auf 180-19o Millionen. Diese um mehr als ein Drittel gestiegene Menschenzahl beruhte auf einem Rückgang der Sterblichkeitsziffern nach der gewaltigen Ausblutung im dreißigjährigen Krieg. Immerhin stieg die Bevölkerungsdichte von etwa fünf Menschen/qkm um 800 auf 42 um 1800 (Henning 1974).

In diesem Klima rapiden Bevölkerungswachstums schrieb der Pfarrer und Volkswirt Thomas Robert Malthus (1766-1834) seinen Essay »On the Principle of Population« (1798). Er vertrat die Ansicht, dass die Einwohnerzahl in geometrischer, die Nahrungsmittelversorgung jedoch nur in arithmetischer Progression ansteige, und deshalb die Menschheit, wenn sie nicht gewaltsam durch Krieg, Hunger und Seuchen reduziert werden solle, ihre Vermehrung durch Enthaltsamkeit einschränken müsse.

Die Landwirtschaft gewann daher doppelt an Gewicht: Zum einen lag vor 1800 der Beschäftigtenanteil nach Sektoren bei etwa 2/3 im Agrarwesen. Nach anderen Schätzungen lebten am Ende des Jahrhunderts von 23 Millionen Einwohnern in Deutschland sogar 3/4 auf dem Lande. Zum andern kam es zu Versorgungsengpässen. Nach 1730 stiegen die Preise für Agrarprodukte stark an. So wurde das Brotgetreide fast doppelt so teuer.

Entsprechend wurde über die Quellen gesellschaftlichen Reichtums neu nachgedacht. Die Physiokraten sahen im Boden die Grundlage des Volkswohlstandes, um einen Gewinn einzubringen, der die Kosten überstieg. Handel 
sank gegenüber der ihm im Merkantilismus zugewiesenen Bedeutung; Industrie begann sich erst zu entwickeln. Es gab am Ende des 18. Jahrhunderts wohl nicht mehr als 50.000 Lohnarbeiter in der Industrie Deutschlands. Die Zünfte, Innungen und Gilden waren noch die dominante Organisationsform des städtischen Handwerks. Die Mehrzahl der vormals selbständigen Städte konnte sich aber nach dem dreißigjährigen Krieg nicht mehr gegen die Landesherrn der Territorialstaaten behaupten.

Die Agrarreformen des 18. Jahrhundert setzten vor allem auf eine Kultivierung bislang unbebauten Bodens und auf einen Übergang von der alten Dreifelderwirtschaft zur Fruchtwechselwirtschaft.

Auch dafür wurden neue Konzepte entwickelt: Die Blütezeit des Kameralismus im 17. und 18. Jahrhundert beförderte eine aktive Wirtschaftspolitik der Territorialstaaten, die auf eine Verbesserung der internen Wirtschaftstruktur setzte. Der eigentliche Beweggrund war die Erhöhung der Einnahmen der »Rechenkammern « der Fürsten, Adligen und Grundbesitzer.

Die Aufwertung der »arbeitenden Stände« stieß gegen die Barrieren der alten Ordnung. Die starre Sozialstruktur der feudalen Herrschaft und dann des absolutistischen Staates ließ besonders dem dritten Stand wenig Raum zu gesellschaftlichem Aufstieg und zu politischer Einflussnahme. So bediente sich das aufsteigende Bürgertum neuer Bündnisse. Mit dem Ende des 18. Jahrhunderts begann die endgültige bürgerliche Umgestaltung in Deutschland von der feudalen zur kapitalistischen Gesellschaftsordnung.

War in der Frühaufklärung zunächst die Selbstaufklärung der Gelehrten und Gebildeten das Hauptthema, so verschob sich das Aktivitätsspektrum bis zur Spätaufklärung in Richtung auf eine Aufklärung des Volkes durch diejenigen, die über Bildung verfügen. In dieser Interaktionsstruktur liegt ein Rückfall in das Priester-Laien-Verhältnis nahe.

Das »gesittete«, »aufgeklärte« Bürgertum wurde Träger einer Bewegung, die anstrebte, alle Volksgruppen einzubeziehen. Die Aufklärer verfolgten das Ziel, das Volk aus Dumpfheit und Aberglauben zu erwecken und zu befreien. Allerdings war die ständische Sozialstruktur hochgradig differenziert. Innerhalb der einzelnen Gruppen gab es feine, vielfach traditionelle Unterscheidungen. Zwischen Dienstboten und Knechten, Handwerkern und Tagelöhnen, Armen und Bettlern, Bauern und Fabrikarbeitern bestanden vielfältige Grenzen. Keine Gruppe der unteren Schichten konnte hegemoniale Ansprüche als Wortführer anmelden (Engelsing 1968, 337. Böning 1998).

Erst gegen Ende des 18. Jahrhunderts erfuhr »Aufklärung « einen Bedeutungswandel. Landgeistliche, Beamte, Ärzte und Apotheker unternahmen es, den Gedanken der Aufklärung auf das Volk zu übertragen. Damit ging es jedoch nicht mehr um Mündigwerden, sondern um Mündigmachen.

Dies hat dazu beigetragen, dass Aufklärung in Verruf gekommen ist. »Also erst in den letzten Jahrzehnten des 18. Jahrhunderts, als die geistige Elite schon 
die Position der Aufklärung zum Teil verlassen hatte, strahlte der Geist der Epoche immer mehr auf das Volk aus.« (Wehrmann 1981, 143) Vorherrschend wurde ein patrimonal-elitäres Aufklärungsverständnis. Eine aufgeklärte Elite versuchte nützliches Wissen dem vormundschaftsbedürftigen Rest nahe zubringen.

Auch hier wieder durchzieht ein Zwiespalt die Bemühungen: Einerseits die Aufklärung zu befördern, um Handel und Sitten voranzubringen, andererseits sicherzustellen, »dass ja die Leute nicht zu klug werden!« (Trapp, zitiert Hermann 1981, 53).

Selbst ein reflektierter Vertreter wie Moses Mendelssohn (1729-1786) spaltete Aufklärung gemäß den gesellschaftlichen Ständen.

"Stand und Beruf im bürgerlichen Leben bestimmen eines jeden Mitgliedes Rechte und Pflichten. [...] Sie erfordern aber auch für jedes Individuum nach Maßgabe seines Standes und Berufs andere theoretische Einsichten und andere Fertigkeit, dieselben zu erlangen, einen anderen Grad der Aufklärung." (In: Bahr 2004, 6)

Konsequent deckt Mendelssohn einen Widerspruch der bürgerlichen Gesellschaft auf, die das Allgemeine der Menschlichkeit bricht an der Besonderheit des Bürgertums:

"Menschenaufklärung kann mit Bürgeraufklärung in Streit kommen." (Ebd.)

Mendelssohn inauguriert auch die patrimonal-elitäre Funktion des »tugendliebenden« Aufklärers, der seine Adressaten als Unmündige behandelt:

"Wenn die wesentliche Bestimmung des Menschen unglücklicher Weise mit seinen außerwesentlichen Bestimmungen selbst in Gegenstreit gebracht worden ist, wenn man gewisse nützliche und den Menschen zierende Wahrheit nicht verbreiten darf, ohne die inm nun einmal innewohnenden Grundsätze der Religion und Sittlichkeit niederzureißen, so wird der tugendliebende Aufklärer mit Vorsicht und Behutsamkeit verfahren und lieber das Vorurteil dulden, als die mit inm so fest verschlungene Wahrheit zugleich zu vertreiben." (Ebd. 7)

Der Aufklärer hat also eine Fürsorgepflicht gegenüber dem »gemeinen Mann«. Eine elitäre Kaste der Aufklärer und Gelehrten verfügt über die Zugänge zur Wahrheit und wählt Wissen aus für andere. Dies öffnet den Umschlag von Aufklären in Herrschen. Mendelsohn sieht allerdings diese Gefahr und warnt davor, dass sich Macht hinter den »Schutzwall der Heuchelei« (ebd.) zurückzieht und verbirgt, aber weiter Aberglauben zulässt und verbreitet. Unterschwellig versteckt sich hier die Angst vor dem Ausbruch der »Aufgeklärten« aus der herrschenden Ordnung.

Die Revolution in Frankreich veränderte schlagartig das Diskussionsklima 
über die Grenzen des Vernunftgebrauchs und die drohende revolutionierende Wirkung der Aufklärung. Der bürgerliche Reformismus hatte Obrigkeit nie völlig infrage gestellt. Der Mensch soll als Untertan, Hausvater, Handwerker, Kaufmann die Kenntnisse erlangen, die er braucht. Er soll das Geschäft, das er treibt, vernünftig und zweckmäßig betreiben, und so dem Wohl des Ganzen dienen. Die »wahre Aufklärung «, die alle Klassen des Volkes weiser, besser und glücklicher macht, soll nicht nur durch die Vermittlung nützlicher Kenntnisse, sondern auch weitergehend durch Bildung des Verstandes, des Willens und der Urteilskraft vorangebracht werden. Der Widerspruch zwischen Aufklärung und Herrschaft bricht auf.

\subsection{Träger Der AufkLÄrung}

Aufklärung bedeutete eine grundlegende Wandlung des Bewusstseins und des Verhaltens, welche unterschiedliche gesellschaftliche Gruppen im Laufe des 18. Jahrhunderts ergriff. Über die Vielfalt einzelner Impulse hinaus, war es eine Veränderung des sozio-kulturellen Klimas und der ökonomischen Struktur, welche alle gesellschaftlichen Bereiche umfasste. Hinter diesem Prozess standen vielfältige konkrete Organisationen und Aktivitäten auf der Ebene der beteiligten Personen, der verbreitenden Medien und der damit gestützten Assoziationen.

Wichtigste Träger der Umsetzung von Aufklärung waren die geselligen Vereine, die sich überall bildeten. Sie waren die Orte, an denen die »Patrioten« Gedankenaustausch pflegten, sich ihrer Selbstverständigung vergewisserten, sich um das Gemeinwohl sorgten, Gleichberechtigung der Entscheidungsfindung einübten. Das 18. Jahrhundert erlebte eine Welle von Vereinsgründungen. Diese hatten vorher laufende Entwicklungen in Lesegesellschaften, allerdings auch in den Ritualen der » Freimaurerei (in England ab 1717, in Deutschland ab 1737) und den »Rosenkreuzern « und »Illuminaten«, die als Geheimbünde Irrationalitäten pflegten. Diese trugen aber gleichzeitig zur Diskussion der Ideen der Aufklärung bei. Gleichzeitig stand ihre Versessenheit auf Geheimnisse und Geheimwissen im Missverhältnis zur Öffentlichkeit der Vernunft.

Die Lesegesellschaften, gemeinnützigen Sozietäten und patriotischen Gesellschaften waren Träger bürgerlicher Aufklärung. Es handelte sich im 18. Jahrhundert zumeist um Gemeinschaften von Akademikern - Juristen, Mediziner, Geistliche und Gymnasiallehrer -, die ihren Wirkungskreis innerhalb der Ständegesellschaft ausbauen und sichern wollten, und versuchten, Fachliteratur untereinander zugänglich zu machen. Zunächst aber ging es um Netzwerke einflussreicher Bürger und Wissenschaftler.

Die »Patriotische Gesellschaft« in Hamburg von 1765 ist eine der bekanntesten dieser Einrichtungen, die als Literaturzirkel konstituierte »Gesellschaft von Freunden der Aufklärung«, die unter dem Namen »Mittwochsgesellschaft« von 
1783 bis 1798 in Berlin bestand, die berühmteste. Bemerkenswert ist, dass die Mitgliederzusammensetzung standesübergreifend angelegt war: es trafen sich Bürger mit Adligen. Allerdings war die formale Gleichheit auch eingeschränkt, durch informelle Kontakte, entstehende Kosten usw., welche die Selektivität sicherstellten.

Die Gesellschaften verfolgten Versuche, wissenschaftliche Entwicklungen in nützliche Verwendungen zu überführen. Schon in den ersten Jahren ihres Bestehens förderte die Hamburger »Patriotische Gesellschaft « die nutzbringende Einführung holzspangefeuerter Stubenöfen, die Verwendung von Steinkohle zum Heizen von Backöfen, die Einführung eiserner Brückengeländer und entsprechend die Entwicklung bestmöglichen Rostschutzes. Ein Preis wurde ausgesetzt für Vorschläge zur Ausbildung der Seemänner in Navigationskursen. Erstmals auf dem Kontinent wurde auf Hamburgs Jacobikirche ein Blitzableiter installiert; die Pockenschutzimpfung wurde eingeführt. Die Verbindung der gemeinnützigen Gesellschaften zur Obrigkeit war deutlich: von den zwischen 1765 und 1792 gewählten Hamburger Senatoren gehörten fast 2/3 der »Gesellschaft zur Beförderung der Künste und nützlichen Gewerbe« an (Müller, 2002, 20).

Eine der wichtigsten Initiativen war die Einrichtung einer Lehranstalt zur Hebung der Bildung von Baugewerksleuten ab 1767. Die Anstalt vermittelte zunächst Unterricht im Bauzeichnen. Ein Maurermeister vermittelte zweimal wöchentlich jungen Baugewerksarbeitern eine berufliche Fortbildung durch Zeichenunterricht.

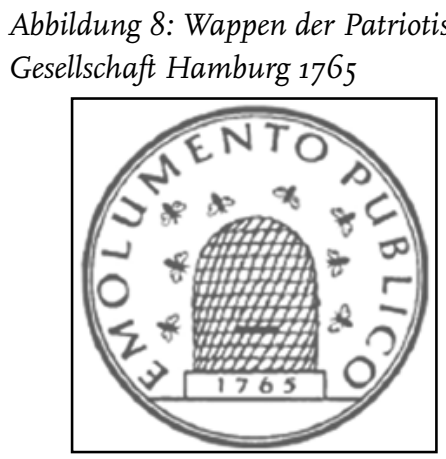

Die Trägerschichten der deutschen Aufklärung waren Beamte, Professoren, Pastoren und Schriftsteller. Sie standen überwiegend in Staatsdiensten oder hatten staatstragende Stellen inne. Mitglieder der Mittwochsgesellschaft z.B. waren: Teller (Oberkonsistorialrat), Engel (Professor der Moralphilosophie und Oberdirektor am Berliner Nationaltheater), Nikolai (Schriftsteller und Verleger), von Dohm (Ministerialbeamter), Möhsen (Leibarzt Friedrich des Großen), Diterich (Prediger an der Marienkirche), Klein (Jurist und später Direktor der Uni- 
versität Halle), Zöllner (Prediger an der Charité, Oberkonsisterialrat), Selle (Arzt an der Charité), Gedike (Direktor des Friedrich-Werderschen-Gymnasiums), Biester (Bibliothekar an der königlichen Bibliothek und Herausgeber der »Berliner Monatsschriften«), von Irving (Oberkonsistorialrat).

Sie verfolgten das Ziel der Bildung und gegenseitiger und gesellschaftlicher Aufklärung in einem streng geordneten Sitzungsablauf, bei dem einschlägige Vorträge gehalten wurden. Die Zusammenkünfte begannen jeweils um $18 \mathrm{Uhr}$ und wurden durch ein gemeinsames Abendessen um 20 Uhr beschlossen. Die Vorträge und Voten zirkulierten in festgelegter Reihenfolge unter den Mitgliedern. Dabei wurde abstraktes Theoretisieren ebenso vermieden wie nur unterhaltsame, ereignisbezogene Gespräche. Es ging um praxisorientierte aufgeklärte Reflexion.

Um 1800 gab es dann schließlich auch vermehrt Leihbibliotheken, in denen sich auch die Kleinbürger, die sich die Mitgliedschaft in einem Lesezirkel oder einer Lesegesellschaft nicht leisten konnten, Zugriff auf Bücher und Zeitschriften erhielten.

Elitär war dagegen die Etablierung der hochbürgerlichen Salons. Berühmt wurden die von Frauen geführten Salons der Frühromantik, zum Beispiel der Jenaer Salon der Caroline Schelling und die Berliner Salons der Henriette Herz und der Rahel Varnhagen.

Seit etwa 1780 gab es den Salon der Henriette Herz (5. September 1764 in Berlin-22. Oktober 1847). Henriette de Lemos war die Tochter des Leiters des jüdischen Krankenhauses in Berlin. Sie ist gebildet erzogen und eignet sich durch Lesen ihr Wissen an, eine Auswirkung des Einflusses Moses Mendelssohns, dessen wöchentliche Lesegesellschaft sie besucht. Sie lernt mehrere Sprachen. 15-jährig wird sie mit dem Arzt Dr. Markus Herz am 1. Dezember 1779 verheiratet. Markus Herz hat sich als praktischer Arzt niedergelassen und ist aus seinen Studientagen begeisterter Anhänger Kants. Er hält in seinen Wohnräumen in der Spandauer Straße zunächst vor Patienten, später vor einem erweiterten Freundeskreis Vorlesungen über die Philosophie Kants und über Experimentalphysik. Seine Frau ist zunächst ebenfalls Zuhörerin, hält aber sehr bald einen zweiten Kreis im Nebenraum ab, der sich mehr literarischen Themen widmet. Im Salon der Henriette Herz sind Männer und Frauen vertreten. Dieser Salon ist nicht der einzige, aber einer der bekanntesten.

Zwischen 1790 und 1806 führte Rahel Varnhagen von Ense, geb. Levin (19. Mai 1771 in Berlin-7. März 1833) einen literarischen Salon, in dem Dichter, Naturforscher, Politiker, Gesellschaftsgrößen und Aristokraten auf einer Ebene miteinander verkehrten. Berühmte Gäste waren Jean Paul, Ludwig Tieck, Ernst von Pfuel, Friedrich Schlegel, Wilhelm und Alexander von Humboldt, Friedrich de la Motte-Fouqué, Prinz Louis Ferdinand und dessen Geliebte Pauline Wiesel.

Trotz der Unterschiedlichkeit ihrer Erscheinungsformen und -orte bleibt den europäischen Salonkulturen letztlich ein gemeinsames, Epochen übergreifendes Verdienst: In ihrer Funktion als Literatur- und Kunstproduktions- und 
Distributionsstätten haben sie die geistige Öffnung Europas zwischen Aufklärung und Romantik befördert.

Zugleich mit den Salons, den Lesegesellschaften und anderen Zusammenschlüssen der frühen Aufklärung bildeten sich in ganz Europa die Logen der Freimaurer und trugen zunächst auch zur Verbreitung aufklärerischer Ideen bei. Die »Maurerei« versteht sich als ein Bund mit der Überzeugung, dass die ständige Arbeit an sich selbst zu einem menschlicheren Verhalten führt. Die fünf Grundideale der Freimaurerei sind zugleich Aufklärungsideen: Freiheit, Gleichheit, Brüderlichkeit, Toleranz und Humanität, sie sollen durch die praktische Einübung im Alltag gelebt werden. Nach ihrem Selbstverständnis vereint sie Menschen aller sozialen Schichten, Bildungsgrade und Glaubensvorstellungen. In allen ihren Ausprägungsformen zählt sie weltweit gegenwärtig etwa fünf Millionen Mitglieder. Freimaurer haben sich der Verschwiegenheit sowie dem Grundsatz verpflichtet, freimaurerische Bräuche nicht nach Außen zu tragen (Arkanprinzip).

\section{Abbildung 9: Symbol der Freimaurerei}

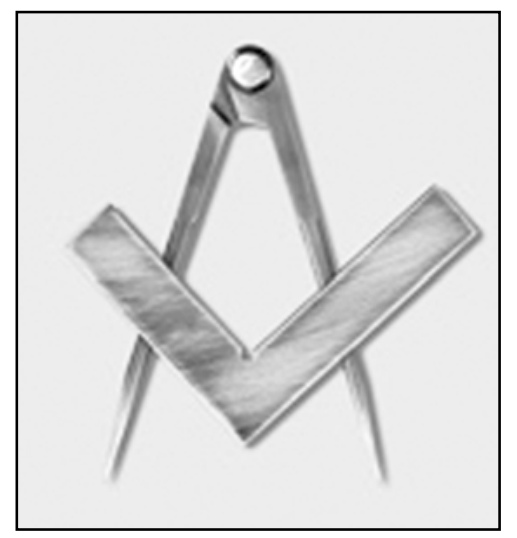

Die potentiellen Risiken zukünftiger progressiver Aufklärung angesichts bestehender despotischer Herrschaft beförderten einen engen Zusammenschluss interner Zirkel in Geheimgesellschaften. Und es ist erstaunlich, wie stark exponierte Vertreter der Vernunft - wie z.B. Lessing und Forster - gleichzeitig eingebunden und gefangen waren in alchemistische Ideenwelten und symbolische Beschwörungsriten. Offensichtlichster Grund war das Fortbestehen des Despotismus, der Öffentlichkeit auf das Private begrenzte. Das System des Absolutismus zwang zum Geheimhalten oppositioneller Aktivitäten. Alle Veröffentlichungen waren prinzipiell der Zensur unterworfen. Aber die Geheimniskrämerei ging weit über diese politischen Restriktionen hinaus. Gerade für vernünftige Denker strömt das Arkanum eine hohe Faszination aus. Mit dem Gebrauch der Vernunft werden auch ihre Grenzen deutlich. 
Gotthold Ephraim Lessing schreibt in den Freimaurergesprächen Ernst und Falk (LW 6, 308-338), es reiche nicht aus, in einer gesetzlichen Loge aufgenommen worden zu sein, um Freimaurer genannt zu werden, sondern es bedürfe der Einsicht und der Erkenntnis, was und warum die Freimaurerei ist. Die Wirkung der Freimaurerei erfolgt in täglicher Umsetzung ihrer Prinzipien durch gute »Taten, welche gute Taten entbehrlich machen sollen«.

Innerhalb der Freimaurerei etablierte sich als geheime, mystische Gesellschaft der Orden der »Rosenkreuzer«, dessen Anfänge vor und im 17. Jahrhundert liegen. In Deutschland wurde die Mutterloge »Zu den drei Weltkugeln« Hauptsitz der Rosenkreuzer in Deutschland. Die Lehrinhalte der Rosenkreuzer bestehen aus alchemistischen, hermetischen und kabbalistischen Elementen. Um 1756 tritt der freimaurerisch-rosenkreuzerische »Orden der Gold- und Rosenkreuzer« in Erscheinung, der sich vor allem durch einen orthodoxen Pietismus auszeichnete, in dem das tägliche Gebet, Fasten und Kasteien gehörte. Darüber hinaus beschäftigte man sich in den einzelnen Zirkeln mit der Kabbala, Alchemie und Magie. Das erklärte Ziel war die Vereinigung mit Gott, in der man die Geheimnisse der Natur zu beherrschen und $\mathrm{zu}$ verstehen versuchte.

\section{Abbildung 10: Geheime Figur der Rosenkreuzer}

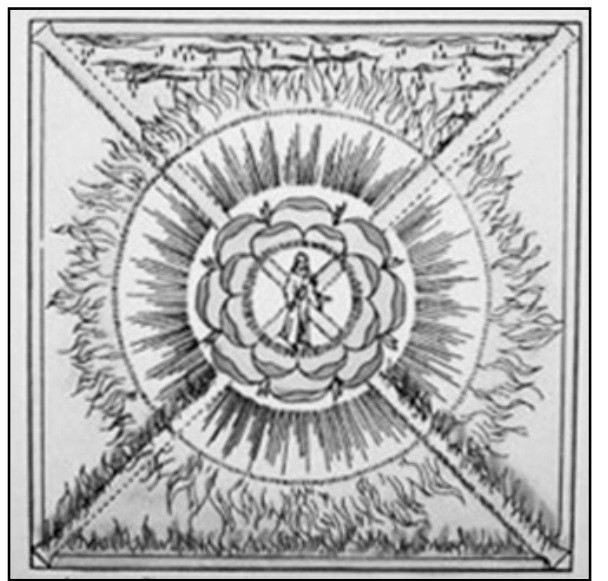

Der Orden der Erleuchteten (Illuminaten) war eine am 1. Mai 1776 von dem Philosophen und Kirchenrechtler Adam Weishaupt in Ingolstadt gegründete Geheimgesellschaft, der in seiner Anfangszeit nicht mehr als ein antiklerikaler Lesezirkel von höchstens zwanzig Mitgliedern war. Darüber hinaus sah Weishaupt im Orden der Gold- und Rosenkreuzer, eines mystisch-spiritualistischen Ordens innerhalb der Freimaurerei, ein immer stärker werdendes Übel. Die Illuminaten entwickelten sich dann aber selbst zur Verschwörungsgemeinschaft, was sie in das Fadenkreuz der Obrigkeit brachte. 


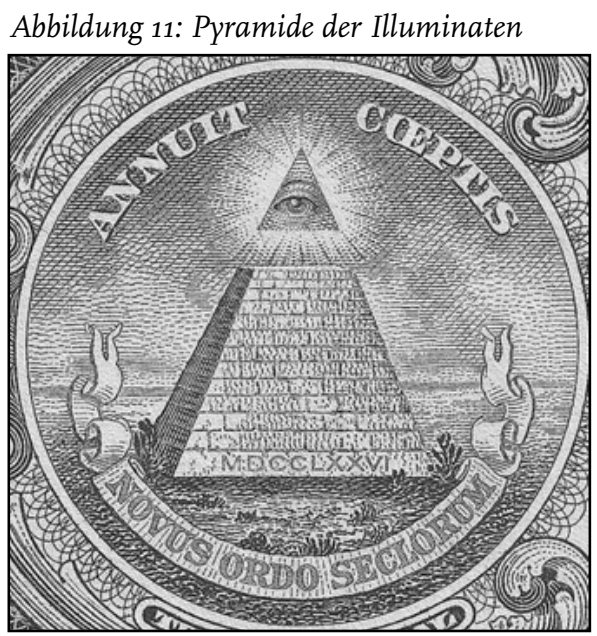

Zunächst waren diese Geheimgesellschaften von humanistischen Idealen wie Freiheit, Gleichheit und Brüderlichkeit ausgegangen. Sie begriffen die Verwirklichung der Aufklärung als Zielsetzung, die aber in der bestehenden politischen und sozialen Ordnung nicht verwirklicht werden konnte. So entstand für sie ein Zwang zur Geheimhaltung und Verschwörung und in der Konsequenz eine interne Organisation, die auf Gehorsam, Entmündigung, sogar Einschüchterung ihrer Mitglieder unter der Steuerung durch die Ordensoberen setzen musste. Deshalb entfernten sich zahlreiche Aufklärer wie Nicolai und Lessing wieder von den Freimaurern. Lessing äußerte in »Ernst und Falk«, den Gesprächen für Freimaurer, den Einwand, dass die vom absolutistischen Staat erzwungene Geheimhaltung von Aktivitäten und Personen die Aufklärung untergraben werde und sich in den Logen selbst reproduziere. Damit war zugleich das Ende der Geheimbünde angesagt. Das Geheime wurde Öffentlich.

Die Personen, die die Aufklärung - auch in den genannten Organisationsformen vorantrieben - waren eine Gruppe von Intellektuellen: Gebildete, Gelehrte, Literaten, Gens des Lettres, Schriftsteller, Geistesarbeiter. Sie waren Fackelträger der Aufklärung und personifizierten ihr Programm, sich seines Verstandes ohne Anleitung zu bedienen.

Sie vertreten eine Gesellschaftskritik, die sich nicht an Machbarkeit, an politischer Umsetzbarkeit, orientiert. Sie sind Exponenten eines allmählich wachsenden Zweifels an bestehenden Herrschaftsstrukturen, der Gestaltung zukünftiger Prozesse, über momentane argumentative Überzeugungen und Durchsetzungsstrategien hinaus. Sie sind Wissenschaftler, Schriftsteller und Dichter, Verleger und Kaufleute, Beamte und Staatsdiener, Geistliche und Philosophen, Pädagogen und Bildungsreformer. Sie vertreten institutionell nicht ermächtigte intellektuelle Kritik und beziehen den sozialen Standort unabhängiger Gelehrsamkeit. Bemerkenswert ist die Selbstwahrnehmung der Gebilde- 
ten gegenüber der Gesellschaft und im politischen Prozess. Sie entfalten einen Lebensstil und einen Habitus außeruniversitärer Gelehrsamkeit. Damit begeben sie sich schließlich in ein Spannungsverhältnis von kritischer Subversion und diskursiver Normstabilisierung durch kontinuierliche intellektuelle Reflexion gesellschaftlicher Werte. Sie sind Intellektuelle avant la lettre. Sie können nicht alle genannt werden. Nur einige wenige:

Wissenschaftler

Newton (1643-1736)

Linné (1707-1778)

Haller (1708-1777)

Lichtenberg (1742-1799

Forster (1754-1794)

\section{Literaten}

Lessing (1729-1781)

La Roche (1730-1807)

Verleger

Voss (1722-1795)

Nicolai (1733-1811)

Philosophen

Thomasius (1655-1728)

Wolff (1679-1754)

Voltaire (1694-1778)

Rousseau (1712-1778)

Diderot (1713-1784)

Kant (1724-1804)

Mendelssohn (1729-1786)

Garve (1742-1798)

Pädagogen und Bildungsreformer

Francke (1663-1727)

Basedow (1724-1790)

Rochow (1734-1895)

Trapp (1745-1818)

Campe (1746-1818)

Villaume (1746-1825) 


\subsection{Aufklärung als Reform}

Mit ihrer Orientierung an Vernunft wird Aufklärung zu einer Bewegung, die alle Lebensgebiete erfasst. Sie setzt ein kritisches Potential frei, das autoritäre und hierarchische Gesellschafts- und Herrschaftsstrukturen in Frage stellt. Kritik hinterfragt das Bestehende und öffnet eine Zukunft, die sie nicht sicher wissen kann. So wird Kritik eine Perspektive auf etablierte Gesellschaftszustände und geregelte Erkenntnisweisen, die nicht mit dem Etablierten assimiliert ist. Sie lässt einen Raum des Möglichen aufscheinen.

Als Emanzipationsstrategie des aufsteigenden Bürgertums propagierten Philosophen, Theologen, Publizisten und Pädagogen ein Selbstverständnis, das auf Gleichheit aller Menschen setzte - zunächst ohne Rücksicht auf Stand, Herkunft, Religion und Kultur. Später erst entwickelte Immanuel Kant 1784 in seiner »Idee zu einer Allgemeinen Geschichte in weltbürgerlicher Absicht « dem entsprechende juristische und politische Prämissen der bürgerlichen Gesellschaft:

"[S]o muß eine Gesellschaft, in welcher Freiheit unter äußeren Gesetzen im größtmöglichen Grade mit unwiderstehlicher Gewalt angetroffen wird, d. i. eine vollkommen gerechte bürgerliche Verfassung die höchste Aufgabe der Natur für die Menschengattung sein." (Kant 1969 XI, 39)

Diese - republikanische - Verfassung umgreift in Kants Entwurf »Zum ewigen Frieden« von 1795 erstens die Freiheit jedes Gliedes der Sozietät, als Menschen; zweitens die Abhängigkeit und Gleichheit aller von einer einzigen Gesetzgebung, als Untertanen; drittens die Selbständigkeit jedes Gliedes eines gemeinen Wesens, als Bürger (Kant 1969 XI, 204). Diese Freiheit ist nicht einfach gegeben, sie geht aber allmählich weiter und greift umfassender. So erweitert sich allmählich trotz aller Irrwege und Sackgassen »Aufklärung, als ein großes Gut« (Kant XI, 46).

Damit wird Kant auch einer der Begründer der Menschenrechte. Für ihn ist Freiheit das einzige Menschenrecht, von dem alle anderen, wie Gleichheit und Selbständigkeit, abgeleitet werden können. Das Recht kann - so Kant im Unterschied zur verbreiteten Naturrechtslehre - nicht von der Natur des Menschen bestimmt werden, ist vielmehr ein Vernunftrecht, das unabhängig von historischen, kulturellen, sozialen und religiösen Umständen gelten muss. Die Legitimation und vorrangige Aufgabe des Rechtsstaates ist demgemäß die Sicherung und Erhaltung der Freiheitsrechte.

Allerdings finden sich in der Aufklärung immer wieder auch Abgrenzungen und Polemiken gegen die Ignoranz der unteren Schichten und Polemiken gegen die Arroganz des Adels. Die Mehrzahl der Aufklärer verband das Postulat der Freiheit aller Menschen mit der Akzeptanz bestehender hegemonial erzeugter Ungleichheit. 
Trotz dieser Gehorsamsbereitschaft stieß die Bewegung zwangsläufig an gesellschaftliche Schranken und auf die geistige Dunkelheit etablierter Herrschaft. Im Kern musste sie auf vernünftiger Begründung bestehen. Deshalb ist Öffentlichkeit des Gedankenaustauschs für die bürgerliche Gesellschaft unverzichtbar. Öffentlichkeit als Strukturprinzip des Politischen erst einmal gedacht, lässt sich nicht eingrenzen - es sei denn durch eine Macht, die aber damit ihre Legitimität einbüßt und dann verliert. Das kritische Potential, das Unbehagen an despotischem Absolutismus, an wirtschaftlicher Rückständigkeit, an religiösen Dogmen, bricht immer wieder auf in der Idee des öffentlichen Vernunftgebrauchs.

Am schärfsten wirkte sie zunächst auf Religion, wobei der Protestantismus der Entfaltung des Aufklärungsdenkens günstigere Voraussetzungen bot als der Katholizismus mit seiner hierarchischen und dogmatischen Geschlossenheit. Religiöse Toleranz wird zum Ideal der Zeit, die alle Dogmen des Christentums und der Religionen der Kritik unterwirft. Bei genauerem Hinsehen ist Toleranz eine Zwischenstufe zur Menschlichkeit und zur Anerkennung der Menschenrechte.

Aus England und Frankreich drang der Deismus nach Deutschland. Zwar wird an einem Schöpfergott festgehalten, aber kein unmittelbares Einwirken auf die gegenwärtige Welt angenommen. Die Bezeichnung »Freigeist« meint im 18. Jahrhundert die Anhänger des Deismus. Sie unterstellen eine Zweiteilung der Welt: in eine der Vernunft erklärbare Erfahrung und eine dahinterliegende Schöpfung. Die Theologie selbst gibt orthodoxe Positionen auf und beschränkt sich auf eine Religion, die vernunftgemäß erscheint. Damit werden aber zugleich Grenzen der Rationalität gezogen und Reservate des Glaubens gesichert.

Die Mehrheit der Aufklärer lehnte das Althergebrachte keineswegs grundsätzlich ab, noch kämpfte sie entschieden für das sich Neuentwickelnde; sie plädierte vielmehr für eine kritische Reflexion als Voraussetzung reformorientierten Handelns. Die notwendige Umgestaltung des Bestehenden wird als allmählicher, langfristiger und friedlicher Reorganisationsprozess gesehen. Es geht darum, die Menschen mitzunehmen auf dem Weg zur Mündigkeit. So wird Bildung zum Kennwort des Zeitalters, das von einem tiefen pädagogischen Impetus geprägt ist. Das Vertrauen in die unbegrenzte Bildsamkeit der menschlichen Seele findet hier Ausdruck. In diesem Glauben ist die Aufklärung nichts anderes als eine einzige große Erziehungsbewegung, die, wie Kant sagt, den Menschen aus seiner selbstverschuldeten Unmündigkeit heraus zu Selbstbestimmung führen will.

Das wirkt sich zunächst im Schulwesen aus - in der Einführung der allgemeinen Volksschulpflicht - das preußische Generallandschulreglement vom 12. August $176_{3}$ wurde unter Friedrich II. verabschiedet -, im Ausbau der höheren Schule, in Ansätzen einer den »Realien« zugewandten Erziehungsweise. Auch die Universitätsgründungen in Halle (1684) und Göttingen (1737) folgen dem Geist der Aufklärung durch Berufsbezug. 
Aufklärung und Bildung werden zu Kennwörtern des Zeitalters, das von einem tiefen pädagogischen Impetus geprägt ist (Herrmann 1981). Das Vertrauen in eine unbegrenzte Bildsamkeit der menschlichen Seele findet hier Ausdruck. Im Glauben an die Plastizität und Perfektibilität aller Menschen wird die Aufklärung zur Erziehungsbewegung.

Wichtiger noch als das Schulwesen ist die Erwachsenenbildung der Aufklärung. Alle Schichten sollen - im Prinzip - Anteil an den Errungenschaften der Zeit und Zugang zum Wissen haben: die »Volksaufklärung« trägt schwer an dem Widerspruch von Bildung und Herrschaft (Heydorn 1970).

Auch die Stellung der Frau wird neu bestimmt. Ihre Beschränkung auf die Hauswirtschaft und Kinderpflege soll gelockert, ein Anschluss an die geistigen Bestrebungen gefördert werden. Ohne Zweifel haben Frauen einen erheblichen Anteil an der Verbreiterung des Lesepublikums und an einer aufklärerischen Gefühls- und Geschmackskultur.

Sein umfassendstes Feld findet der Reformeifer der Aufklärung in Staat und Gesellschaft. In Frankreich führt das Ringen um ihre zeitgemäße Einrichtung zur Revolution, in Deutschland zum »aufgeklärten Absolutismus«, wie er sich in der Regierungsweise Friedrichs II. (Regierungszeit 1740-86) oder Josephs II. (Regierungszeit 1765 als Kaiser und Mitregent Maria Theresias -1790) darstellt.

Abbildung 12: Goya »Auf dir, dem Schwachen« Caprichos 42

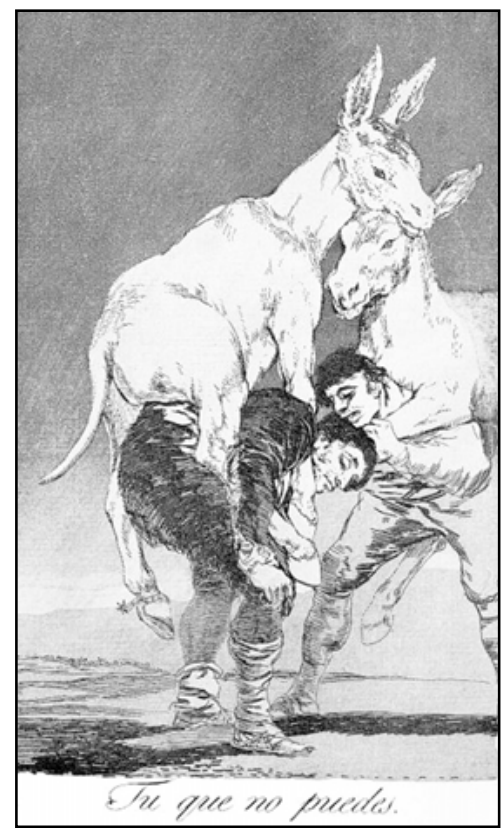


Allerdings sind diese Staaten keineswegs »aufgeklärt« im Sinne »praktischer Vernunft « und Urteilskraft. Sie stellen machtpolitisch gestützte Konflikte still, die sich zwischen legitimierender Rationalität und brutalem Militarismus herstellen. So ist nur konsequent: Im Juni 1740 erging kurz nach dem Regierungsantritt Friedrichs II. seine Verfügung, nach der keine Folter mehr angewandt werden dürfe; im Dezember 1740 marschierten die preußischen Truppen in Schlesien ein.

Die weitere Regierung des Preußenkönigs verweist auf einen zynischen Missbrauch der Aufklärung als Legitimationsstrategie, mit der Kritiker eingefangen wurden, während gleichzeitig die Soldaten für den Ruhm Friedrichs II. starben.

Die Bauern und Handwerker tragen die herrschenden Esel. Das hat José de Goya y Lucientes (30. März 1746 Fuendetodos, Aragón - 16. April 1828 Bordeaux) seiner Graphikserie Los Caprichos (Launen, Einfälle) unmissverständlich karikiert. Die Folge von 8o Aquatinta-Radierungen, entstanden zwischen 1796 und 1797, zeigt eine radikale Kritik am spanischen Gesellschaftsleben, insbesondere an Adel und Klerus. Sie erschien 1799 in einer Auflage von 270 Stück, wurde aber aus Furcht vor Repressalien der Inquisition zwei Tage nach dem Verkauf von nur 27 Stück von Goya aus dem Handel gezogen. Erst 1850 erschien eine Neuausgabe.

\subsection{Aufklärung als Horizont}

Der in Deutschland berühmteste Text zur Aufklärung ist erst spät - im Jahr 1784 - erschienen. Wie kein anderer hat Kant, den die deutsche Tradition nicht zu den Aufklärern rechnet, das Denken seiner Zeit präzise und konzis auf den Begriff gebracht.

Kants Theorie stellt den Scheitelpunkt der Aufklärung und zugleich einen Höhepunkt der idealistischen deutschen Philosophie dar. Einerseits hat er einen Programmtext geschrieben, der die Ideen und Prinzipien der Aufklärung aufgreift. Andererseits dreht sich seine Erkenntnistheorie immer wieder neu um die Grenzen der Vernunft und die Möglichkeit von Wahrheits-, Gültigkeitsund Schönheitsurteilen.

Kants äußeres Leben war wie kaum ein anderes gekennzeichnet durch ein äußeres geringes Maß an Aufgeregtheit. Er wurde 1724 in Königsberg geboren und starb 1804 in Königsberg. Ab 1840 studierte Kant dort Philosophie, Mathematik und Naturwissenschaft. Danach war er als Hauslehrer bei drei verschiedenen Familien in der Umgebung tätig. Bereits 1746 veröffentlichte er seine erste Schrift:

»Erste Abhandlung Gedanken von der wahren Schätzung der weltlichen Kräfte« (in Deutsch geschrieben und erschienen 1747). Er versuchte zwischen 
Cartesianern und Leibnizianern einen Ausgleich herzustellen. Mit einer lateinischen Abhandlung »De Igne« (Über das Feuer) promovierte er am 12. Juni 1755. Mit einer zweiten lateinischen Schrift über die Grundprinzipien der metaphysischen Erkenntnis, die er am 27. September verteidigte, wurde Kant Privatdozent für Philosophie an der Universität Königsberg. Die weitere Bedingung für das Lehramt erfüllte er im April 1756 mit der lateinischen Schrift »Über die physische Monadologie «.

Danach nahm er seine Lehrtätigkeit auf und begann seine Vorlesungen täglich von sieben bis neun Uhr. Oftmals über zwanzig Stunden wöchentlich. Der Bogen der Fächer war thematisch breit: Mathematik, Naturlehre, Anthropologie, physische Geographie, Logik, Metaphysik, Moralphilosophie, selbstverständlich Theologie, philosophische Enzyklopädie, Pädagogik und sogar Fortifikation und Pyrotechnik. Er bewarb sich auf eine Professur für Mathematik und Philosophie. Diese wurde ihm verwehrt. Er sollte allerdings die nächste frei werdende Stelle bekommen. Dies war 1764 die Professur für Dichtkunst, die neu besetzt werden musste. Diese lehnte er ab; nicht zuletzt deshalb, weil ihrem Inhaber die Aufgabe zufiel, alle jene Gelegenheitsgedichte zu verfassen, zu denen das akademische und öffentliche Leben einen Anlass bot. Er entzog sich also dem Zwang, offizielle Lobreden und -lieder zu dichten. Er trat stattdessen die keineswegs herausragende Stelle eines Unterbibliothekars an der königlichen Schlossbibliothek an. Es war seine erste feste Anstellung; er war damals 42 Jahre alt.

Nach abgelehnten Rufen nach Halle und Erlangen wurde 1770 die Professur für Logik und Metaphysik in Königsberg wieder vakant - die gleiche Stelle, um die Kant sich zwölf Jahre vorher vergeblich bemüht hatte. Hauptaugenmerk lag zunächst auf den Lehrveranstaltungen. Sein Vortrag bestand weniger in einer Wiedergabe vorhandener Lehrbücher, sondern er benutzte diese als Ausgangspunkt für eigene Gedanken, bei den öffentlichen Vorlesungen betrug die Zahl seiner Hörer zwischen 80 bis 100 - für die damalige Zeit ein sehr zahlreiches Auditorium.

Das Leben, das Kant vierzig Jahre als akademischer Lehrer führte, nahm äußerlich einen monotonen Verlauf. In seiner Regelmäßigkeit von Spaziergang, Lehrveranstaltung und Essen ist es berühmt-berüchtigt worden. Seine Bewegung fand hauptsächlich in seinem Kopf statt. Fast elf Jahre erschien von ihm keine nennenswerte Veröffentlichung. Immer wieder angekündigt hat er ein Hauptwerk, das endlich Ostern 1781 unter dem Titel »Critik der reinen Vernunft« herauskam.

Ziel dieser Schrift ist, kritisch den Nachweis zu führen, dass die spekulative Metaphysik in die Sackgasse des Selbstwiderspruchs geraten muss. Kant unternimmt den Versuch ein neues gesichertes wissenschaftliches Fundament der Wahrheit zu schaffen. Er setzt sich dazu kritisch mit seinen Vorgängern auseinander und zentraler Kritikpunkt ist die Vermischung zwischen sinnlicher und begrifflicher Erkenntnis. 
Die Auseinandersetzung mit Irrationalität und Schwärmerei hatte Kant bereits gegen Emanuel von Swedenborg (1688-1722) geführt. In der kleinen Abhandlung »Versuch über die Krankheiten des Kopfes« (1764) hat Kant versucht eine Ironie derjenigen Philosophen vorzulegen, die säkularisiert-religiöse »Auskunfteien für das Jenseits« seien, ohne allerdings die eigene Krankheit, die »Tobsucht eines gelehrten Schreiens«, zu bemerken.

"In diesem Fall aber wäre es ratsam, die Natur einen anderen Weg der Reinigung anzuweisen, damit das Übel gründlich und stille abgeführt werde, ohne das gemeine Wesen dadurch zu beunruhigen." (1764, in: Kant: Werke II, 901)

Solche Vorwürfe wurden konkretisiert am Beispiel Swedenborg, der als Visionär gleichzeitig den Ruf des exakten Wissenschaftlers genoss. Dieser Theosoph besaß sowohl mythische Fähigkeiten wie kühlen, klaren Verstand, der ihn zu Weltruf führte. Seine Schwärmerei jedoch artete aus in Religionsstiftung. Kants Schrift »Träume eines Geistersehers« ist eine aufklärerische Auseinandersetzung mit dem Spiritismus. Er prüfte die Wahrheit einiger Erzählungen; »er fand wie gemeiniglich, wo nichts zu suchen hat - er fand nichts« (1766, in: Kant: Werke II, 924). Kritisch nennt er die positiv-spekulativen Systeme der Metaphysik »Hypochondrische Winde, die in den Eingeweiden toben« (ebd.). Er wirft diesen Systemen einen »Erschleichungsfehler « vor, der darin besteht, dass eine mangelhafte Unterscheidung von mundus sensibilis (Sinneswelt) und mundus intelligibilis (Verstandeswelt) vorliegt.

Die Grenzen der Sinnlichkeit einerseits und der Vernunft andererseits ausführlich zu bearbeiten ist Absicht der »Kritik der reinen Vernunft«. Die Frage geht auf den Nachweis, welche Fragen die Vernunft als Denktätigkeit zu beantworten vermag und welche nicht. In Auseinandersetzung mit philosophischen Konzeptionen seiner Vorgänger, der Rationalisten wie Leibniz und in der Folge Wolff einerseits und der Empiristen wie Hume und Locke andererseits, hat er deren Erkenntnisarten gefasst: Dogmatiker stützen sich auf den Satz des Widerspruchs und lassen keinen Raum für die Erfahrung. Es können nur analytische Urteile gefällt werden. d.h. Urteile, die von vorhergehenden Begriffen ausgehen und diese zerlegen. Skeptiker dagegen lehnen jede Erkenntnis a priori - unabhängig von der Erfahrung - ab. Alle Erkenntnis wäre demnach nur a posteriori, nur durch sinnliche Wahrnehmung zu vollziehen. Die präzise Fragestellung der »Kritik der reinen Vernunft« ist: sind synthetische Urteile a priori möglich?

Die Kopernikanische Wende ist für Kant Beispiel einer transzendentalen - d.h. Sinnlichkeit und Vernunft verbindenden - Erkenntnis. Sie stellt ein synthetisches Urteil da, indem sie Erfahrungen einordnet in die Kategorien der Vernunft von Raum und Zeit. Es sind Erfahrung und Denken, welche einen logischen Fortgang von Wahrheit begründen. 
Damit hat Kant gegenüber der spekulativen Metaphysik einen wesentlichen Fortschritt erzielt, gleichzeitig gegenüber dem empiristischen Ansammeln von Daten. Es geht ihm um die Verbindung von Wahrnehmen und Denken. Dies erfolgt durch die reinen Anschauungen apriori: Raum und Zeit. Das Meer, das die Inseln der Wahrheit umgibt, wird von der Vernunft erfahren. In alle Himmelsrichtungen da es in ihrem Wesen liegt, der Dialektik, der Logik des Scheins notwendig zu verfallen:

"Es gibt also eine natürliche unvermeidliche Dialektik der reinen Vernunft, nicht eine, in die sich etwa ein Stümper, durch Mangel an Kenntnissen, selbst verwickelt, oder irgendein Sophist, um vernünftige Leute zu verwirren, künstlich ersonnen hat, sondern jeder menschlichen Vernunft anhängt, und selbst nachdem wir ihr Blindwerk aufgedeckt haben, dennoch nicht aufhören wird ihr vorzugaukeln [...] Dieses Land aber ist wie eine Insel, und durch die Natur selbst in unveränderliche Grenzen eingeschlossen. Es ist das Land der Wahrheit (ein reizender Name), umgeben von einem weiten stürmischen Ozeane, dem eigentlichen Sinn des Scheins, wo manche Nebelbank und manches bald weg schmelzendes Eis neue Länder lügt, und indem es auf den Entdeckungen herum schwärmende Seefahrer unaufhörlich mit leeren Hoffnungen in Abenteuer verflechtet, von denen niemals ablassen und sie doch noch niemals zu Ende bringen kann." (Ebd.)

Etikettierend könnte man Kant als idealistischen Konstruktivisten bezeichnen. Er nimmt allerdings nicht auf, dass sich auch die Kategorien historischen und kulturellen Konstellationen verdanken, dass auch Raum und Zeit unterschiedlich gefasst und vorgestellt werden können.

Die Vernunft ist für Kant zentrale menschliche Fähigkeit. Insofern schließt er an die Tradition der Frühaufklärung an und wird $\mathrm{zu}$ ihrem bekanntesten Propagator. Gleichzeitig geht er deutlich über deren Naivitäten hinaus. Kant ist ein ironischer Mensch und hält Widersprüche aus. Er erhofft, dass das freie Denken die Sinnesart des Volkes allmählich verändert und am Ende sich ein Mensch entwickelt, »der nun mehr als Maschin ist, seiner Würde gemäß zu handeln« (Kant 1784)

Die berühmte Schrift »Was ist Aufklärung?« (1784) ist geschrieben von einem Befürworter der französischen Revolution und deren Ehrenbürger im Bewusstsein, dass er im preußischen Staat mit Sanktionen rechnen musste. Kernbotschaft der Schrift ist es, dass Vernunft immer mehr zunehme, und somit Aufklärung ein Prozess ist, der letztlich alle erreicht.

Die »Beantwortung der Frage: Was ist Aufklärung?«, die Immanuel Kant in der »Berlinischen Monatsschrift« vom 5. Dezember 1784 gegeben hat, ist die in Deutschland entschiedenste und berühmteste Stellungnahme: 
Abbildung 13: Immanuel Kant

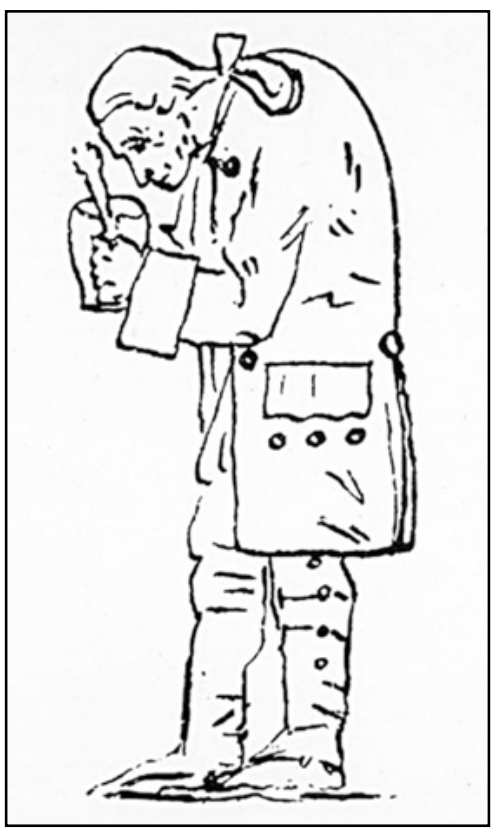

"Aufklärung ist der Ausgang des Menschen aus seiner selbstverschuldeten Unmündigkeit. Unmündigkeit ist das Unvermögen, sich seines Verstandes ohne Leitung eines anderen zu bedienen. Selbstverschuldet ist diese Unmündigkeit, wenn die Ursache derselben nicht am Mangel des Verstandes,sondern der Entschließung und des Mutes liegt, sich seiner ohne Leitung eines anderen zu bedienen. Sapere aude! Habe Mut, dich deines eigenen Verstandes zu bedienten! ist also der Wahlspruch der Aufklärung." (Kant: Werke XI, 53)

Es geht um die Freiheit, »von seiner Vernunft in allen Stücken öffentlichen Gebrauch zu machen« (ebd. 55). Das Wissen soll allen gehören. Wissenschaftlichkeit und Verständlichkeit, Scholastik und Popularität werden nicht als Gegensatz gesehen, sondern Klarheit und Nachvollziehbarkeit gelten als Beweis für die Tiefe der Erkenntnis.

Kant betont den Gang, nicht das Ergebnis, den Prozess, nicht das Resultat. Aufklärung wird demgemäß nicht als Zustands- sondern als Entwicklungsbegriff aufgenommen. Es geht um Ausgang aus Unmündigkeit. Hier schon - im ersten Satz - wird die kritische Perspektive deutlich: Aufgehoben werden soll die Leitung durch andere. Und die Reichweite geht bis zu Selbstkritik, indem Unterwerfung als selbstverschuldet der eigenen Faulheit und Feigheit angelastet wird. Es ist jedoch vom abstrakten Menschen die Rede, nicht vom Einzelnen.

Aber zugleich steckt hier auch schon in der Entschuldigung eine Anklage der Herrschenden, die die Führung übernommen haben. Erst nachgeordnet wird erwähnt, aber dann wütend betont, dass diese die »Oberaufsicht« »gütigst auf sich genommen haben. Nachdem sie ihr Hausvieh zuerst dumm gemacht haben, und sorgfältig verhüteten, dass diese ruhigen Geschöpfe ja keinen Schritt außer dem Gängelwagen, darin sie sie einsperreten, wagen durften: so zeigten sie ihnen nachher die Gefahr, die Ihnen drohet, wenn sie versuchen allein zu gehen « (ebd. 54).

Dagegen soll der aufgeklärte Mensch nicht mehr an die Vorgaben der Obrigkeiten oder Zwänge von Mode und Zeitgeist gebunden sein, sondern sein Leben und Denken selbst bestimmen. 
Inwieweit dies Kant bewusst ist, wird deutlich, wenn er davon spricht, dass »ein Publikum nur langsam zur Aufklärung gelangen« kann« (ebd.). Insofern kann ein Umsturz nicht zum Erfolg führen:

"Durch Revolution wird vielleicht wohl ein Abfall von persönlichem Despotism und gewinnsüchtigere oder herrschsüchtiger Bedrückung, aber niemals wahre Reform der Denkungsart zu Stande kommen; sondern neue Vorurteile werden, eben sowohl als die alten, zum Leitbande des gedankenlosen großen Haufens dienen." (Ebd. 54/55)

So steht die Möglichkeit des öffentlichen Vernunftgebrauchs lediglich einer gebildeten Elite von Beamten, Offizieren, Geistlichen und Gelehrten zur Verfügung, während die Masse der Bevölkerung, des Lesens und Schreibens unkundig, von vornherein ausgeschlossen ist, mithin am Prozess der Aufklärung nicht partizipiert, weder als Rezipienten, noch als Multiplikatoren.

Daraus ergibt sich eine doppelte Einschränkung der Aufklärung: Zum einen ergibt sich eine Beschränkung auf Gebildete. Offensichtlich unterstellt Kant, dass der »große Haufen« zunächst weiter der Führung bedarf.

Zum andern vollzieht er eine Eingrenzung des Vernunftgebrauchs auf den »öffentlichen« Bereich. Der Mensch ist hier »Glied eines gemeinsamen Wesens, ja sogar der Weltbürgerschaft« (ebd. 56$)$. Im »privaten« Bereich - gemeint ist hier die berufliche Stellung - würden »die Geschäfte leiden« und »räsonieren« wäre »sehr verderblich« (ebd.). Während sich ein Mensch also im privaten Gebrauch, also z.B. im Rahmen der Ausübung eines Amtes, dessen Erfordernissen uneingeschränkt zu fügen hat, indem er eben dort keine Kritik üben wird, kann derselbe empfundene Missstände bspw. eben seiner Tätigkeit im Rahmen von Schriften als Gelehrter kritisieren. Es ergibt sich daraus eine herausragende Rolle der Gelehrten. Die Einschränkung der Raison führt zu einer Spaltung von Person und Amt.

So ergibt sich die paradoxe Aussage über den Preußenkönig Friedrich II.

"der, selbst aufgeklärt, sich nicht vor Schatten fürchtet, zugleich aber ein wohl diszipliniertes zahlreiches Heer zum Bürgen der öffentlichen Ruhe zur Hand hat, kann das sagen, was ein Freistaat nicht wagen darf: räsoniert, so viel ihr wollt, und worüber ihr wollt; nur gehorcht! So zeigt sich hier ein befremdlicher nicht erwarteter Gang menschlicher Dinge; so wie auch sonst, wenn man inn im großen betrachtet, darin fast alles paradox ist." (Ebd. 61)

Raison wird abgesichert durch Militär. Kant stützt so die Einordnung der Vernunft in »aufgeklärte Herrschaft«. Aber er ist sich selbst dieser Widersprüchlichkeit bewusst und lässt das aufscheinen. Der Professor im preußischen Königsberg vollzieht eine Gradwanderung, hinter deren Überschreiten er sein Amt verlieren würde. 
Allerdings strickt bereits Kant so auch mit an der Legende Friedrichs II. (als der Große bezeichnet). Um den Despoten Friedrich II als Geistesverwandten der Aufklärung erscheinen zu lassen, werden die immer gleichen Zitate angeführt, die den Charakter geflügelter Worte erhalten haben: Erstens: Der Fürst sei der erste Diener des Staates. Zweitens: Ich will ein König der Armen sein. Drittens: Gazetten dürfen nicht genieret werden. Viertens: In meinen Staaten kann jeder nach seiner Facon selig werden. (Genannt bei Mehring 1983, 67)

Diese Grundsätze stehen allerdings mit der tatsächlichen Regierung des Königs in schreiendem Widerspruch. Es geht letztlich um eine Erweiterung und Modernisierung des Absolutismus. Gleichzeitig förderte Friedrich II. die Junkerherrlichkeit wie keiner der preußischen Potentaten vor oder nach ihm. Lessing nicht in Preußen sesshaft - betonte, dass es in dem sklavischsten Land Europas unmöglich sei, seine Stimme klar für die Volksrechte zu erheben.

\subsection{AufkLÄrung als Fiktion}

Leben in Widersprüchen und Umbrüchen wird angesichts der gesellschaftlichen Diskrepanz fortdauernder Unterdrückung und beginnender Befreiung zur Normalität. Der Ausgang aus der religiösen und politischen Unmündigkeit gelingt nur als Ausnahme. Leiden an der Gesellschaft verkrümmt die individuelle Biographie.

Mitleid ist es, was Karl-Philipp Moritz (1756-1793) in seinem mehr oder weniger autobiographischen Roman »Anton Reiser« anruft. Die eigene Biographie wird ihm zum Medium. Er zeigt die eigenen Wunden, die ihm in seiner Erziehung durch religiösen Wahn, familiäre Enge und disziplinierenden Schulzwang zugefügt worden sind. Er stilisiert sich selbst in theatralischer Pose. Sein Leiden an der Welt führt ihn zum Schauspiel und zum autobiographischen Roman, in dem der Weg aus pietistischer Schwärmerei über die kontrollierende Schule bis zur individualistischen Seelenkunde verdichtet wird.

Moritz - geb. 15.9.1756 in Hameln, gestorben am 26.6.1793 in Berlin - war mit zwölf Jahren Hutmacher-Lehrling in Braunschweig, beging 1770 einen Selbstmordversuch, erhielt dann ab 1771 bis 1776 ein Stipendium zum Besuch der Stadtschule in Hannover, 1776 Student in Erfurt und schloss sich im gleichen Jahr in Gotha der Wanderbühne Johann Konrad Dietrich Ekhofs an. Er wurde Lehrer am Philanthropin in Dessau, dann am Berlinischen Gymnasium zu Grauen Kloster, wurde 1779 in die »Johannis-Loge zur Beständigkeit« in Berlin aufgenommen, gab das Lehramt auf, reiste nach England und durch Deutschland. Ab 1783 bis 1793 gab er das »Magazin zur Erfahrungsseelenkunde« heraus. 1791 wurde Moritz zum »Kgl. Preußischen Hofrat« ernannt und Mitglied der Akademie der Wissenschaften. Er wurde berühmt als Verfasser von Romanen, kunsttheoretischen Abhandlungen und Schriften über Grammatik und Sprach- 
philosophie, Mythologie und Altertumskunde, Psychologie und Pädagogik, Poetik und Stilistik.

Moritz ist selbst - wie auch sein Protagonist Anton Reiser - in Armut aufgewachsen; die Familienverhältnisse waren durch religiöse Streitigkeiten der Eltern zerrüttet. Der Vater, ein in militärischen Diensten stehender Oboist, war Quietist und Anhänger des Separatisten Johannes Friedrich von Fleischbein, die Mutter setzte ein kirchentreues, dabei pietistisch gefärbtes Luthertum dagegen. Nach Ende des Siebenjährigen Kriegs 1763 zog die Familie nach Hannover, wohin das Regiment des Vaters verlegt worden war. Der Vater befasste sich anfangs selbst mit der Erziehung des Sohnes. 1768 wurde Moritz nach Braunschweig zu einem quietistischen Hutmacher in die Lehre gegeben. Ständige Unterdrückung durch seinen Lehrherrn führte nach anderthalb Jahren körperlicher und seelischer Qualen zu einem Selbstmordversuch. Während des obligatorischen Konfirmandenunterrichts wurde der Garnisonspfarrer auf die Begabung des Jungen aufmerksam und verschaffte ihm Freitische und ein Stipendium, so dass Moritz im Frühjahr 1771 das Gymnasium in Hannover »beziehen« konnte. Die armseligen Lebensbedingungen verdüsterten jedoch seinen weiteren Lebensweg.

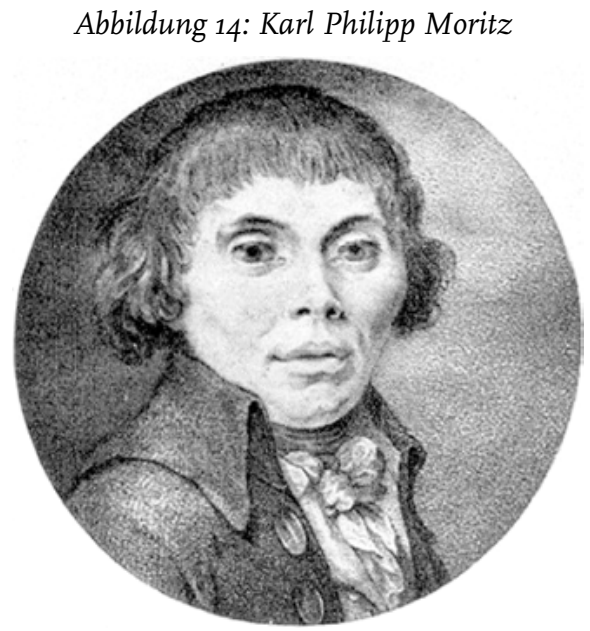

Schon zu seinen Lebzeiten war Moritz vor allem als der Verfasser des »Anton Reiser« (4 Teile, Berlin 1785-90) bekannt. Dieser Ruhm ist verständlich, denn es handelt sich um einen historisch aufschlussreichen und menschlich erschütternden Text. Laut Untertitel »ein psychologischer Roman« ist er zugleich Autobiographie. Bemerkenswert ist v.a. der psychologische Tiefblick, mit dem Moritz die seelischen Regungen des Kindes und des jugendlichen Anton Reiser durchdringt und analysiert. Immer wieder überrascht die psychologische Pathographie des Romans durch die Vorwegnahme späterer Erkenntnisse der 
Psychologie. Phänomene des Unbewussten wie Minderwertigkeitskomplex, Verdrängung, Ersatzbefriedigung, Kompensation sind präzise erkannt und beschrieben. Die Selbsttäuschungen und Verstellungen des jungen Reiser, seine ästhetisierende Empfindsamkeit und Flucht in die Phantasiewelt des Theaters werden schonungslos bloßgelegt und im vierten Teil mit dem objektivistischen Konzept klassischer Ästhetik und Anthropologie als dem positiven Gegenbild konfrontiert.

"Dieser psychologische Roman könnte auch allenfalls eine Biographie genannt werden, weil die Beobachtungen größtenteils aus dem wirklichen Leben genommen sind. - Wer den Lauf der menschlichen Dinge kennt und weiß, wie dasjenige oft im Fortgange des Lebens sehr wichtig werden kann, was anfänglich klein und unbedeutend schien, der wird sich an die anscheinende Geringfügigkeit mancher Umstände, die hier erzählt werden, nicht stoßen. Auch wird man in einem Buche, welches vorzüglich die innere Geschichte des Menschen schildern soll, keine große Mannigfaltigkeit der Charaktere erwarten: denn es soll die vorstellende Kraft nicht verteilen, sondern sie zusammendrängen und den Blick der Seele in sich selber schärfen. - Freilich ist dies nun keine so leichte Sache, daß gerade jeder Versuch darin glücken muß - aber wenigstens wird doch vorzüglich in pädagogischer Rücksicht das Bestreben nie ganz unnütz sein, die Aufmerksamkeit des Menschen mehr auf den Menschen selbst zu heften und inm sein individuelles Dasein wichtiger zu machen." (Moritz: Reiser Vorrede 1785)

Moritz projiziert seine eigenen Leiden auf seine Romanfigur: »Reiser« gerät in ein Elternhaus, das zerrissen ist durch religiösen Streit gesteigert zu persönlichem Hass:

"Wenn er in das Haus seiner Eltern trat, so trat er in ein Haus der Unzufriedenheit, des Zorns, der Tränen und der Klagen.

Diese ersten Eindrücke sind nie in seinem Leben aus der Seele verwischt worden und haben sie oft zu einem Sammelplatze schwarzer Gedanken gemacht, die er durch keine Philosophie verdrängen konnte. [...] So schwankte seine junge Seele beständig zwischen $\mathrm{Haß}$ und Liebe, zwischen Furcht und Zutrauen zu seinen Eltern hin und her." (Moritz 1785 [1979] 15/16)

Sein Bedürfnis nach Zuwendung und Liebe blieb unerfüllt. Die Eltern gaben ihm kaum

"Überreste väterlicher und mütterlicher Liebe, so daß er nun fast ganz vernachlässiget wurde und sich, sooft man von ihm sprach, mit einer Art von Geringschätzung und Verachtung nennen hörte, die ihm durch die Seele ging“ (ebd.).

"Am Ende freilich ward dies Gefühl ziemlich bei inm abgestumpft; es war inm beinahe, als müsse er beständig gescholten sein, und ein freundlicher Blick, den er einmal er- 
hielt, war inm ganz etwas Sonderbares, das nicht recht zu seinen übrigen Vorstellungen passen wollte." (Ebd.)

Auch Freundschaft und Kameradschaft blieben ihm fremd:

"Er fühlte auf das innigste das Bedürfnis der Freundschaft von seinesgleichen: und oft, wenn er einen Knaben von seinem Alter sahe, hing seine ganze Seele an ihm, und er hätte alles drum gegeben, sein Freund zu werden; allein das niederschlagende Gefühl der Verachtung, die er von seinen Eltern erlitten, und die Scham wegen seiner armseligen, schmutzigen und zerrißnen Kleidung hielten inn zurück, daß er es nicht wagte, einen glücklichern Knaben anzureden.

So ging er fast immer traurig und einsam umher, weil die meisten Knaben in der Nachbarschaft ordentlicher, reinlicher und besser wie er gekleidet waren und nicht mit inm umgehen wollten, und die es nicht waren, mit denen mochte er wieder wegen ihrer Liederlichkeit und auch vielleicht aus einem gewissen Stolz keinen Umgang haben.

So hatte er keinen, zu dem er sich gesellen konnte, keinen Gespielen seiner Kindheit, keinen Freund unter Großen noch Kleinen." (Ebd. 16/17)

»Anton« setzt, nachdem er auf alle Erwartungen auf Elternliebe und Freundschaft aufgegeben hat, alle seine Hoffnungen auf die Schule.

"Nun war doch einer von Antons eifrigsten Wünschen, einmal in eine öffentliche Stadtschule gehen zu dürfen, zum Teil erfüllt.

Beim ersten Eintritt waren ihm schon die dicken Mauern, dunklen gewölbten Gemächer, hundertjährigen Bänke und vom Wurm durchlöcherten Katheder nichts wie Heiligtümer, die seine Seele mit Ehrfurcht erfüllten.

Der Konrektor, ein kleines muntres Männchen, flößte inm, ohngeachtet seiner nicht sehr gravitätischen Miene, dennoch durch seinen schwarzen Rock und Stutzperücke einen tiefen Respekt ein.

Dieser Mann ging auch auf einen ziemlich freundschaftlichen Fuß mit seinen Schülern um: gewöhnlich nannte er zwar einen jeden Ihr, aber die vier öbersten, welche er auch im Scherz Veteraner hieß, wurden vorzugsweise Er genannt.

Ob er dabei gleich sehr strenge war, hat doch Anton niemals einen Vorwurf noch weniger einen Schlag von inm bekommen: er glaubte daher auch in der Schule immer mehr Gerechtigkeit als bei seinen Eltern zu finden." (Ebd. 39)

Aber auch seine Schullaufbahn entwickelte sich unglücklich. Die unerfüllbaren Anforderungen des Vaters, die sich in der Schule fortsetzten, entzog er sich durch Heuchelei, der geforderten Disziplin durch Fiktion. Er flüchtete in eine Welt der Buchstaben und verfiel einer Lesewut. Was er im Leben nicht fand, suchte er in der Literatur, zuerst in Erbauungsschriftchen und Heiligengeschichten, dann im Roman und im Theater. 
"Seine Begierde zu lesen war nun unersättlich. Zum Glücke standen in dem Buchstabierbuche außer den biblischen Sprüchen auch einige Erzählungen von frommen Kindern, die mehr wie hundertmal von inm durchgelesen wurden, ob sie gleich nicht viel Anziehendes hatten. [...]

Durch das Lesen war inm nun auf einmal eine neue Welt eröffnet, in deren Genuß er sich für alle das Unangenehme in seiner wirklichen Welt einigermaßen entschädigen konnte. Wenn nun rund um inn her nichts als Lärmen und Schelten und häusliche Zwietracht herrschte oder er sich vergeblich nach einem Gespielen umsah, so eilte er hin zu seinem Buche.

So ward er schon früh aus der natürlichen Kinderwelt in eine unnatürliche idealistische Welt verdrängt, wo sein Geist für tausend Freuden des Lebens verstimmt wurde, die andre mit voller Seele genießen können." (Ebd. 18)

Moritz Leben ist ein Musterbeispiel einer Biographie im 18. Jahrhundert. Langsam nur konnte er sich aus der quietistischen bzw. pietistischen Atemnot befreien. Die Schule der Vernunft aber war ebenfalls gekennzeichnet durch Disziplin und Kontrolle. So wurde er in die Zick-Zack-Sprünge verschiedener Fluchten getrieben. Genuss fand er nur in der Fiktion des Romans und des Theaters. Vor den gesellschaftlichen Zwängen zog er sich zurück ins eigene Ich und versuchte in der »Erfahrungsseelenkunde« eine tragfähige Grundlage zu finden. Glücklich war dieses Leben nur in Augenblicken. Hauptkennzeichen waren seine Zerrissenheit und Unstetigkeit. Reisen bedeutete für »Reiser« die weitergehende Suche nach Einheit, das immer wieder neue Verlassen der Orte als Zwischenhalte und eine nie beendete Unstetigkeit. Von frühester Kindheit an war Moritz verfolgt von schmerzhaftesten Krankheiten. Er starb an einem »Lungenleiden«, das wie Feuer in ihm brannte und ihn nach Eis betteln lies.

Die sozialen und politischen Widersprüche der Aufklärung kumulieren in biographischen Zerstörungen. Beginnende Vernunft bricht sich an weiterwirkender Unmündigkeit. Die Epoche kann ihre eigenen Ansprüche nicht einlösen.

\subsection{Probleme mit der Aufklärung}

Die Widersprüche der Aufklärung öffnen das Einfallstor für konservative und auch reaktionäre Gegenaufklärung. »Aufklärung« hat besonders in Deutschland immer schon einen schwierigen Mitklang. Ihre Rezeption ist versperrt durch die Entwicklung im 19. Jahrhundert, das sich mit einer ungeheuren Ereignis-, Ideen- und Stilfülle »vor das 18. geschoben« (Vierhaus 1981, 15) hat. Die Vorstellung, »Aufklärung sei einseitig rationalistisch, abstrakt, ahistorisch und areligiös, der Staat dieser Zeit eine seelenlose Maschine, die Kirche erstarrt, die Dichtung bloß lehrhaft gewesen« (ebd.) ist lange vertreten worden und noch 
vorherrschend. Klassik, Neuhumanismus, Idealismus, Romantik, das Aufbrechen des geschichtlichen Denkens wurden als Gegenschlag gegen den Rationalismus und das naturrechtliche Denken der Aufklärung und als Überwindung des 18. Jahrhunderts verstanden. Schon die geschichtswissenschaftliche Periodisierung isoliert in diffamierender Absicht Aufklärung von den folgenden Epochen.

Aufklärung hat deshalb nach wie vor gerade in Deutschland keinen guten Ruf. Nachdem die Widersprüchlichkeit des bürgerlichen Emanzipationsprozesses nachgewiesen worden ist, scheint sie Opfer einer hämischen Vernunftkritik, die eh immer schon zu wissen glaubt, dass gesellschaftliche Rationalität und individuelle Freiheit nicht möglich seien. Aufklärung gilt - besonders in Deutschland - als flach, vernünftlerisch und gefühlskalt. »Flachheit« wird unterstellt gegenüber der »eigentlichen« philosophischen »Tiefe«. Es wird gegen platten, intellektualistischen Schmutz, »Aufklärischt«, polemisiert gegenüber einer tiefgründigen, gefühlsbeladenen religiösen Dunkelheit. In nationalhistorischer Perspektive wird Aufklärung als eine dem »deutschen Wesen« unangemessene, feindliche Tendenz diffamiert, vor der eine romantische bis nationalsozialistische Idee der volkhaften Seelengemeinschaft zu schützen sei. Vernunft wird gegen Gefühl ausgespielt.

Der Schock der Französischen Revolution ist dem deutschen Bürgertum in die Glieder gefahren. So weit sollte die Freiheit dann doch nicht gehen, dass sie tatsächlich alle Menschen erreichte. Die Idee der Menschheit war angenehmer als die schmutzigen Pariser Marktfrauen. Vor den Konsequenzen der Politik flüchtete die Philosophie in den Idealismus. Die Bürger traten den Rückzug in die Innerlichkeit an, empfindsamere Geister sogar - wie Friedrich Hölderlin - in den Wahnsinn.

Die dem angemessene bildungstheoretische Reaktion war die »HumboldtStrategie «: die Trennung des »Allgemeinen«, d.h. auch des Politischen, vom Beruflichen, d.h. Ökonomischen. Diese Desintegration fand ihren Niederschlag im Begriff der Bildung - in der Abspaltung von allgemeiner und beruflicher Bildung.

Dies verweist auf ein fortbestehendes Strukturprinzip der kapitalistischbürgerlichen Gesellschaft in der Ausbeutung in unterdrückender Produktion und der vertraglichen Regulation der Distribution: Wenn die Diskussion überhaupt einen Sinn haben kann, so dann, weil Individuen in unterschiedlichen Bezügen stehen, je nachdem, ob es um den Einsatz des Arbeitsvermögens oder um das Herstellen gesellschaftlicher Zusammenhänge geht. Nach wie vor ist Arbeitstätigkeit in der kapitalistischen Wirtschaft geprägt durch Entfremdung, Ein- und Unterordnung. Gleichzeitig ist es Legitimationsprinzip der bürgerlichen Gesellschaft, ausgehend von demokratischen Postulaten nach Gleichheit und Freiheit, die Entfaltung aller zu ermöglichen. Diesen Widerspruch spiegeln die Bildungstheorien in ihren verschiedenen Ausformungen im Hinundher- 
schwingen zwischen Mündigkeit und Nützlichkeit. Das Berufliche steht dann für Einsatzfähigkeit und Verwertbarkeit, das Allgemeine, das sich als das Politische darstellt, für das Gemeinsame und Befreiende.

Dies spiegelt sich in der bürgerlichen Gesellschaft auch in der Spaltung von Privatheit und Öffentlichkeit. Spätestens der Neuhumanismus setzte die begriffliche Trennung des Beruflichen und des Allgemeinen, wobei das Kulturelle und das Politische mit gemeint war, durch und begründete damit - teils ungewollt - eine Abwertung von Beruf und Arbeit. Als Exponent dieser Position, welche die Berufsbildung aus der Allgemeinbildung ausschließt, wird immer wieder Wilhelm von Humboldt (1767-1835) zitiert.

»Aufklärung « behielt einen schwierigen Mitklang und durchlief eine steinige Geschichte. Ein revidiertes Verständnis der Aufklärung setzt also eine Kritik der Romantik und ihrer Folgen voraus.

Moses Mendelssohn hat die »Dialektik der Aufklärung « früh erkannt. Unter dem Deckmantel der Befreiung kann sich die Unterdrückung fortsetzen. Er unterscheidet zwischen Gebrauch und Missbrauch, und er sieht die Gefahr: »Je edler ihre Blüte, desto scheußlicher in ihrer Verwesung und Verderblichkeit.« (Mendelssohn in: Bahr 1996, 7)

Mindestens die »Dialektik der Aufklärung (Horkheimer/Adorno 1969 [1944]) ist nunmehr mitzudenken. Die Grenzen des Fortschrittsglaubens sind aufgedeckt und dessen Perversion in Unterdrückung und Verdummung. Insofern können wir heute nicht mehr über Aufklärung so nachdenken wie noch die Traditionslinie von Thomasius (1655-1738), der 1687 die erste Vorlesung auf Deutsch ankündigte, bis Kant (1724-1804), der 1784 auf die Frage »Was ist Aufklärung? « die bis heute nachhaltigste Antwort gab. Es geht um »reflexive« Aufklärung, welche sich der Grenzen und Gefahren technischer Rationalität bewusst ist.

Kern der Reflektion ist eine Kritik der »instrumentellen Vernunft«, welche beschränkten Zweckhaftigkeiten und Nützlichkeiten dient (Horkheimer 1937). Technische Rationalität immer effizienterer Ausbeutung von Natur und Menschen wird irrational bezogen auf die Gesamtheit und hat einen Grad erreicht, der das Weiterleben der Gattung selbst bedroht. Die Erfahrungen mit dem nationalistischen später finanzkapitalistischen Imperialismus sind nicht mehr wegzudenken - höchstens zu verdrängen. Eine zumindest in der Frühaufklärungen mitschwingende Fortschrittsgläubigkeit trägt schon lange nicht mehr.

Die Begründungen aufklärerischer Aktivitäten lagen auf drei Ebenen: Eine volksfreundliche (philanthropische): das Volk solle aus Unterdrückung befreit werden; eine volkswirtschaftliche (politisch-ökonomische): die nach den Glaubenskriegen daniederliegende Wirtschaft solle in Schwung gebracht werden und eine - diesen dienende - volksbildnerische (pädagogische). 
Diese Legitimationsstränge geraten notwendig in Widerspruch zueinander insofern gibt es hohe Vielfalt, Spannung und Gegensätzlichkeit in der Aufklärung. Am Problem, dass Bildung und Wirtschaftswachstum keineswegs einlinig ineinander aufgehen, arbeitet die historische Bildungswissenschaft seit ihren Anfängen.

Abbildung 15: Wolken vor der Sonne (Zeitgenössischer Druck)

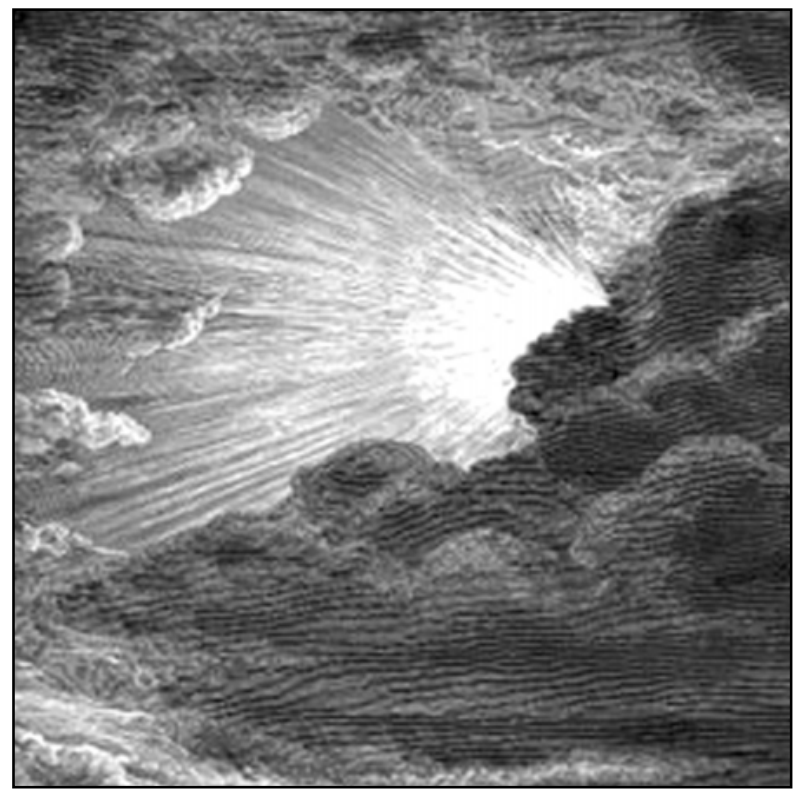

In dieser Tradition hat sich Aufklärung über eine »zweite« und »dritte« Aufklärung (Meissner 1969) zu einem allgemeinen Prinzip kritischer Vernunft entwickelt. Allerdings hat der Glaube an die Vernunft auch Gegenströmungen erzeugt und die Kritik der Kritik.

\subsection{WeiterWirKende TENDENZEN}

Mit dem Spannungsverhältnis von Vernunft und Herrschaft sind Perspektiven und Risiken des Prozesses der Aufklärung benannt. Der Widerspruch von Macht und Wissen wirkt fort. Wissen ist einerseits Prämisse von Freiheit, andererseits Instrument von Herrschaft. Der Spruch »Wissen ist Macht!« ist im Deutschen ein geflügeltes Wort, das auf den englischen Philosophen Francis Bacon (15611626) zurückgeht. Sein Bestreben, den Menschen in einen höheren Stand seines Daseins zu bringen, drückte sich 1597 in seinen »Meditationes sacrae« in der Formulierung »Nam et ipsa scientia potestas est« (Denn die Wissenschaft 
selbst ist Macht.) aus. In der englischsprachigen Fassung von 1598 lautete der Satz: »For knowledge itself is power« (Denn Wissen selbst ist Macht.).

Diese hoffnungsvolle, weil anspornende These gibt der Wissensaneignung eine wichtige Aufgabe bei der Beseitigung unbegründeter Herrschaft. Diese naive, weil nur halb richtige Illusion hat Wilhelm Liebknecht (1826-1900) in seiner berühmten Dresdener Rede 1872 »Wissen ist Macht - Macht ist Wissen« (Liebknecht 1968, 49-95) kritisiert. Der Vorsitzende der aufstrebenden Sozialdemokratie unterstellt die These »Wissen ist Macht!« den Gegnern:

"Ja, im Munde unserer Gegener und gegen uns angewandt, zur Widerlegung des von uns, von der Sozialdemokratie verfochtenen Satzes, dass die Haupttätigkeit des Arbeiters sich auf die Umgestaltung der staatlichen und gesellschaftlichen Verhältnisse zu richten habe und dass die ausschließliche Verfolgung von Bildungszwecken für die Arbeiter nichts sei als eine zeitraubende Spielerei, welche weder dem einzelnen noch dem Ganzen zum Vorteil reicht." (Liebknecht 1968, 58)

Die Macht kann den Zugang zum Wissen kontrollieren und seinen Gebrauch limitieren und verdrehen. »Das Wissen ist unter dem Verschluß der Herrschenden, den Beherrschten unzugänglich, außer in der Zubereitung und Verfälschung, die den Herrschenden beliebt.« (Ebd. 59)

Damit verweist Liebknecht darauf, dass der Zugang zum Wissen beschränkt wird durch bestehende Machverhältnisse. Er vertritt die Forderung, die Arbeiterklasse solle die politische Macht erringen und die Schranken beseitigen, die großen Teilen der Bevölkerung den Zugang zu Wissen, Bildung und Kultur verwehrten. Liebknecht zieht den Schluß:

"Wir müssen hinwegschreiten über Staat und Gesellschaft. Verzichten wir auf den Kampf, auf den politischen Kampf, so verzichten wir auf die Bildung, auf das Wissen. 'Durch Bildung zur Freiheit، das ist die falsche Losung, die Losung der falschen Freunde. Wir antworten: Durch Freiheit zur Bildung! Nur im freien Volksstaat kann das Volk Bildung erlangen. Nur wenn das Volk die politische Macht erkämpft, öffnen sich inm die Pforten des Wissens. Ohne Macht für das Volks kein Wissen! Wissen ist Macht! Macht ist Wissen!“ (Ebd. 94)

In dieser dialektischen Formel lassen sich die Erfahrung der Arbeiterbewegung mit der Aufklärung verdichten. Gesellschaftsreform und Bildungsreform stellen eine Einheit her, die mit bloßer Wissensaneignung nicht gesichert werden kann.

Die Aufklärer waren sich der durch Herrschaft festgelegten Grenzen ihres Wirkens sehr wohl bewusst. Wer zu weit ging, wurde gemassregelt, gedemütigt, inhaftiert, mit Schreibverbot belegt. Immer wieder zeigte der »aufgeklärte $\mathrm{Ab}$ solutismus« sein wahres Gesicht als Despotismus. 


\section{Abbildung 16: Wilhelm Liebknecht \\ (Photographie aus den $1870 e r$ Jahren)}

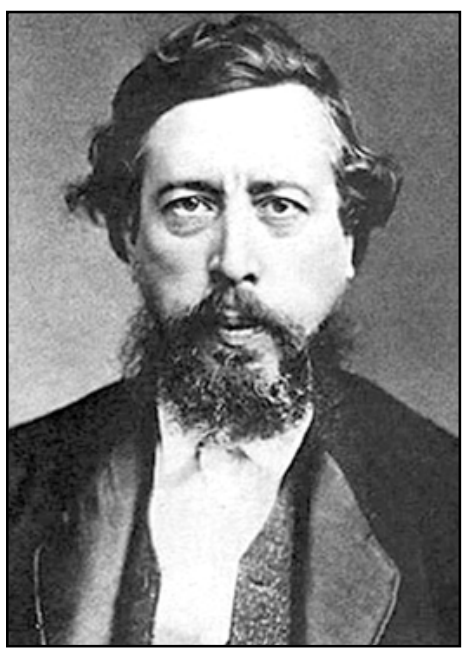

In Einzelfällen ging der Staat Bündnisse gegen die Kirche ein, um deren Macht zu begrenzen, wie z.B. in Preussen unter Friedrich II. Gleichzeitig blieb die Kirche aber wesentliche Stütze der Herrschaftsverhältnisse. Als der Offenbarungsglaube erodierte, lieferte der Deismus ein illustres Reservat. Die Spaltung von Realität und Transzendenz begründete auch die Trennung der Herrschaftsbereiche von Wissen und Glauben. Die Religionskritik hörte beim Glauben an einen allmächtigen Gott auf.

Durch die Weltreisen wurde Europa mit anderen Religiositäten konfrontiert. Kulturelle Perspektiven der Völker der Welt tauchten aus dem Dunkel auf. Die Selbstverständlichkeit der Überlegenheit der Zivilisation in Europa wurde mit dem Bild des »edlen Wilden« konfrontiert. Darin stecken bis heute die Wurzel in der Kritik am Eurozentrismus.

Die moderne Wissenschaft begann ihren Siegeszug. Ihre technologische Nutzung liefert die Grundlage gegenwärtiger Lebensweise bis hin zu Herstellung immer neuer Güter, die ihre Märkte suchen, bis hin zum sich weltweit verbreitenden Konsumismus.

Die Libertät der Bürger allerdings verkümmert immer mehr zur Freiheit des Konsumenten, zwischen Waren wählen zu können. Die Bevölkerung spaltet sich in kaufkräftige und in wachsende prekäre Teile. Das Menschenrecht der Freiheit trennt sich von Gleichheit und Gerechtigkeit.

Das gilt auch für den Zugang zu Bildungsmöglichkeiten. Adressaten werden zu Kunden und unterliegen dem »Matthäusprinzip«, nach dem wer viel hat auch mehr bekommt. Träger werden zu Anbietern auf einem zunehmend einzelwirtschaftlich regulierten Markt. Konsequenz ist fortbestehende, sogar 
wieder zunehmende Selektivität beim Zugang zu Lerninstitutionen. Bildungsarmut breitet sich aus. Die Teilhabe an »Lebenslangem Lernen« ist beschränkt durch Fehlen der materiellen, besonders der finanziellen Prämissen.

Wir erleben ein Zeitalter der Ökonomie, nicht der Bildung. Wo diese hochgehalten wird geht es um einsatzfähige und verwertbare Kompetenzen. Die großen Konzerne und Banken kalkulieren mit dem Bankrott ganzer Staaten. Damit wird das Soziale auf Kosten der Mehrheit geschwächt und riskiert.

Gleichzeitig und im Widerspruch dazu steigt der Stellenwert von Bildung für die Einzelnen. Schon die Protagonisten der Aufklärung wussten, dass die Entfaltung der Person nur möglich ist über individuelle Bildung. Aneignung und Vermittlung wissenschaftlichen Wissens ist zwar nicht ausreichend aber unverzichtbar, wenn Partizipation und Demokratie nicht aufgegeben werden sollen. 


\section{Prinzipien der Aufklärung}

In der Epoche der Aufklärung werden Probleme relevant, die bis heute die Grundlinien der Gesellschaftsentwicklung bestimmen. Mit der Idee der Bildung werden Prinzipien formuliert, wie mit den entstehenden Spannungen umgegangen werden kann. Die gesellschaftlichen Widersprüche zwischen Vernunft und Herrschaft, Privatem und Öffentlichem, Wissen und Macht, Rationalität und Religiosität, Universalismus und Relativismus, Realität und Fiktion spannen das Feld auf, in dem das Ich sich in Gegensatz zur Welt stellt und sich zu bestimmen versucht.

»Identität « - als hier auftauchende Problemkategorie - beruht auf der Annahme, dass menschliche Wesen ein grundsätzliches Interesse daran haben, sich selbst als reins $<$ zu verstehen: sowohl im Sinne einer Kontinuität ihrer Biographie, als auch im Sinne der Unterschiedenheit von anderen. Identität ist nicht vorgegeben, sondern zu erzeugen. In einem solchen theoretischen Kontext kann man Bildung begreifen als einen lebensgeschichtlichen Vorgang, in dessen Verlauf die Individuen sich bemühen, Identität herzustellen. Sie eignen sich Kultur an und entfalten dabei ihre Persönlichkeit. In diesem Prozess entsteht in der individuelle Biographie mögliche Identität. Bildung in diesem Sinn kann es nur geben in modernen Gesellschaften, in denen der Ort, die Stellung und der Lebenslauf der Einzelnen nicht festgelegt sind.

Die Inhalte einer solchen Bildung bestimmen sich nicht aus einem zeitlosen Kanon, sondern historisch konkret angesichts der gegenwärtig sich stellenden Probleme. Bildung heißt demnach, diejenigen Kompetenzen zu erwerben, um Probleme zu verstehen, die eigene Position dazu zu finden, entsprechende Entscheidungen zu treffen und handelnd einwirken zu können. Das zentrale Bildungsproblem, die Perspektive der Entfaltung von Persönlichkeit, ist demnach gebunden an die Gewinnung von Souveränität für das eigene Leben. Man kann - wie Klafki es tut - die sich stellenden Perspektivfragen auch als »Schlüsselprobleme« von Bildung aufgliedern. Bildung heißt demnach, diejenige Kompetenz zu erwerben, um die Ursachen solcher für die weitere gesellschaftliche Entwicklung zentralen Probleme zu verstehen, die eigene Position dazu zu finden, entsprechende Entscheidungen treffen zu können und handelnd einwirken zu können. 
Die Struktur unserer Weltsicht ist durch unauflösbare Spannungen, gegenläufige Entwicklungen und vielfältige Verwerfungen gezeichnet. Sie kennzeichnen den Widerspruch von Vernunft und Herrschaft (2.1), indem sie verweisen auf das grundlegende Verhältnis von Macht und Wissen, wie es in unterschiedlicher Weise von Bacon einerseits und von Liebknecht andererseits artikuliert worden ist.

Die Französische Revolution hat die Herrschaftsfrage bis an ihre Grenze getrieben. Aber sie hat die resultierenden Probleme keineswegs gelöst. Die Auswüchse der Rousseauschen Ideen bei Robespierre, Danton und Saint-Just und die immer wieder zitierte Gegenüberstellung von volontè de tous und volontè general ließen die konkreten Konsensbildungsprozesse unbelichtet, für die Condorcet den Begriff der Öffentlichkeit stark gemacht hatte. Diese spielt auch in der aktuellen Form massenmedialer Öffentlichkeit und um den Stellenwert »öffentlicher« Wissenschaft (Faulstich 2006) im politischen Diskurs und Konflikt eine wichtige Rolle (2.2).

Die Spannungen der Aufklärung lösen weiter Fragen aus nach der Akzeptanz wissenschaftlichen Wissens und der Ordnung unseres Wissens der Welt (2.3). Sie knüpfen einerseits an die enzyklopädischen Ideale der Aufklärer um Diderot an, sie setzen sich aber fort bis zu Foucault und Deleuze/Guattari als »postmoderne« Umgangsweise mit Wissen.

Immer noch bleibt die Frage nach den Grenzen des Wissens und der Beziehung von Wissen und Glauben (2.4) virulent ausgehend von einer Zweiweltenannahme, wie sie der Deismus kreierte und die sich bis in die modernste Physik fortsetzt.

In der Falte des Vorhangs zwischen Idee und Realität einer von Wissenschaft gestützten Aufklärung auf dem Weg zu lebensentfaltender Bildung tritt eine Scheinwelt auf. Die Literatur ersetzt durch Fiktion, was real nicht lösbar scheint - als Hoffnung auf Freiheit oder als Erniedrigung durch die Herrschaft (2.5). Im Schauspiel finden unruhige Geister ihren Tanzplatz. Die Unerträglichkeit despotischer Herrschaft und Willkür wird von Lessing im Trauerspiel bei »Emilia Galotti« beweint, im Lustspiel bei »Minna von Barnhelm« ausgelacht. Karl Philip Moritz hat diese Theatersucht selbst nacherlebt. Erst Brechts »episches Theater«, das durch Verfremdung Reflexion anregen will, hat versucht die Unmittelbarkeit der Gefühle durch Vernunft aufzufangen.

Die Fiktion wurde ergänzt durch das Exotische. Gleichzeitig hat sich gegenwärtig besonders befördert durch die Globalisierungsdiskussion - die Vorstellung der »einen Welt« als ökonomische Unterwerfung unter einen triumphierenden Kapitalismus durchgesetzt. Die Beziehung der Kulturen, wie sie in den Weltreisen und militärischen Expeditionen des 17. Jahrhundert, die Entdeckungs- und Eroberungsreisen (2.6), massiv aufbrachen, setzen sich fort. Der Imperialismus der Markterschließung und -sicherung wird kaum noch verhüllt hinter scheinbar humanitären Argumenten. Der Verweis auf die Einhaltung der Menschenrechte ist zum Kampfmittel geworden.

Umgekehrt findet sich das Rousseausche Motiv der Reinheit des Ursprüng- 
lichen wieder in der Eurozentrismuskritik, welche die Beziehung der Völker der Welt problematisiert. Ganze Länder und Erdteile werden vom im Nordwesten gestiegenen Wohlstand ausgeschlossen.

Neu stellt sich auch die Frage, wen wissenschaftliches Wissen überhaupt erreicht. Volksaufklärung ohne Volk (2.7) war schon ein Problem der ersten Aufklärung und wird durch die massenmediale Öffentlichkeit noch bis ins Extrem gesteigert. Die »doppelte Selektivität« der Erwachsenenbildung setzt sich fort, indem sie nur einen Teil ihrer Adressaten erreicht und diese milieuspezifisch diskriminiert werden.

Die Medien der Aufklärung mussten sich auch erst entwickeln. Die technischen Voraussetzungen des Buch- und Zeitschriftenwesens waren seit Johannes Gutenberg (1400-1468) im Wesentlichen bekannt und hatten in den Flugschriften Martin Luthers (1483-1546) auch eine erste Hochwelle erreicht, die im 30jährigen Krieg brach. Erst langsam konnte sich das Druckereiwesen im Strom eines sich verbreitenden Marktes erholen (2.8). Ohne kaufkräftiges und lesekundiges Publikum und engagierte Schriftsteller und Verleger wäre Aufklärung noch enger geblieben.

Zentral für alle Aufklärungsbemühungen ist die Spannung von Aufklärung und Bildung (2.9), da alle gesellschaftliche Entwicklung nicht vorangeht ohne die Entfaltung der Einzelnen. Zunächst war vorrangig die Entwicklung der Kinder gemeint. Aber schon in der Intention der Volksaufklärung steckte das Paradox, dass die Kinder das Lesen für die Eltern übernahmen. Gedanken der Weiterbildung spielten bei den Philanthropen schon eine Rolle und sie wurden durch ähnliche Motive wie heute vorangetrieben: ökonomische Brauchbarkeit und kulturelle Mündigkeit.

\subsection{Vernunft und Herrschaft}

Das aufscheinende Licht kontrastiert auch die Schatten deutlicher. An der Anerkennung oder Bekämpfung der Fürstenherrschaft spaltet sich die Aufklärung in Spektren. Die Widersprüche bürgerlicher Emanzipation scheinen dabei auf: Ein aufgeklärter Staat soll entwickelt, anerkannt, und gleichzeitig mit dem Absolutismus vereint und akzeptiert werden. Was aber bleibt, ist feudaler Despotismus, der sich der Aufklärung und der Bildung als Legitimationsinstrumenten bedient, und in dem sich das Bürgertum einrichtet. Die Idee der Demokratie als gleichberechtigte Beteiligung aller an allen das Gemeinwesen betreffenden Entscheidungen bricht sich an fortbestehenden Ungleichheiten. Die Suche nach einer gerechten Gesellschaftsordnung ist der unabgegoltene Gedanke, der bis heute weiterwirkt. Die Fragen, die sich im 18. Jahrhundert neu stellten, warten immer noch auf Antwort. Vernunft treibt die Probleme weiter und stellt Unterdrückung und Ungerechtigkeit immer wieder neu in Frage. 
Aufklären und Hinterfragen von Herrschaft konnte und kann gefährlich sein. Deutlich erfahren hat dies der Organist, Komponist und Journalist Christian Friedrich Daniel Schubart (1739-1791). Gelegentlich arbeitete er als Hilfslehrer oder Hilfsprediger, bis er 1763 die Stelle eines Schulmeisters in Geislingen erhielt. 1769 wurde er Organist und Musikdirektor am Hof des Herzogs von Württemberg in Ludwigsburg; als Klaviervirtuose wurde er für unerreichbar gehalten. Er führte ein wildes Leben und schrieb selbst: »Wein und Weiber waren die Skylla und Charybdis, die mich wechselweise in ihren Strudeln wirbelten.« Da er auch die Geistlichkeit attackierte, wurde er im Mai 1773 wegen von ihm provozierten »in so mancherley Betracht gestiffteten Ärgernisses« des Landes verwiesen. Er durchstreifte die südwestdeutschen Städte, bis er in Augsburg eine Zeitung, die »Teutsche Chronik« herausgeben konnte.

Deren publizistische Wirkung führte im Januar $1777 \mathrm{zu}$ seiner Verhaftung; Herzog Karl Eugen lockte ihn mit Hilfe eines Spitzels nach Blaubeuren, um ihn auf württembergischem Territorium verhaften zu können. Ohne Verhör und Gerichtsurteil saß er zehn Jahre im Kerker der Bergfestung auf dem Hohenasperg bei Ludwigsburg, wo er die folgenden Jahre das Opfer absolutistisch motivierter Willkür war. Vier Jahre durfte er nicht schreiben, nach acht Jahren erst konnten ihn Frau und Kinder das erste Mal besuchen. Sein berühmtestes Gedicht »Die Forelle«, auf dem Hohenasberg 1783 geschrieben, erzählt fast autobiographisch von der List und Heimtücke des Fängers.

Erst im Mai 1787 ließ der Herzog ihn frei - vor allem angetrieben durch Einflussnahme Preußens. Zwei Jahre nach seiner Entlassung aus dem Kerker schrieb Schubart 1789 im Jahr der Revolution:

\section{An die Freiheit}

0 Freiheit, Freiheit! Gottes Schooß entstiegen,

Du aller Wesen seligstes Vergnügen,

An tausendfachen Wonnen reich,

Machst du die Menschen Göttern gleich.

Wo find' ich dich, wo hast du deine Halle?

Damit auch ich anbetend niederfalle;

Dann ewig glücklich - ewig frei

Ein Priester deines Tempels sey.

Einst walltest du so gern in Deutschlands Hainen,

Und ließest dich vom Mondenlicht bescheinen,

Und unter Wodanseichen war

Dein unentweihtester Altar. ...

Bald aber scheuchten Fürsten deinen Frieden,

Und Pfaffen, die so gerne Fesseln schmieden;

Da wandtest du dein Angesicht

Wo Fesseln rasseln - bist du nicht. 
Dann flogst du zu den Schweizern, zu den Britten;

Warst seltner in Palästen, als in Hütten;

Auch bautest du ein leichtes Zelt

Dir in Kolumbus neuer Welt.

Und endlich, allen Völkern zum Erstaunen,

Als hätt' auch eine Göttin ihre Launen,

Hast du dein Angesicht verklärt

Zu leichten Galliern gekehrt.

Solche Freiheitslieder gingen den Fürsten entschieden zu weit. Schubarts Schicksal wurde zum abschreckenden Beispiel und zur Drohgebärde gegen alle aufmüpfigen Literaten. Sie wirkte auf Hölderlin, Schiller und Goethe. Was weiterwirkt, ist die Suche im Spannungsverhältnis von Demokratie und Gewaltanwendung, von Freiheit und Herrschaft.

Als die Französischen Revolution und die Revolutionskriege den deutschen Adel unmittelbar bedrohten, wendete sich auch das Bürgertum und seine Vordenker von der Aufklärung ab. Die Freiheitsgesänge verhallten und wurden nach überschießendem »Sturm und Drang « im geordneten Versmaß der »Klassik« zurückgenommen. Die Revolution 1789 wurde dämonisiert und mit La Grande Terreur 1793/94 gleichgesetzt.

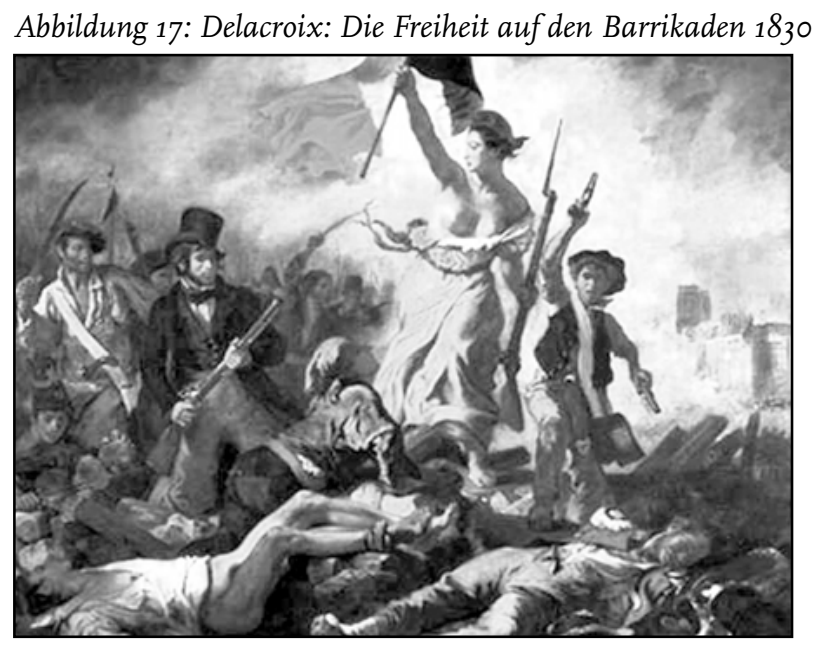

Die Radikalisierung und Brutalisierung der französischen Revolutionspolitik aber wäre ohne den Krieg, der seit 1792 von Österreich und Preußen und dann auch von Großbritannien gegen Frankreich geführt wurde, sowie ohne die inneren Aufstände so nicht erfolgt. Die Ideen der Freiheit, Gleichheit und Brüderlichkeit jedoch blieben fortbestehen und ergriffen in immer wieder neuen Wellen das gesellschaftliche Bewusstsein. »Die Freiheit auf den Barrikaden« 
wurde 1830 wieder nachträglich von Delacroix heroisiert als die Juli-Revolution das französische Königtum endgültig beseitigte.

Wer die grassierende Desillusion und Resignation nicht teilte, war wiederum Immanuel Kant. Er hatte die Naivitäten und Siegeshoffnungen der frühen Aufklärung nicht geteilt, und also auch keinen Anteil an ihren Niederlagen. Nicht die Ereignisse der Revolution, gleichgültig ob sie als gescheitert oder gelungen angesehen werden kann, sondern die dahinter stehenden grundlegenden Umwälzungen, waren ihm für den weiteren Geschichtsverlauf wesentlich.

Schon in den neun Sätzen für die »Idee zu einer allgemeinen Geschichte in staatsbürgerlicher Absicht « (Kant XI, 33-50) fragt Kant, wie der »Antagonism die ungesellige Geselligkeit der Menschen; d. i. den Hang derselben, in Gesellschaft zu treten, der doch mit einem durchgängigen Widerstande, welcher diese Gesellschaft beständig zu trennen droht, verbunden ist « (ebd. 37). Das ungelöste Problem ist für ihn »die Erreichung einer allgemein das Recht verwaltenden bürgerlichen Gesellschaft« (ebd. 39).

In den Schriften Kants werden die Widersprüche der Aufklärung deutlich. Zum einen wird eine entschiedene vernunftbasierte Herrschaftskritik vorgetragen. Die Vernunft erhebt sich über die Enge des Aberglaubens und der Angst vor der Macht. Aber zum anderen begründet sie auch Argumente für das Fortbestehen unlegitimierter Herrschaft und sichert die bestehende Gesellschaftsordnung. Bestehende Ungleichheit liefert die Rechtfertigung für ihr eigenes Weiterwirken. Herrschafts- und Eigentumsverhältnisse werden zwar hinterfragt, bleiben aber im statischen Umgang mit der drohenden Reaktion der Macht weitgehend unangetastet. Dies gilt bis heute.

Kant versuchte seinen eigenen Landesherrn durch literarische Komplimente auf die Förderung der Aufklärung festzuschreiben. Diese Taktik hat aber nicht dagegen geholfen, dass sich ein »Königtum der Widersprüche« (Reed 2009, 25) herausbildete, das offiziell mit der Aufklärung kokettierte, real diese aber in einem brutalen Militärstaat vergewaltigte. Friedrich II. dekretierte zwar, das Gesetz solle sprechen und der Souverän schweigen, aber er handelte oft nach dem umgekehrten Grundsatz. Es blieb bei der Willkür des Despoten. Preußen hat dann als Militärstaat das Deutsche Reich nach und nach okkupiert.

Es geriet damit in Konflikt mit Frankreich - eine Konstellation die sich erst nach der Französischen Revolution und dem Sieg der deutschen Reaktion herstellte. In der Aufklärung gab es - sogar bei Friedrich II. und in seinem Verhältnis zu Voltaire - verbreitete Frankophilie. Die Französischen Denker und Künstler galten als Vorbild und Vorreiter.

Das gilt auf alle Fälle für Jean Jaques Rousseau (1712-1778) als einen der wichtigsten geistigen Wegbereiter mit großem Einfluss auf die Philosophie, Pädagogik und die politischen Theorie des 18., 19. und 20. Jahrhunderts. Rousseaus Schriften wurden in allen europäischen Ländern breit rezipiert. Sein Denken bestimmte die politischen Ideen bis heute. 
Im Herbst 1749 besuchte er den in der Festung Vincennes inhaftierten Diderot und las unterwegs in der Zeitschrift Mercure de France die Preisfrage der Académie von Dijon: »Hat die Wiederherstellung der Wissenschaften und Künste dazu beigetragen, die Sitten zu reinigen?« Er verfolgte die provokante Idee, die Frage zu verneinen, und behauptete in seinem Discours sur les Sciences et les Arts (»Abhandlung über die Wissenschaften und die Künste«), die nach Luxus strebende europäische Gesellschaft gleite in die sittliche Dekadenz ab. Damit bezog er eine Kritikposition, die ihm ermöglichte, die Strukturen des ancien régime, als ein überholtes, monarchisches Regierungssystem, das nicht mehr im Einklang mit den Erfordernissen der Zeit steht, zu hinterfragen.

1755 publizierte Rousseau, vorsichtshalber in Amsterdam, die »Abhandlung über Ursprünge und Grundlagen der Ungleichheit unter den Menschen«, der wiederum auf eine Preisfrage der Académie de Dijon antwortete: »Was ist der Ursprung der Ungleichheit unter den Menschen, und wird sie vom Naturrecht erlaubt?« Rousseau erklärte die soziale Ungleichheit aus der Arbeitsteilung und der dadurch ermöglichten Aneignung der Arbeitserträge Vieler durch Wenige, die den Staat aufbauen, um ihre Eigentum zu schützen.

Rousseau legitimiert in Du contrat social ou Principes du droit politique (Vom Gesellschaftsvertrag oder Prinzipien des Staatsrechtes, 1760/61, erschienen 1762), die Rechte der Individuen gegenüber dem Staat und prägt den Begriff der Volkssouveränität, auf dem die Legitimität des Volksentscheids und allgemeiner Wahlen gründet. Er stellt sich in seinen staatstheoretischen Texten die Frage, wie ein von Natur aus wildes und freies Individuum seine Freiheit behalten kann, wenn es aus dem Naturzustand in den Zustand der Gesellschaft eintritt. Er geht davon aus, dass die Menschen im Naturzustand unabhängig voneinander leben. Sie verfügen über ausreichend Güter und sind friedlich. Insbesondere ist der Mensch weder der Wissenschaft noch der Gier nach Luxus verfallen. Im Unterschied zu Hobbes oder Locke zeichnet Rousseau ein positives Bild vom Menschen im wilden, tiernahen Zustand.

Durch das Auftauchen der Institution des Eigentums entstehen gesellschaftliche Strukturen. Der Mensch ist nicht mehr autark, sondern wird von anderen abhängig, sei es als Herr oder als Knecht. Rousseau entwirft den Sozialvertrag (contrat social) als wieder gewonnene Grundlage, die es jedem ermöglicht, sich wieder frei zu entwickeln wie im Naturzustand. Dabei unterscheidet Rousseau »natürliche Unabhängigkeit« von »bürgerlicher Freiheit«.

Nach Rousseaus Auffassung ordnet sich jeder Bürger zum Zwecke eines rechtmäßig geordneten Zusammenlebens freiwillig dem Gesellschaftsvertrag unter. Grundlage ist der Gemeinwille, welcher auf das Wohl des ganzen Volkes gerichtet ist. Jeder Einzelbürger ist somit Teil eines konfessionell neutralen Staates, welcher den allgemeinen Willen vollstreckt und zugleich Verfügungsgewalt über ihn hat. Der Staat verabschiedet Gesetze, die den Willen des Volksganzen zum Ausdruck bringen. 
»Emile oder über die Erziehung« kann als Erziehungs- oder Bildungsanleitung für den perfekten Erzieher und Gesetzgeber gelesen werden.

Emile ist ein gesunder, durchschnittlich begabter Junge aus reichem Hause Zum Einen soll er als erwachsener Mensch in der Lage sein, in der Zivilisation zu bestehen, zum Anderen soll er bereit sein, den Gesellschaftsvertrag zu schließen. Dieser Vertrag soll die politische Ordnung sichern, und ihm müssen deshalb alle Mitglieder einer Gesellschaft (ideell) zustimmen. Emile soll als Glied einer Gemeinschaft die von ihr geforderten Pflichten erfüllen.

"Dazu gehört Menschenkenntnis, und es genügt nicht mehr nur die durch Lektüre erworbene, sondern sie muss erprobt und angewendet werden. Daher wird der junge Mensch eine längere Reise durch Europa antreten, binnen welcher er sich prüft, seine Wünsche und Vorstellungen von der Zukunft konkretisiert. Er vergleicht die Fremde mit dem Heimatland, um dann eine freie Wahl treffen zu können. Mit welchem Volk, in welchem Land möchte er seine Existenz aufbauen und als Glied der Gemeinschaft den Gesellschaftsvertrag schließen?" (Rousseau 1997, 53)

Abbildung 18: Frontispiz zu Jean-Jacques Rousseau: Emile ou de l'éducation. Den Haag, Amsterdam 1762

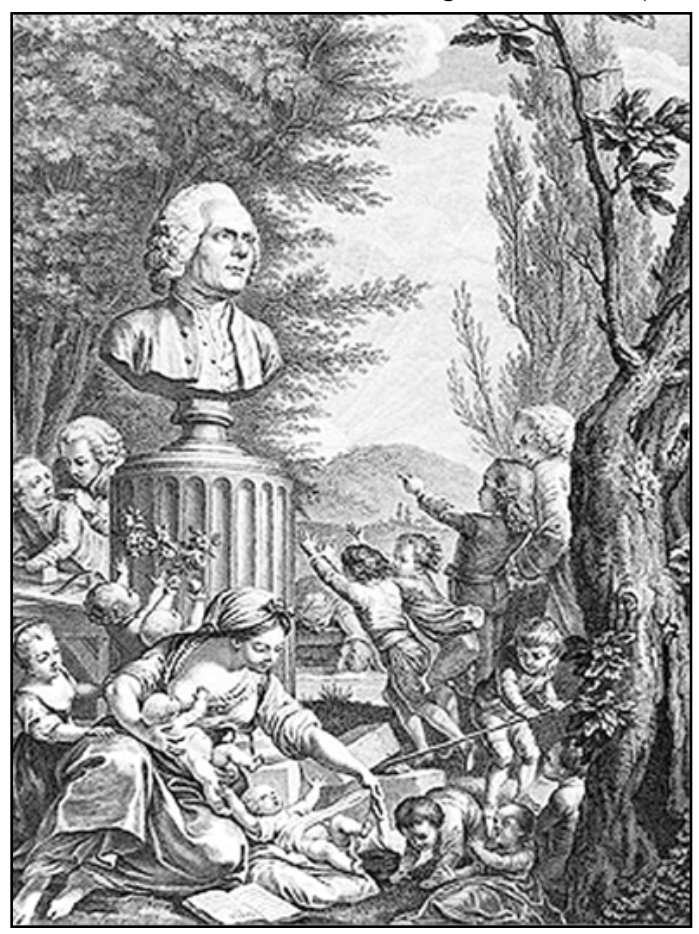


Im »Gesellschaftsvertrag « hat Rousseau 1762 das Regierungsmodell der Demokratie in die Neuzeit übertragen. Er konnte sich ein freies Gemeinwesen nur vorstellen, wenn die Gesetzgebung durch das Volk unmittelbar geregelt ist. Im Verlauf der Revolution wurde diese Idee der Souveränität von den Jakobinern um Maximilien Robespierre adaptiert. In den Wochen des terreur herrscht am Ende im Kampf darum, wer den legitimen Willen des Volkes repräsentiere, die nackte Gewalt. Robespierre, Marat und Saint-Just okkupierten die Volkssouveränität in demagogischer Pose für ihre Zwecke der politischen und sozialen Integration zu deren blutigem Instrument die Guillotine wurde.

Abbildung 19: Guillotine: Exekution Robespierres

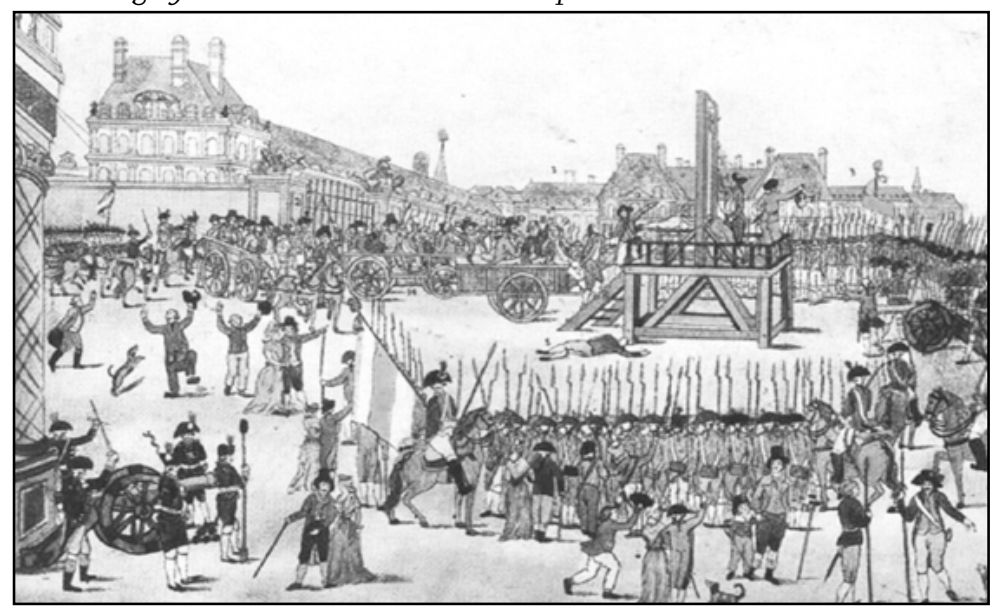

Die Stellung zur französischen Revolution markierte in Deutschland die Scheidelinie zwischen weiterdenkenden Aufklärern und dem Rückfall in Konservativismus und Reaktion. Einerseits stieg die Begeisterung für die Versuche die Idee der Demokratie zu verwirklichen; anderseits wurde die Brutalität des Terrors gegen die Vertreter der alten Mächte mit Entsetzen und Abscheu aufgenommen. Die meisten Literaten, Publizisten und auch Wissenschaftler zogen sich zurück, flüchteten in Innerlichkeit oder Religion wie z.B. Schelling.

$\mathrm{Zu}$ den brillantesten deutschen Augenzeugen und Befürwortern des großen Aufbruchs gehörte der Schriftsteller, Pädagoge und Verleger Joachim Heinrich Campe (1746-1818) (s.u. Teil 2.9). Seine Briefe aus Paris machten Furore - gespalten in begeisterte Zustimmung und wütende Ablehnung (vgl. zum Folgenden: Overhoff 2008, Schmitt 1989).

Entschiedenster Unterstützer und Begründer der Revolution wurde Georg Forster (1754-1794), der als deutscher Jakobiner seine letzten Lebensjahre in Paris verbrachte und trotz aller Zweifel an den Ideen der Aufklärung und der Menschenrechte festhielt. 
Schon als Helmstedter Theologiestudent (1765-1768) hatte Campe nach England reisen wollen - ins Land der Aufklärung, dessen Bürger seit der Glorreichen Revolution von 1688 kontinuierlich in den parlamentarischen Entscheidungsprozess einbezogen waren. Ihm fehlte allerdings das Geld. Mit »Robinson der Jüngere« (1779/80) gelang ihm ein »bestseller« des Kinderbuchs, der in viele europäische Sprachen übersetzt wurde. Die Tantiemen machten Campe finanziell unabhängig. 1787 gründete er in Braunschweig erfolgreich eine eigene Schulbuchhandlung; danach hatte er genug Geld und berufliche Unabhängigkeit, um auch längere und teurere Touren zu planen. Als sich die USA nach ihrer Loslösung vom britischen Mutterland dauerhaft in ihrer neuen republikanisch-demokratischen Gesellschaftsordnung einzurichten begannen, spielte Campe mit dem Gedanken, dorthin aufzubrechen, um die Verfassung des Nordamerikanischen Freistaats zu studieren.

Doch dann folgen ab 5. Mai 1789 mit der Einberufung der Generalstände die Tage von Versailles. Campe ist begeistert. Unterwegs auf einer Geschäftsreise, weiht er seine 14-jährige Tochter Lotte als Erste in seine Pläne ein. Die jüngst in Frankreich vorgefallenen Ereignisse, teilt er ihr mit, seien so »seelenerhebend « und ließen noch andere große Begebenheiten in jenem Lande ahnen, dass er das unbändige Verlangen verspüre, sich aufzumachen, um den bevorstehenden »Sieg der Menschheit über den Despotismus anzusehen und ihn feiern zu helfen«. Etwas Interessanteres könne in diesem historischen Augenblick auf dem ganzen Erdenrunde wohl nirgends zu sehen sein (Campe 1961, 63; vgl. zum Folgenden Schmitt 1989, 1996).

So bricht er zu Pferde, am 17. Juli 1789 bei Sonnenaufgang auf. Tags darauf stößt er in Holzminden an der Weser auf Wilhelm von Humboldt, der gerade in Göttingen das Studium beendet hat und seinen früheren Hauslehrer nach Paris begleiten will. Dem Adligen ist daran gelegen, auf einer ereignisreichen Grand Tour seinen Horizont zu erweitern.

Am zwölften Tag ihrer Fahrt in einer rumpelnden und überladenen Kutsche erreicht die Reisegesellschaft dann kurz vor der Ankunft in Brabant die Nachricht von jenen - wie Campe schreibt - »gräulich schönen Begebenheiten«, die sich bei der Erstürmung der Bastille am 14. Juli zugetragen haben. Der symbolische Triumph über die verhasste Zwingburg, den großen Kerker, in dem auch Voltaire einsaß, wird in Frankreich als Beginn einer neuen Zeit gefeiert und löst im ganzen Land einen revolutionären Enthusiasmus aus.

Nur wenige Stunden von der Grenze entfernt werden Campe und seine Gefährten von fliehenden Adligen eindringlich vor den Risiken der Weiterreise gewarnt.

"Noch ehe ich die Grenzen von Brabant erreichte, flog mir die Nachricht von den gräulich schönen Begebenheiten des 12ten, 13ten und 14ten Julius, theils in öffentlichen Blättern, theils durch den Anblick der fliehenden französischen Nebenkönige entgegen, 
welche dem Rachschwerte des richtenden Volks entkommen waren. Diese Nachrichten lauteten schreckhaft genug. Der Erwürgten sollten über 15000 seyn; das Volk, mit Schwert und Strick bewafnet, sollte noch immer durch alle Straßen wider Schuldige und Unschuldige wühten, statt der Lichtwerfer (Reverberes) sollte man an allen Ecken, auf allen Brücken und auf allen öffentlichen Plätzen Erhenkte, wie Krammetsvögel in einem Dohnenstrich, schweben sehn. Wohin wir kamen, schüttelte man über unsere Unvorsichtigkeit, zu einer Zeit, wo Tausende aus Frankreich floghen, nicht nur nach Frankreich, sondern sogar nach dem Mittelpunkt alles Gräuels, nach Paris selbst, muthwilliger Wiese hinreisen zu wollen, misbilligend den Kopf." (Campe 1790, 7)

Schon auf der Hinreise ins Zentrum der Revolution nach Paris empfindet Campe begeistertes Hochgefühl und abgestoßenes Erschrecken zugleich. Bei der Durchreise in Valenciennes werden die Reisenden gewahr, dass die Warnungen der Flüchtlinge nicht von Ungefähr kamen. Dort säumen Gehenkte den Weg. Die aufgeknüpften Männer seien, erfährt Campe, zum abschreckenden Beispiel hingerichtet worden, weil sie sich der neu gebildeten Bürgerwache widersetzt hatten. Er schwankt zwischen Mitleid und Rechtfertigung.

"Wir kamen à la grande Place. Hier hatte man eben ein paar arme Bauern aufgeknüpft, die nebst einigen hundert andern, im Taumel der Freude über die innen ungewohnte Freiheit, nach einer benachbarten Abtei gelaufen waren, um den Prälaten zu zwingen, innen die Kosten eines Processes herauszugeben, den sie vor einigen Jahren über den Zehnten mit inm geführt und verloren hatten. Die Unglücklichen hatten sich dabei verschiedene Gewaltthätigkeiten erlaubt, und sich der bewafneten Bürgerschaft von Valenciennes, welche herbei eilte, um den Lerm zu stillen, zu widersetzen gewagt. Diese hatte sich darauf der Unruhigsten unten innen bemächtiget, und zwei derselben mussten nun, zum abschreckenden Beispiel für die Uebrigen, mit dem Leben büßen." (Ebd. 14)

Campe zeigt sich vom Schicksal der Opfer berührt. Doch unterstellt er, dass der große und gewagte Schritt eines Volkes, seine Ketten mit Gewalt zu zerbrechen, wohl unweigerlich mit Blut gezeichnet sein müsse. Er spürt in den Straßen einen neuen Geist:

"Erst seit ehegestern hatte man hier die Waffen ergriffen; erst seit ehegestern also hielt man sich hier für geborgen und für frei. Bis dahin hatte man, seit der ersten großen Explosion der Volkskraft zu Paris, in ängstlicher Erwartung der Dinge, die da kommen können, gelebt. Jetzt waren Unentschlossenheit, Furcht und Aengstlichkeit verschwunden; jetzt fühlte man, das was man war und was man konnte; und wunderte sich, dass man das nicht schon längst gefühlt hatte - die gewöhnliche Empfindung eines unterdrückten Volks, das nach einer langen Reihe in sclavischer Indolenz verträumter Jahre mit dem so natürlichen Gedanken: ich will frei seyn! Erwacht; und nun 
zum erstenmal und mit Erstaunen sieht, dass es weiter nichts, als dieses Gedankens bedurfte, um wirklich frei zu seyn!“ (Ebd.)

Als er dann an den Hüten und Mützen der ihm Begegnenden die blau-weiß-rote Kokarde der Revolution leuchten sieht und frohe und stolze Gesichter wahrnimmt, steigert sich seine Stimmung sprunghaft. Ein Hochgefühl erfasst ihn, eine unmäßige Freude über die »glücklich errungene Freiheit« der Franzosen, dass er die Ersten, die ihm so begegneten, hätte umarmen mögen.

Am 3. August erreichen die Reisegefährten Paris. Der Lärm und das Geschrei in der riesigen Stadt, die zu diesem Zeitpunkt bereits nahezu eine Million Einwohner hat, betäuben den Beobachter - im Kontrast zu Braunschweig, in dem damals gerade 27.000 Menschen wohnen.

Bedrückend wirken die grauen, engen und schmutzigen Vorstädte Saint-Denis und Saint-Martin. Aber Campe weiß, dass in diesen Quartieren die eigentlichen »Helden« von Paris, die Bezwinger der Bastille, wohnen; dass es die zerlumpten Vorstädter gewesen sind, die »das große Werk der bürgerlichen Erlösung « entscheidend vorangetrieben haben, hält Campe sich vor Augen, als er die Bastille, diese »schaurige Burg«, das ehemalige »Bollwerk des französischen Despotismus «, sieht. Er fragt sich, was dieses zum Teil schon als Ruine dastehende Gebäude zu einem derart verhassten Ort des Gräuels gemacht hatte. Dies war - so seine Antwort auf die selbst gestellte Frage: die gesetzlose Willkürlichkeit, mit der man »Schuldige und Unschuldige, ohne alles vorhergegangene rechtliche Verfahren, an diesen Ort des Jammers schleuderte, um sie hier auf viele Jahre, oft auf Lebenszeit lebendig zu vergraben, oder wol gar, wie es mehr als wahrscheinlich ist, sie zum Theil heimlich, durch Gift oder Strang, aus der Zahl der Lebendigen verschwinden zu lassen« (ebd.).

Diesen Zustand der Willkür und Rechtlosigkeit sollte die Nationalversammlung durch die Ausarbeitung einer auf Vernunft und Menschenrecht gegründeten Konstitution überwinden. Die Verfassungsdebatte interessiert Campe am meisten. Tatsächlich kann er am 12. und 13. August zwei Sitzungen der Nationalversammlung mit verfolgen - auf persönliche Einladung des Grafen Mirabeau, des Protagonisten der Revolution in jener ersten Phase.

Durch einen einfachen Mehrheitsentscheid der Assemblée nationale wurden Adel und Klerus sämtliche Privilegien - am 4./5. Juli, den Tagen nach Campes Ankunft in Paris - entzogen; damit wurde in wenigen Stunden eine tausendjährige Gesellschaftsordnung zu Grabe getragen. Nicht mehr Geistliche, Adlige und Bürgerliche stehen sich fortan im Lande gegenüber, sondern alle sollen nur noch Gleiche unter Gleichen sein. Das war das Ende des ancien régime.

Bemerkenswerterweise beginnt sogar Campe ausgerechnet im Reisebericht aus Paris mit einer Apologie des aufgeklärten Absolutismus: Der Text ist eine Mischung von Unterwürfigkeit, Drohung vor Volksaufstand und dem eigenen Glauben an die notwendige Ordnung. 
"Ich glaube der Regierung, worunter ich zu leben das Glück habe, durch die Herausgabe dieser Briefe ein so würdiges Denkmal zu setzen, als ein Mann von meinen geistigen Vermögensumständen es ihr zu setzen vermag. Nur in einem Lande, wo man nichts von Despotismus weiß, ist es erlaubt, über Despotismus und Freiheit so zu schreiben, wie ich darüber geschrieben habe. Der Schriftsteller, der dies unter den Augen seines angebeteten Fürsten thut, beweist dadurch mehr als durch die schmeichelhafteste Lobrede, dass er den erhabenen Character und die großen Regententugenden desselben kennt und innen Gerechtigkeit wiederfahren lässt; und der edle Fürst, der das nicht ungnädig bemerkt, der den freimüthigen Schriftsteller sogar mit neuen ungesuchten Gunstbezeugungen überhäuft, legt dadurch vor aller Welt Augen einen herrlichen und überzeugenden Beweis $a b$, wie sehr er dieses seiner würdige - nicht in Worten, sondern in Handlungen bestehende - Lob verdiene." (Ebd.)

Campe sieht in der Revolution einen Impuls für die Herrschenden, milder und gerechter zu regieren:

"Er glaubt indeß, dass die alleslenkende Vorsehung, Begebenheiten dieser Art, von Zeit zu Zeit in der weisen und wohlthätigen Absicht herbei führe, um diejenigen Regenten, welche sich eine gesetzwidrige Gewalt anmaßen und diese Gewalt zu Ungerechtigkeiten und Unterdrückungen misbrauchen, an die Zerbrechlichkeiten ihres despotischen Regierungssystems zu erinnern, und sie dadurch zu bewegen, künftig mildere und gerechtere Maaßregeln zu befolgen."

Campe bestimmt die Position und die Perspektive des »Intellektuellen«:

"Er glaubt, dass denjenigen, welche den hohen Beruf zu haben meinen, Wächter und Rathgeber der Menschheit, d.i. Schriftsteller zu seyn, die heilige Pflicht obliege, jene wohltätigen Absichten der Vorsehung bei Vorfällen dieser Art nach Vermögen zu befördern; also auch gerade bei solchen Gelegenheiten, wo die Herzen der Despoten und ihrer Diener sich einer wohlgemeinten Warnung noch am ersten öffnen, für die Rechte der Menschheit am nachdrücklichsten zu schreiben." (Ebd. 12)

Man werde nun zum ersten Mal ein Frankreich sehen, frohlockt Campe, in dem »keine Hierarchie und kein Despotismus mehr Statt finden, wo vielmehr Alle gleich, Alle zu allen Aemtern, wozu ihre Verdienste sie fähig machen, fähig « sind. Sämtliche Einwohnerwerden jetzt »wirklich in der gesetzgebenden Versammlung repräsentiert«, somit jeder, »auch der armseligste Landmann, Mitregent und Mitgesetzgeber seines Vaterlandes seyn«.

Die »Briefe aus Paris«, formal gerichtete an Trapp, sind unwiderstehliche Dokumente eines deutschen Bürgers, der zwischen Begeisterung und Abschreckung schwankt, allerdings die Revolution insgesamt positiv einschätzt. An Trapp schreibt Campe als an einen fiktiven intendierten Leser: 
"Also was? - Sie erinnern sich vielleicht, dass ich mit den Worten abreisete: ich hofte, noch immer früh genug zu kommen, um dem Leichenbegängniß des französischen Despotismus beizuwohnen; und diese Hofnung - wohl mir! - ist nun glücklich in Erfüllung gegangen. Der kühne Stoß, welcher das Herz des Drachen traf, und den ich, ohne ein Politiker zu seyn, vorherzusagen wagte, war, als ich hier ankam, zwar schon vollführt; ich fand das Unthier bereits in seinem Blute liegen; aber noch ist Leben in seinen hundert Köpfen, noch kräummt und windet es sich im Staube, und kann, der vielen tödtlichen Wunden, die ihm stündlich beigebracht werden, ungeachtet, sich noch immer nicht entschließen, die schwarze Seele vollends auszuhauchen. Aber es wird, es muß sie aushauchen; und ich kehre eher nicht zu Euch zurück, bis ich der Freude theilhaftig geworden bin, es völlig eingescharrt zu sehn. Dieser Tag des Leichenbegängnisses wird einer der köstlichsten meines Lebens seyn; so wie er für die großen und kleinen Menschendrücker, Menschenquäler und Menschenaussauger an allen Orten und Enden der Welt einer der lehrreichsten seyn wird, welche die Geschichte zu ihrer Warnung jemals aufgestellt hat. [...] Haben Sie je ein edles Roß beobachtet, das seinen ungeschickten Reuter abgeworfen hatte? Und haben Sie bemerkt, wie es von dem Augenblick an, da es den Rücken frei, die Zügel schlaff fühlte, noch eins so leicht, noch eins so kraftvoll und muthig über Feld und Anger, über Graben und Hügel muthwillig scherzend und vor Freude wiehernd dahin sprengte, und nun noch eins so wohl gebaut und nun noch eins so edel erschien, als es vorher war? Dies ist das Bild einer freigewordenen Nation, die ihren Despoten oder gar, wie es hier der Fall war, ihre zwanzig oder dreißig Despoten abgeschüttelt hat." (Ebd.)

Der Abschaffung der Privilegien folgt die Erklärung der Menschen- und Bürgerrechte, wenige Tage später in der Nationalversammlung verabschiedet und von 1791 an Teil der Verfassung. »Die Menschen werden frei und gleich an Rechten geboren und bleiben es für immer«, lautet ihr berühmter erster Satz. Aufschreien vor Freude will der Besucher aus Deutschland über die Konsequenzen, die das alles für Europa, für die Welt haben wird. Denn nach dem Vorbild der entstehenden französischen Konstitution werde auch jedes andere Land seine Verfassung nach und nach abändern oder bei gegebener Gelegenheit umbilden können. Frankreich habe den Beweis angetreten, dass sich eine freiheitliche Verfassung eben nicht ausschließlich evolutionär wie in der Schweiz oder in England entfalte oder bestenfalls noch in einer entlegenen Wildnis wie in Amerika gedeihe. Sondern dass sie sich überall und jederzeit in einem revolutionären Akt zum Glück und Nutzen der Menschheit verwirklichen lasse. Demokratie ist machbar.

Campes Reisegefährten Wilhelm von Humboldt allerdings bleibt dessen Überschwang fremd. Der Aristokrat, der die Aufhebung der Privilegien als Beginn einer neuen gesellschaftlichen Unordnung kritisiert, kann nicht nachvollziehen, wie der Bürger und Geschäftsmann aus Braunschweig die Ereignisse sieht. Ihre Gesichtspunkte liegen weit auseinander. Ende August treten die Gefährten die Rückreise an. 
Bereits im Oktober 1789 lässt Campe die Korrespondenz, die er von Paris aus mit der Tochter und zwei guten Freunden geführt hat, im Braunschweigischen Journal abdrucken. Ein Jahr später erscheinen die Briefe aus Paris dann als Buch, wiederum in Braunschweig und, von der Zensur unbeanstandet dank der Fürsprache des Herzogs - derselbe, der dann 1792, als Frankreich endgültig auf die Republik zusteuert und der Krieg gegen Europas ancien régime beginnt, öffentlich droht, die Truppen des Reiches würden Paris dem Erdboden gleichmachen, wenn es sich nicht wieder dem König unterwürfe.

Der Feldzug scheitert. Bei Valmy in der Champagne bleiben die Reichstruppen stecken; Ludwig XVI. ist nicht mehr zu retten. Frankreich wird Republik und ernennt noch im selben Jahr 1792 neben Klopstock und Schiller auch Campe zu ihrem Ehrenbürger. Es ist eine Würdigung, die ihn trotz all der Irrungen und blutigen Wirrungen, welche die Revolution noch nehmen sollte, bis zu seinem Tod 1818 mit Stolz erfüllt.

Als zweiter Paris-Bericht als Beleg für die Haltung des fortgeschrittenen Bürgertums kann auf Georg Forster zurückgegriffen werden, der als Abgesandter der »Mainzer Republik« seine letzte Lebenszeit in Paris verbrachte (zu Forster s.a.u. Teil 2.6).

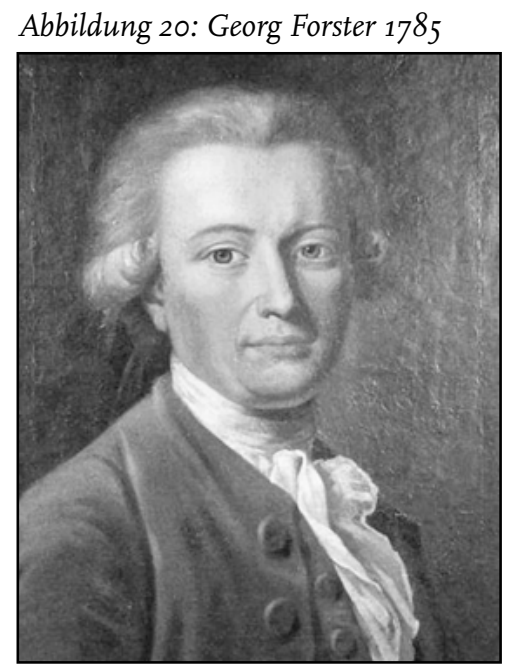

Bereits in der »Anrede an die Gesellschaft der Freunde der Freiheit und Gleichheit« am Neujahrstag 1793 im Mainz proklamierte er:

"Mitbürger, Brüder, Freunde der Freiheit und Gleichheit!

Die willkührlichen Zeitabschnitte des Kalenders sind Erfindungen des menschlichen Geistes, die blos auf seine beschränkte Art zu sein und zu empfinden eine Beziehung haben; an und für sich sind sie nichts; das Jahr, die Umlaufszeit der Erde um die Son- 
ne, könnte eben sowohl vom 20. März, oder von jedem andern Tage, und bei uns freien Republikanern, vom Geburtstage der Republik, vom 10. August anfangen. Allein eben das gleichgültige dieser Abtheilungen erlaubt es uns auch, hier dem Gesetze der Gewohnheit zu folgen und so wie sich alle Völker Europens bequemt haben, die neue Zeitrechnung des verbesserten Kalenders anzunehmen, jetzt bei der Eintheilungsart desselben, weil sie gerade den allgemeinen Gebrauch für sich hat, stehen zu bleiben. [...] Am Neujahrstage scheint es uns, als giengen wir aus einem alten Leben in ein neues über." (Forster 1968, I, 106)

Gleichzeitig bedauert Forster die Schwachheit und geringe Verlässlichkeit, vieler, die sich zunächst der Revolution angeschlossen hatten:

"Zwar erschallte hier noch nie die Stimme der Furie Zwietracht; zwar entgiengen wir bis jezt noch ihrem Geisselhiebe; allein wir waren auch nur ein kleines Häuflein, an welchem der große Haufe unserer Mitbürger, wohl nur mit einem ahndungsvollen Schauer vorüber gieng; wir fühlten also unwillkührlich, daß brüderliche Eintracht unsere einzige Stärke sei. Dennoch erlebten wir schon Augenblicke der Trennung; schwache Brüder, oder auch falsche Brüder, wandten uns den Rücken, sobald nur von fern eine Gefahr sich blicken ließ, entzogen sich unsern Versammlungen, strichen ihre Namen aus unserm Buche, und hoffen durch ihr verführerisches Beispiel der Gesellschaft den Todesstoß der Auflösung zu versetzen. (Ebd. 107)

In einem neugebohrnen Freistaate ist eine Gesellschaft, die nach unsern Grundsätzen arbeitet, unentbehrlich, und zu keiner Zeit war das Salz, die Würze oder der Gährungsstoff, nennen wirs mit welchem Gleichniß wir wollen, unserm Vaterlande unentbehrlicher, als jezt. Die erhabene Versammlung der Stellvertreter Frankreichs hat die Einwohner dieses Landes aufgefodert, sich in Ur- und Wahlversammlungen als freie Menschen zu organisiren, und nicht länger anzustehen, sich in Besitz der Rechte, die innen gebühren, zu setzen. Dies, meine Brüder, ist also der wichtigste Zeitpunkt, wo auf unserm Rathe, unserer Belehrung, unserm Beispiele vielleicht das Heil des ganzen Staates beruht. Ihr kennt den Grad künstlicher Erschlaffung, den das lange getragene Joch der Unwissenheit und der Sklaverei nothwendig hat hervorbringen müssen; Ihr wißt, wie schwer es dem guten, redlichen Landmanne insbesondere werden wird, eine neue Einrichtung, sei sie auch noch so einfach, zu fassen und zu befolgen. Wie viel Gutes könnten nicht die Freunde der Freiheit und Gleichheit hier stiften, wenn sie sichs zum Geschäfte machten, ihren Landsleuten richtige Begriffe, sowohl von den Formen der Wahl, als insbesondere vom Zwecke derselben zu ihrem eignen Glücke zu geben? Wenn sie den Geist der Freiheit, das heißt, den Stolz des Menschen, der immer dem Gesetze gehorcht, übrigens aber seinen freien Willen fühlt, ihnen einzuathmen suchten, und sie anführten zu einem Sinne für die Würde und Wichtigkeit ihres Geschäfts und ihres künftigen Daseins? Wenn sie mit unermüdetem Eifer wesentlichen Unterschied zwischen der Maschine lehrten, welche ein anderer in Bewegung sezt, und dem moralischen, denkenden, freien Wesen, das sich selbst durch Vernunftgründe bestimmt?« (Ebd. 111) 
Forster hebt in seiner Neujahrsrede 1793 vor allem die Bildungsbemühungen hervor:

"Ich nannte Euch jetzt nur dieses Geschäft, das erste, das nächste, das dringendste von allen. Wie vielfältig aber sind nicht die Rücksichten, in welchen der Jacobiner auf seine Mitbürger wirken kann und wirken soll? Wie unendlich mannigfaltig sind nicht die Zweige und die Mittel der Belehrung? Welch eine schöne, thatenreiche und rühmliche Aussicht thut sich nicht für uns auf in der Zukunft, wenn unser junges Institut erst tiefere Wurzeln geschlagen, Kräfte gewonnen und selbst gefühlt haben wird, was es vermag? Einen großen Schritt hiezu können wir in kurzem von den Bemühungen unseres Unterrichtsausschusses erwarten, dessen angelegentlichstes Geschäft die Ausarbeitung unsers Gesetzbuches sein wird, worin dem eifrigen Bruder seine Pflichten von selbst entgegen leuchten werden. Jeder wird, wenn erst diese Richtschnur vor seinen Augen liegt, sich in der Ordnung der zweckmäßigen, patriotischen Geschäftigkeit üben, zu wichtigen Vorlesungen und Debatten seine Kräfte aufbieten, oder seine Aufmerksamkeit bei dem, was andere vortragen, mit so gutem Erfolg anstrengen, daß er durch ihre Gründe belehrt, sich in Stand gesetzt sieht, in seinem Kreise diese Belehrung wieder mitzutheilen, und den Samen des Wissens wuchern zu lassen." (Forster 1968, I, 111-112)

Als Abgeordneter des Nationalkonvents, des ersten demokratischen Parlaments in Deutschland, war Forster nach Paris entsandt worden, um die Angliederung der allein nicht lebensfähigen Mainzer Republik an Frankreich zu beantragen. Der Auftrag wurde zwar angenommen, hatte sich aber durch die Rückeroberung der Stadt Mainz durch die Truppen der anti-französischen Koalition erledigt. In den »Parisischen Umrissen«, die die Erfahrungen seiner letzten Lebensjahre spiegeln, schreibt er:

"Die Hauptstadt Frankreichs war seit langer Zeit die hohe Schule der Menschenkenntniß. Mehr als jemals ist sie es jetzt, und es bedarf nur eines kurzen Aufenthalts und eines flüchtigen Blicks, um hier inne zu werden, was man anderwärts in Jahrzehenden kaum ergrübelt, und nicht nur den Geist der Gegenwart, sondern auch die Zeichen der Zukunft zu enträthseln. [...]

Die Revolution hat alle Dämme durchbrochen, alle Schranken übertreten, die ihr viele der besten Köpfe hier und drüben bei Ihnen, in ihren Systemen vorgeschrieben hatten. $[\ldots]$

Die öffentliche Meinung ist also bei uns in Absicht auf die Natur der Revolution jetzt so weit im Klaren, daß man es für Wahnsinn halten würde, ihr Einhalt thun oder Gränzpfähle stecken zu wollen. Eine Naturerscheinung, die zu selten ist, als daß wir ihre eigenthümlichen Gesetze kennen sollten, läßt sich nicht nach Vernunftregeln einschränken und bestimmen, sondern muß ihren freien Lauf behalten [...]

Die ersten Anfänge der Bewegung waren aber wegen des Umfangs, der Masse und des Gewichts so unmerklich, daß Klügere als er, sich täuschten, und diese ungeheu- 
re Triebfeder umspannen zu können, sich vermaßen. Allein wie bald entwand sie sich aus ihren ohnmächtigen Händen! - Es entstand ein chaotisches Ringen der Elemente; es erfolgten die heftigsten Konvulsionen, die furchtbarsten Erschütterungen. Kleinere gegenstrebende Bewegungen wurden von den größeren, allgemeineren verschlungen; so gab es denn eine gleichartige Bewegung, oder mit andern Worten: der Wille des Volks hat seine höchste Beweglichkeit erlangt, und die große Lichtmasse der Vernunft, die immer noch vorhanden ist, wirf ihre Strahlen in der von ihm verstatteten Richtung." (Forster 1968, 215ff.)

Abbildung 21: Erstürmung der Bastille

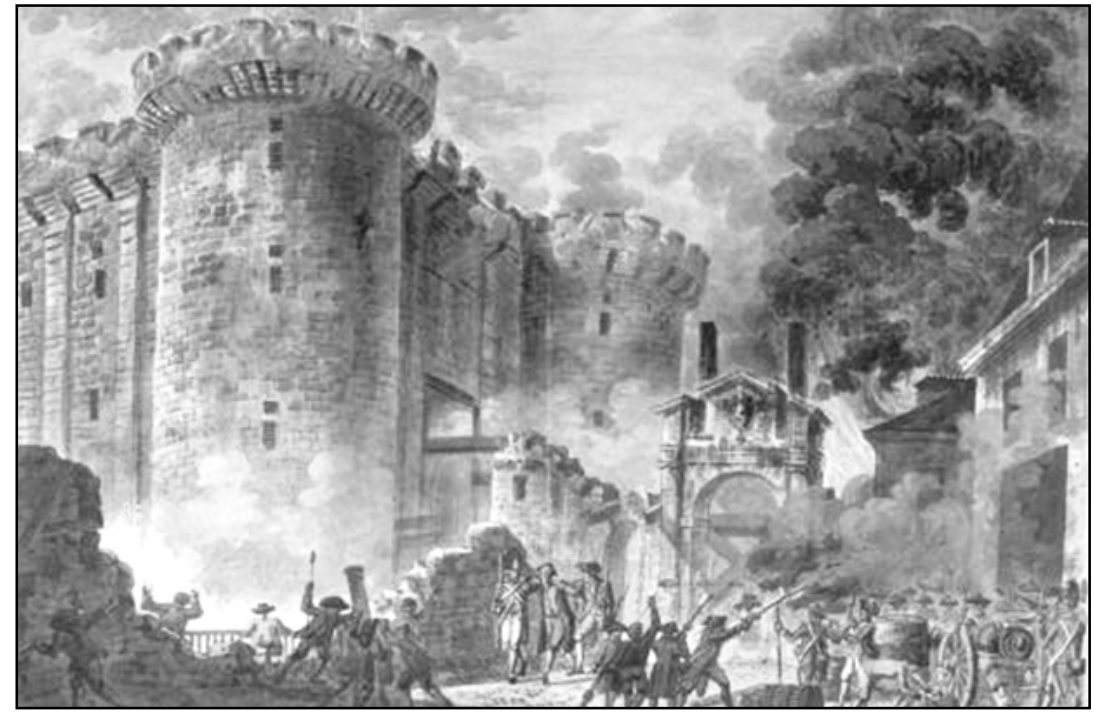

"Die Erscheinungen unter dem Joche des Despotismus können denen, die sich während einer republikanischen Revolution ereignen, sehr ähnlich sehen, und die letzteren sogar einen Anstrich von Fühllosigkeit und Grausamkeit haben, den man dort wohl hinter einer sanfteren Larve zu verbergen weiß; doch sind sie schon um deswillen himmelweit verschieden, weil sie durch ganz verschiedenartige Kräfte bewirkt werden, und von der öffentlichen Meinung selbst einen ganz verschiedenen Stempel erhalten. Eine Ungerechtigkeit verliert ihr Empörendes, ihr Gewaltthätiges, ihr Willkührliches, wenn die öffentliche Volksmeinung, die als Schiedsrichterin unumschränkt in letzter Instanz entscheidet, dem Gesetze der Nothwendigkeit huldigt, das jene Handlung oder Verordnung oder Maßregel hervorrief." (Forster 1968, I, 220)

Forster macht es sich nicht leicht, die erlebte Gewalttätigkeit und Willkür zu verarbeiten. Er leugnet die Auswüchse der Revolution nicht. 
Worte: Zwang, Gewaltthätigkeit, Tyrannei; ich finde Vergleichungen mit der vorigen monarchischen Regierung, die gegen unsere jetzige noch golden gepriesen wird." (Forster)

"So wenig wünschenswerth unser Zustand in Absicht auf die Regierung immerhin genannt und geschildert werden mag, so irrt man doch bei Ihnen gar zu sehr, wenn man von ihrer heterokliten Beschaffenheit auf ihre Zerstörbarkeit schließt; denn was ihr Dauer und Stärke verspricht, ist ja gerade diese durch das Ganze jetzt unwiderstehlich herrschende Einheit des Volkswillens, verbunden mit der Repräsentantenvernunft. Setzen Sie diese letztere so tief herab, wie es Ihnen gut dünkt; dennoch bleibt noch immer ein solcher Lichtherd übrig, daß, sobald nur jener Einklang mit dem allgemeinen Wollen vorhanden ist, nichts dem politischen Riesen widerstehen kann. Warum verhält es sich beim Despotismus anders? Die Auflösung liegt am Tage. Die Einheit fehlt; Vernunft und Wille sind beide nur im Kopfe des Herrschers und seiner Räthe; das Volk ist eine leblose Masse, ein todter Körper, der bloß mechanischen Antrieben gehorcht; jene geistigen Kräfte durchströmen und beleben ihn nicht, verbinden ihn nicht mit sich selbst zu einem lebendigen Ganzen. Beider Zweck und Streben sind gänzlich verschieden. Freilich giebt es noch ein Mittel, die Trägheit, oder die Kraft des Widerstandes im Volke zu überwinden; aber das Beispiel Frankreichs haben wir zu deutlich vor Augen." (Ebd. 772)

"Ich ahnde auch manchmal, daß es ohne manchen harten Kampf nicht abgehen wird; allein wer auf diese innerlichen Reibungen die ganze Hoffnung setzt, Frankreich wieder unter das Joch zu bringen, und ungequetscht davon zu kommen, - guter Himmel! Nicht doch, Ihr Herren, Ihr schlagt die Volte falsch, wie Ihr möget. Paris ist immer unsere Karte, und Ihr habt verloren." (Ebd. 770)

Georg Forster ist am 10. Januar 1994 an einer Lungenentzündung in einer Dachwohnung in der Rue des Moulins gestorben. Im Gegensatz zu vielen anderen deutschen Befürwortern der Revolution, wie etwa Friedrich Schiller, wandte er sich selbst unter dem Eindruck des Terrorregimes nicht von den revolutionären Idealen ab. Aber das Rad der Geschichte drehte sich unaufhaltsam weiter. Die Radikalität steigerte sich zu Brutalität. Der fortschreitende Gedanke überholte die Menschlichkeit. Mit der Machtübernahme durch die radikaleren Jakobiner unter Robespierre wurden Abweichler angeklagt und verhaftet. So erging es auch Marie Jean Antoine Nicolas Caritat, Marquis de Condorcet (1743-1794) französischer Philosoph, Mathematiker und Politiker, weil er heftig gegen die, nach seiner Meinung stümperhafte neue Verfassung argumentierte.

Condorcet war überzeugter »Sozial-Liberaler« und kultureller Neuerer. Er trat 1790, kurz nach der Verkündung der Menschen- und Bürgerrechte, vehement dafür ein, diese auch den Frauen zu gewähren. In seinem am 3. Juli 1790 veröffentlichten Essay »Sur l'admission des femmes au droit de cité« sprach 
er sich für die Einführung des Frauenwahlrechts aus. Darüber hinaus trat er für die Gleichberechtigung von Schwarzen verbunden mit der Abschaffung der Sklaverei und für den Freihandel ein.

Condorcets eigenes Demokratieideal unterschied sich von Rousseaus »Contrat« zum einen durch die Form der Willensbildung. Dazu schlug er regionale und lokale Instanzen vor. Deren Zusammenkünfte sollten Orte der Debatte schaffen, in denen die Bürger Argumente und Kritik artikulieren. Zum andern muss dabei die Möglichkeit der Korrektur demokratischer Entscheidungen möglich sein, um die Bürgerrechte und die Freiheit zu schützen. Condorcet entwirft dafür das Konzept der »Zensur des Volkes«, das es möglich machen soll, gegen Gesetze auf Verletzung der Rechte zu klagen.

Dies sind zwei wesentliche Aspekte der Herausbildung von Öffentlichkeit, wobei der freie Zugang zu allen wichtigen Gegebenheiten sowie deren ungehinderte Diskutierbarkeit entscheidende Kriterien sind. Zwischen Staat und Individuum tritt eine vermittelnde »Sphäre«, ein Netz, das sich nach der Kommunikationsdichte, der Organisationskomplexität, und Reichweite differenziert, von der Kneipe bis zu den Massenmedien.

Abbildung 22: Der Denkerclub. Karikatur von 1820

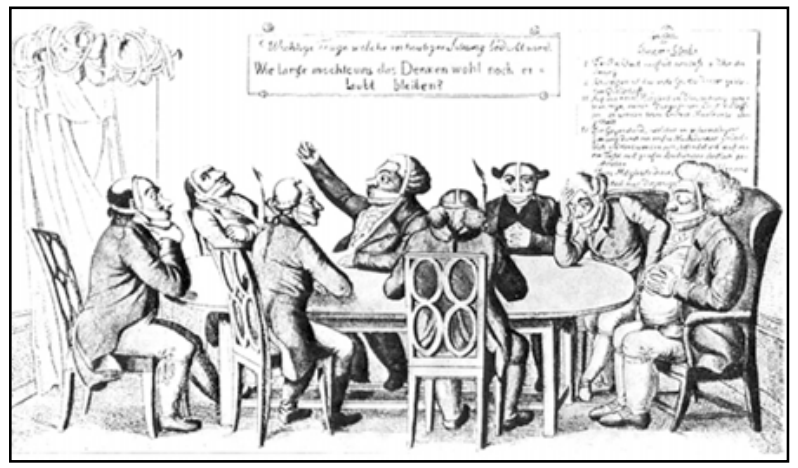

Die einprägsamste Begriffsbestimmung »Bürgerlicher Öffentlichkeit« findet sich immer noch bei Habermas:

"Bürgerliche Öffentlichkeit lässt sich vorerst als die Sphäre der zum Publikum versammelten Privatleute begreifen; diese beanspruchen die obrigkeitlich reglementierte Gewalt alsbald gegen die öffentliche Gewalt selbst, um sich mit dieser über die allgemeinen Regeln des Verkehrs in der grundsätzlich privatisierten aber öffentlich relevanten Sphäre des Warenverkehrs und der gesellschaftlichen Arbeit auseinander zu setzen. Eigentümlich und geschichtlich ohne Vorbild ist das Medium dieser Auseinandersetzung: das öffentliche Räsonnement." (Habermas 1962, 38) 
Öffentlichkeit ist dem gemäß ein Ort der Kritik, das Forum, auf dem Meinungen ausgetragen und Entscheidungen vorbereitet werden. Sie schiebt sich zwischen Staat und Gesellschaft und konstituiert »eine Sphäre des Gemeinwesens, der allgemeinen Volksangelegenheiten in idealer Unabhängigkeit von den besonderen Elementen des bürgerlichen Lebens« (Marx zit. Habermas 1962, 137).

In der Rhetorik der Demokratie besitzt Öffentlichkeit eine besondere Dignität als letzte Instanz der Entscheidungsfindung. Die politischen Prozesse sollen nicht geheim, zugänglich, also offen sein (Gerhards/Neidhardt 1991, 32).

Der »Soziale Strukturwandel der Öffentlichkeit« (Habermas 1962, 157) wird ausgelöst durch Tendenzen der Majoritätendemokratie, die auf ein erweitertes Publikum rekurriert, das nicht nur aus den bürgerlichen Privateigentümern besteht, sondern alle Bevölkerungsschichten berücksichtigen muss. Dies provoziert Eingriffe des Staates in die private Sphäre und die permanente Intervention im staatlich regulierten Kapitalismus. Dem entspricht eine Transformation in eine massenmedial konstruierte Form der Öffentlichkeit, welche fortbestehende Ausbeutung und Unterdrückung durch Manipulationsstrategien $\mathrm{zu}$ überdecken und aufzufangen versucht und Teilhabe breiterer Schichten an Öffentlichkeit kommerziell begrenzt.

Dies muss nicht durch bewusste Lüge oder Verdrehung erfolgen, sondern die Massenmedien sind selbst Teil des Verblendungszusammenhangs, den sie erzeugen. Öffentlichkeit wird dem Umfang nach immer weniger durch direkte Kommunikation hergestellt. Habermas konstatiert: »Der Kommunikationszusammenhang eines räsonierenden Publikums von Privatleuten ist zerrissen.« (Ebd. 268)

Der Austausch von Wissen und Meinen ist nicht mehr gebunden an Gespräch, Rede und Zuhören. Ihr Forum ist nicht mehr durch Eigentum, Bildung und Geschlecht definiert - zumindest nicht ausschließend. Schon die Popularisierungsdiskussion im 19. Jahrhundert war getragen durch Printmedien: Buch, Broschüre, Zeitschrift. Seit Mitte des 20. Jahrhunderts sind die elektronischen Massenmedien (Radio, Film, Fernsehen, Internet) dazu getreten, sodaß es bildungsungewohnten Bevölkerungsgruppen besser möglich wäre, auf der Grundlage zeitgenössischer Informationstechniken (z.B. Blog, Print on Demand) tatsächlich öffentlich zu agieren.

Dies konstituierte eine völlig veränderte, in Partialforen zerfallende und verbreiterte und zugleich diffusere Öffentlichkeit. Die mediale Öffentlichkeit konstruiert ihre Themen selbst und sie sind organisierten Interessen unterworfen. Die Legitimationsmuster der massendemokratischen Herrschaftsstrukturen erweitern gleichzeitig die Partizipationsansprüche, die sich auch an Wissenschaft richten. 


\section{2 ÖFfentlichKeIt UNd Wissenschaft}

Schon bei den frühen Aufklärern wie Mendelssohn finden wir die Einsicht, dass die Möglichkeit, wahr zu reden, verbunden ist mit der Fähigkeit, die Diskussion zu beherrschen. Nicht alle können und dürfen am wissenschaftlichen Diskurs teilnehmen, der also abhängt von gesellschaftlichen Positionen und Interessen. Die sich zuspitzenden, zunehmend komplexer und abstrakter werdenden Fragen wissenschaftlichen Forschens auf der einen Seite machen in der Folge Bemühungen des Rückbezugs von Wissenschaft auf Gesellschaft immer schwieriger. Auf der andern Seite stehen die Auflösung der bürgerlichen Öffentlichkeit und ihre Ersetzung durch eine massenmedial gestützte und gefährdete Demokratie. In der vorerst letzten Phase werden die persönlichen oder schriftlichen Kommunikationsformen durch fortschreitende Medialisierung im Internet aufgesogen, das aber gleichzeitig neue Netze entstehen lässt.

Die Medien unterliegen einer weitgehenden Kommerzialisierung. Dagegen stellt sich das lange diskutierte Theorie-Praxis-Problem in der alten Fassung so nicht mehr. Theorie ist zur Praxis großer Beschäftigtengruppen geworden und Praxis fordert Theorie als Lieferanten brauchbaren Wissens ein. So ergeben sich neue Transferformen und Übergangsprozesse. Öffentlichkeit der Wissenschaft wird zu einem wunden Punkt und zugleich zum Desiderat für Demokratie.

Wissenschaft, kommerziell verwertet, wird zum Berichtserstattungsgegenstand einer weitgehend kommerzialisierten und selbstbezüglichen Medien- und Kulturindustrie. Diese ist interessiert an als Neuigkeiten verkaufbaren Meldungen. Umgekehrt kann Wissenschaft die Medien nutzen, um sich Aufmerksamkeit und in der Folge Ressourcen zu sichern (Weingart 2003, 115). Dies verschiebt auch die Kommunikationsformen innerhalb der Wissenschaft, indem die Medien für Prioritäts- und Dominanzansprüche instrumentalisiert werden. Beide Seiten tendieren zu einer Katastrophenkommunikation, die spektakuläre Warnungen präferiert: Waldsterben, Ozonloch, Klimawandel, Aids und Klonen - z.B. »Öffentlichkeit kann sich empören« (Gerhards/Neidhardt 1991, 32) - über Korruption, Studentendemonstrationen, angeblich verschwendete Steuermittel. Da über wissenschaftliche Ressourcen im politischen Interessenkonflikt entschieden wird, sind Image und Präsenz von Wissenschaftlern und Disziplinen in den Medien mitentscheidende Faktoren für Mittelzuweisung.

Die Medien verfügen aber über eine unkalkulierbare Eigendynamik, welche sich der direkten Steuerung entzieht. Sie entwickeln interne, relativ autonome Konstellationen, Prioritäten und Manipulationsstrategien. Ihre Macht generieren sie, indem sie das knappe Gut Aufmerksamkeit lenken und verteilen. Durch Fokussierung von Aufmerksamkeit verleihen sie Bekanntheit und Prominenz. Vermittelt durch die massenmediale Präsenz dringen politische Machtstrategien in den wissenschaftsinternen Wahrheitsdiskurs.

Mit den internen Kriterien von Wissenschaft hat dies meist wenig zu schaf- 
fen. Während einige - auch schillernde - »öffentliche Wissenschaftler« auf dieser Welle der Bekanntheit reiten, gilt nach dem Ethos der Wissenschaft Publizität oft als anrüchig und geschmacklos und kann sogar der Reputation schaden. Beides sind Fehlentwicklungen. Vielmehr muss Wissenschaft in der Demokratie ein Interesse daran haben, dass Prioritäten- und Ressourcenentscheidungen auf der Grundlage vernünftiger Argumente gefällt werden. Dazu benötigen die am Entscheidungsprozess beteiligten, sowohl die politischen Akteure als auch ein demokratisches Publikum Wissen über Wissenschaft. Dies zu verbreitern, zugänglich und öffentlich zu machen ist Aufgabe von Wissenschaft selbst (vgl. zum Folgenden: Faulstich 2006).

Es geht um neue und intensivierte Kommunikationsstrukturen zwischen Wissenschaft und Gesellschaft als Basis des öffentlichen Diskurses in der Perspektive »Öffentlicher Wissenschaft« und demokratischer Gesellschaft. Auch hier wieder stehen Aufklärung, Bildung und Wissenschaft eng zusammen.

Das erreichte schon einen ersten Höhepunkt bei Christian Thomasius (s.o. Teil 1.2), als er die deutsche Sprache an die Universität brachte. Heute noch bekannt ist sein - zitierter (s.o. Teil 1.2) - Hinweis am Schwarzen Brett der Universität Leipzig, in der er am 31. Oktober 1687 eine Vorlesung auf Deutsch ankündigte. Hauptthese war, dass die Franzosen ihre Werke großteils auf Französisch herausgäben und auch lateinische, griechische, auch deutsche Autoren in ihre Muttersprache übersetzten. Dadurch werde die Gelehrsamkeit unmittelbar fortgepflanzt und nicht durch das Erlernen einer Fremdsprache gebremst. Thomasius begann die Durchsetzung einer bürgerlichen, patriotisch gefassten wissenschaftlichen Öffentlichkeit, an der sich - im Prinzip - alle beteiligten konnten.

Die Muttersprache war Kennzeichen einer Kritik an der scholastischen Universitätstradition, die vor allem in Exegese klassischer Schriften auf Latein beruhte. Erst dadurch ist auch das Interesse der bürgerlichen Öffentlichkeit für die Themen und Resultate der Wissenschaft gewährleistet. Die Spitzfindigkeiten scholastischer Exegese werden überwunden und lächerlich gemacht.

Der beschränkte Kopf des wissenschaftlichen Pedanten, den Thomasius in seiner Zeitschrift »Der Teutsche Merkur « 1688 karikiert, schlägt vor - nur dies gilt ihm als wirkliche akademische Wissenschaft -, dass in der Historie untersucht werden solle, »ob David schon Coffée getrunken, weil Abigail ihm unter anderen Präsenten gedörrte Bohnen überbracht«. In der Physik solle man, gemäß der Lehre, dass die Luft und nicht das Wasser das feuchteste Element sei, per deductionem beweisen, es könne Wasser geben, das nicht nass sei. Die Medizin solle, gegen die Entdeckung des Blutkreislaufs, per inductionem diese Lehre widerlegen, weil die Anatomie zeige, dass es keinen Kreislauf gebe. Die Rechenkunst solle eine christliche Mathematik mit geistlichen Beispielen durchdrungen werden und beweisen, dass die Probe beim Addieren, da sie mit dem Kreuz geschieht, viel christlicher und richtiger sei als die per subtractonem - soweit der beschränkte Kopf. 
Thomasius nimmt mit seinem Hohn und Spott eine Renaissance- und Humanistentradition auf, gegen abstrakte Spinnerei und wertlose Pedanterie. Er selbst will dagegen in seiner Wissenschaft das Neue erkunden und seine Brauchbarkeit finden.

Dies war auch Intention der immer wieder diffamierten Popularphilosophie, für die in Deutschland Christian Garve (1742-1798) steht, der in der Spätaufklärung neben Immanuel Kant und Moses Mendelssohn zu den bekanntesten Philosophen zählte. Er gilt als Repräsentant und Exponent der Popularphilosophie, die sich selbst als vernünftiges Denken für die Welt verstand, d.h. sie nahm gegenwartsbezogene Probleme und Aspekte aus ihrer Umwelt auf (zu Garve vgl. a. Lorenzen 1986, 249-264).

Garve zielte auf das Handeln und auf das Denken und Empfinden der Menschen. Der Begriff der Popularität löste eine zwischen ihm und Immanuel Kant fast zwei Jahrzehnte dauernde Auseinandersetzung aus um innerweltliches Glück vs. den Pflichten, die sich aus dem kategorischen Imperativ ergeben. Garve verstand sich selbst als Moralphilosoph, der sich mit Fragen der Sitte, Sitten und Sittlichkeit - also den Begründungen und Rechtfertigungen des Handelns befasst. Moralphilosophie in seiner Perspektive behandelt die Bedingungen, Möglichkeiten und Grenzen, auf der Grundlage der allen Menschen gemeinsamen Vernunft ein humanes und glückliches Leben zu führen.

Garve befürchtete, dass sich die Philosophie nach Kant immer mehr von den Geschäften der Welt zurückziehen könne, und sich so eine unüberbrückbare Kluft zwischen System und Alltagsverständnis öffnet. Im Gegensatz zu Kant, den er hoch verehrte, sah Garve seine Aufgabe darin, als Philosoph auch für den »schwerbegreifenden und flatterhaften Leser« zu schreiben, weniger »die Wahrheiten von ihren ersten Elementen an zu untersuchen«. So war sein Anliegen weniger ein erkenntnistheoretisches als ein belehrendes, sein größtes Verdienst die Anregung und Förderung anderer. Er veröffentlichte in seinen Vermischten Aufsätzen (1796) einen Aufsatz mit dem Titel »Von der Popularität des Vortrages«. Garve bezieht Position für die Notwendigkeit populären Sprechens in der Philosophie und wehrt sich gegen eine Erneuerung esoterischer Bestrebungen. Er bestimmt die Eigenschaften eines populären Vortrages: Ein Vortrag müsse verstanden werden können. Dazu müsse er deutlich sein. Ein populärer Vortrag müsse einen vollkommenen Gebrauch der Sprache aufweisen. Er müsse sich an die Einbildungskraft wenden. Die Imagination erleichtere das Denken, und die Begriffe gerieten in einen leichteren Fluss. Schließlich erfordere der populäre Vortrag besonders Bilder und Beispiele.

Zusammenfassend sagt Garve:

"[D]iejenige philosophische Schrift ist gemacht, auf das größere gesittete Publicum zu wirken, die, mit der Vollkommenheit des lehrenden Vortrags, einen natürlichen leichten Fluß der Gedanken verbindet; und in deren Schlußreihen so viel Geschichte, oder Poe- 
sie eingewebt ist, als zur Aufhellung der abgezognen Begriffe, oder zur Bestätigung der allgemeinen Sätze erfordert wird." (Garve 1796 [1985], 341)

Damit wäre eine Voraussetzung eines Diskurses zwischen Wissenschaft und Öffentlichkeit erfüllt: eine wechselseitig verstandene Sprache. Popularphilosophie - im Sinne Garves - will aber ihre Gegenstände nicht nur allgemeinverständlich darstellen, sie soll auch jedem ermöglichen, selbst zu denken. Philosophie und Wissenschaft sind allen zu öffnen - nicht nur in der Rezeption der Ergebnisse, sondern auch in der Produktion des Wissens.

Vorliegende - bis in die Aufklärung zurückgehende - Modelle der Beziehung von Wissenschaft und Gesellschaft für die Handlungsbegründungen haben also unterschiedliche Reichweite. Prämisse aller Vermittlung ist gegenseitige Information über Probleme, Resultate und Strategien in der Spannung von Konflikt und Konsens. Allerdings beschränkt sich dies oft auf bloße Erzeugung von Akzeptanz. Um die gegenseitigen Aversionen zwischen Experten und Laien aufzuheben, bedarf es eines kontinuierlichen Dialogs.

Erschwert und zugleich möglicherweise erleichtert wird die Diskussion durch das Dazwischentreten der Medien. Es zeigt sich eine merkwürdige Ambivalenz medienvermittelter Wissenschaftsresultate: Einerseits werden durchaus relevante Themen aufgegriffen, andererseits dem wissenschaftsfernen, Kultur konsumierenden Publikum ein Schauspiel wissenschaftlich räsonierender Akteure vorgeführt mit unnachprüfbaren Argumenten und aufgeladener Rhetorik, reduziert auf news und stories.

Es bestehen also eine große Reichweite und erhebliche Schwierigkeiten bei der Aufgabe Wissenschaft und Öffentlichkeit zu vermitteln, um Demokratie zu ermöglichen und zu entfalten. »Öffentlichkeit« ist außerdem nur ein Ausschnitt aus den vielfältigen Verhältnissen zwischen Wissenschaft und Gesellschaft. In einem umfassenden Konzept von Transfer als beiderseitigem Austausch erhält die alte Theorie-Praxis-Frage ihre gegenwärtige Form - nicht mehr nur als punktuelle Anwendung, sondern als kontinuierliche Vermittlung. Es geht um Versuche, wissenschaftliche Aktivitäten sowohl in Forschung als auch in Lehre auf gesellschaftliche Probleme zu beziehen und umgekehrt wissenschaftliche Impulse für eine verbesserungswürdige Wirklichkeit zu geben. Wissenschaft kann das Unbelegte aufdecken und das Falsche sichtbar machen. Es gibt keinen Wissenschaftsbereich, der aus der Vernetzung mit gesellschaftlichen Aufklärungs- und Verwendungszusammenhängen ausgeschlossen wird.

Ein umfassendes Konzept des Wissenschaftstransfers beinhaltet Öffentlichkeitsarbeit, Beratung und Weiterbildung bezogen sowohl auf mögliche Verwendung wissenschaftlichen Wissens als auch auf Aufklärung durch und über Wissenschaft - durchaus in einem emphatischen Sinn.

Der stärkere Rückbezug auf gesellschaftliche Problemlagen ist angesichts intensivierter Zugriffsversuche durch Politik und Ökonomie für den wissen- 
schaftsspezifischen Wahrheitsdiskurs durchaus riskant. Die schwierige Leistung von Wissenschaftstransfer ist es, Mittellagen zu organisieren. Hochschulen dürfen, wenn sie ihren Wissenschaftsanspruch behalten wollen, einerseits nicht zu verlängerten Werkbänken der Unternehmen werden, gleichzeitig darf andererseits aber kein erneuter Rückzug in den Elfenbeinturm erfolgen. Es geht um relative Autonomie wissenschaftlichen Denkens, dass sich der unmittelbaren Umsetzung und Verwertung entzieht. Versuche, Forschungsprozesse unmittelbar kommerziellen oder politischen Strategien unterzuordnen, erzeugen selbst Transferhemmnisse. Mit dieser Diskussion um Wissenschaftstransfer werden Grundfragen des Selbstverständnisses von Wissenschaft aufgeworfen. Ihr zentrales Moment, die Suche nach Wahrheit, wäre durch direkte Indienstnahme für außerwissenschaftliche Interessen gefährdet. Es wird ein Prozess der Selbstreflexion und der Aktivitätenbegründung angestoßen.

Dies trifft innerhalb des laufenden Wissenschaftsbetriebs auf konkurrierende Begründungsmodelle mit widerstreitenden Legitimationsannahmen. Unterschiedlich wissenschaftstheoretische und -politische Hintergrundannahmen variieren auf divergierende Theorie-Praxis-Verhältnisse. Eine pragmatisch reflektierte Transferstrategie benötigt einen Wissenschaftsbegriff, der die Trennung von Technologie und Reflexionstheorie überwindet. Nur so kommen die verschiedenen Dimensionen von Leistungen, welche von Transferaktivitäten zu erwarten sind, ins Blickfeld. Dies hilft, Rezeptillusion zu vermeiden. Die Vorstellung, die Wissenschaft habe fertige Antworten auf gesellschaftliche Fragen, hat sich als Illusion erwiesen. Falsch ist auch die Vorstellung einer Transferkaskade, nach der Wissenschaft eine Quelle des Wissens sei, die dann überfließend sich in Unternehmen und Verwaltungen ergießt. Demgegenüber erzeugt Wissenschaft selber die Fragen, auf welche sie die Antwort gibt.

»Aufgeklärte« Transferstrategien müssen die Beschränktheit von Instrumentalität reflektieren. Es geht bei den Anforderungen und Konzepten an Wissenschaftstransfer nicht nur um ein Effizienz-, sondern auch um ein Legitimationsproblem von Wissenschaft. Je größer das Gewicht von Wissenschaft für gesellschaftliche Entwicklung, je höher ihr Anteil an ökonomischen Ressourcen, desto stärker wachsen auch die an ihre Funktion und Leistung gestellten Anforderungen.

Unter dem Stichwort »Popularisierung « hat das Problem der Vermittlung zwischen Wissenschaft und Öffentlichkeit eine lange Tradition, die in immer neuen Varianten auftaucht. Die vorerst letzte Bewegung ist ausgelöst worden durch den im Auftrag der Royal Society 1985 vorgelegten »Bodmer-Report«: »The Public Understanding of Science« (PUSH). Die Diskussion hat sich erweitert zu »Public Engagement in Science and Technology« (PEST). Betont wird die Notwendigkeit von Vermittlung eines individuelle Erlebnisse übersteigenden kulturellen Wissens. Hinter der Kontroverse verbirgt sich ein reales Problem, 
nämlich die Tatsache, dass Wissenschaft immer deutlicher unser Leben bestimmt und ihm gleichzeitig fremd bleibt und sogar immer entfernter wird. Es entsteht eine unaufhebbare Lücke zwischen der Masse wissenschaftlicher Einzelerkenntnisse und der Kraft diese zu begreifen, jedenfalls dann, wenn man einem stoffbezogenen Begriff von Wissen hinterher rennt. Ergebnis kann dann nur hoffnungs- und atemlose Resignation gegenüber einer anwachsenden Flut diffuser Information sein.

Aber auch eine für die »niederen « »Stände« oder »Schichten« zurechtgemachte »volkstümliche« Bildung kann dem Vorwurf der Vereinfachung und Verflachung unterliegen - dies war der Kern der Popularisierungskritik. Die Spaltung zwischen Eingeweihten und Unwissenden, zwischen Priestern und Laien ist zutiefst hierarchisch und elitär. Das dichotome Modell, das Wissensformen nach der Dimension exklusiv versus populär trennt, vereinfacht unzulässig das Kontinuum von Übergängen zwischen wissenschaftlichem Wissen und Alltagswissen.

Bezogen auf Öffentlichkeit zeigt Wissenschaft eine doppelte Schwäche: Öffentlichkeitssucht und Öffentlichkeitsflucht. Wissenschaft braucht einerseits öffentliche Anerkennung, zu viel und vorschnelle öffentliche Präsentation aber verdirbt den Ruf. Einsicht in die Kontingenz wissenschaftlicher Erkenntnisproduktion erlaubt es nicht nur, sondern erfordert sogar, dass öffentliche Rechnungslegung und Einschätzung erfolgen. Bei aller Problematik medienüberformter und massenmedialer Formen von Öffentlichkeit gibt es für die Demokratie keine Alternative, als Foren der Partizipation zu öffnen.

In den Aktivitäten des Wissenschaftstransfers lernt man schnell, dass es nicht darum geht, fertiges Wissen weiterzugeben, sondern gegenseitiges Problemverständnis zu entwickeln und gemeinsam Theorie-Praxis-Fragen zu bearbeiten (Faulstich 1995). Wissenschaft in traditionellem Verständnis (Modus I) wurde erzeugt in etablierten Institutionen, gekennzeichnet durch ein Ensemble von Ideen, Theorien, Methoden und Normen. Die neue Form der Wissenserzeugung (Modus II) breitet sich aus und erstreckt sich auf die kontinuierliche Kombination und Rekonfiguration von Wissensbeständen in unterschiedlichen Problemkontexten. Sie wird vielfach in komplexen Netzwerken vollzogen, in denen kein Akteurstyp per se die dominante Rolle übernimmt. Generierung, Diffusion und Implementation von Wissen ist dann ein Prozess der Interaktion zwischen vielen Beteiligten.

Die Brücke zwischen Wissenschaft und Öffentlichkeit zu schlagen wird zur Aufgabe von Vermittlungsagenturen im Spektrum von Massenmedien und Lerninstitutionen. Dabei ergibt sich ein grundlegendes Spannungsverhältnis: Wissen wird zunehmend zu einer Ressource gesellschaftlicher Innovationsund Modernisierungsprozesse, zugleich zerbricht aber das Monopol des Wissenschaftssystems auf die Erzeugung und Verwaltung von Expertise.

Zugänge durch Teilhabe am Wissen zu schaffen, steht unvermeidlich in der 
umstrittenen Tradition der Aufklärung. Eine neue »Apologie« der Aufklärung wird überlebenswichtig. Hier entsteht das Ideal einer aufgeklärten Demokratie, in der eine Gesellschaft mündiger Menschen frei über sich selbst bestimmt. Die Konsensherstellung in einer unverzerrten Kommunikationsgemeinschaft wird als Legitimationsmuster etabliert.

Der Prozess gewalt- und vorurteilsfreier Selbstbestimmung durchläuft immer wieder neu ein permanentes Provisorium einer vorläufigen, unvollkommenen Ordnung. Etwas Besseres hat die politische Theorie bis heute nicht zu bieten.

\subsection{Wissen DeR WeLt}

Zentrale Strategie der Aufklärung gegen Adel und Klerus war es, aus dem Gefängnis der Glaubenssätze auszubrechen und einen erfahrungsbezogenen Zugang zum Wissen zu öffnen, die Wahrheit zu klären. Ein neues Verständnis von Wissen breitete sich aus. Wahrheit blieb nicht mehr in der Obhut der Priester und Schriftgelehrten eingesperrt, sondern ein Zugang stand prinzipiell jedem offen. Seine Grenzen wurden geöffnet. Nicht nur wissenschaftliches Wissen, sondern auch technische und künstlerische Kenntnisse - des Sciences, des Arts et des Métiers - sollten zugänglich gemacht werden.

Damit wurde auch die Verfügbarkeit des Wissens entgrenzt. Nicht das geheime Wissen, sondern die öffentliche Wissenschaft stand zur Debatte - bei gleichzeitigen Irritationen der Zurücknahme ins Arkanum der Geheimgesellschaften. Das von den Herrschenden unter Verschluss gehaltene Wissen, das denen die Macht sicherte über die Welt und deren Interpretation, sollte für Wissenschaft, Geschäft und Kunst nutzbar werde. »Öffentliche Wissenschaft« (Faulstich 2006) hat immer zugleich instrumentelle und reflexive Horizonte. Diese zentrale Problematik durchzieht neuzeitliches Denken von Francis Bacon (s.o.) bis Michel Foucault, von der »Enzyklopädie« bis zur »Wikipedia«: das Verhältnis von Macht und Wissen.

Foucault hat als Inhaber des Lehrstuhls für die Geschichte der Denksysteme am Collège de France die Frage nach der »Ordnung der Dinge« (Foucault 1974) bis in seine letzte Vorlesung »Mut zur Wahrheit« weiterverfolgt. Er fragt:

"Welche Bedingungen hatte Linné (oder Petty oder Arnauld) zu erfüllen, um seinen Diskurs nicht nur kohärent und im Allgemeinen wahr zu machen, sondern inm zu der Zeit, in der er geschrieben und aufgenommen wurde, Wert und praktische Anwendung als wissenschaftlichem Diskurs zu geben?« (Foucault 1974, 15)

Er fragt also nach der Form der Darstellung und der Wirkung des im Diskurs als Wissen akzeptierten Bestandes an als wahr geltenden Aussagen.

Schon die Aufklärung war vor die Aufgaben gestellt, die vielfältigen, unübersichtlichen und anwachsenden empirischen Daten zu klassifizieren und zu 
systematisieren. Die großen Namen der Zeit sind: Arnauld (1612-1694), französischer Theologe, Logiker und Mathematiker, Linguist und Grammatiker; Petty (1623-1687), britischer Ökonom und Statistiker und Philosoph; Linné (1707-1778) schwedischer Naturwissenschaftler, Schöpfer der binominalen Nomenklatur als Grundlagen der botanischen und zoologischen Taxonomie; Buffon (1707-1788), französischer Naturforscher, Klassifikator und Systematiker.

Das bekannteste Unternehmen war die »Enzyklopädie« mit dem Versuch der Aufbereitung, Zusammenfassung, Darstellung und Verbreitung der Gesamtheit allen Wissens und der verstreuten und vereinzelten Kenntnisse. Dieses großartigste Vorhaben früher Aufklärung verbindet sich mit Denis Diderot und der »Encyclopédie, ou Dictionaire Raisonné des Sciences, des Arts et des Métiers « - erschienen von 1751 bis 1776 in 17 Text-, 11 Bild-, vier Ergänzungs- und zwei Registerbänden mit insgesamt etwa 72.000 Artikeln. Absicht der Herausgeber war es, Licht in die Geheimnisse zu bringen, das Wissen ohne Ausnahme öffentlich bekannt zu machen. Der »Discours preliminaire« geht aus von der Notwendigkeit, nach Wissen zu suchen, das für die Erfordernisse einer »modernen« Welt wappnet.

"Enzyklopädie: Dieses Wort bedeutet ,Verknüpfung der Wissenschaften ‘ [...] Tatsächlich zielt eine Enzyklopädie darauf ab, die auf der Erdoberfläche verstreuten Kenntnisse zu sammeln, das allgemeine System dieser Kenntnisse den Menschen darzulegen, mit denen wir zusammenleben, und den nach uns kommenden Menschen zu überliefern, damit die Arbeit der vergangenen Jahrhunderte nicht nutzlos für die kommenden Jahrhunderte gewesen sei; damit unsere Enkel nicht nur gebildeter, sondern gleichzeitig auch tugendhafter und glücklicher werden, und damit wir nicht sterben, ohne uns um die Menschheit verdient gemacht zu haben." (Diderot 1972, 396)

Man hört eine Stimmung des Aufbruchs, die Hoffnung auf Fortschritt und die Bedeutung der Kenntnisse, nicht nur für die Wahrheit, sondern auch für das Glück. Absicht der Herausgeber war es, Licht in die Geheimnisse zu bringen, das Wissen ohne Ausnahme öffentlich zu machen, aus der reinen Fachgelehrsamkeit herauszuholen und es zu verbreiten.

"Mit der Zeit wird dieses Werk bestimmt eine Revolution in den Köpfen herbeiführen. Und ich hoffe, dass die Tyrannen, Unterdrücker, Fanatiker und Intoleranten dabei nicht gewinnen werden." (Diderot 1984, 182)

Das enzyklopädische Ideal der Aufklärung und der politischen Emanzipation unternimmt den Entwurf einer neuen Ordnung des Wissens angesichts des Zerbrechens alter Hegemonie. So geht es nicht um ein Abbild des Bestehenden, das zu katalogisieren wäre, vielmehr wird das Überliefernswerte kritisch ausgewählt als Antizipation des Möglichen. 
Der Urheber Denis Diderot (5. Oktober 1713 in Langres (Champagne-Ardenne) - 31. Juli 1784 in Paris) gilt heute als einer der originellsten Denker der europäischen Aufklärung. 1746 erhielt Diderot von dem Pariser Verleger und Hofdrucker Le Breton den Auftrag, die kurz zuvor abgeschlossene Cyclopaedia, or Universal Dictionary of the Arts and Sciences zu übersetzen. Er nahm an, beschloss aber, das zweibändige Werk beträchtlich zu erweitern, um daraus eine Summe des gesamten Wissens seiner Zeit zu machen. Hierzu gewann er als Mitarbeiter zuerst seinen Freund Jean-Baptiste le Ronde d'Alembert, einen Mathematiker und Naturwissenschaftler, sowie nach und nach andere Autoren (die teils sonst wenig bekannte Spezialisten, teils aber auch berühmte Leute waren wie z.B. Montesquieu oder Voltaire).

1749 musste er einige Monate unterbrechen, da er wegen seiner mehr nebenher verfassten und veröffentlichten religionskritischen »Lettre sur les aveugles « in der Festung Vincennes inhaftiert wurde. Hierbei kam sicher erschwerend hinzu, dass er schon zwei Jahre vorher vom Pfarrer seiner Gemeinde als gottloser, »sehr gefährlicher Mensch« denunziert worden war. In Zukunft war er deshalb vorsichtiger und ließ vorsichtshalber, um den Fortgang der Encyclopédie nicht zu gefährden, viele andere Schriften unpubliziert.

1750 verfasste er einen in ganz Europa verschickten Prospekt, in dem er Interessenten zur Subskription der Encyclopédie aufrief. 1751 erschienen die beiden ersten Bände der Encyclopédie ou Dictionnaire raisonné des sciences, des arts et des métiers (»Enzyklopädie oder (alphabetisch) geordnetes Lexikon der Wissenschaften, Künste und Gewerbe, von einer Autorengemeinschaft «). Der buchhändlerische Erfolg des Werkes war enorm, doch die Jesuiten und die Sorbonne diagnostizierten eine unchristliche Tendenz und erwirkten beim königlichen Kronrat ein Verbot. Da aber Madame de Pompadour (die Mätresse Ludwigs $X V$.), einige Minister, viele einflussreiche Freimaurer und der oberste Zensor Malesherbes auf der Seite der Encyclopédisten standen, konnten 1753-1756 trotz des Verbots vier weitere Bände erscheinen.

Danach jedoch wuchs der Druck der Gegner. 1758 wurde das Verbot erneuert; 1759 setzte Papst Clemens XIII. das Werk auf den Index. Inzwischen hatte aber die Regierung die Deviseneinnahmen schätzen gelernt, die trotz des Siebenjährigen Krieges (1756-1763) durch den Verkauf der Encyclopédie aus ganz Europa hereinkamen, und man ermutigte Diderot unter der Hand zum Weitermachen. Er brachte die letzten zehn Bände samt fünf Bänden Abbildungen heraus (1765), zog sich dann aber - nach 20 Jahren Arbeit - zurück und überließ seinen Nachfolgern die Herausgabe der letzten Abbildungsbände, die, wie schon die ersten, viel zum Ruhm des Unternehmens beitrugen.

Der große Erfolg der »Encyclopédie ou Dictionnaire raisonné des sciences, des arts et des métiers « - führte dazu, dass mit dem Begriff Enzyklopädie vor allem tiefgehende und damit umfangreiche alphabetische Nachschlagewerke und systematische Darstellung der Gesamtheit des Wissens bezeichnet werden.

Unterstellt wird bei dem Vorhaben einer Enzyklopädie, dass Unübersicht- 
lichkeit, Vielfalt und Wachstum menschlicher Kenntnisse in systematisches Wissen geordnet werden könne. Diderot versteht darunter ein als System gedachtes und den Einzelwissenschaften vor geordnetes Denkgebäude, dem eine Fülle des empirischen Wissens noch nachzufolgen hat. So wird der Anspruch formulierte, die Enzyklopädie müsse alle Wissensbereiche, d.h. die Gesamtheit des Wissens umfassen und darstellen.

Die Gesamtheit des Wissens wird eingeteilt in »Memoire, Raison und Imagination«. Dem entsprechen die Wissenschaftsbereiche Historie, Philosophie und Poesie. Die Darstellung in der Enzyklopädie ist aber strikt alphabetisch von A bis Zzuéné in 60.000 Artikeln.

"Bei der lexikalischen Zusammenfassung alles dessen, was in die Bereiche der Wissenschaften, der Kunst und des Handwerks gehört, muss es darum gehen, deren gegenseitige Verflechtungen sichtbar zu machen und mithilfe dieser Querverbindungen die innen zugrunde liegenden Prinzipien genauer zu erfassen [...] es geht darum, [...] ein allgemeines Bild der Anstrengungen des menschlichen Geistes auf allen Gebieten und in allen Jahrhunderten zu entwerfen." (D'Alembert in der Vorrede)

Abbildung 23: Enzyklopädie

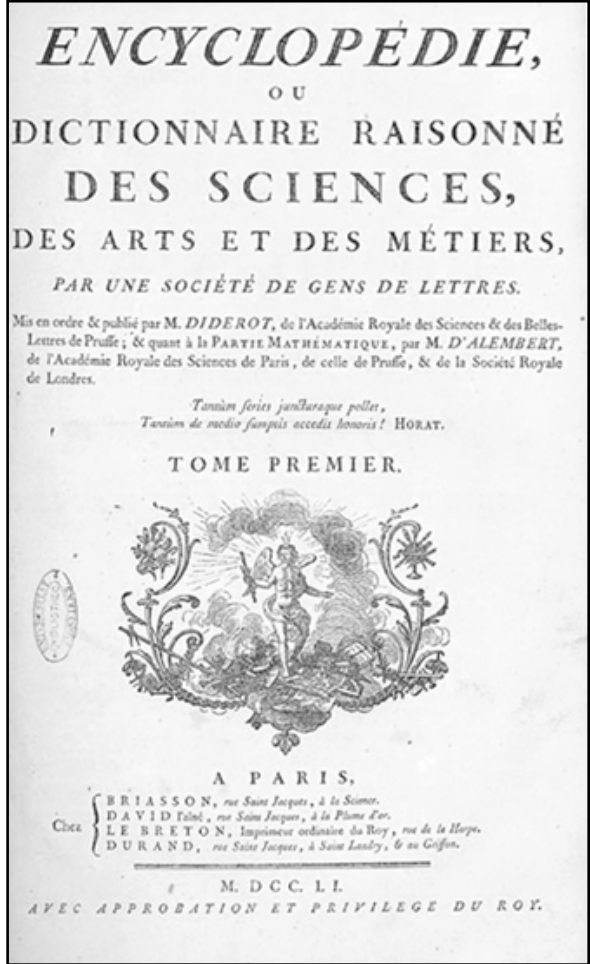


Die im 18. Jahrhundert außerdem erscheinenden Enzyklopädien und ihre Nachfolger erreichen bei weitem nicht die wissenschaftliche und literarische Brillanz Diderots und seiner Mitarbeiter. Sie sind eher Wörterbücher, manchmal auf fragwürdigem Niveau veranlasst durch die Profitstrategien der Verleger.

Auch das von dem Buchhändler und Verleger Johann Heinrich Zedler (17061751) herausgegebene und in den Jahren 1732 bis 1754 erschienene »Grosse vollständige Universal-Lexicon Aller Wissenschafften und Künste« erhebt einen Vollständigkeitsanspruch. Es umfasst rund 68.000 Seiten mit 288.000 Einträgen und ist damit das umfangreichste enzyklopädische Projekt des 18. Jahrhunderts. In 64 Bänden und weiteren vier Supplementbänden sind rund 288.000 alphabetisch geordnete Einträge verzeichnet. Das Lexikon soll alles bekannte Wissen aus sämtlichen Fachgebieten verzeichnen. Der Ausdruck »universal« bezeichnet diesen Anspruch auf inhaltliche Vollständigkeit. Dabei listet der Titel 33 Wissensbereiche auf, die drei etwa gleich große Klassen bilden: Biographie, Geographie und Fachwissen. Heute ist bekannt, dass der überwiegende Teil der Artikel plagiiert wurde und dabei viele Verweise ins Leere führen.

Das in Deutschland bekannteste Lexikon ist der »Große Brockhaus«. In der Vorrede der Redaktion und Verlagshandlung zum 15. Band der 11. Auflage des Brockhaus von 1868 wird die Zielsetzung benannt:

"Das Conversations-Lexikon [hat] die Flüssigmachung und Popularisierung der wissenschaftlichen, künstlerischen und technischen Ergebnisse, nicht für die geschäftliche Praxis, sondern für die Befriedigung und Förderung der allgemeinen Bildung zur Aufgabe. [...] Denn jene allgemeine Bildung ist nichts Geringeres als die humane Bildung, welche das Individuum innerhalb des Culturlebens seiner Zeit erlangt, die für ihren Ausgangspunkt die Berufsbildung voraussetzt und, wie den intellectuellen so den moralischen Menschen umfassend, als der Quellpunkt socialer und nationaler Kraft und Entwicklung betrachtet werden muß. [...] Den Kreis der Ideen und Thatsachen, wie er sich für den einzelnen unabsehbar in Geist, Geschichte und Natur auseinanderlegt, in begrenztem Rahmen, gleichsam als Mikrokosmos, zur Anschauung zu bringen, nicht zur Lösung eines wissenschaftlichen Problems oder zur Uebung einer Kunstfertigkeit, sondern um den Menschen als solchen mit der Welt, die über seinen alläglichen Horizont hinausliegt, bekannt zu machen, indem inm die Einsicht in den Begriff und den organischen Zusammenhang der Dinge, sowie die Uebersicht über das Ganze, wenn nicht erschlossen, so doch erleichtert wird.“

Der Brockhaus war als Universalenzyklopädie Vorbild für andere Länder, z.B. Niederlande, Russland, Schweden und die 13-bändige amerikanische Encyclopaedia Americana.

Die bereits ab 1768 von Adam und Charles Black in Edinburgh, Schottland, verlegte Encyclopadia Britannica war dagegen ein Produkt der schottischen Aufklärung. Die Artikel sind geschrieben für »educated adults«, von etwa 100 Vollzeitredakteuren und mehr als 4.000 Experten. 
Die Britannica erhält ihre Reputation als Summe des Wissens. Selbstverständlich muss aber eine editorische Selektion erfolgen. Angesichts beschränkten Umfangs von immerhin 32 Bänden und begrenzter Seitenzahlen in der Druckfassung ist es notwendig, Stichwörter zu kürzen oder auszusondern und anzupassen. Daraus resultieren kontroverse Auswahlentscheidungen.

Sie markieren auch die Grenzen der Systematik. Spätestens wuchernde Information, explodierende Veröffentlichungszahlen und ungeordnete, kontroverse Interpretationen zwingen Vollständigkeitsansprüche der Wissensordnung aufzugeben. Postmodernes Wissen stellt daher darauf ab, dass alle Einteilungsvorschläge offen, historisch, polyzentrisch angelegt sein müssen (Foucault 1971). Die reflexive Moderne hat die Vorstellungen geschlossener und endgültiger Definitionen und Klassifikationen mit Spott und Hohn belegt. Die Beantwortung aller Fragen wäre auch das Ende jeden Erfahrungsbezugs in der Wissenschaft. Begriffsklärungen sind umstritten, ungesichert und niemals endgültig. Wissensnetze sind flexibel und fragil.

Michel Foucault ironisiert die Totalität jeder Systematik, indem er ein Zitat von Jorge Luis Borges zitiert:

"Dieser Text zitiert reine gewisse chinesische Enzyklopädie، in der es heißt, daß , die Tiere sich wie folgt gruppieren: a) Tiere, die dem Kaiser gehören, b) einbalsamierte Tiere, c) gezähmte, d) Milchschweine, e) Sirenen, f) Fabeltiere, g) herrenlose Hunde; h) in diese Gruppierung gehörige, i) die sich wie Tolle gebärden, k) die mit einem ganz feinen Pinsel aus Kamelhaar gezeichnet sind, I) und so weiter, $m$ ) die einen Wasserkrug zerbrochen haben, n) die von weitem wie Fliegen aussehen ‘." (Foucault 1971, 17)

Ergebnis ist ein Lachen, das

"alle Vertrautheiten unseres Denkens aufrüttelt, des Denkens unserer Zeit und unseres Raumes, das alle geordneten Oberflächen und alle Pläne erschüttert, die für uns die zahlenmäßige Zunahme der Lebewesen klug erscheinen lassen und unsere tausendjährige Handhabung des Gleichen und des Anderen (du Meme et de l'Autre) schwanken lässt und in Unruhe versetzt“ (ebd.).

Foucault hat die systematischen Begriffsverhältnisse durchbrochen, durch diskursive Denkweise ersetzt und in der »Archäologie des Wissens« vorgeschlagen, die Begriffe Dezentralität und Diskontinuität, Ausschnitt und Grenze, Schwelle und Bruch, Transformation und Serie zu nutzen (Foucault 1981, 33). Er greift dann eine für die Wissensordnungen zentrale Frage - die nach den Disziplinen und ihrem Verhältnis untereinander - auf. Dieses Problem entsteht überhaupt erst:

"wenn man als 'Disziplinen، Gesamtheiten von Aussagen bezeichnet, die ihre Organisation wissenschaftlichen Modellen entleihen, zur Konkurrenz und zur Beweisfähigkeit 
neigen, [...] angenommen, institutionalisiert, übermittelt und manchmal gelehrt werden « (ebd. 254).

Foucault bezweifelt die Tragfähigkeit dieses Konzepts und er führt als Konstituens von Wissenschaft den Begriff der »diskursiven Formationen« ein (ebd.). Pierre Bourdieu hat eine in diesem Punkt nahe Vorstellung in der Diskussion des »wissenschaftlichen Feldes« verankert.

$\mathrm{Zu}$ Ende gebracht erscheint die Vorstellung der Wucherungen, Umlenkungen und Verflechtungen von Wissenschaft bei Giles Deleuze und Felix Guattari (1977) mit der Metapher des Rhizoms. Sie repräsentiert einen Gegenentwurf zum klassischen Baum des Wissens als traditionellem Organisationsmodell, das die Hierarchie des Wissens und der Wissenschaften beschreiben soll. Entsprechend sind beispielsweise Taxonomien, Klassifikationen, Enzyklopädien und Bibliotheken strukturiert. Baum-Modelle sind hierarchisch und dichotomisch angelegt: Jedes Element befindet sich auf einer (und nur einer) Ordnungsebene, ist einer höheren Ebene untergeordnet und kann einem oder mehreren Elementen übergeordnet sein. Es gibt keine Querverbindungen, die Hierarchieebenen überspringen oder Elemente verbinden.

Deleuze und Guattari halten das dichotomische Baummodell für epistemologisch unangemessen, weil es nicht offen ist für mögliche Veränderungen der Sichtweise wie etwa Verschiebungen und Verknüpfungen der Forschungsperspektiven. Sie finden das Gegenbild in der Vorstellung des Rhizoms als ein meist unterirdisch oder dicht über dem Boden wachsendes Sprossachsensystem. In einem rhizomatischen Modell kann ein Element mehreren Ordnungsebenen (Plateaus) angehören; es sind Querverbindungen erlaubt (Konnektivität) und unterschiedliche Elemente können miteinander in Verbindung treten (Heterogenität). Genau dies erscheint für ein angemessenes Bild von Wissenschaft unumgänglich. Die Frage bleibt aber trotzdem: »Wie entsteht Ordnung in wissenschaftlichen Rhizomen?«

Ohne einen Grundkonsens über tragfähige Paradigmen, wäre wissenschaftliche Diskussion nicht möglich. Wenn man nicht in postmoderner Beliebigkeit versinken will, ist es also doch wieder nötig, nach Ordnungen zu suchen. Hilfreich kann dafür eine kritisch-pragmatistische Epistemologie sein. Wir kommen, um den Diskurs weitertreiben zu können, nicht aus ohne vorläufig geklärte Begriffe und angemessene Begriffsnetze. Also stellt sich die Urfrage des wissenschaftlichen Pragmatismus »How to make our ideas clear? « (Peirce 1878) Wissenschaftliche Ordnungen sind demgemäß nicht einfach vorgegeben, sondern Erkenntnisinteressen geschuldet, die sich auf Probleme beziehen.

Moderne Wissenswelten nach einem klassischen Baummodell zu ordnen und zu kategorisieren ist jedoch ein unmögliches Unterfangen. Zwar können bestimmte Ordnungsstrukturen geschaffen werden, diese werden jedoch von internen Verknüpfungen und Verbindungslinien wieder untergraben.

Es ist aber nicht der reine Wildwuchs, sondern ist geht um die Ordnung der 
Rhizome durch ihre Angemessenheit im Handeln. Diese wird hergestellt im offenen Diskurs und durch Aushandeln von Interessen, die Problemperspektiven erzeugen. Es geht darum, diskursive Systematiken, die begrenzt und zeitlich beschränkt gelten, auszuhandeln.

Um also nicht in naive Systematik zurückzufallen, muss die Wissensordnung die Anforderungen der Heterogenität, der Konnektivität und des Auf- und Absteigens zwischen den Plateaus einlösen.

Jede Systematik des Wissens ist nur noch als offene Enzyklopädie denkbar. Mit dem Internet sind auch die technischen Voraussetzungen für ein solches Vorhaben entstanden: Die Wikipedia ist eine 2001 gegründete freie Online-Enzyklopädie in zahlreichen Sprachen. Der Name Wikipedia ist ein Kofferwort, das sich zusammensetzt aus »Wiki« (der mit dem hawaiischen Wort für »schnell« bezeichneten Technik zur kollektiven Erstellung von Internetseiten) und »Encyclopedia«.

„Im März 2000 startete der Internet-Unternehmer Jimmy Wales mit dem damaligen Doktoranden der Philosophie Larry Sanger über die Firma Bomis ein erstes Projekt einer englischsprachigen Internet-Enzyklopädie, die Nupedia. Sanger amtierte als Chefredakteur, Autoren mussten sich bewerben und inre Texte anschließend ein langwieriges Peer-Review-Verfahren durchlaufen. Ende 2000/Anfang 2001 wurden Sanger und Wales auf das Wiki-System aufmerksam, mit dessen Hilfe Benutzer einer Website diese nicht nur lesen, sondern auch direkt im Browser verändern können. Am 15. Januar 2001 war das Wiki der Nupedia unter der eigenständigen Adresse wikipedia.com abrufbar, was seither als die Geburtsstunde der Wikipedia gilt." (http://de.wikipedia.org/wiki/Wikipedia Zugriff 21.4.11)

Die Artikel der Online-Enzyklopädie werden von einer weltweiten Autorengemeinschaft kollektiv und unentgeltlich erstellt. Jeder Internetbenutzer kann Wikipedia-Artikel nicht nur lesen, sondern auch bearbeiten, auch formal anonym. In einem offenen, nicht notwendigerweise konfliktfreien Bearbeitungsprozess hat letztlich Bestand, was von der Gemeinschaft der Mitarbeitenden akzeptiert wird. Bisher haben international etwa 1.016.000 angemeldete (Stand: 31. Oktober 2009) und eine unbekannte Zahl nicht angemeldeter Nutzer zur Wikipedia beigetragen. Mehr als 6.700 Autoren (Stand: 31. Oktober 2009) arbeiten regelmäßig bei der deutschsprachigen Ausgabe mit.

Eine eigentliche Redaktion gibt es nicht, das Prinzip basiert vielmehr auf der Annahme, dass sich die Benutzer gegenseitig kontrollieren und korrigieren. Die deutschsprachige Wikipedia hat 2008 das System der Sichtung eingeführt. Dadurch wird allen unangemeldeten Benutzern automatisch die letzte gesichtete Version eines Artikels angezeigt. Neuere ungesichtete Versionen bereits gesichteter Artikel werden nur angemeldeten Benutzern angezeigt.

Vier Grundsätze gelten als unumstößlich und dürfen nach Diskussionen nicht geändert werden: 
1. Wikipedia ist eine Enzyklopädie; sie verfolgt weiterhin den Anspruch, die Summe menschlichen Wissens in möglichst großer Vollständigkeit und Tiefe bereitzustellen.

2. Beiträge sind so zu verfassen, dass sie dem Grundsatz des neutralen Standpunkts entsprechen.

3. Geltendes Recht - insbesondere das Urheberrecht - ist strikt zu beachten.

4. Andere Benutzer sind $\mathrm{zu}$ respektieren und die Wikiquette einzuhalten. (http://de.wikipedia.org/wiki/Wikipedia:Hauptseite 1. September 2010)

Die Grundsätze »Neutraler Standpunkt«, »Nachprüfbarkeit« und »Keine Theoriefindung « legen die inhaltliche Ausrichtung der Artikel fest. In der Wikipedia kooperieren Autoren mit unterschiedlichen politischen, religiösen und weltanschaulichen Hintergründen, als offene Enzyklopädie schließt sie niemanden wegen seiner Anschauungen aus. Um dadurch unweigerlich aufkommende Kämpfe um Artikelinhalte zu verhindern bzw. zu schlichten und um den Lesern zu ermöglichen, sich eine eigene Meinung zu bilden, und ihre intellektuelle Unabhängigkeit zu unterstützen, hat Wikipedia die Richtlinie des neutralen Standpunkts (NPOV, von englisch neutral point of view) aufgestellt. Danach soll ein Artikel so geschrieben sein, dass ihm möglichst viele Autoren zustimmen können. Existieren zu einem Thema verschiedene Ansichten, so soll ein Artikel diese beschreiben, aber nicht selbst Position beziehen. Der neutrale Standpunkt verlangt jedoch nicht, dass alle Ansichten gleichwertig präsentiert werden. Soziale Prozesse sollen gewährleisten, dass er eingehalten wird, was bei kontroversen Themen oft zu Diskussionen führt.

Eine netzwerkanalytische Untersuchung der Wikipedia kann zeigen, dass eine zunehmende Schließung der Gruppe der Administratoren mit Selbstrekrutierung stattfindet. Es ergibt sich ein Selbststeuerungsprozess. Identifiziert werden können acht soziale Rollen: neben den Führungseliten noch Artikelschreiber, Vandalen, Vandalenjäger, Administratoren, Begrüßer, Trolle und Propagandisten (Stegbauer 2009).

Vielen modernen Medientheoretikern scheint die Metapher des Rhizoms, wie sie sich in der Wikipedia umsetzt, daher geeignet, um Strukturen von Hypertexten, sozialen Netzwerken oder Computernetzen wie dem Internet zu beschreiben.

Die Wikipedia ist Ausdruck eines immer noch der Aufklärung verpflichteten Wissensverständnisses. Zwar sind die Vorstellungen einer abschließenden Systematik aufgegeben. Nichtsdestoweniger wird festgehalten an der Idee einer wachsenden Vollständigkeit. Auch achten die Verantwortlichen darauf Unsinn, Werbung und Propaganda aus den Internet-Seiten herauszuhalten. Die Beiträge unterliegen der Kritik, und es wird versucht ein Mindestniveau einzuhalten. So kann man die Wikipedia durchaus in die Tradition der Aufklärung stellen. Sie folgt - bei allen Bedenken und Unvollkommenheiten - deren Prinzip, Wissen zugänglich zu machen und in einen demokratischen Diskurs einzubeziehen. 
Abbildung 24: Vergleich einiger Enzyklopädien und Lexika

\begin{tabular}{|c|c|c|c|c|}
\hline Titel & Untertitel & Medium & Artikel & Bilder \\
\hline $\begin{array}{l}\text { Encyclo- } \\
\text { pédie }\end{array}$ & $\begin{array}{l}\text { Encyclopédie ou Dictionnaire } \\
\text { raisonné des sciences, } \\
\text { des arts et des métiers } \\
1751 \text { bis } 1772\end{array}$ & $\begin{array}{c}28 \text { Bände } \\
\text { (17 Text- und } \\
11 \text { Tafelbände) } \\
4 \text { Erg.- } 2 \text { Regis- } \\
\text { terb. }\end{array}$ & 71.818 & 2.885 \\
\hline Britannica & Encyclopædia Britannica & 32 Bände & $>65.000$ & $>24.000$ \\
\hline $\begin{array}{l}\text { Brock- } \\
\text { haus }\end{array}$ & $\begin{array}{l}\text { Die Enzyklopädie 21., neu } \\
\text { bearbeitete Auflage 2005 bis } 2006\end{array}$ & 30 Bände & $>300.000$ & $>40.000$ \\
\hline Meyers & $\begin{array}{c}\text { Meyers Enzyklopädisches } \\
\text { Lexikon in } 25 \text { Bänden 9. Auflage } \\
1971 \text { bis } 1979 \\
\end{array}$ & 25 Bände & $>250.000$ & \\
\hline Meyers & $\begin{array}{c}\text { Meyers Großes Taschenlexikon } \\
\text { in } 26 \text { Bänden } \\
\end{array}$ & 26 Bände $+C D$ & $>150.000$ & $>5.000$ \\
\hline Wikipedia & $\begin{array}{l}\text { Die freie Enzyklopädie } \\
\text { (deutsch) }\end{array}$ & online & $\begin{array}{l}1.184 .247 \\
\text { (Dez. } \\
2010) \\
\end{array}$ & $>500.000$ \\
\hline Zedler & & 64 Bände + 4 Supp. & 288.000 & \\
\hline
\end{tabular}

\subsection{Wissen und Glauben}

Zentrale Figur der deutschen Aufklärung war Gotthold Ephraim Lessing (17291781) - als Literat, Intendant und Kritiker, als Wissenschaftler und Schriftsteller. Er hat sich immer wieder mit den Fragen nach dem Wissen, dessen Verhältnis zum Glauben und seiner Wirksamkeit im Handeln auseinandergesetzt. Zum Exponenten der Aufklärung wurde er vor allem durch seine rückhaltlose Kritik. Sie verhindert bis heute, dass er von bestehenden Machtverhältnissen vereinnahmt werden kann, wie es schon Preußen versuchte. Die im 19. Jahrhundert aufgebaute »Lessing-Legende« bemühte sich ihn in die Lobhudelei für die Hohenzollern zu integrieren. Franz Mehring hat nachgewiesen, dass das an dem großen Kritiker abprallt. Lessings Schriften entziehen sich der Indienstnahme.

Thomas Mann schrieb »Zu Lessings Gedächtnis« anlässlich der Feiern zum 2oojährigen Geburtstag:

"Er hat das Licht gelebt - darum nannte man inn mit Recht einen Aufklärer. Er hat die Dummheit gestachelt, die Lüge verfolgt, Knechtsinn und Geistesfaulheit gegeißelt und die Freiheit des Geistes mit ernstester Ehrfurcht geschützt." (Mann 1929)

Dies folgte dem Antrieb der bürgerlichen Aufklärung: gegen Aberglauben, Pfaffentum und Adelshochmut das Licht der Vernunft zu setzen. Mit seinen Impulsen war Lessing zentrale und repräsentative Figur der deutschen Aufklärung - zentral, weil sein Leben, das nur 52 Jahre dauerte, beide Hälften des 18. Jahr- 
hunderts umspannt, repräsentativ aufgrund der Breite und dem Wirken seines Werkes (Nisbet 2008, 13): Sein Leben lang misstraute er jeder Autorität.

Lessing war zweifellos ein »tüchtiger Gelehrter«, ein hervorragender Theologe, ein scharfsinniger Theaterwissenschaftler, ein feinfühliger Kunsttheoretiker und ein breit gebildeter Philologe, besonders jedoch ein geschliffener Polemiker. Gelehrt im Sinne traditionellen Abhaltens von Vorlesungen hat er nie: Aber er war ein vielfältiger Wissenschaftler, der mit seiner Kritik in seinen Theaterstücken, Streitschriften und Fabeln ein breites Publikum erreichte.

Geboren wurde Gotthold Ephraim Lessing am 22. Januar 1729 in Kamenz, Sachsen, als drittes Kind und zweitältester Sohn des Kamenzer Archidiakons Johann Gottfried Lessing und seiner Frau Justina Salome (geb. Feller); am 24. Januar 1729 wurde er dort in der St. Marienkirche von seinem Großvater Gottfried Feller getauft. Ab 1741 besuchte er als »Alumnus mit einer freyen Kost-Stelle« die Fürstenschule St. Afra in Meißen. Erste literarische Versuche reichen in diese Zeit zurück. 1746 wurde er wegen ausgezeichneter Leistungen vorzeitig entlassen.

Er begann ein Studium an der Universität Leipzig, wo er sich am 20. September auf Wunsch seines Vaters zunächst für Theologie immatrikulierte. 1748 wechselte er zum Medizinstudium und am 20. August an die Universität Wittenberg. Im November 1748 ging er jedoch zunächst in die brandenburgische Residenzstadt Berlin. Dort rezensierte er die »Berlinerische Privilegierte Zeitung « (die spätere »Vossische Zeitung«), wurde 1750 Mitarbeiter der »Critischen Nachrichten aus dem Reiche der Gelehrsamkeit«. In Berlin begegnete er 1750 Voltaire.

$\mathrm{Ab} 1751$ konzentrierte sich Lessing wieder auf sein Studium in Wittenberg und setzte sein Studium der Medizin an der philosophischen Fakultät fort. Dort gab es Vorlesungen in Poetik, Ethik, Geschichte, in griechischer Sprache und Literatur, in Philosophie, über Mathematik und Physik sowie in Rhetorik. Im Medizinstudium gab es ein breites Lehrangebot. So gebildet absolvierte Lessing am 29. April 1752 die Promotion zum Magister der Sieben Freien Künste. Die Vielfalt seiner Studienthemen spiegelt sowohl Breite als auch Unstetigkeit.

Im November 1752 schon kehrte Lessing nach Berlin zurück. Dort machte er Bekanntschaft mit Nicolai, Ewald, Forster und Sulzer und schloss Freundschaft mit Moses Mendelssohn. Im Oktober 1755 zog er weiter nach Leipzig. 1756 brach er als Begleiter mit Johann Gottfried Winkler zu einer auf mehrere Jahre angelegten Bildungsreise durch die Niederlande, England und Frankreich auf. Dieses Vorhaben musste er aber wegen des beginnenden Siebenjährigen Krieges bereits in Amsterdam abbrechen. Im selben Jahr begegnete er Johann Wilhelm Gleim, Friedrich Gottlieb Klopstock und Conrad Ekhof.

1758 zog Lessing erneut nach Berlin, wo er mit Friedrich Nicolai und Moses Mendelssohn zusammen die »Briefe, die neuste Literatur betreffend « veröffentlichte. Von 1760 bis 1765 war er - immer in Geldnot - in Breslau als Sekretär beim General Tauentzien beschäftigt. 1765 kehrte er zurück nach Berlin und ging dann 1767 für drei Jahre als Dramaturg und Berater an das Hamburger National- 
theater, welches aber bereits 1769 wegen finanzieller Engpässe wieder geschlossen wurde. Am 30. September 1767 war dort sein Stück »Minna von Barnhelm« uraufgeführt worden. Während seiner Tätigkeit in Hamburg machte er unter anderem Bekanntschaft mit Philipp Emanuel Bach, Johann Melchior Goeze, Johann Friedrich Löwen und den Familien Reimarus und König. Im selben Jahr wurde er zum auswärtigen Mitglied der Berliner Akademie der Wissenschaften gewählt.

$\mathrm{Ab}$ 7. Mai 1770 war Lessing Bibliothekar in der Herzog August Bibliothek in Wolfenbüttel. Am 14. Oktober 1771 wurde Lessing in die Freimaurerloge »Zu den drei Rosen « in Hamburg aufgenommen. Er schätzte die Freimaurerei, wie sein 1778 und 1780 erschienenes Werk »Ernst und Falk« belegt, nicht aber deren zeremonielle Skurrilitäten. In den fünf »Gesprächen für Freymäurer« lieferte er ein Plädoyer für aufrechten Bürgergang wider Standesdünkel und nationale und religiöse Vorurteile.

1771 verlobte er sich mit der seit 1769 verwitweten Eva König. 1775 wurde seine Arbeit in der Bibliothek unterbrochen durch mehrere Reisen zu dem jeweiligen Aufenthaltsort der Geschäftsfrau Wwe. König, nach Wien über Leipzig, Berlin, Dresden und Prag. Als Begleiter des Braunschweiger Prinzen Leopold reiste er nach Italien über Mailand, Venedig, Florenz, Genua, Turin, Rom, Neapel und Korsika.

Am 8. Oktober 1776 heirateten er und Eva König in Jork bei Hamburg. Am Weihnachtsabend 1777 gebar sie einen Sohn (Traugott), der aber am folgenden Tag starb. Am 10. Januar 1778 starb auch Eva Lessing an Kindbettfieber. 1779 verschlechterte sich Lessings Gesundheit. Am 15. Februar 1781 starb er an »Brustwassersucht« bei einem Besuch in Braunschweig nach vierzehntägiger Krankheit. Sein 1779 fertig gestelltes und bekanntestes Stück »Nathan der Weise« wurde erst am 14. April 1783 in Berlin uraufgeführt.

Bescheiden schreibt er über sich selbst: »Ich bin weder Schauspieler noch Dichter«. Er verstand sich als Kritiker, einer der aus seiner Belesenheit Funken schlagen konnte. Im »Laokoon oder Über die Grenzen der Malerei und Poesie« (1766) hat er sich mit der Antikenrezeption des Altertumswissenschaftlers Winkelmann auseinandergesetzt, diese aber gleichzeitig weitergeführt. Lessing hebt hervor, wie der Künstler den »fruchtbaren Augenblick « gefunden hat, in dem die Geschichte des Priesters Laokoon und seiner Söhne, in einem einzigen Augenblick nebeneinander zusammengefasst ist. Die Poesie dagegen ordne die Wörter nacheinander.

Lessings Methode ist eine der produktiven Kritik. Er formuliert seine rücksichtslosen und furchtlosen Streitschriften gegen Dogmatiker, Obskuranten, Schmeichler und ihre Herren.

Lessing geriet so zwangsläufig auch in die Religionskonflikte der Zeit. In Hamburg hatte er sich mit Hermann Samuel Reimarus (1694-1768), Professor für Hebräisch und orientalische Sprachen am »Akademischen Gymnasium«, angefreundet. Reimarus starb noch während Lessings Hamburger Zeit und die Witwe übergab ihm eine unvollendete Schrift, aus der er Anfang 1774 ein erstes »Fragment« und 1777 fünf weitere Auszüge unter der Schutzbehauptung, er habe sie in der Bibliothek in Wolfenbüttel gefunden unter dem Titel »Aus 
den Papieren eines Ungenannten« veröffentlichte. Diese brisanten Texte enthielten eine konsequente Theologie- und Bibelkritik, indem sie die »Heilige Schrift« als historische Quelle in Frage stellten. Sie vertraten Grundgedanken des »Deismus« mit der Annahme, dass eine »natürliche Religion« die zentralen Glaubensartikel - Dasein eines weisen und wohlwollenden Gottes; Freiheit des Menschen, zwischen gut und böse zu entscheiden; Unsterblichkeit der Seele - durch die Vernunft als Naturwahrheiten zu beweisen seien. Ein ohnehin nicht beweisbarer Offenbarungsglaube dagegen sei überflüssig und schädlich. Gleichzeitig wurde die Bibel als Schriftzeugnis immer strenger der Textkritik und philologischer und historischer Untersuchung unterworfen. Besonders provozierend war die Befragung der Berichte über die Auferstehung Jesu mit dem Ergebnis, diese seien widersprüchlich und unglaubwürdig. Diese Darstellung hätte Reimarus, wenn er als Autor zu fassen gewesen wäre, sicher seine Stelle als Gymnasialprofessor gekostet und ihn ins Gefängnis gebracht.

Als Kontrahent Lessings trat vor allem der Hamburger Hauptpastor Johann Melchior Götze mit seiner Schrift »Etwas Vorläufiges gegen des Herrn Hofrats Lessing mittelbare und unmittelbare feindselige Angriffe auf unsere allerheiligste Religion und auf den einigen Lehrgrund derselben, die heilige Schrift« 1778 als Vertreter der lutherischen Dogmatik auf: Lessing, den er für den Verfasser der Fragmente hielt, greife die Religion frontal an und er habe die Apostel als die ärgsten Lügner und Betrüger hingestellt, als Bösewichter und Leichenräuber bezeichnet. Gegen die Tendenz, die »Heilige Schrift« nicht mehr wörtlich zu nehmen und ihre Bilder im übertragenen Sinn als Metaphern zu verstehen, wurde eine verbindliche Auslegung der »Schrift« mit fundamentalistischer Autorität versehen.

Demgegenüber war die Veröffentlichung der Schriften des Reimarus ein wichtiger Schritt zur Emanzipation der Vernunft von der Bevormundung durch die Theologie. Lessing schrieb elf Schriften »Anti-Götze«. Götze forderte schließlich ein Publikationsverbot. Damit verschob sich die Front auf Grundsatzfragen der Aufklärung: Ungehinderten Gebrauch der Vernunft, Öffentlichkeit der Meinungsbildung und Unabhängigkeit der Wissenschaft von der Kirche. Der »Fragmentenstreit« wurde zu einer Schlüsseldebatte der deutschen Aufklärung. Bemerkenswert ist das Resultat: Anfang Juli 1778 erschien die letzte »Anti-Götze« -Schrift; am 6. Juli entzog der Herzog von Braunschweig als Dienstherr Lessing die Befreiung von der Zensur. Dies zeigt auch den Zustand der Aufklärung in Deutschland unter dem Despotismus der Duodezfürsten in ihren Zwergstaaten.

Lessing war »Intellektueller « bevor es den Begriff gab: jemand der zu reden und zu schreiben versteht und durch Kritik öffentlich ausgegrenzte Probleme zur Sprache bringt. Die Erfolgschance der Intellektuellen, ihre Einflussstrategie beruht auf ihrer Legitimationsfähigkeit durch Rückbezug auf als verbindlich unterstellte Werteakzeptanz und gleichzeitigem Störpotenzial. Der Intellektuelle hinterfragt, interveniert und kritisiert in öffentlichen Auseinandersetzungen, Streitfragen und Diskursen, um deren Entwicklung zu beeinflussen. 
Gegen Fundamentalismus stellt er Toleranz. Eine Offenbarung als »Wort Gottes«, das nur an auserwählte Gläubige gerichtet ist, erscheint Lessing unglaubwürdig und menschenverachtend. Religionsschöpfer und ihre irdischen Repräsentanten sind prinzipiell intolerant. Die Rivalität zwischen den Religionen erzeugt fundamentalistische Fanatiker. Konkurrierende Glaubensbekenntnisse müssen sich rigoros bekämpfen, weil sie nicht irren dürfen.

Konsequent werden für Lessing die Exegesen der Bibel, egal welcher Herkunft - ob aus der lutheranischen Orthodoxie oder aus dem Deismus - zunehmend unwichtiger. Er unterscheidet zwischen Geist und Buchstabe der Schrift.

In seiner 1776 verfassten Arbeit »Die Erziehung des Menschgeschlechts « verglich er die Bibel mit einem Schulbuch, dessen älteste Teile voller Märchen und Fabeln für Kinder geschrieben sind, dessen neuere Teile für Heranwachsende Beispiele guter Taten geben und das von Erwachsenen aus der Hand gelegt werden kann. Die Offenbarung ist als Ganze eine Metapher für die Wahrheit, die die Vernunft im Verlauf der Gattungsgeschichte aufdeckt. In 100 Paragraphen legt Lessing die Menschheitsgeschichte als Entwicklung dar.

"§ 1 Was die Erziehung dem einzelnen Menschen ist, ist die Offenbarung bei dem ganzen Menschengeschlechte." (Lessing Werke 6, 340)

Das Alte Testament gleicht einem Elementarbuch.

"§51 Aber jedes Elementarbuch ist nur für ein gewisses Alter."

"§ 53 Ein besserer Pädagoge muß kommen, und dem Kinde das erschöpfte Elementarbuch aus den Händen reißen. - Christus kam." (Ebd. 348)

Die dritte Stufe der Entwicklung steht noch aus.

"§ 81 Oder soll das menschliche Geschlecht auf diese höchste Stufen der Aufklärung und Reinigkeit nie kommen? Nie?"

"§ 85 Nein, sie wird kommen, sie wird gewiß kommen, die Zeit der Vollendung, da der Mensch, je überzeugter sein Verstand einer immer besseren Zukunft sich fühlet, von dieser Zukunft gleichwohl Bewegungsgründe zu seinen Handlungen zu erborgen, nicht nötig haben wird; da er das Gute thun wird, weil es das Gute ist, nicht weil willkürliche Belohnungen darauf gesetzt sind, die seien flatterhaften Blick ehedem bloß heften und stärken sollten, die inneren besseren Belohnungen zu erkennen.“ (Ebd. 352-353)

Im Sinne der Aufklärung moralisch Erzogene brauchen keinen Offenbarungsglauben mehr. Allerdings schließt Lessing mit der nur ironisch zu verstehenden Bemerkung: 
Lessings bekanntester Text ist zweifellos die Ring-Fabel in »Nathan der Weise«, auf die hinzuweisen in keiner wohlmeinenden Sonntagsrede über Toleranz fehlen darf:

Vor grauen Jahren lebt' ein Mann im Osten, Der einen Ring von unschätzbarem Wert Aus lieber Hand besaß. Der Stein war ein Opal, der hundert schöne Farben spielte, Und hatte die geheime Kraft, vor Gott Und Menschen angenehm zu machen, wer In dieser Zuversicht inn trug. Was Wunder, Daß inn der Mann in Osten darum nie Vom Finger ließ; und die Verfügung traf, Auf ewig inn bei seinem Hause zu Erhalten? Nämlich so. Er ließ den Ring Von seinen Söhnen dem geliebtesten; Und setzte fest, daß dieser wiederum Den Ring von seinen Söhnen dem vermache, Der inm der liebste sei; und stets der liebste, Ohn' Ansehn der Geburt, in Kraft allein Des Rings, das Haupt, der Fürst des Hauses werde. -

Versteh mich, Sultan.

Saladin. Ich versteh dich. Weiter!

Nathan.

So kam nun dieser Ring, von Sohn zu Sohn, Auf einen Vater endlich von drei Söhnen; Die alle drei inm gleich gehorsam waren, Die alle drei er folglich gleich zu lieben Sich nicht entbrechen konnte. Nur von Zeit

Zu Zeit schien inm bald der, bald dieser, bald

Der dritte, - sowie jeder sich mit inm Allein befand, und sein ergießend Herz Die andern zwei nicht teilten, - würdiger Des Ringes; den er denn auch einem jeden Die fromme Schwachheit hatte, zu versprechen.

Das ging nun so, solang es ging. - Allein Es kam zum Sterben, und der gute Vater Kömmt in Verlegenheit. Es schmerzt inn, zwei

Von seinen Söhnen, die sich auf sein Wort Verlassen, so zu kränken. - Was zu tun? Er sendet in geheim zu einem Künstler, Bei dem er, nach dem Muster seines Ringes,

Zwei andere bestellt, und weder Kosten Noch Mühe sparen heißt, sie jenem gleich, Vollkommen gleich zu machen. Das gelingt Dem Künstler. Da er inm die Ringe bringt, Kann selbst der Vater seinen Musterring Nicht unterscheiden. Froh und freudig ruft Er seine Söhne, jeden insbesondre; Gibt jedem insbesondre seinen Segen, Und seinen Ring, - und stirbt. -

Du hörst doch, Sultan?

Saladin (der sich betroffen von inm gewandt).

Ich hör, ich höre! - Komm mit deinem Märchen

Nur bald zu Ende. - Wird's?

Nathan. Ich bin zu Ende.

Denn was noch folgt, versteht sich ja von selbst. -

Kaum war der Vater tot, so kömmt ein jeder

Mit seinem Ring, und jeder will der Fürst Des Hauses sein. Man untersucht, man zankt,

Man klagt. Umsonst; der rechte Ring war nicht

Erweislich; (nach einer Pause, in welcher er des

Sultans Antwort erwartet)

Fast so unerweislich, als

Uns itzt - der rechte Glaube. 
Abbildung 25: Aufführung des »Nathan«

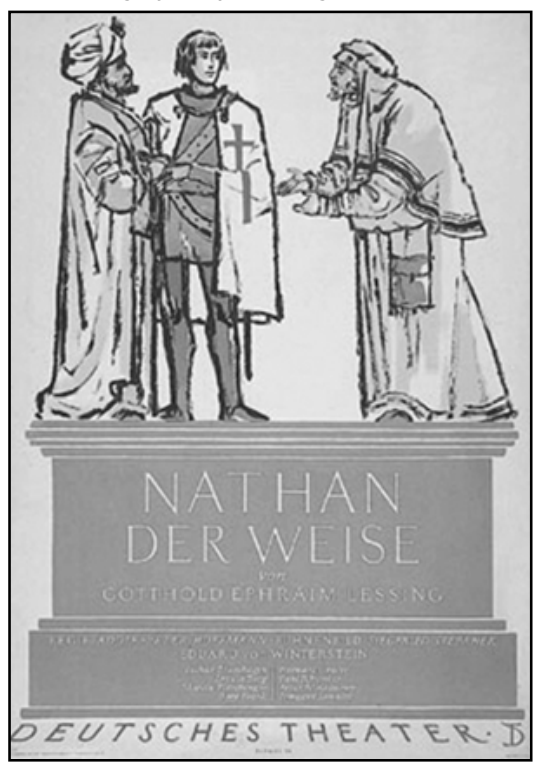

Diese zum oft wiedergekauten Schulstoff herabgesunkene Fabel zeigt einerseits die Abneigung Lessings gegen jeden offenbarten Glauben, anderseits die Schwierigkeit, Ideen schriftstellerisch umzusetzen. Die literarische Verkörperung moralischer Anschauungen im »Lehrstück« und »Ideendrama « steht in Gefahr blutleer und hohl zu klingen. Lessing hat das selbst gemerkt und ironische, sogar groteske Passagen eingestreut. Nicht anders sind die öfters wiederholten Ausrufe des bösartigen christlichen Patriarchen zu hören: »Der Jude wird verbrannt«. Trotzdem bleibt die penetrante Gutartigkeit der Figuren Lessings literarisch problematisch. Die Akteure können immer wieder bei einer Wohltat ertappt werden.

Die Geschichte der drei Ringe ist alt; sie endet meist, indem die Frage nach der Wahrheit der Religionen unbeantwortet bleibt. Lessing dagegen verharrt nicht im Agnostizismus, sondern die Söhne suchen einen Richter auf, der einen Ausweg weist: Jeder soll so handeln, als ob sein Ring der echte wäre. Anstrengung und Leistung ersetzen also den magischen Effekt des Ringes. Diese Tugenden überführen ein gnoseologisches Problem in ein moralisches. Erkenntnis wird an Ethik gebunden (Pütz 1991, 9).

Nun machten allerdings schon die frühen Vertreter der Aufklärung kein Hehl aus ihrem Wunschdenken. Aufklärung galt als ein Prozess hin zu Wünschbarem und Möglichem, das sich in Wirklichkeit umsetzt. Entsprechende Vorsicht war geboten. Lessing schrieb den »Nathan« nach dem Entzug der Zensurfreiheit. Die Uraufführung 1783 erlebte er nicht mehr.

Wahrheit ist nach der Ring-Fabel eine Frage des Suchens, nicht des Besitzes. 
Damit wendet sich Lessing gegen jeden Dogmatismus, sei er religiös oder szientifisch. Die »Tyrannei des einen Rings« wird gebrochen durch einen Relativismus der Wahrheitssuche. Lessing entschärft den Kampf der Religionen, indem er ihren transzendenten Kern durch eine irdische allgemein menschliche Moral ersetzt. Moral braucht keine Religion. Über die Wahrheit schreibt er, dass nicht die Wahrheit, in deren Besitz irgendein Mensch ist oder zu sein meint, sondern die Mühe, die er angewandt hat, hinter die Wahrheit zu kommen, den Wert des Menschen ausmache. Denn nicht durch den Besitz, sondern durch die Nachforschung der Wahrheit erweitern sich seine Kräfte, worin seine immer wachsende Vollkommenheit bestehe. Der Besitz mache ruhig, träge, stolz.

»Nathan der Weise« ist der Versuch, die Einheit des Menschengeschlechts aufzuweisen. Die allegorische Handlung geht um die Aufdeckung der Blutsverwandtschaft aller Menschen in einer Familie, die eine verschlungene Einheit von Christen, Moslems und Juden zustande gebracht hat. Die berechtigte literarische Kritik an der Konstruiertheit der Konstruktion und der Personen nimmt Lessings Witz, seinen treffenden Sprüchen und den anregenden Wechselreden der Figuren nichts von ihrem Charme. Fast schon überschwänglich klingt die Laudatio in Franz Mehrings »Lessing-Legende«:

"Ehrlichkeit und Mannhaftigkeit, eine unersättliche Begierde des Wissens, die Lust mehr noch am Trachten nach der Wahrheit als an der Wahrheit selbst, die unermüdliche Dialektik, die jede Frage kehrte und wandte, bis ihre geheimsten Falten offen lagen, die Gleichgültigkeit gegen die eigene Leistung, sobald sie einmal vollbracht war, die großartige Verachtung aller weltlichen Güter, der Haß gegen alle Unterdrücker und die Liebe zu den Unterdrückten, die unüberwindliche Abneigung gegen die Großen der Welt, die stete Kampfbereitschaft gegen das Unrecht, die immer bescheidene und immer stolze Haltung in dem verzehrenden Kampfe mit dem Elend der politischen und sozialen Zustände - alles das und wie manches andere Erhebende und Erquickende noch! spiegelt sich in Lessings Briefen und Schriften." (Mehring 1983, 30)

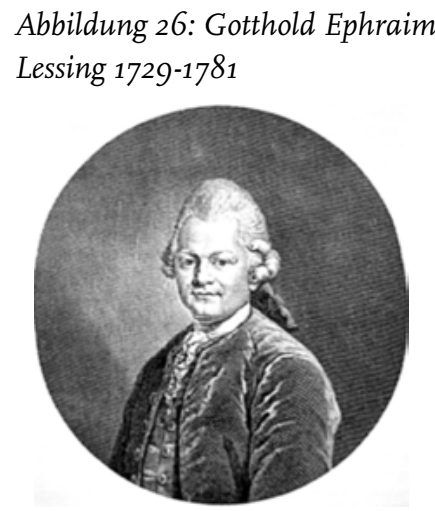


Lessing stellt sein Selbstverständnis dar im Gedicht »Ich«:

Die Ehre hat mich nie gesucht;

sie hätte mich auch nie gefunden.

Wählt man, in zugezählten Stunden, ein prächtig Feierkleid zur Flucht?

Auch Schätze hab ich nie begehrt.

Was hilft es sie auf kurzen Wegen

für Diebe mehr als sich zu hegen, wo man das wenigste verzehrt?

Wie lange währt's, so bin ich hin, und einer Nachwelt untern Füßen?

Was braucht sie wen sie tritt zu wissen?

Weiß ich nur, wer ich bin.

Als Vertreter der Wissenschaft hat Lessing vor allem gewirkt in der Auseinandersetzung in der Theologie. Er argumentierte gegen den Glauben an die Offenbarung und gegen das Festhalten an den Buchstaben der Bibel als »Heilige Schrift«. Er glaubte, dass die menschliche Vernunft, angestoßen durch Kritik, sich auch ohne Hilfe einer göttlichen Offenbarung entwickeln werde.

So wird Lessing zum Vertreter eines pragmatischen Konzepts von Wissenschaft in der Aufklärung, das sich auf vier Grundannahmen zuspitzt: Zunächst wird angenommen, dass alle wissenschaftlichen Befunde und Theorien sozial konstruiert sind - die Brüder müssen an die Wirksamkeit des Ringes, also ihre Wahrheit glauben. Eine zweite Basisannahme ist, dass es keine Trennung zwischen kognitiven und sozialen Aspekten von Wissen gibt. Die Wahrheit setzt sich erst im Erfolg durch. Drittens lassen sich also auch Wissenschafts- und Technikentwicklung sinnvoll nur als Arbeit betrachten. Die vierte Annahme schließlich ist Wissenschaft als Arbeit, als Institution und als Wissen ein Bereich der Gesellschaft.

Frappierend sind die Parallelen zu einer pragmatistisch-interaktionistischen Perspektive als einem Wissenschaftsverständnis, das nicht primär Resultate und Institutionen in Universitäten, Laboren, Akademien und Instituten sieht, sondern eine Vielzahl in unterschiedlicher Weise miteinander verknüpfter Prozesse, in denen fortwährend nicht nur Wissen, sondern auch Konsens und Legitimation hervorgebracht, bewahrt und modifiziert werden. So entstehen soziale Welten oder Gemeinschaften, die bei der Suche nach Wissen fortgesetztem Wandel unterliegen.

Pierre Bourdieu (1998) versucht über die systemische und interaktionistische Perspektive hinaus in reflexiv-praktischer Absicht, Strukturen eines selbst geregelten Austauschs in der Wissenschaft als Form der Reflexion einzuführen. Dabei greift er zurück auf den für ihn zentralen Begriff des Feldes als einem relativ autonomen Mikrokosmos, in welchem Kämpfe um die Bewahrung oder 
Veränderung der Kräfteverhältnisse zwischen den Akteuren stattfinden. Solche Felder verfügen über mehr oder weniger ausgeprägte Autonomie (ebd. 18). Sie erhalten Grade von Unabhängigkeit je nachdem, wie weit äußere Zwänge Herkunft und Umfang von Geldern, Verordnungen, Vertragsbestimmungen, Forschungsaufträge - durchschlagen oder aber gebrochen werden durch eine interne »Übersetzungsmacht« (ebd. 19). Diese »Brechungsstärke« (ebd.) strukturiert die Felder im sozialen Raum Wissenschaft. Festgelegt wird diese Struktur durch die jeweilige Verteilung wissenschaftlichen Kapitals (ebd. 21). Es geht um Kämpfe, um Anerkennung und auch um Macht.

Bourdieu benutzt diese Sichtweise, um die verschiedenen Blickwinkel auf das wissenschaftliche Feld zu verstehen.

"Weit davon entfernt, [...] einem Relativismus den Weg zu ebnen, [...] erlaubt es die Konstruktion des Feldes, die Wahrheit verschiedener Stellungen zu verstehen und die Grenzen der Gültigkeit unterschiedlicher Stellungnahmen aufzuzeigen." (Ebd. 40)

Die Warnung vor der unmittelbaren »Politisierung« (ebd.) des wissenschaftlichen Feldes soll es ermöglichen, an einer »ungeschminkten, aber nicht enttäuschten Sicht der Wissenschaft« (ebd.) festzuhalten. Bourdieu plädiert für eine »Realpolitik«, an die Strukturen, in denen sich Kommunikation erfüllt, selbst Hand anzulegen (ebd. 59).

"Nur so lässt sich jenes Ideal verwirklichen, dass als Wirklichkeit der Kommunikation auftritt, durch ein politisches Handeln spezifischer Art, nämlich in der Lage, in spezifischen sozialen Widerständen gegen Vernunft geleitete Kommunikation, gegen einen aufgeklärten Diskurs entgegenzutreten." (Ebd.)

Dies könnte als eine handlungsleitende Maxime für alle, welche im Wissenschaftsbereich arbeiten, geltend gemacht werden.

Die diskursive Suche nach der Wahrheit setzt sich deutlich ab gegen einen Glauben, der sich im Besitz der Antworten wähnt. Wenn Wissenschaft sich nicht selbst aufgeben will, muss sie sich entschieden gegen jede Art religiösen Fundamentalismus wehren. Und sie darf sich nicht selbst Grenzen des Unverstehbaren setzen. Vielmehr ist Arbeit an der Theorie gleichzeitig zu messen an Praxis.

Die Umsetzung der Ergebnisse der Wissenschaft in Technologie für Wirtschaft und Staat war schon der Hauptgrund des Interesses der Landesfürsten an wissenschaftlicher Arbeit besonders in den Akademien, von denen man die schnellsten Transfereffekte erwartete. Wissenserzeugung wurde finanziert in Erwartung wirtschaftlicher Verwertung. Aber das hat schon vor zweihundert Jahren nicht einfach so funktioniert. Die sozialen Prämissen wissenschaftlicher Innovation sperren sich gegen die Unmittelbarkeit von Transferillusionen. Sie entziehen wissenschaftlichen Modellen die Legitimation unmittelbarer Brauch- 
barkeit. Wenn der Fundamentalismus des Glaubens erst einmal erfasst und ersetzt worden ist vom Skeptizismus der Wissenschaft zerplatzen die Rezeptillusionen und Anwendbarkeit und Brauchbarkeit sind nur durch Reflexivität wieder zu begründen, aber auch zu relativieren.

\subsection{Schauspiel der Freiheit}

Wenn die Realität nicht nachgibt, flüchtet die Idee in die Fiktion. Aufklärung wird zur Dramaturgie des Diskurses, die Bühne zum Ersatz der bürgerlichen Freiheit. Dies gilt für die Unterdrückten, am entschiedensten in Schillers »Räubern «, und auch für die Frauen z.B. in Goethes »Iphigenie«, also bei zwei Autoren, die selbst später von der Aufklärung abrückten - bzw. in der kulturhistorischen Geschichtsschreibung separiert wurden. Lessing war auch als Kritiker zugleich ein Mann des Theaters.

Das Theater entwirft seine eigene Realität. Es entsteht eine Welt, in der stellvertretend verstanden und gelitten wird. In der »Hamburgischen Dramaturgie« stellt Lessing als Bedingung, sich auf Aristoteles berufend, dass die erste Wirkung der Tragödie auf den Zuschauer das Mitleiden sein müsse. Damit wendet er sich gegen die bisherige Dramenpoetik, die, ebenfalls Aristoteles für sich in Anspruch nehmend, neben dem Mitleid die Furcht als wesentliche Wirkung betont. Lessing erklärt, man habe Aristoteles falsch verstanden, der »phobos« des Aristoteles, der von den bisherigen Dramentheoretikern »Schrecken « genannt werde, müsse in Wahrheit als mitfühlende Angst, das, was auf der Bühne geschieht, könne auch einem selbst widerfahren, interpretiert werden. Damit sei der Begriff der Furcht untrennbar mit dem des Mitleids (eleos) verbunden. Das Theater solle jedoch nicht den moralischen Zeigefinger heben, sondern Rührung durch Mitleid erzeugen; dies ist aber nur möglich, wenn sich der bürgerliche Zuschauer mit der Bühnenfigur identifizieren kann. (Vgl.: »Briefe, die neueste Literatur betreffend.«1759-1765)

Somit werden diese Vorstellungen zum Kern dessen, was man als die aufklärerische Katharsis-Lehre des Dramas bezeichnet: Durch das Mitfühlen solle im Zuschauer eine Wandlung vor sich gehen, die ihn tugendhafter mache. Daher ergibt sich für ihn die Notwendigkeit, dass die Helden der Dramen »von gleichem Schrot und Korne« (ebd. 75. Stück) wie die Zuschauer sein sollten. Dies gelte gerade auch bei der Darstellung von Monarchen: »Wenn wir mit Königen Mitleiden haben, so haben wir es mit ihnen als mit Menschen, und nicht als mit Königen « (ebd. 14. Stück) - eine durchaus revolutionäre Vorstellung in der damaligen Zeit.

Aristoteles diene - so Lessing - nicht deswegen als Vorbild, weil er ein hohes Ansehen genieße, sondern weil sein Theoriengebäude vernünftig sei; eine Haltung, die dem Zeitalter der Aufklärung entspricht. Entscheidend ist nach Lessing die Einheitlichkeit, Natürlichkeit und Wahrscheinlichkeit der Handlung. 
Verwickelte Episoden und romanhafte Wendungen, wie sie das Barocktheater kannte, lehnte er ab.

Lessings Neuinterpretation der aristotelischen Dramentheorie bewirkte einen fruchtbaren Wandel bei der Konzeption von Bühnenstücken. An die Stelle opulenter Schauspiele mit noblen Figuren und grellen Charakterrollen traten zunehmend bürgerliche Stücke, in denen sich der Zuschauer leichter wiederfinden konnte; das bürgerliche löste das barocke Drama ab.

Begeisterung für das Theater findet sich durchgängig bei vielen Aufklärern. Die Bühne wurde zur Ersatzspielstätte gesellschaftlicher Konflikte. Dazu musste es aus den Fürstenhöfen ausziehen und zum Schauplatz des Bürgertums werden. In verschiedenen Städten, Mannheim, Wien und Hamburg, wurde die Idee eines Nationaltheaters verfolgt.

Vorher, Anfang des 18. Jahrhunderts, existierte das Theater in Deutschland fast nur in Wandertruppen, die von Markt zu Markt zogen und mit ihren Stücken das »gemeine Volk « unterhielten, jedoch von der »guten Gesellschaft« nicht besucht wurden. Die Schauspieler dieser Gruppen »fahrender Leute« waren meist materiell verarmt und führten eine gesellschaftlich verachtete Existenz. Es wurden hauptsächlich Stehgreifspiele aufgeführt, in denen nur der Szenenablauf festgelegt wurde und es gab in jedem Stück standardisierte Typen: den Liebhaber, den Lüstling, die schlaue Tochter, den alten Vater und den Harlekin, der sich nicht in die Handlung einfügte, sondern sie durch spontane Handlungen unterbrach. Dieser Harlekin war die Hauptattraktion der Wandertruppen.

Neben diesen fahrenden Schaustellern gab es nur noch das angesehene und privilegierte Staatstheater, das zur Unterhaltung der aristokratischen Hofgesellschaft diente und von fest engagierten italienischen und französischen Schauspielertruppen getragen wurde.

In dieser Situation setzte der Leipziger Literaturprofessor Johann Christoph Gottsched (1700-1766) mit Kritik und Reformen beim verachteten »Pöbeltheater« an. Vorbild für Gottsched war dabei das klassizistisch-französische Theater. Nach diesen Reformen sollten die Volkstheater (also die Wandertruppen) in ihren Stücken die Ständeklausel beachten, den Harlekin von der Bühne verbannen, moralisch belehrend und erzieherisch wirken, allgemeine Sittenkritik leisten (also die Fehler und Schwächen der einzelnen Personen aufzeigen), nicht über die Vorstellungskraft der Menschen hinausgehen und die Einheit des Ortes, der Handlung und der Zeit einhalten.

Nach Gottsched sollte das Theater der Aufklärung vor allem eine erzieherisch-belehrende Wirkung bei den Menschen erzielen, der Dichter sollte einen Erzieher der Leserschaft darstellen. Lessing, einer der schärfsten Kritiker Gottscheds und des Belehrenden, forderte die Überwindung der Ständeklausel und die Einführung eines Nationaltheaters für die gesamte Bevölkerung. Dieses Nationaltheater sollte, anders als das Wandertheater oder das Hoftheater, nicht von anderen Ländern beeinflusst werden und aktuell sein. 
Abbildung 27: Lessing Denkmal

auf dem Hamburger

Gänsemarkt. Enthüllung 1881

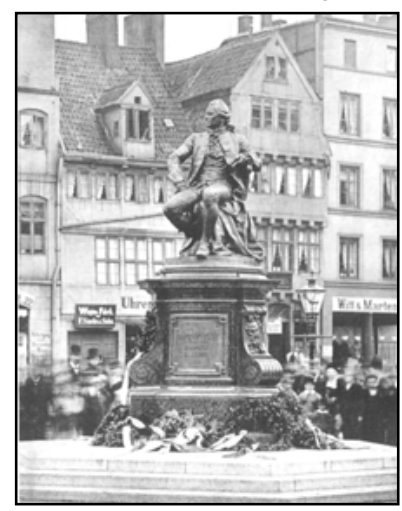

Im Drama soll die Welt in Form menschlicher Handlungen dargestellt werden. Wie müssen aber diese Handlungen gebaut sein, damit sie Welt wiedergeben können, welche Wirkungen gehen von der so erzählten Geschichte aus und wie ist das Verhältnis von realer und mimetisch erzeugter Welt? Mitleid kann nur derjenige empfinden, der sich in die handelnden Figuren einfühlt und sie als ihm selbst ähnlich erkennt. Der Zuschauer spürt, dass auf der Bühne Stellvertreter stehen, die ein Schicksal verkörpern, welches auch ihm zustoßen kann. Lessing beruft sich auf Aristoteles, den er von Vertretern des »französischen Theaters « wie Corneille als falsch verstanden sieht:

"Denn er, Aristoteles, ist es gewiß nicht, der die mit Recht getadelte Einteilung der tragischen Leidenschaften in Mitleid und Schrecken gemacht hat. Man hat inn falsch verstanden, falsch übersetzt. Er spricht von Mitleid und Furcht, nicht von Mitleid und Schrecken; und seine Furcht ist durchaus nicht die Furcht, welche uns das bevorstehende Übel eines anderen, für diesen andern, erweckt, sondern es ist die Furcht, welche aus unserer Ähnlichkeit mit der leidenden Person für uns selbst entspringt; es ist die Furcht, daß die Unglücksfälle, die wir über diese verhängt sehen, uns selbst betreffen können; es ist die Furcht, daß wir der bemitleidete Gegenstand selbst werden können. Mit anderen Worten: Diese Furcht ist das auf uns selbst bezogene Mitleid." (Ebd. 411-414)

Mitleid erzeugt auch Karl-Philipp Moritz (1756-1793; s.o. Teil 1.7) in seinem mehr oder weniger autobiographischen Roman Anton Reiser. Wie andere Altersgenossen, darunter sein Schulfreund Iffland, wurde Moritz von »Theatromanie« ergriffen.

"Er wünschte sich denn eine recht affektvolle Rolle, wo er mit dem größten Pathos reden und sich in eine Reihe von Empfindungen versetzen könnte, die er gern hatte und 
sie in seiner wirklichen Welt, wo alles so kahl, so armselig zuging, nicht haben konnte. [...] Er hatte Gefühle für Freundschaft, für Dankbarkeit, für Großmut und edle Entschlossenheit, welche in inm schlummerten; denn durch seine äußere Lage konnte er sie nicht leben. Im Schauspiel schien er sich gleichsam wiederzufinden, nachdem er sich in seiner wirklichen Welt beinahe verloren hatte." (Moritz 1979, 296-303)

Moritz/Reiser machte 1776 den ersten von mehreren vergeblichen Versuchen, Schauspieler zu werden. Es sind Anerkennung und Hochschätzung, nach denen er sucht.

"Ruhm und Beifall sich zu erwerben, das war von jeher sein höchster Wunsch gewesen; - aber der Beifall mußte inm damals nicht zu weit liegen - er wollte inn gleichsam aus der ersten Hand haben und wollte gern, wie es der natürliche Hang zur Trägheit mit sich bringt, ernten ohne zu säen. - Und so griff nun freilich das Theater am stärksten in seinen Wunsch ein. - Nirgends war jener Beifall aus der ersten Hand so wie hier zu erwarten. - Er betrachtete einen Brockmann, einen Reineck immer mit einer Art von Ehrfurcht, wenn er sie auf der Straße gehen sahe, und was konnte er mehr wünschen, als in den Köpfen anderer Menschen einst ebenso zu existieren, wie diese in seinem Kopfe existierten. - So wie jene Leute vor einer so großen Anzahl von Menschen, als sonst nur selten oder nie versammlet sind, alle die erschütternden Empfindungen der Wut, der Rache, der Großmut nacheinander durchzugehen und sich gleichsam jeder Nerve des Zuschauers mitzuteilen, - das deuchte inm ein Wirkungskreis, der in Ansehung der Lebhaftigkeit in der Welt nicht seinesgleichen hat." (Moritz 1979, 302/303)

Reiser steht für eine ganze Generation von Theatromanen. Das Leiden an der Gesellschaft suchte einen Ausweg in der Fiktion. Das Gefühl des an den sozialen Verhältnissen leidenden Individuums bricht sich in der Aufklärung als Freisetzung einerseits, fortgesetzte Unterdrückung andererseits. Die weiterbestehende Demütigung sucht auf der Bühne nach Befreiung.

"Es war wirklich damals gerade die glänzendste Schauspielerepoche in Deutschland, und es war kein Wunder, dass die Idee, sich in eine so glänzende Laufbahn, wie die theatralische war, zu begeben, in den Köpfen mehrerer jungen Leute Funken schlug und ihre Phantasie erhitzte - das war denn damals auch der Fall bei der dramatischen Gesellschaft in Hannover - sie hatte gerade die vortrefflichsten Muster, einen Brockmann, Reineck, Schröder zu einem Zweck der Kunst vereinigt, täglich Lorbeern einernten sehen, und es war wirklich kein unrühmlicher Gedanke, solchen Mustern nachzueifern." (Ebd. 306)

Reiser erlebt in seinem Bemühen um Anerkennung immer wieder Zurückweisung und Demütigung. Aber er wird auch immer weiter getrieben: 
"Weil er doch aber nun, um sein Glück in der weiten Welt zu suchen, sich irgendeinen Ort in der weiten Welt zum Ziel seiner Wanderung machen mußte, so wählte er Weimar hierzu, wo sich damals die Seilersche Truppe, über welche Ekhof die Direktion führte, aufhalten sollte. - Hier wollte er seinen Entschluß, sich dem Theater zu widmen, ins Werk zu richten suchen." (Ebd. 317)

Sein Versuch sich einer Schauspielergruppe anzuschließen scheitert jedoch. Die Strukturen des Theaters und der Fiktion waren zu fragil, um dem desorientierten Individuum Stabilität geben zu können.

"Als er in die Stube trat, fand er denn auch schon eine ziemliche Anzahl von den Mitgliedern der Speichschen Truppe vor, die er als seine künftigen Kollegen begrüßen wollte, indem er an allen eine außerordentliche Niedergeschlagenheit bemerkte, welche sich inm bald erklärte, als man inm die tröstliche Nachricht gab, daß der würdige Prinzipal dieser Truppe gleich bei seiner Ankunft in Leipzig die Theatergarderobe verkauft habe und mit dem Gelde davongegangen sei. - Die Speichsche Truppe war also nun eine zerstreuete Herde." (Ebd. 429)

So lautet der letzte Satz des »Anton Reiser«. Die Fiktion der Freiheit scheitert an ökonomischen und politischen Strukturen. Momente der Anerkennung werden erkauft durch den Rückfall der Akteure in die permanente Verunsicherung. Moritz selbst erlebt einerseits sozialen Aufstieg und Hochschätzung bis zum Akademie-Mitglied, andererseits psychische Verstörung und Krankheit. Leiden entsteht durch die Spaltung von Gefühl und Vernunft.

Mittlerweile ist dem modernen Theater die Mitleids-Lehre fremd geworden. Die Übermacht der Gefühle sieht Bertolt Brecht (1898-1956) als Exponent der Gegenposition eher skeptisch. Das »epische Theater« stellt eine grundlegend veränderte Sichtweise im geordneten Aufbau des Theaters dar. Brecht verstand das »epische« aber nicht als Gegensatz zum »dramatischen« Theater; es lägen nicht absolute Gegensätze, sondern lediglich Akzentverschiebungen vor.

Episches Theater soll in seiner Form erzählend sein, das Nachdenken der Zuschauer wecken zu Entscheidungen. Nachahmung (Mimesis) und Identifikation sollen im epischen Theater vermieden werden. Vom Schauspieler wie vom Zuschauer verlangte Brecht ständige Reflexion. Der Darsteller sollte sich nicht wie in der traditionellen Theaterpraxis in die Rolle emotional hineinversetzen, sondern sie und ihre Handlungen zeigen und diese gleichzeitig bewerten. Wesentliche dramaturgische Methode ist dabei die Verfremdung, die eine Handlung durch unterbrechende Kommentare oder Lieder so modifiziert, dass die Zuschauer eine Distanz zum Stück und seinen Darstellern aufbauen können. Einen Vorgang oder einen Charakter verfremden, heißt bei Brecht, dem Vorgang oder dem Charakter das Selbstverständliche, Bekannte, Einleuchtende zu nehmen und über ihn Staunen und Neugierde zu erzeugen. 
Brecht verstand seine Dramen als Instrument der Aufklärung im Sinne einer revolutionären gesellschaftlichen Praxis. Um Impulse zur Aufklärung zu geben, müsse beim Zuschauer ein Denkprozess ausgelöst werden. Dazu soll dieser sich der Illusion des Theaters bewusst werden und dürfe sich nicht, wie in der klassischen Theatertheorie der aristotelischen Katharsis angestrebt, von der Handlung gefangen nehmen lassen; mit dem Protagonisten Mitleid empfinden, wie Lessing forderte; das Geschehene als Schicksal empfinden und als solches hinnehmen. Er soll das Dargebotene als Parabel auf allgemeine gesellschaftliche Verhältnisse sehen und sich fragen, wie etwas an den dargestellten Missständen verändert werden könnte. Brecht versteht seine Dramentheorie und seine im Exil geschriebenen Stücke als Versuche für ein neuartiges Theater, für das »Theater des wissenschaftlichen Zeitalters«.

Brecht wollte ein analytisches Theater, das den Zuschauer zum distanzierten Nachdenken und Hinterfragen anregt. Zu diesem Zweck verfremdete und desillusionierte er das Spiel absichtlich, um es als Schauspiel gegenüber dem wirklichen Leben erkennbar zu machen. Schauspieler sollten analysieren und synthetisieren, d.h. von außen an eine Rolle herangehen, um dann ganz bewusst so zu handeln, wie es die Figur getan hätte.

An die Stelle des Trauer- und des Lustspiels tritt das Lehrstück. Man versetzt sich jedoch in beiden Fällen in eine andere Wirklichkeit. Damit treffen sich in der Suche nach Wahrheit das Fiktive und das Exotische, die beide die Enge des scheinbar Gegebenen durchbrechen und alternative Perspektiven eröffnen. Der Name »Reiser « ist von Moritz bewusst gewählt, um das Unstetige und Suchende der Biographie hervorzuheben.

\subsection{VöLKeR DeR WeLt}

Reisen, möglichst Weltreisen, als Suchen war Horizont der Aufklärung. Das Bekannte zu verlassen, um seine Gültigkeit zu prüfen und sich selbst zu finden war Intention. Reisen ist eine Suche nach Wahrheit. Es ist Form der Erfahrungswissenschaft. Gesucht wurde rund um die Welt ein Standpunkt, von dem aus die Vernunft sich verorten konnte und ihre Allgemeingültigkeit zu prüfen war. Denn nur was überall galt, konnte als vernünftig gelten.

Nach dem Zerbrechen des scheinbar selbstverständlichen Untertanenbildes richtete sich die Suche auf ein neues Menschenbild, das nicht durch Tradition und Privilegien verschmutzt war. Das Wesen der Menschheit wurde in ihrer Ursprünglichkeit vermutet; Menschlichkeit schien am klarsten in ihren Anfängen. Die Kantische Frage »Was ist der Mensch?« trieb die Weltreisenden über unbekannte, wüste Kontinente, durch gefahrvolle, stürmische Ozeane bis in die Arktis und zur Antarktis, wo vorher noch nie ein Mensch war, schon gar kein Europäer. Natürlichkeit schien als Ursprungsglauben Gesellschaft und Menschenrech- 
te erst zu begründen. Das Treffen mit fremden Völkern sollte den Blick öffnen auf »edle Wilde«, unverdorbene und ursprüngliche Menschen. Die Perspektive wechselt zwischen der Position unterstellter Überlegenheit oder Verdorbenheit Europas - schließlich sollten die Expeditionen auch Märkte öffnen und Ansprüche sichern. Die Entdeckungsreisen erhielten die Aufgabe, die wirtschaftlichen Bedingungen für die Ausnutzung und Besiedlung fremder Länder zu erforschen.

Alles säkulare Denken stößt auf die Fragen, was der Mensch bzw. das Wesen der Menschheit sei. Lessing hatte dieses Problem in Richtung auf das gemeinsame Menschliche hinter den Offenbarungsreligionen gelenkt und mit der Entwicklungsidee verbunden. Gebrochen wurde das durch Rousseaus Frage nach dem Ursprünglichen, dem Unverdorbenen außerhalb der europäischen Zivilisation (s.o. Teil 2.1).

Louis Antoine de Bougainville (1729-1811), der als erster Franzose die Welt umsegelte und nach dem die Wunderblumen benannt sind, veröffentlichte 1771 seinen Reisebericht und verhalf einem idealisierten Bild der Südsee-Insulaner weite Popularität. Den Höhepunkt seines Berichts stellt der Aufenthalt auf Tahiti dar, dessen Landesinnere er als Garten Eden beschreibt, der seinen Bewohnern alles böte, was sie zum Leben brauchten. Die Insulaner beschreibt er als freundliche, naive, sexuell freie und glückliche Menschen, die noch nicht von der Zivilisation verdorben seien. Er beeinflusste damit Sichtweise und Blickwinkel nachfolgender Weltreisender.

Durch die Eroberungs- und Entdeckungsfahrten erhielt Reisen eine neue Dimension - die nach der Maßgeblichkeit und Vorbildhaftigkeit europäischer Kultur. Fast jede zivilisationskritische Pose bedient sich des Relativismus, der durch Herder mit dem Hinweis auf die Orts- und Zeitgebundenheit jeder Kultur eingebracht worden ist. Noch die Kritik am Eurozentrismus folgt dieser Argumentationsfigur, die schon von Montaigne in seinem Essay »Von den Menschenfressern« als Loblied für die Einfachheit und die Ursprünglichkeit der »Wilden« angestimmt worden war. Von Rousseau wurde dann das romantisierende und idealisierende Modell des »edlen Wilden« geprägt. Die Frage blieb seitdem virulent, ob die als minderwertig und widerwärtig eingestuften Wilden nicht doch die besseren Menschen seien.

Die Schiffe des sich selbst als zivilisiert klassifizierenden Europa - allen voran die englische Marine - fuhren im 18. Jahrhundert aus, um die Welt zu erkunden und zu erforschen, zu erobern und zu unterwerfen. Wesentlicher Durchbruch waren die Weltumseglungen von Captain James Cook. Mit an Bord bei der zweiten Umrundung waren zwei Deutsche: Reinhold Forster und sein Sohn Georg, die als wissenschaftliche Beobachter und Sammler angeheuert worden waren.

Georg Forster (1754-1794), der den groß angelegten Reisebericht verfasste, wurde früh berühmt als Wunderkind, Übersetzer, Weltumsegler, Empirist, Alchemist, Naturforscher, Reiseschriftsteller, Professor, Bibliothekar, Journalist und später verdammt als Revolutionär - Deutscher, Franzose, Europäer und Weltbürger. Nachträglich aber wurde er in Deutschland lange aus der Erinne- 
rung verdrängt: das Wunderkind, das 12 Jahre alt als Übersetzer in die Analen der berühmten Londoner »Antiquarischen Gesellschaft« aufgenommen wurde; der Weltumsegler, der mit Kapitän Cook 1772-1775 so weit wie niemand vorher in die Antarktis vorgedrungen war, Südseeinseln erforscht und unter Menschenfressern gelebt hat; der Professor, der in Kassel, Wilna und Mainz lehrte, wurde als deutscher Jakobiner zur Unperson.

Der entschiedene Aufklärer und seit 1792 Vorkämpfer der Mainzer Republik wurde aufgrund seines Engagements während der französischen Revolution als Vaterlandsverräter verfemt. Am 15. November 1792 hielt der berühmte Gelehrte eine flammende Rede als Jakobiner, die ihn zu einem der meistgehassten Intellektuellen in der deutschen Feudalstaaterei machte (s.o. Teil 2.1). Von da an wurde sein Name in Deutschland beschmutzt, geschändet, verdrängt und ausgelöscht. Forster wurde aus Gesellschaft und Geschichte in Deutschland verbannt, weil er Wissenschaft nicht nur dachte, sondern entsprechend handelte. Sein Menschenbild als Ethnologe beruhte auf Freiheit und Gleichheit; entsprechend wurden diese zu seinem politischen Ideal.

Georg Forster wurde am 26. November 1754 in Nassenhuben - einem Dorf von 40 Bauernfamilien bei Danzig - geboren. Als Zehnjährigen nahm ihn 1765 sein ehrgeiziger Vater, der Pfarrer Johann Reinhold Forster, mit auf eine Forschungsreise zur Untersuchung der Siedlungsbedingungen am Unterlauf der Wolga. Nach Streit mit dem Auftraggeber Graf Orlov, dem Liebhaber der Zarin Katharina II. siedelten die Eltern nach England um. Mit 12 Jahren arbeitete Georg an Übersetzungen, um die Eltern und die sechs Geschwister zu unterstützen.

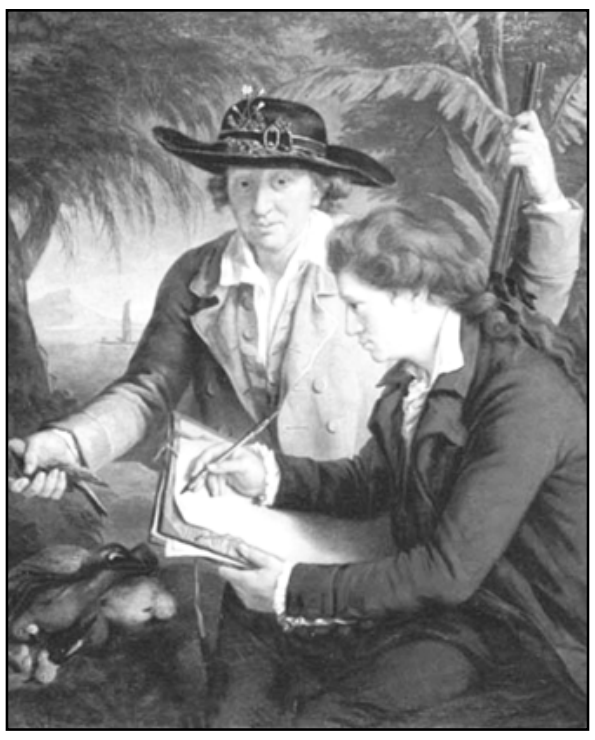

Abbildung 28: Georg und Reinhold Forster
Mit 18 Jahren begleitete er zusammen mit seinem Vater James Cook bei der zweiten Weltumseglung des Kapitäns vom 13. Juli 1772 bis zum 30. Juli 1775 - 1111 Tage. Sie umsegelten zweimal den südlichen Polarkreis und besuchten die meisten Inseln des Pazifiks. Forsters selbständige Forschungen bezogen sich auf Länder- und Völkerkunde. Seine bis heute hochgeschätzten Berichte über die Polynesier zeichnen sich aus durch Einfühlung und Anerkennung der Traditionen der Bewohner der Südsee-Inseln. Er vermeidet sie am Maßstab europäischer Vorurteile zu messen, hütet sich aber auch vor der Illusion »edle Wilde« zu sehen. 
Damit wurde er zu einem Begründer der modernen Ethnographie. Der Umgang der Autochthonen mit den Seefahrern war geprägt durch die jeweils eigenen kulturellen Traditionen. Meist wird übersehen, dass die Einwohner der Südsee sehr unterschiedlichen Stämmen angehören, eine einheitliche Betrachtung beispielsweise von Feuerländern und Tahitianern, auf die die Cooksche Expedition stieß, also gar nicht möglich ist.

Forsters Einschätzungen sind ambivalent. Er versucht Vorurteilen zu entgehen und die Lebensverhältnisse der Menschen und Völker im Zusammenhang mit Natur, Landschaft und Geschichte zu sehen. Einerseits kann er seine eigene Herkunft und die europäischen Maßstäbe schwer ablegen, andererseits hütet er sich vor dem Bild von glücklichen, unverdorbenen Ureinwohnern.

Die Problemkonstellationen bei den Landgängen konzentrieren auf die Felder Sexualität und Gewalt. Forster kritisiert die Bereitschaft der polynesischen Frauen, kann sich aber selbst der Attraktivität der Tahitianerinnen nicht entziehen. Deutliche Unterschiede der Kulturen sieht er zwischen den »Pesserähs«, die er auf Feuerland trifft, den Maoris auf Neuseeland, die ihm als leicht erregbar und unberechenbar erscheinen, und den schönen und vertrauensvollen Eingeborenen Tahitis.

Am Abend des 15. August 1773 sieht man vom Schiff aus die Berge der Insel Tahiti »aus den vergoldeten Wolken über den Horizont hervorragen«. Die Landschaft und ihre Einwohner erwecken paradiesische Träume. Auch Georg Forster ist durchaus empfänglich für die Reize der Insel und ihrer Bewohner.

"Ein Morgen war's, schöner hat inn schwerlich je ein Dichter beschrieben, an welchem wir die Insel 0-Tahiti 2 Meilen vor uns sahen. Der Ostwind, unser bisheriger Begleiter hatt sich gelegt; ein vom Lande wehendes Lüftchen führte uns die erfrischendsten und herrlichsten Wohlgerüche entgegen und kräuselte die Fläche der See. Waldgekrönte Berge erhoben ihre stolzen Gipfel in mancherley majestätischen Gestalten und glühten bereits im ersten Morgenstrahl der Sonne." (Forster 1784; 2007, 177)

Die Faszination wird auch aufgenommen und ausgestrahlt von den Menschen, die dieses Paradies bewohnten:

"Die Leute, welche uns umgaben, hatten soviel Sanftes in ihren Zügen, als Gefälliges in ihrem Betragen. Sie waren ungefähr von unserer Größe, blaß mahagony-braun, hatten schöne schwarze Augen und Haare, und trugen ein Stück Zeug von ihrer eigenen Arbeit mitten um den Leib, ein anderes aber in mancherley mahlerischen Formen, als einen Turban um den Kopf gewickelt. Die Frauenspersonen, welche sich unter innen befanden, waren hübsch genug, um Europäern in die Augen zu fallen, die seit Jahr und Tag nichts von ihren Landsmänninnen gesehen hatten. Die Kleidung derselben bestand in einem Stück Zeug, welches in der Mitte ein Loch hatte um den Kopf durchzustecken und hinten und vornen bis auf die Knie herabhieng. Hierüber trugen sie ein 
anderes Stück von Zeuge, das so ein als Nesseltuch und auf mannigfaltige, jedoch zierliche Weise, etwas unterhalb der Brust als eine Tunica um den Leib geschlagen war, sodaß ein Theil davon, zuweilen mit vieler Grazie, über die Schultern hieng. War diese Tracht gleich nicht vollkommen so schön als jene an den griechischen Statüen bewunderten Draperien, so übertraf sie doch unsere Erwartungen gar sehr und dünkte uns der menschlichen Bildung ungleich vortheilhafter als jede andere, die wir bis jetzt gesehen." (Forster 2007, 178)

Forster tendiert dazu, die »Wilden« gegen die Europäer in Schutz zu nehmen. Aber er fühlt eine grundlegende Skepsis, die ihm nicht erlaubt, an der glücklichen Wildheit teilzunehmen. Er spürt, dass sich im Zusammentreffen der Kulturen auch schon das Ende jeder Idylle ankündigt. Es gibt auch hier schon soziale Hierarchie, Faulheit, Unterwürfigkeit und Herrschaft.

"[...] jenseits kamen wir zu einem hübschen Hause, in welchem ein sehr fetter Mann ausgestreckt da lag, und in der nachlässigsten Stellung, das Haupt auf ein hölzernes Kopfküssen gelehnt faulenzte. Vor inm waren zwei Bediente beschäftigt seinen Nachtisch zu bereiten. [...] Inmittels setzte sich eine Frauensperson neben ihn und stopfte inm von einem großen gebackenen Fische und von Brodfrüchten jedes Mal eine gute Hand voll ins Maul, welches er mit sehr gefräßigem Appetit verschlang. Man sahe offenbar, dass er für nichts als den Bauch sorgte, und überhaupt war er ein vollkommenes Bild pflegmatischer Fühllosigkeit. Kaum würdigte er uns eines Seitenblicks und einsylbige Wörter, die er unter Kauen zuweilen hören ließ, waren nur eben so viel Befehle an seine Leute, dass sie über dem Hergucken zu uns, das Füttern nicht vergessen mögten. Das große Vergnügen, welches wir auf unseren bisherigen Spaziergängen, besonders aber heut, empfunden hatten, ward durch den Anblick und durch das Betragen dieses vornehmen Mannes nicht wenig vermindert. Wir hatten uns bis dahin mit der angenehmen Hoffnung geschmeichelt, dass wir doch endlich einen kleinen Winkel der Erde ausfündig gemacht, wo eine ganze Nation einen Grad von Civilisation zu erreichen und dabei doch eine gewisse frugale Gleichheit unter sich zu erhalten gewusst habe, dergestalt, dass alle Stände mehr oder minder die gleiche Kost, gleiche Vergnügungen, gleich Arbeit und Ruhe mit einander gemein hätten. Aber wie verschwand diese schöne Einbildung beym Anblick dieses trägen Wollüstlings, der sein Leben in der üppigsten Unthätigkeit ohne allen Nutzen für die menschliche Gesellschaft, eben so schlecht hinbrachte, als jene privilegirten Schmarotzer in gesitteteren Ländern, die sich an dem Fett und dem Überflüsse des Landes mästen, indeß der fleißige Bürger desselben im Schweiß seines Angesichts darben muß." (Ebd. 194)

Die Hoffnung der Weltreisenden, eine gerechte Gesellschaft freier Menschen zu finden, zerbrach. Auch in den hintersten Winkeln der Welt fanden sie Ungleichheit und Herrschaft.

Der wissenschaftlich abgesicherte Reisebericht (»A voyage round the world« 
1777; dt.: »Reise um die Welt.« 1778, 1780) wurde durch Offenheit und Belegbarkeit Vorbild für eine neue literarische Form. Exakt und fundiert und zugleich spannend und lesbar bietet Georg Forster anschauliche und verlässliche ethnographische Empirie, die über bloße Erzählung, Aufzählung oder Beschreibung hinausgeht. Gelungen ist ein herausragendes Dokument der Aufklärung, das abwertende aber auch idealisierende Vorurteile gegenüber den »Eingeborenen « durchbricht. Forster bleibt zwar in der Position des zivilisierten Europäers und steht zwischen zwei gegensätzlichen Auffassungen von Kultur und Natur: Naturschwärmern, die - in der Nachfolge Rousseaus - die »Wilden« als Bewohner eines unberührten Paradieses sehen, einerseits und den Fortschrittsgläubigen, die herabblicken auf deren »Barbarei« andererseits. In dieser Spannung versucht er dem eigenen Sinn der Lebensweise der Insulaner gerecht zu werden. Er hatte damit großen Einfluss auf seine Zeitgenossen, besonders auf Alexander von Humboldt (1769-1759), mit dem er 1790 die Niederlande, Großbritannien und Frankreich bereiste; der Bericht erschien als »Ansichten vom Niederrhein « (1791; 1968), womit nicht nur geographische Perspektiven, sondern auch politische Positionen gemeint waren.

»Ein Blick in das Ganze der Natur « (1790) war Forsters Anliegen. Es ging ihm nicht um Ansammeln einzelner Kenntnisse, sondern um eine umfassende Zusammenschau:

„Wir sind Aufbewahrer der unzähligen Begebenheiten, der Erfahrungen, der Erfindungen und der Werke des menschlichen Geistes, welche jener große Zeitraum beschließt. Ungeheuer ist die Summe dieser Kenntnisse; sie wächst noch immer fort, und bleibt in keinem Ebenmaße mit den engen Schranken dieses Lebens. Zwar erwacht zuweilen noch ein vielfassender Kopf, der, in mehreren Wissenschaften gleich groß, nicht an inrer Fläche dahinschwebt, sondern ihre Tiefen versucht und ergründet. Allein wie selten wird der Welt ein solches Göttergeschenk?" (Forster 1971, Bd. 2, 10)

Daraus erwächst eine scharfe Kritik am Wissenschaftsbetrieb:

"Man zerstückte also die Wissenschaft, und glaubte, nun sey jede Schwierigkeit besiegt. Es entstanden Facultäten, und in diesen fast unzählige Unterabtheilungen und Fächer. Jeder einzelne Theil der menschlichen Kenntnisse erhielt eigne Beobachter, die auf das ganze Verzicht thun, sich nur dem Theile widmen sollten. Da entwich dem schönen Körper die schönere Seele, und jedes erstarrte, abgeschnittene Glied wuchs durch innerliche Gährung zum Unholde von eigner Art. Jeder schätzte nur die Wissenschaft, die er gewählt, und schien zu vergessen, daß sie nur in Verbindung mit den andern das Glück der Menschheit befördert." (Ebd. 12)

Hinter den zerstückelten Einzelkenntnissen sieht Forster einen Zusammenhalt, eine Kraft, die die Fakten integriert: 
"Die thätige, lebendige Kraft, die alles in der uns bekannten Schöpfung wirkt, ist geistig und unsichtbar. Eine erstaunlich große körperliche Masse ist der Stoff, den sie bearbeitet, und den sie, anstatt inn zu erschöpfen, unerschöpflich macht. Zeit, Raum und diese Materie sind ihre Mittel, das Weltall inr Schauplatz, Bewegung und Leben ihre Endzwecke.

Alle Erscheinungen in der Körperwelt sind Wirkungen dieser Kraft. Alle Kräfte und Triebfedern in dieser Welt entstammen von ihr, und führen wieder auf sie zurück. Vielleicht sind Anziehen, Fortstoßen, Wärme und Formen der Körper überall nur Modificationen jener allgemeinen, ursprünglichen Kraft, wodurch sie alles durchdringt und alles erfüllt." (Ebd. 15/16)

Abbildung 29: Georg Forster 1784

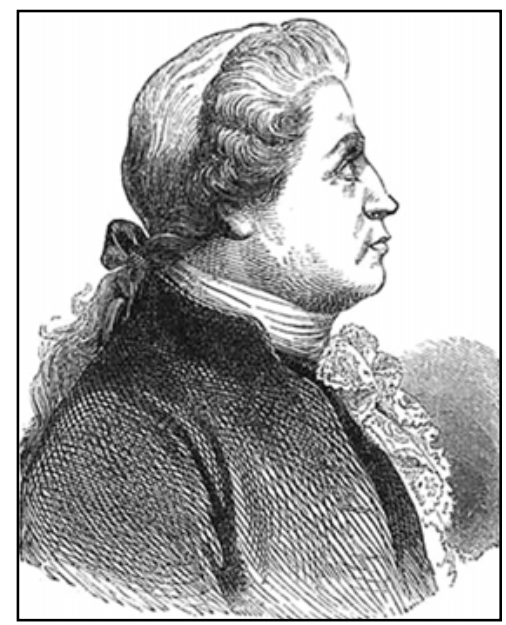

Seine Forschungsveröffentlichung brachte ihm wissenschaftliche Anerkennung und Ehrungen in ganz Europa ein. Er wurde 1777 - 23 Jahre alt - Mitglied der Royal Society in London sowie der Akademien in Berlin und Madrid. Mit 24 Jahren wurde er 1778 Professor für Naturkunde am Collegium Carolinum in Kassel.

Dort wurde er auch Mitglied der Freimaurerloge »Zum gekrönten Löwen« und einbezogen in den Rosenkreuzer-Zirkel. Die Spaltung der wissenschaftlichen Erkenntnis und Fragen des Glaubens verleitete ihn zusammen mit seinem Freund, dem berühmten Mediziner Sömmering zu mystizistischen Experimenten und vorübergehend zu okkultistischer Schwärmerei. Von Kassel aus lernte er im nahen Göttingen den Altertumswissenschaftler Christian Gottlob Heyne und den Experimentalphysiker und Philosophen Lichtenberg, sowie in Braunschweig Lessing kennen.

1784 ging Forster als Professor ins polnische Wilna und heiratete 1785 Therese Heyne, die Tochter des Göttinger Professors, mit der er dann drei Kinder hatte. 
1788 wechselte er auf eine Stelle als Oberbibliothekar der Universität Mainz. Die Ehe war unglücklich. Therese verliebte sich zweimal in andere Männer. Forster schlug beide Male eine ménage à trois vor, aber die Ehefrau verließ ihn mit den Kindern.

Nach der Eroberung der Stadt Mainz durch französische Revolutionstruppen am 19. Oktober 1792 trat er nach einigem Zögern am 7. November dem Jakobinerklub »Verein der Freunde der Gleichheit und Freiheit« bei. Er wurde Vizepräsident des »Rheinisch-deutschen Nationalkonvents« und reiste in dessen Auftrag nach Paris (s.o. Teil 2.1). Er verhandelte dort über das Gesuch zum Anschluss der Mainzer Republik, das nach seiner Rede am 30. März 1793 vom Nationalkonvent angenommen wurde. Er erlebte den terreur des Wohlfahrtsausschusses unter Robespierre. In den 1793 als Briefe verfassten »Parisischen Umrissen« (1971, Bd. 3, 729-776) spiegelt sich sein Zweifeln aber gleichzeitiges Festhalten an der Revolution:

Aufgrund eines Dekrets, das die Kooperation deutscher Untertanen mit der französischen Revolution verbot, verfiel Forster der Reichsacht und konnte nicht nach Deutschland zurück. Als Vaterlandsverräter geächtet, verlassen von seiner Frau und ohne Freunde starb er am 11. Januar 1794 krank, entkräftet, einsam und verarmt im Alter von 39 Jahren an Lungenentzündung.

\section{Grabschrift auf Georg Forster}

Weltumsegler! Du suchtest auf pfadlosem Ozean Zonen, Wo die Unschuld der Ruh böte vertraulich die Hand! Edler Forscher, was fandest du dort? Die Kinder der Erde All' an Schwachheit sich gleich, alle dem Tode geweiht. Sohn der Freiheit! Du öffnetest ihr die männliche Seele, Ihr, die vom Himmel herab sandte der Vater zum Heil. Ach! Es wandte die Göttin sich schnell von der blutigen Erde; Forster! Du schwebtest mit ihr, hin wo dein Suchen sich lohnt. Friederike Brun (1765-1835)

Forster lebte Kants Idee des Weltbürgers. Dieser Gedanke ist perspektivisch angelegt und riskant. Das Verhältnis der Kulturen und die Gemeinsamkeit der Menschlichkeit und Menschenrecht ist strittig, seit die Griechen die Fremden als Barbaren bezeichneten.

Das Menschenbild der Aufklärung ist gekennzeichnet durch eine Spannung von Gleichheit und Differenz. Ein Streit um Verwandtschaft oder Verschiedenheit wurde auf der Basis des Linnéschen Systems geführt und in der »Berlinischen Monatsschrift« 1785/1786 und im »Teutschen Merkur« 1786 zwischen Kant und Forster ausgetragen. Konsensuale Diskussionsbasis ist, dass beide zwischen Natur und Kultur als dritten Erklärungsbereich Geographie und Klima 
einführen. Kant betont allerdings das Vereinheitlichende der Rassen, während Forster deren Vielfalt unterstreicht, also gerade in der Unterschiedlichkeit eine größere Gemeinsamkeit sieht. Moralischer Hintergrund der Debatte ist sicherlich auch das Fortbestehen der Sklaverei. Letztlich bleibt unbestimmt, was denn eine »Rasse« sein soll.

Kant relativiert zwar die Einteilung in »Rassen« mit dem Hinweis, dass aus biologischer Sicht alle Menschen zweifellos der gleichen Gattung angehören, da sie von einem einzigen Paare abstammen und gemeinsame Nachkommen zeugen können. »Von den verschiedenen Rassen der Menschen « (Kant XI, 11) spricht er jedoch in geographischer und klimatischer Hinsicht.

"Nach diesem Begriffe gehören alle Menschen auf der weiten Erde zu einer und derselben Naturgattung, weil sie durchgängig miteinander fruchtbare Kinder zeugen, so große Verschiedenheiten auch sonst in ihrer Gestalt mögen angetroffen werden." (Ebd.)

Am Begriff der Rassen aber hält Kant fest. Die Entgegnung schreibt Forster auf der Grundlage seiner eigenen Erfahrung der Weltreise mit Cook und macht die Polemik gegen Kant stark in der Frage nach der Farbe der Südseeinsulaner (Forster 1968, 7). Als Hauptargument führt er die Vielfalt an und die Unbelegtheit der Aussagen Kants. Er warnt davor ein logisches System der Empirie überzustülpen und den Wissenschaftlern zu glauben, die nie einen Insulaner gesehen hätten und ihre Erfahrung nur am Schreibtisch beim Licht der Kerze gewinnen.

In seiner Schrift »Über lokale und allgemeine Bildung « betont Forster das breite Spektrum der klimatischen Differenz. Seine Argumentation liegt nahe bei dem, was später Lamarckismus genannt wurde - die Theorie, dass Organismen Eigenschaften an ihre Nachkommen vererben können, die sie während ihres Lebens erworben haben. Der Weltgereiste Forster wirft dem Philosophen Kant vor, allgemeine Schlüsse aus unzureichenden Erfahrungen zu ziehen.

"Was der Mensch werden konnte" - so Forster -, "das ist er überall nach Maasgabe der Lokalverhältnisse geworden. Klima, Lage der Örter, Höhe der Gebirge, Richtung der Flüsse, Beschaffenheit des Erdreichs, Eigenthümlichkeit und Mannichfaltigkeit der Pflanzen und Thiere haben inn bald von einer Seite begünstigt, bald von der andern eingeschränkt, und auf seinen Körperbau, wie auf sein sittliches Verhalten, zurückgewirkt. So ist er nirgends Alles, aber überall etwas verschiedenes geworden, das dem Verstande des Forschers, wenn er über die Schicksale und Bestimmungen seiner Gattung nachdenkt, Aufschluß verspricht, oder wenigstens den Stoff zu einer eigenen Hypothese über den wichtigsten Gegenstand unseres Grübelns in die Hände spielt.“ (Forster 1968, I, 65)

Forster betont die Vielfalt der Entwicklungsmöglichkeiten: 
"Wenn wir, auf unserer jetzigen Stufe der Kultur, den weiten Umfang aller in den Menschen gelegten Kräfte überscheuen und es uns dann scheint, wir hätten mehr an unser ganzes Geschlecht zu fordern, als es wirklich geleistet hat, so täuschen wir uns selbst durch die Verwechselung unserer individuellen Erkenntnis mit jener andern, welche sich unter minder vorteilhaften Verhältnissen entwickelte. Die Zerstreuung der Völkerschaften über die Erdoberfläche gieng vor ihrer sittlichen Ausbildung vorher und dadurch geschah es, daß von so vielen, zum Theil widersprechenden Anlagen eine jede sich irgendwo und wann unter günstigen Umständen bis auf den äussersten Grad vervollkommnen und anwenden ließ. Ohne diese vereinzelte Darstellung der menschlichen Kräfte ist nicht einmal die Zusammenfassung und Idealisirung denkbar, die uns zum Zeitvertreibe dient, wenn wir unsern Mitmenschen eine abstrakte Norm der Vollkommenheit anmessen, und sie dann im moralischen, wie im physischen Sinne, zu lang oder zu kurz, oder sonst auf irgend eine Art unförmlich finden.

Führte nicht die Spekulazion, wie eine philosophische regula falsi, zu gewissen brauchbaren und zuverlässigen Resultaten, wenn schon sie von Voraussetzungen ausgeht, die keine Wirklichkeit haben, so mögte man vielleicht fragen, welche Untersuchung die müßigste sei, die: wie die Menschengattung anders hätte werden können, als sie schon geworden ist? Oder die: was eigentlich noch aus ihr werden solle? Gewiß würde man nie den Traum der allgemeinen Gleichförmigkeit geträumt haben, wenn man richtige Vorstellungen von Europa und Indien, von Grönland und Guinea zum Grunde gelegt hätte. Zugestanden, es sei möglich, dass gänzlich gesittete Völker unter jeden Himmelsstrich verpflanzt, eine gewisse überlieferte oder verabredete Übereinstimmung beibehalten könnten, so ist es wenigstens bis zur augenscheinlichen Ungereimtheit des Gegensatzes offenbar, dass die Kräfte der Natur ihrer Nachkommenschaft bereits im ersten Gliede ein nach dem Ort und seinen Beziehungen jedes Mal wesentlich verschiedenes Gepräge aufdrücken müssten. Die Hitze des Äquators, die Kälte des Eisgürtels verändern die Gestalt und Proporzion der festen Theile, die Konsistenz und die Bestandtheile der Säfte; die verschieden gestimmten Sinnesorgane besitzen eine andere Reizbarkeit, eine andere Empfänglichkeit, eine andere Verwandtschaft mit der äusseren, umgebenden Natur; die Bedürfnisse des Wallfischfängers in seiner beschneiten Jurte schieden sich von jenen des Pflanzers im Palmehain; die ersten gestalten, die sich dem neuen Geschöpf aufdringen und die tiefsten unauslöschlichsten Eindrücke in seiner Phantasie zurüklassen, sind unter jedem Grad der Breite, auf Inseln und festen Ländern, im Gebirg und auf der Ebene verschieden, und wenn sie aufgefasst werden von klimatisch veränderten Organen, so entsteht unfehlbar eine Eigenthümlichkeit der Bilder, die ihren Einfluß auf die Denkungsart und selbst auf die Handlungsweise der Menschen äussern muß." (Ebd.)

Der Streit »über die Menschenrassen«, wie er zwischen Kant und Forster geführt wurde, war damals letztlich nicht entscheidbar, weil humangenetische Forschung nicht vorlag. So konnten in den Feldern der Unkenntnis wieder politisch interessierte Vorurteile und Menschenfeindlichkeit Platz greifen. Absurd 
ist, wenn »Rassen« aufgrund äußerer physischer Merkmale wie z.B. der Hautfarbe unterschieden und folgend Unterschiede der »Charaktere« und der Fähigkeiten angenommen werden. Skurril ist, aus phänotypischer menschlicher Variabilität so klassifizierter »Rassen« auf genetische Stabilität dieser Populationen zu schließen.

Für die »Fremden « wurden vor allem Mangeldefinitionen geprägt: geschichtslose, schriftlose, primitive, nicht zivilisierte, nicht-europäische, nicht entwickelte, nicht-moderne, nicht-industrielle, nicht-staatliche Kulturen. Gezeichnet wurde das Bild von »savages«, »sauvages«, »Wilden«. Mit der Entdeckung und Kolonialisierung anderer Kontinente begann für viele Ureinwohner der Niedergang. Man betrachtete sie als primitiv, als Menschen, die zivilisiert werden mussten. Dies rechtfertigte auch das Fortbestehen der Sklaverei. An der Einstellung zu den »Wilden « zeigen sich Grenzen der Aufklärung als europäischer Prozess.

Das Fremde wurde begleitet durch einen ausgrenzenden Exotismus. Die Wilden wurden behandelt als Nicht-Menschen, als Tiere. ${ }^{8} 896$ beispielsweise gab es bei der Gewerbeausstellung in Berlin ein »Negerdorf«, in dem Afrikaner ihre Kleidung und Bräuche vorführen mussten. Vier Jahre später wurde bei der Weltausstellung in Paris eine Pygmäenfrau im Käfig zur Schau gestellt. Über Jahre zeigte der Tierhändler Carl Hagenbeck in Hamburg und Berlin exotische Menschengruppen aus aller Welt im Zoo.

Die Eingeborenen Europas sahen diese fremden Gestalten mit wohligem Gruseln und dümmlichem Schauern. Man konnte sich über die Fremden erheben. Die eigene Bösartigkeit wurde verlagert auf andere »Menschenrassen«. Dies half den Imperialismus zu rechtfertigen.

Die bis heute fortdauernde Fremdenfeindlichkeit, die sich hauptsächlich gegen anders Aussehende richtet, liegt unter anderem daran, dass in Deutschland Rassismus unlösbar mit der menschenverachtenden und mörderischen Rassepolitik der Nationalsozialisten verknüpft wird und diese immer noch nachwirkt.

Unterstellt wurde, es gehe um »Naturvölker« im Gegensatz zu »Kulturvölkern«. Als Kritikfolie zu europäischen Zuständen oder der westlichen Zivilisation malten die Weltreisenden und später die Ethnologen Bilder nicht entfremdeter unberührter Kulturen, aber auch erniedrigende, menschenverachtende Karikaturen.

Die Alltagskultur ist auch nach dem Ende des Nationalsozialismus stark von einem historisch gewachsenen Rassismus geprägt. Der unterlegte Rassenbegriff aber ist unsinnig, überholt und längst widerlegt: Die Varianz innerhalb der Gruppen ist mindestens so groß wie zwischen ihnen.

Zahlreiche Beispiele gab und gibt es aber immer noch in Lehrbüchern, Kinderliedern - z.B. die »Zehn kleinen Negerlein « - oder auch in der Alltagssprache. Ein Beispiel: Der Begriff »Mischling « wird auch heute noch in der Alltagssprache z.B. für die Kinder schwarzer und weißer Eltern genannt. Der Begriff 
setzt voraus, dass weiße und schwarze Menschen unterschiedliches »Blut« haben, das sich bei den Nachkömmlingen »mischt«. Das ist eine Annahme unaufgeklärter Rassentheorie, die nach den Erkenntnissen der Humangenetik nicht mehr haltbar ist. Die Diskriminierung und Vorbehalte, die Menschen anderer Hautfarbe oder anderer Kulturen im Alltag erfahren, beruhen häufig auf einer auch unbewussten Vorstellung, dass die Menschen anderer Kulturen »von Natur aus « anders sind. Dabei wird in der Regel die eigene Kultur gegenüber der anderen als höherwertig angesehen. Diesen - häufig unreflektierten - Alltagsrassismus kann man aber nicht gleichsetzen mit einem rassistischen Weltbild.

\section{Abbildung 30: Menschenrassen}

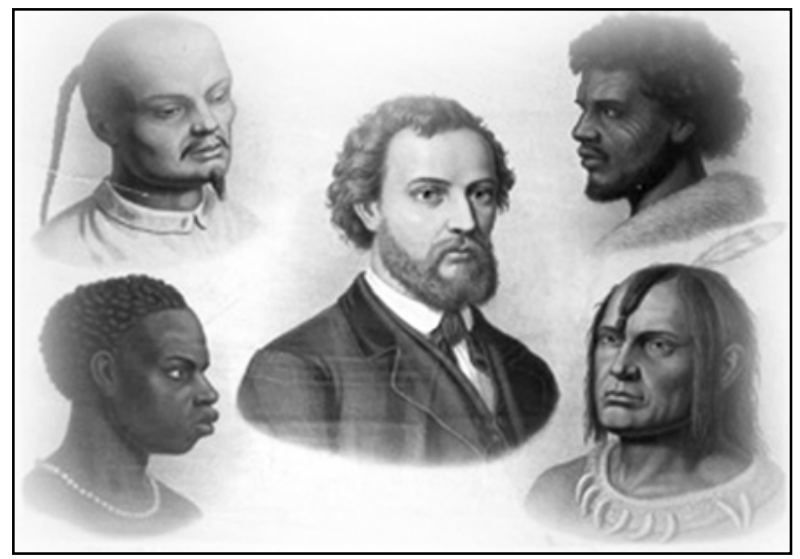

Rassismus ist nicht nur eine Form der Herabsetzung, Diskriminierung oder Verfolgung bestimmter Gruppen, sondern immer auch eine Form der Weltsicht. Ein rassistisches Weltbild strebt eine Gesellschaftsform an, die »homogen « von Herrenmenschen beherrscht wird. Sie soll gereinigt und frei sein von schädlichen Bevölkerungsgruppen. Das können Menschen anderer Länder und Kulturen sein, aber auch Bevölkerungsgruppen mit »unerwünschten « Eigenschaften. Die Maßnahmen, die für eine homogene Gesellschaft ergriffen werden, reichen von rassistischen Beschimpfungen über Ausschluss aus wichtigen gesellschaftlichen Bereichen - wie dem »Berufsbeamtentum« - bis hin zum Völkermord. »Ausgemerzt« aus der »Volksgemeinschaft« werden Minderheiten wie Juden, Sinti und Roma, aber auch religiöse Gemeinschaften - wie Christen, Muslime oder geistig Behinderte oder homosexuell Orientierte. Dies ist noch lange nicht überwunden. Die Stichwörter »Eurozentrismus« vs. »Kulturrelativismus« betreffen genau das Spannungsverhältnis, in dem sich schon Forster befand.

Auch die Ethnologie als »Wissenschaft vom kulturell Fremden« oder »dem Anderen « gefasst, dem Nicht-Eigenen, geriet in solche Fallen. Noch Margaret Mead (1901-1978) als »große, alte Dame« der US-amerikanischen Kultur-Anthropologie 
und Ethnologie glaubte in der Südsee ein unberührtes und freizügiges Paradies zu finden. Sie gilt als eine der entschiedensten Vertreterinnen des Kulturrelativismus im 20. Jahrhundert mit der Auffassung, dass alles Sozialverhalten formbar und kulturell bestimmt sei. 1925 reiste sie allein nach Samoa, wo sie junge Mädchen an der Schwelle zum Erwachsenwerden studierte. Mit Erstaunen hielt sie fest, dass die bis dahin als starr geltenden sozialen Rollen kulturell entwickelt und nicht wie bis dahin unterstellt - für alle Menschen allgemein gültig wären.

Weltberühmt wurde Mead durch ihre Forschungsreisen 1931 nach Neuguinea, wo sie die Gesellschaftsstrukturen der Arapesh, Tchambuli und Mundugumor erforschte und aus ihrem Material folgerte, dass auch die bis dahin bekannten Geschlechterrollen kulturell bedingt und nicht genetisch vorgegeben seien. Besonders in den $1960 e r$ und in den 1970er Jahren waren ihre Arbeiten sehr populär. Mead galt mit ihren Studien über die Sexualität in südpazifischen Kulturen als eine Wegbereiterin der sexuellen Befreiung. Seit den $1980 e r$ Jahren wurde aber verstärkt Kritik an ihren Forschungsmethoden geübt.

Der Anthropologe Derek Freeman widersprach Meads Samoa-Ergebnissen in seinen Studien. Seiner Auffassung nach entsprang ihr Samoa-Bild eigenem Wunschdenken. Er hinterfragte die Legende von der Friedfertigkeit der Naturvölker. Wider ging es um die »edlen Wilden«. Die Projektion des Gartens Eden auf eine Südsee-Insel, auf der Liebe ohne Aggression und Sexualität ohne Unterdrückung zu finden seien, erwies sich als Wunschtraum.

Die in der Epoche der Welterkundung aufgebrochene Frage, nach natürlichen oder aber kulturellen Differenzen zwischen den Völkern setzt sich fort. Eine selbst vorurteilsbelastet wunscherfüllte Wissenschaft verstärkt die Glaubensbekenntnisse, die sie bekämpft. Sie ersetzt Aberglauben durch Wissenschaftsgläubigkeit, lässt aber die Belege ungeprüft. Genau diese kritische Reflexion allen zugänglich zu machen, wäre aber Aufgabe der Aufklärung. Noch im Streit um die Behandlung der Migration als Bildungsaufgabe setzt sich der Streit fort. Die Heterogenität der Adressaten fordert die Bildungsarbeit heraus.

Wie kann Aufklärung aus regionaler bzw. eurozentrierten und sozialer Selektivität heraustreten und ihren weltbürgerlichen Absichten gerecht werden?

\subsection{VolksaufkLÄrung OHNe VolK}

Wen erreicht die Aufklärung? Keineswegs kann man davon ausgehen, dass die gesamte Bevölkerung auch nur Europas in den gesellschaftlichen Umbruchprozess einbezogen war. In einer Gesellschaft, die sozialstrukturell noch die Merkmale des Feudalismus trug und in der erst langsam Umbrüche zum Kapitalismus stattfanden, ist selbstverständlich auch die Teilhabe an hegemonialen Weltinterpretationen hochgradig selektiv.

Seit etwa 1770 wurde das »niedere Volk« als Adressat einer Bildungsbewe- 
gung erfasst, die nicht nur aus pädagogischen, sondern auch aus politischen und vor allem aus ökonomischen Gründen gefördert wurde. Die »Volksaufklärung« ist der geschichtliche Ursprung des Volksbildungsgedankens (Götze 1932).

Die Aufklärer verfolgten das Ziel, das Volk aus Dumpfheit und Aberglauben zu erwecken und zu befreien. »Entgrenzte Aufklärung (Böning 2007, 13) wurde von einer ökonomischen Reform- zu einer politischen Emanzipationsbewegung und provozierte zugleich restaurative Gegenentwicklungen. Diese Bewegung erreichte das »Volk« allerdings erst in den letzten Jahrzehnten am Ende des 18. Jahrhunderts als die geistige Elite der Klassiker und Romantiker die Positionen der Aufklärung bereits verlassen und aufgegeben hatte.

Die Klärung und Verbreitung des Begriffs folgte erst später auf die Sache. Schon bevor Heinrich Gottlieb Zerrenner 1786 »Ein Buch für unsre Zeit« mit dem Titel »Volksaufklärung « überschrieb, gab es diese Bewegung.

Im September 1784 setzte Moses Mendelssohn (1729-1786) sich doppelt an die Spitze der Diskussion: Er war nicht nur der erste, der in der »Berlinischen Monatsschrift« - drei Monate vor Kant - «Über die Frage: was heißt aufklären?« schrieb und damit eine der wichtigsten Debatten anführte; sondern er war es auch, der bei dieser Gelegenheit erstmals den Begriff der Aufklärung aufspaltete in »Menschenaufklärung « und »Bürgeraufklärung« (s.o. 1.3). Damit wollte er bezeichnen, wie weit in einer Nation der Mensch als Mensch und der Mensch als Bürger praktisch und theoretisch gebildet werden.

"Die Aufklärung, die den Menschen als Menschen interessiert, ist allgemein ohne Unterschied der Stände; die Aufklärung des Menschen als Bürger betrachtet, modifiziert sich nach Stand und Beruf." (Mendelssohn. In: Bahr 2004, 6)

Mendelssohn trennte sorgfältig zwischen praktischer Kultur und theoretischer Aufklärung, wobei klar ist, wo er selbst stand: Philosoph und Kopf der jüdischen Aufklärung - Haskala -, er war aber kein Volksaufklärer.

Getragen wurde die Volksaufklärung zunächst personell von Kameralisten, Naturwissenschaftlern, Gutsbesitzern sowie institutionell u.a. in den ökonomischen und gemeinnützigen, »patriotischen« Gesellschaften. Ab den siebziger Jahren des 18. Jahrhunderts kamen Geistliche beider Konfessionen sowie Ärzte, Beamte, Schriftsteller und Publizisten hinzu. Sie standen oft in staatlichen Diensten oder hatten entsprechende Stellen inne. »Die entscheidende gesellschaftliche Grundlage der deutschen Aufklärung war also ihre Staatsnähe.« (Bödeker 1987, 10) Zwar von einzelnen Regierungen unterstützt, blieb die Volksaufklärung aber in erster Linie Privatinitiative.

Zugleich erfuhr »Aufklärung« einen Bedeutungswandel (Ewald 1790). Es ging nicht mehr um Mündigwerden, sondern um Mündigmachen. Dieser patrimoniale Impetus hat dazu beigetragen, dass Aufklärung als Bevormundung in Verruf gekommen ist: Lenkung und Beschränkung der Aufklärung des »nie- 
deren Volkes« durch die »gehobenen«, gebildeten Stände war Absicht. Gleichzeitig mit der Öffnung des Zugangs zum Wissen soll die Entwicklung weiterführender Gedanken und die Entdeckung eigener Wege eingegrenzt werden. Dieses Paradox der Aufklärung, Befreien und zugleich Einschränken, hat die Herrschenden zu allen Zeiten umgetrieben und beunruhigt.

Mit der Revolution in Frankreich veränderte sich schlagartig das Diskussionsklima über die Grenzen des Vernunftgebrauchs und eine drohende revolutionierende Wirkung. »Falsch und schädlich ist jede allzu ausgedehnte Aufklärung; alles, was das Volk zu Vielwisserei bringt.« (Ewald 1790, 18/19) Der bürgerliche Reformismus hat die Macht und das Wirken der Obrigkeit nie völlig infrage gestellt. Der Mensch soll als Untertan, Hausvater, Landmann, Handwerker, Kaufmann die Kenntnisse erlangen, die er braucht - mehr nicht. Er soll das Geschäft, das er treibt, vernünftig und zweckmäßig ausfüllen und so dem Wohl des Ganzen dienen.

In seiner Schrift »Über Volksaufklärung; ihre Gränzen und Vortheile« von 1790 setzte sich der Generalsuperintendent Johann Ludwig Ewald (1747-1822) mit den Ereignissen der französischen Revolution auseinander und entwarf anschließend sein Programm der »Volksaufklärung«. Es geht ihm um »zweckmäßige Aufklärung «: Jeder solle soweit belehrt werden, wie es seinem Stande brauchbar ist. Eine Vermischung der Stände soll vermieden werden und jeder soll das erlernen, was sein Beruf erfordert. Es sollen nicht gelehrte Grübler entwickelt werden, die Pflug und Egge stehen lassen, die sich hinsetzen, Streitfragen entwerfen und über Torheiten zanken. Sie sollen vielmehr gute Menschen und brave Untertanen werden.

Eine »wahre Aufklärung« allerdings, die alle Klassen des Volkes weiser, besser und glücklicher machen soll, soll nicht nur durch die Vermittlung nützlicher Kenntnisse, sondern auch durch Bildung des Verstandes, des Willens und der Urteilskraft vorangebracht werden. Ewald beschwichtigt mögliche Befürchtungen der Herrschenden, indem er aufzuzeigen versucht, dass eine aufgeklärte Despotie, indem sie bei den Untertanen den Menschengeist weckt, um des eigenen Vorteils willen handelt und dass Bildungsausgaben - heute Investitionen in Humankapital - das einträglichste Finanzgeschäft seien. Demgemäß wäre es ein unverzeihlicher Fehler in der Berechnung der Staatsmacht, wenn man das Volk unaufgeklärt lässt (Ewald 1790, 150).

Adressaten der Aufklärer waren alle, die über keine höhere Bildung verfügten. Ein Fokus lag angesichts der demographischen Struktur des 18. Jahrhundert in Deutschland bei der bäuerlich-ländlichen Bevölkerung.

Volksaufklärung verfolgte den Versuch, die kollektive Mentalität zu verändern; sie aus der schützenden, aber auch lähmenden Einbindung in als selbstverständlich empfundene Vorstellungen herauszureißen; sie für Einflüsse außerhalb ihres jeweiligen Kommunikationssystems zugänglich zu machen; sie dazu zu bringen, sich auf ihr individuelles Urteil zu verlassen und allem Vertrauten und scheinbar Selbstverständlichen mit der kritischen Frage zu begegnen. 
Angestrebt wurde eine Wirtschafts- und Lebensweise, die auf den von den Aufklärern als vernünftig erkannten Prinzipien basieren sollte, die Vermittlung auf Vernunft gründender Moralvorstellungen, die Zurückdrängung von Aberglauben und Vorurteilen und bäuerlichem Traditionalismus. Intensiv wurde medizinische Volksaufklärung betrieben.

Die Grundsatzfrage stellt sich also unvermeidbar nach dem unterliegenden Gesellschaftsbild und den resultierenden sozialen Strukturen. Für einen angemessenen Begriff sozialer Ungleichheit reicht es nicht aus, die soziale Lage anhand äußerer Merkmale zu beschreiben. Soziale Gruppen konstituieren sich zugleich in Interaktionsstrukturen und Selbstbildern. Es geht um die grundsätzlichen Teilungen der Gesellschaft. Die dual kodierten Begriffspaare wie Arbeiter/Angestellte, Männer/Frauen, Alte/Junge, Stadt/Land, Arme/Reiche, Gebildete/Ungebildete, Führende/Ausführende, Herrschende/Beherrschte, körperlich Arbeitende/geistig Arbeitende, Ausländer/Deutsche verweisen auf das Herrschaftsgefüge und auf die »feinen Unterschiede«, die die Gesellschaft differenziert. Mit diesen Trennungen sind dann jeweils Lebensbedingungen und Befugnisse verbunden. Sie gehen einher mit Ein- und Ausschließungen, Privilegierungen und Diskriminierungen.

In allen diesen Differenzen gibt es keine unschuldigen, nur beschreibenden Begriffe, sondern es sind soziale Konstruktionen, an denen die Gesellschaftswissenschaften selbst beteiligt sind. Schicht steht gegen Klasse, Mittelstandsgesellschaft gegen Klassengesellschaft, Schmelztiegel gegen Ungleichheit.

Die Frage nach der »Zielgruppe« stellte sich bereits für die Anfänge der »Volksaufklärung«. Wer sind eigentlich die Akteure oder Adressaten der Aufklärung? Zunächst waren es die »Gebildeten« selbst, die sich in der Diskussion bewegten, die sich als »gesittete Stände« von der Masse der Bevölkerung abhoben. Der »ungebildete« Teil der Bevölkerung nahm an diesem Prozess nicht teil. Wenn man vom Volk sprach, meinte man den Landmann, Dienstboten und Taglöhner, Handwerkergesellen in Städten und die meisten Einwohner kleiner Dörfer. Das »einfache Volk« als »gemeiner Mann« war schon im 18. Jahrhundert abwertend gemeint: als Nichtadlige. Nichtkleriker, Nichtakademiker, Nichtgebildete und Nichtreiche.

Allerdings war die ständische Sozialstruktur zusätzlich intern hochgradig differenziert. Innerhalb der einzelnen Gruppen gab es feine, vielfach traditionelle Unterscheidungen. Zwischen Dienstboten und Knechten, Handwerkern und Tagelöhnen, Armen und Bettlern, Bauern und Fabrikarbeitern bestanden vielfältige Grenzen. Keine Gruppe der unteren Schichten konnte hegemoniale Ansprüche anmelden oder sich zum Sprecher aufschwingen (Engelsing 1968, 337).

Dies änderte sich erst mit der »industriellen Revolution«, als die neu entstandene Arbeiterschaft zur Mehrheit der Bevölkerung aufstieg. Das Proletariat in seiner politischen Form als Arbeiterbewegung trat in Gegensatz zum Bürgertum und fand im Begriff der Arbeiterklasse eine gemeinsame Orientierung. 
Seitdem ist Arbeiterbildung Thema der Volksbildung. In den Frühphasen hatte diese auch bei allen internen Differenzen einen eigenen institutionellen Ort in der Bildungsarbeit der Sozialdemokratie und der Gewerkschaftsbewegung.

Parallel gab es die sozialwissenschaftliche Beschäftigung mit dem Teilnehmerproblem, die sich zunächst auf Klassen- oder Schichtmodelle bezog. Die Erträge sind vielfach dokumentiert (eine Übersicht: Faulstich/Zeuner 2010). In der vorerst letzten Phase der Debatte sind milieutheoretische Ansätze dominant geworden. Milieukonzepte sind seit den 1970er Jahren in die Lücke gestoßen, die durch die Kritik an der schichtbezogenen Sozialstrukturforschung entstanden ist. Entsprechend dem Theoriewechsel hat sich die Diskussion mittlerweile vom Modell sozialer Schichten abgelöst und ist weitgehend ersetzt worden durch die Debatte um soziale Milieus. Diese schließen an Pierre Bourdieu und sein Werk »Die feinen Unterschiede« (Bourdieu 1982) an. Bourdieus Konzept des Habitus liefert hierzu eine Lösung für das Problem gemeinsamer Sichtweisen auf die Sozialstruktur durch erworbene Wahrnehmungs-, Denk- und Handlungsschemata. Die von sozialen Akteuren im Denken und Handeln eingesetzten kognitiven Strategien sind analog zu inkorporierten sozialen Strukturen. Die aus den gesellschaftlichen Teilungen, besonders der Arbeitsteilung hervorgehenden äußeren Positionen entsprechen inneren Dispositionen. Bourdieu konzipiert den Habitus als »einheitsstiftendes Prinzip« (Bourdieu 1982, 283).

Aufgegriffen wurde dies in Deutschland vor allem durch zwei sozialwissenschaftliche Forschungsgruppen: Die politikwissenschaftliche Position von $\mathrm{Mi}$ chael Vester u.a.; die marketingbezogene Position von SINUS. Beide Stränge spielen in der Erwachsenenbildung eine große Rolle, wobei unterschiedliche Niveaus von Instrumentalität bzw. Reflexivität vorliegen. Die umfangreichste Bearbeitung des Themas für die Weiterbildung haben Heiner Barz, Rudolf Tippelt u.a. in drei Bänden vorgelegt (Barz/Tippelt 2004). Adressaten- und Milieuforschung zu Weiterbildungsverhalten und -interessen werden bis »Weiterbildungsmarketing « vorangetrieben: die Lernenden bzw. Adressaten werden zu Kunden.

Unternommen wird explizit eine Differenzierung im Hinblick auf die immer wichtiger werdenden subjektiven Faktoren der Lernmotivation, der spezifischen Aneignungsprozesse und ihrer Einbettung in Selbstverständnis und Lebensstil der Adressaten. Vollzogen wird eine »Abkehr vom groben Raster der traditionellen Sozialstrukturanalyse « und angezogen wird ein Modell der »Lebensstilforschung«. Absicht ist es, sich von der traditionellen Ungleichheitsforschung mit »ihrer Fixierung auf Klassen und Schichten zu lösen und nach milieuspezifischen Bildungskarrieren und Bildungsaspirationen $\mathrm{zu}$ fragen « (Barz/Tippelt 2004, Bd. 2, 10). Inwieweit damit das Problem sozialer Ungleichheit verwischt wird und ein Fortbestehen primärer Asymmetrien relativiert, bleibt zunächst offen.

Gefragt werden kann aber nach der Reflexivität des Konzeptes: Indem milieuspezifische Daten in Marketingstrategien überführt werden, geht es für 
die Lernanbieter nur noch um erfolgreiches Agieren am Markt, die kritische Dimension des Begriffs »Milieu« gekennzeichnet durch Distinktion geht verloren, wenn sie nicht kritisch hinterfragt auf dahinter stehende Herrschaftsformen wird. In der Bezugnahme auf kommerzielle Marktforschung findet eine Pazifizierung der Milieutheorie statt und gleichzeitig eine Instrumentalisierung der Empirie. Deskriptiv konstatiert werden verdinglichte Milieus, die als Problem und als Tendenz nicht mehr aufbrechen. Das zeigt sich an den - von Sinus übernommenen - etikettierenden, sogar stigmatisierenden Gruppennamen: Etablierte, Postmaterielle, Moderne Performer, Konservative, Traditionsverwurzelte, DDR-Nostalgische, Bürgerliche Mitte, Konsum-Materialisten, Experimentalisten, Hedonisten. Aufzubrechen ist ein solches Schachteldenken in einer kritischen Theoriedebatte über ihre eigenen Erkenntnisinteressen und die Perspektiven der Bildung über den Markt hinaus.

Die Dialektik des Bildungsbegriffs, gebildet $\mathrm{zu}$ werden und sich selbst $\mathrm{zu}$ bilden, hat im Aufklärungsbegriff eine Wurzel. In der Kontroverse um Adressatenorientierung und selbstbestimmtes Lernen setzt sich dies fort.

\subsection{Verbreitung der AufkLärung}

Gerade um die »kleinen Leute « zu erreichen, bedarf es der Medien der Massenverbreitung. Es müssen technische und ökonomische Prämissen der Informationsproduktion und -diffusion, der Kommunikationswege und vor allem der Umschlagmärkte geschaffen und gesichert werden. Voraussetzung für die Verbreitung der Aufklärung war die Entstehung einer Publizistik, welche zugleich Fortschritte in der Buchdruckerei, im Verlagswesen und Vertrieb voraussetzte, aber auch einen Markt mit zahlungskräftigen Abnehmern.

Voraussetzung dafür ist ein lesefähiges Publikum. Damit die Literaturproduktion bei ihren Adressaten ankommen kann, müssen diese zum Textkonsum bereit sein. Bücher, Zeitschriften, Kalender u.a. müssen ihre Leserschaft finden. Zur Beurteilung der Resonanz der Aufklärung wird häufig auf Schätzungen des Alphabetisierungsgrades zurückgegriffen, wonach in Mitteleuropa um 1770: $15 \%$, um 1800: $25 \%$, um 1830: $40 \%$ der Bevölkerung über sechs Jahren als potentielle Leser in Frage kamen (Schenda 1970; s. dazu auch: Böning 1988, 2001; Siegert 1994). Die Angaben stützen sich u.a. auf archivalische Erhebungen über Unterschriften bei Eheschließungen oder Mitgiftverträgen sowie Rekrutierungsakten.

Der Zugang zum Geschriebenen, Lesen und Schreiben können, stand also - gleichgültig wie hoch die Zahlen tatsächlich waren - keineswegs allen offen, sondern war ein Machtmittel in den Händen der Herrschenden, der Geistlichen, Beamten und Gebildeten. Das Lesepublikum bestand zunächst hauptsächlich aus akademisch gebildeten Menschen des »dritten Standes«, besonders Theologen, Sprachgelehrte sowie Lehrer. 
Der Antrieb des in Europa einsetzenden Prozesses der Alphabetisierung der unteren Schichten war zunächst ein religiös-indoktrinärer und dann erst ein ökonomischer oder politischer (Schenda 1981). Die neuen Leser sollten die Grundbekenntnisse der christlichen Kirche aufnehmen: Heiligengeschichten, Leseblättchen und Bibellektüre waren meist die ersten Leseerlebnisse.

Zunehmend verband sich bei den Philanthropen die Glaubens- mit der Wirtschaftsaufgabe. Friedrich Eberhard von Rochow (1734-1805) wollte ein zukünftiges Geschlecht besserer Menschen bilden (Rochow 1781). Als Gutsbesitzer wollte er die landwirtschaftliche Produktion ertragreicher gestalten. Dabei musste er feststellen, dass der Bildungsstand der Bauern und Gutsarbeiter nicht ausreichte, um Reformen einzuführen und wirksam werden zu lassen. Daraus folgte für ihn, dass die soziale und wirtschaftliche Lage der Landbevölkerung durch Bildung zu verbessern sei: Physiokratische Interessen verbanden sich mit moralischem Impetus. Die Bauern sollten Lesen können, um tugendhaft Landwirtschaft $\mathrm{zu}$ betreiben und zu verbessern.

Trotz oder gerade wegen der zunächst geringen, dann aber steigenden Alphabeten-Rate dieser Zeit, zeigt die Gründung von Lesegesellschaften und Lesezirkeln, die zur Verbilligung der Lektüre von Büchern und Zeitschriften dienten, das wachsende Bedürfnis des Lesepublikums an Information und Diskussion. Das sich etablierende Verlagswesen schuf wesentliche Voraussetzungen. Von der für das gesamte 18. Jahrhundert auf 175.000 Titel geschätzten Produktion deutschsprachiger Schriften erschienen etwa 2/3 seit 1760. An den Katalogen der Leipziger Buchmesse können Volumen und Sparten der Veröffentlichungen abgelesen werden. Die »schöne Literatur « belegte 1800 den ersten Rang mit einem Fünftel der Angebote. »Lesewut« und »Büchersucht« machte besonders die Romanliteratur beliebt. Damit stieg auch das Gewicht der deutschen Sprache: In den Katalogen der Leipziger Ostermesse von 1740 betrug der Anteil der lateinisch geschriebenen Bücher noch mehr als ein Viertel, um dann bis 1800 auf etwa $5 \%$ zu sinken (Müller 2002, 30).

Das von Friedrich Nicolai herausgegebene Rezensionsorgan Allgemeine Deutsche Bibliothek (1765-1791; nach 1793-1803: »Neue Allgemeine deutsche Bibliothek«), das »Nachrichten von allen neuen in Deutschland herauskommenden Büchern geben « sollte, gewann bald den Status des wichtigsten Organs der Aufklärung in deutscher Sprache. Hierin wurden von zeitweilig mehr als 150 Mitarbeitern alle wichtigen Veröffentlichungen der Zeit rezensiert. Insgesamt wurden über 80.000 Neuerscheinungen besprochen. Die ADB hat somit auf die literarische Geschmacksbildung des deutschen Publikums über vier Jahrzehnte starken Einfluss genommen.

Trotz der Expansion der Literaturproduktion und der Leserschaft blieb die Verbreitung hochgradig selektiv. Lange wurde vom »Volk ohne Buch« geredet. Eine ländliche Zeitschrift - der »Dorfkonvent« - notierte 1786 summarisch: »Der Landmann liest nicht. Alles was für ihn geschrieben wird, ist verloren.« Und ebenso steht im »ABC für große Kinder«, das 1798 in Hamburg erschien: 
»So wenig eine Post zum Monde hinauf geht, [...] ebenso wenig wird der Landmann eines der Bücher lesen, die für ihn geschrieben sind.« (Zit. Engelsing 1974, 87)

Es wurden nichtsdestoweniger gerade für »einfache« Leser zahllose Bücher produziert. Die volksaufklärerische Literatur gehörte quantitativ zu den bedeutendsten Gattungen der Druckproduktion. Von der Mitte des 18. Jahrhunderts an erschienen während der folgenden hundert Jahre etwa 15.000 Schriften von gut 3.000 Autoren, die sich entweder direkt an die unteren Stände der Bevölkerung wandten oder diskutierten, mit welchen Mitteln, Zielen und Strategien aufklärerisches Gedankengut popularisiert werden könne (Böning 2004).

Das Spektrum der Schriften reichte von der Anleitung zur Stallfütterung über Informationen zur Bekämpfung von Viehseuchen oder zur Gesunderhaltung des Menschen bis zum unterhaltsamen Roman. Bedeutende Namen sind als Autoren dabei: Auf eine Schrift Christian Wolffs über Getreide von 1717/18 folgten verschiedene Wegweiser und Ratgeber für »Gelehrte Bauern« und anderes Landvolk aus den Jahren 1738 bis 1774. Darunter war auch der »Katechismus der Sittenlehre für das Landvolk« von Goethes Schwager Johann Georg Schlosser, bis zu Johann Friedrich Meyers "Maximen in dem Lebenslaufe eines Bauern« von 1776. Johann Heinrich Pestalozzi schrieb seinen Roman »Lienhard und Gertrud«, und Georg Christoph Lichtenberg wandte sich 1778 gegen die kursierende abergläubische Kometenfurcht. Viele deutsche Gelehrte und Literaten waren Autoren von Unterhaltungsschriften, Moralischen Wochenschriften und Intelligenzblättern - darunter Gotthold Ephraim Lessing und Friedrich Gottlieb Klopstock. Zu nennen wären auch Johann Wilhelm Ludwig Gleim, Johann Heinrich Jung-Stilling, Christian Gotthilf Salzmann, Johann Heinrich Merck, Johann Gottfried Seume oder Johann Kaspar Lavater.

Alle waren sie volksaufklärerisch engagiert und zugleich auch Autoren von Zeitungen und Zeitschriften (Habel 2007). Bei ihnen wie insgesamt in der Publizistik der Spätaufklärung, in den Journalen für gebildete Leser und ganz besonders in den Zeitschriften für Pfarrer ist die Volksaufklärung ein Hauptthema. Mehrere hundert Zeitungen, Zeitschriften und Intelligenzblätter wandten sich unmittelbar an das »Volk«. Das Zeitschriftenwesen expandierte enorm von etwa 60 deutschen Zeitungen um 1700 auf über 200 mit einer geschätzten Gesamtauflage von 250.000 bis 300.000 Exemplaren bis zum Ausgang des Jahrhunderts.

Die aus England herüber dringende Einrichtung der Moralischen Wochenschriften war von besonderer Bedeutung. Dieser neu entstehende Typ von Zeitschriften, der in der ersten Hälfte des 18. Jahrhunderts in Umlauf kam, hat wesentlich zur Verbreitung der Ideen der Aufklärung beigetragen. Die Wochenschriften waren wichtiges Sprachrohr aufklärerischer Bemühungen und trugen zur politischen und moralischen Urteilsfähigkeit der Leserschaft bei. Es waren Zeitschriften belehrenden und zugleich unterhaltenden Charakters. 
In Erzählungen, Typen- und Sittenschilderungen, Essays, Dialogen oder Briefen verbreiten sich die Autoren oft unter der Maske fingierter Figuren, die aus verschiedenen Blickwinkeln betrachten und urteilen, über alle großen und kleinen Fragen des geistigen und Alltagslebens. Die meisten bedeutenderen Schriftsteller der Zeit haben Moralische Wochenschriften herausgegeben oder zeitweilig an ihnen mitgearbeitet.

In Deutschland gab es wohl über 500 Moralische Wochenschriften, in England, dem Ursprungsland, circa 200. Jedoch existierten viele von ihnen nur einige Monate oder ein Jahr. Zentren in Deutschland waren Hamburg und Leipzig.

Die in Deutschland erschienenen moralischen Wochen- oder Monatsschriften entstanden Ende des 17. bis Anfang des 18. Jahrhunderts in Anlehnung an Vorbilder aus England, die von Joseph Addison, der Verfasser, und Richard Steele, der Herausgeber, veröffentlichten moral weeklies: The Tatler (1708-1711), The Spectator (1711-1712, 1714), The Guardian (1712-1713).

Zunächst wurden diese Originale als Übersetzungen und Nachahmungen in Deutschland herausgegeben: Hier ist vor allem die frühe Wochenschrift »Der Vernünftler. Teutscher Auszug aus den Engelländischen Moral-Schriften Des Tatler Und Spectator « zu nennen, die von Johann Mattheson herausgegeben wurde und 1713 bis 1714 erschien.

Neben englischen Vorbildern gab es aber auch in Deutschland frühe eigenständige Ansätze von kritischen Wochen- und Monatsschriften, die sich an ein bürgerliches Publikum wandten.

Dazu zählen vor allem die von Christian Thomasius in Leipzig herausgegebenen »Monatsgespräche« (erschienen 1688 bis 1690), mit denen erfolgreich die deutsche Sprache als Mediensprache etabliert wurde und in denen ein unterhaltsamer, ironischer bis satirischer Sprachstil gepflegt wurde, der im Gegensatz zu den bis dahin vorherrschenden gelehrten Abhandlungen der Barockzeit stand.

Ein weiteres Beispiel der frühaufklärerischen Literaturtradition waren die von Johann Frisch herausgebrachten »Erbauliche Ruhstunden«, die seit 1676 wöchentlich in Hamburg erschienen.

Der Patriot (erschienen 1724 bis 1726 in Hamburg; 4 Neuauflagen von 1737 bis 1765) markierte den Durchbruch der moralischen Wochenschriften in Deutschland.

»Gespräche in dem Reiche derer Todten«, herausgegeben von David Faßmann (1718 bis 1739), erzielten Auflagen von 3.000 Exemplaren, Nachdrucke sogar bis zu 15.000 Exemplaren.

Die »Abbildungen der Begebenheiten und Personen wodurch der Zustand jetziger Zeiten monatlich vorgestellt und ihn dazu dienlichen Kopffern gezeigt wird (erschienen 1725 in Augsburg beim Verleger Augustus Sturm) waren die erste Zeitschrift mit kleinen Illustrationen.

»Die vernünftigen Tadlerinnen«, herausgegeben von Johann Christoph Gottsched in Leipzig (1725 bis 1727) richtet sich an die Zielgruppe Frauen. 
Der Biedermann wurde von Johann Christoph Gottsched in Leipzig herausgegeben (1727 bis 1729).

»Der Vernünffler«, herausgegeben von Johann Mattheson in Hamburg (17131714), ist zweimal wöchentlich erschienen.

»Der Menschenfreund« erschien in Hamburg 1737-1739.

Abbildung 31: Der Patriot 1737

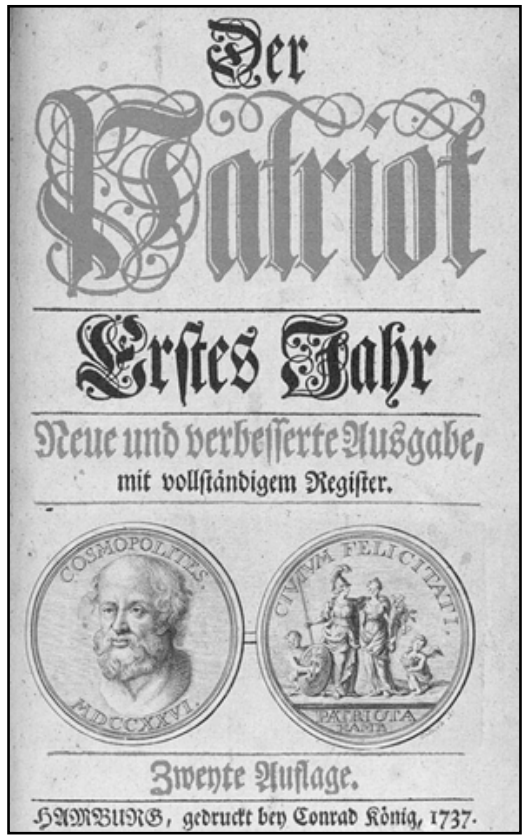

Aus dem Vorbild der Moralischen Wochenschriften entstanden die ersten Frauenzeitschriften. Mit Sophie von La Roches' (1730-1807) Zeitschrift »Pomona für Teutschlands Töchter« wurde 1783/84 die erste Zeitschrift publiziert, die von Frauen für Frauen geschrieben wurde und Fragen der Moral und der praktischen Lebensführung thematisierte.

Ausgebaut wurde das Zeitschriftenangebot durch die seit 1720 verbreiteten Intelligenzblätter, die in mindestens 220 Städten nachweisbar sind und deren Auflage in der Regel zwischen 500 und 1.000 Exemplaren lag. Ein Intelligenzblatt (engl.: intelligence, Nachricht) war im 18. Jahrhundert ein Nachrichtenblatt nach englischem Vorbild mit amtlichen Bekanntmachungen wie Gerichtsterminen, Ausschreibungen, Konkursen, Zwangsversteigerungen, Listen der in den Hotels abgestiegenen Fremden u.a. sowie geschäftlichen und privaten (Klein-) Anzeigen u.a. Vermietungs-, Verkaufs- und Familienanzeigen (Geburts-, Hochzeits- und Sterbe-Anzeigen). Das Intelligenzblatt war die erste Form eines Anzeigenblattes. Das Wort Intelligenz zielt nicht etwa auf das Geistesvermögen 
der Leser, sondern hat eine ältere Bedeutung im Sinne von Nachricht oder Information (lat. intellegere, Einsicht nehmen).

Der Kalender ist ein gutes Beispiel für diese Art der Kommunikation, da dieser ein Medium darstellt, welches von einigen gelesen, aber vielen vorgelesen wird. Immerhin gab es mutmaßlich über 200 verschiedene Kalender mit einer jährlichen Gesamtauflage von zwei bis drei Millionen Exemplaren (Knopf 1999, 129). Das primäre Ziel des Kalenders war die konkrete Lebenshilfe für den Rezipienten. Angaben zur vermutlichen Witterung, Wetter- und Bauernregeln sowie Ratschläge für den Alltag standen neben Tafeln, die Auskunft darüber gaben, bei welchem Mondstand der Aderlass günstig sei.

Es mischen sich meteorologische, astronomische sowie astrologische Aussagen bzw. Spekulationen und Kuriositäten und ergeben ein skurriles Sammelsurium. Hierin finden sich Berichte von Ungeheuern aus aller Welt, wild bewegte Reiseberichte, ungewöhnlichen Naturerscheinungen Missbildungen bei Menschen und Tieren - das ganze Repertoire der Jahrmärkte. Angeboten wird eine Mischung von heimatlich-volkstümlicher Geborgenheit und exotisch-kurioser Welterfahrung als charakteristische Inhalte der Kalender im 18. Jahrhundert.

Schon vor Beginn der Aufklärung waren Kalender ein Instrument der Lebenshilfe für die unteren Bevölkerungsschichten. Die weite Verbreitung der Kalender ergibt das Bild von einem Medium, welches über eine starke Verwurzelung in der ländlichen Unterschicht verfügte und einen festen Bestandteil der bäuerlichen Lektüre darstellte, das über Generationen zum traditionellen Gebrauchsgegenstand geworden war.

Speziell der bäuerliche »Lesestoff « umfasste drei Hauptbereiche. Zum Ersten war religiöse Literatur ein wichtiger Bestandteil des Haushalts. Da Religiosität und regelmäßiger Kirchgang in der Gesellschaft und insbesondere auf dem Lande weit verbreitet waren und der Katechismus schon im Schulunterricht eine wichtige Rolle spielte, resultiert zweifelsfrei große Bedeutung dieser Lektüre für die Bauern und ihre Familien. Ein »Minimal-Buchbesitz« der Bibel, des Katechismus, eines Gesang- samt Gebetbuchs sowie einer Hauspostille stellte in protestantischen Haushalten sogar einen Pflichtbestand dar (Siegert 1994). Es lässt sich eine tiefe Verankerung religiöser Texte in der ländlichen Gesellschaft nachweisen.

Ein zweiter Teil der - neben den religiösen Texten - in der bäuerlichen Bevölkerung üblichen Lesestoffe sind kleinere Druckschriften, die beispielsweise wunderbare Geschichten, Armesünder- oder Liebeslieder, Zauberhistorien oder Traumdeutungen enthielten. Diese Volksbücher enthielten teilweise kuriose, abergläubische, bigotte und hexengläubige Inhalte. Sie hatten dennoch einen großen Einfluss auf die Gestaltung späterer Aufklärungsschriften.

Doch schon in der dritten bei Bauern üblichen Literatur, dem Kalender, die zum festen Bestandteil des Lesestoffs gehörten, ist eine solche Benutzung des gewohnten Formats bei gleichzeitiger Veränderung in aufklärerischer Hinsicht 
erkennbar. Dies wird aber nur begrenzt umgesetzt: So wird in vielen Schriften am ptolemäischen Weltbild festgehalten, bei dem die Erde das Zentrum des Universums bildet, oder eine an der Bibel orientierte Zeitrechnung betrieben, wobei Ereignisse wie die Erschaffung der Welt oder die Sintflut rückwirkend genau datiert sind.

Für die Volksaufklärer waren Kalender doppelt interessant: Zum einen standen Kuriosa, Bigotterie und Aberglaube der Forderung nach Klarheit des Verstandes und des Geistes diametral entgegen; zum anderen bot die Verankerung und Verbreitung des Kalenders die Möglichkeit, dieses Medium zu nutzen und die eigenen Botschaften an die Adressaten zu bringen. Die begrenzte Laufzeit und Gültigkeit der Kalender und die damit verbundene regelmäßige Neuanschaffung stellten - ähnlich wie bei einer periodisch erscheinenden Zeitung - eine gute Möglichkeit dar, Neuerungen zu publizieren.

Verbreiteteste Schrift der Volksaufklärung und der erfolgreichste unterhaltsame Titel für das Volk war das »Noth- und Hülfsbüchlein für Bauersleute« (Becker 1788) des Philanthropen Rudolph Zacharias Becker (Siegert 1978).

Becker (9. Mai 1752 in Erfurt - 28. März 1822 in Gotha) war Volksschriftsteller der Aufklärung, Lehrer, Journalist und Verlagsbuchhändler. Er fasste Aufklärung als »Wahrheit und richtige Verbindung der Begriffe« $(1785,18)$.

Becker war Lutheraner, Sohn eines Mädchenschullehrers mit kleinem Einkommen und großer Familie. Er besuchte das Evangelische Ratsgymnasium Erfurt und studierte Philosophie und Theologie in Erfurt und Jena. Sein Einkommen verdiente er als Straßensänger und durch Kopieren von Kollegheften. Er wurde anschließend Hofmeister - also Hauslehrer der Kinder reicher Eltern - in Erfurt, wo er aber auch den kurmainzischen Statthalter Karl Theodor von Dalberg (1744-1817) kennenlernte, der bedeutenden Einfluss auf Beckers Ausbildung ausübte und ihn lebenslang förderte.

1779 wurde seine Antwort auf die von der Berliner Akademie der Wissenschaften gestellte Preisfrage: »Kann irgendeine Art von Täuschung dem Volke zuträglich sein, sie bestehe nur darin, dass man es zu neuen Irrtümern verleitet, oder die alten eingewurzelten fortdauern lässt? « zu einem Umbruch in seinem Lebenslauf. Becker nahm kein Blatt vor den Mund:

"Man strengt alle Kräfte an, das Volk im Irrthum zu erhalten, das ist, es außer Stand zu sezzen, dem Vaterlande durch das Licht, das die Aufklärung verbreiten würde, nüzzlich zu werden. Wenn ein solches Verfahren nicht nach dem Despotismus und der Tyrannei schmekket, so verrät es wenigstens Unwissenheit der ersten Gründe einer gesunden Staatklugheit." $(1781,141)$

Dies ging dem sich gerne als Aufklärer feiern lassenden Friedrich II. zu weit und Becker wurde von seinem Landesherrn als Radikaler von der Berufung in den Staatsdienst ausgeschlossen. Trotzdem konnte er seinen mit der Preisschrift 
erworbenen Ruhm in eine andere Karriere umsetzen. Im Jahre 1782 ging Becker als Lehrer an das Philanthropin in Dessau, das von Johann Bernhard Basedow gegründet worden war.

$\mathrm{Ab} 1782$ gab er die wöchentlich erscheinende »Dessauische (ab 1786: Deutsche) Zeitung für die Jugend und ihre Freunde « heraus, ab 1791 daneben auch ein Intelligenzblatt unter dem Titel »Anzeiger«, welcher im folgenden Jahr unter einem kaiserlichen Privileg zum »Allgemeinen Reichs-Anzeiger « erhoben wurde und endlich 1806 den Titel »Allgemeiner Anzeiger der Deutschen« erhielt.

Im Jahre 1797 gründete Becker die Becker'sche Buchhandlung in Gotha, um seine Zeitschriften und Bücher besser vertreiben $\mathrm{zu}$ können und führte sie auch bis zu seinem Tode 1822 fort. Sein »Allgemeiner Anzeiger der Deutschen« zählte zu den meist verbreiteten moralisch-politischen Zeitungen. Das »Noth- und Hülfsbüchlein für Bauersleute« machten ihn zum auflagenstärksten Autor der Zeit.

Die sagenhafte Zahl von mehr als einer halben Million recht- und unrechtmäßig gedruckter Exemplare des »Noth- und Hülfsbüchleins« ist nicht nur Konsequenz eines breiten Bedürfnisses nach brauchbaren wissenschaftlichen Resultaten, sondern auch Erfolg einer beispiellosen Subskriptionskampagne. Statt eines bloßen Aufrufs publizierte Becker die Werbeschrift »Versuch über die Aufklärung des Landmannes« (1786). Mit der breit rezensierten Schrift wandte er sich nicht an die ländlichen Halbalphabeten, sondern wollte die Gebildeten mobilisieren.

Seine These in der Folge Rousseaus lautet: Nicht »Verfeinerung und Vielwisserey« bewirken Aufklärung, sondern »Einfalt und Zweckmäßigkeit«. Zum Selbstdenken und zur Selbsthilfe kann aber nur erziehen, wer verständlich und nicht belehrend schreibt, anschaulich darstellt, sich auf den Volkston einlässt, vorwiegend Erprobtes und Anwendbares empfiehlt. Sein Buch wurde durch Holzschnitte verziert und vor allem wurde es $\mathrm{zu}$ einem erschwinglichen Preis angeboten.

Seine Zielsetzung richtete vorrangig sich auf die »Aufklärung des Landmannes«. Dieser wird sogar als für aufklärerisches Gedankengut als besonders empfänglich dargestellt:

"Es muss leichter sein, wahre Aufklärung in demselben zu verbreiten als in den gelehrten und höheren Ständen; weil bei inm weniger Schutt wegzuräumen ist, und weil er mehr ungebrauchte Kräfte vorrätig hat. Das Gefühl der menschlichen Würde ist bei ihm noch nicht abgenutzt, sondern noch unentwickelt. Es bedarf folglich nur eines Anstoßes und einiger Leitung; so wird sich der Trieb zu Vervollkommnung allmählich bei inm aus den bisherigen Fesseln herauswinden." (Becker 1785, 34)

Im Vordergrund stehen der Nutzen und die Anwendbarkeit des Wissens: 
"Aber ich dächte doch, es sey gut, wenn der Bauersmann zuweilen ein Buch läse, woraus er lernte, wie und auf welche Art er diese und jene Wirtschaftssachen aufs beste einrichten, und wie er sich und anderen in gewissen Nothfällen des Lebens helfen könne." (Becker 1788, 40)

Diese Worte legt Rudolph Zacharias Becker einem aufklärerisch orientierten Adligen in den Mund. Das »Noth- und Hülfsbüchlein« soll nicht nur Erbauliches und Ratschläge sammeln, sondern dem »gemeinen Mann« Anstöße zum Selbstdenken geben.

Ein starker Glaube an die universelle Bildungsfähigkeit des Menschen, seine »Perfektibilität« und die Allmacht der Erziehung kennzeichnete Becker. Die höchste Stufe menschlicher Vollkommenheit und Glückseligkeit sollte durch einen stetig fortschreitenden Bildungsprozess erreicht werden - und das im 18. Jahrhundert, als in Deutschland wohl 9/10 der Bevölkerung nicht lesen und schreiben konnten, und die eiserne Druckpresse gerade erst erfunden war.

"Ich wollte für Menschen arbeiten, die des Lesens ungewohnt und darunter viele sind, denen es saurer ankommt, als das Dreschen. Das Buch muss also eine äußere Form haben, welche die Neugierde dieser Classe von Lesern errege könnte, und der erste Versuch, darin zu lesen, musste sie reitzen, weiter fort zu fahren. Daher der rothe Titel, die Holzschnitte, der epopöenmäßige Anfang des Buches mit dem schauderhaften Beyspiel einer Frau, die im Grabe erwacht und ein Kind zur Welt bringt, und die mannichfaltigen Abänderungen der Einkleidung." (Becker 1788; 1980, 471 )

Eingebettet in eine Rahmenhandlung eines Gesprächs, an dem der Herr Hauptmann von Mildheim und der Herr Pfarrer Wohlgemut sich über das menschliche Leben unterhalten, steht »wie man vergnügt leben, mit Ehren reich werden, und sich und Anderen in allerhand Nothfällen helfen könne, alles in glaubhaften Historien und Exempeln bewiesen und mit Bildern gezieret« (Becker 1788 [Nachdruck 1980] 8). Insgesamt 56 Hilfestellungen werden geboten; eine Auswahl:

Nr. 1: Was bey dem Brodbacken zu beobachten ist

Nr. 2: Wie man verdorbenes Getraide zu verbessern und gesundes Brod daraus zu backen sey.

Nr. 3: Von den Kartoffeln...

Nr. 20: Warum bei einer ungeschickten, säuischen und unordentlichen Hausfrau immer alles kränkelt und elend ist...

Nr. 26: Was dabey heraus kommt, wenn Bauernmädchen sich mit vornehmen Herren gemeinsam machen ...

Nr. 27: Angstbrief eines Wollüstlings und Verführers, auf dem Todtenbette geschrieben ... 
Abbildung 32: Noth und Hülfsbüchlein 1788

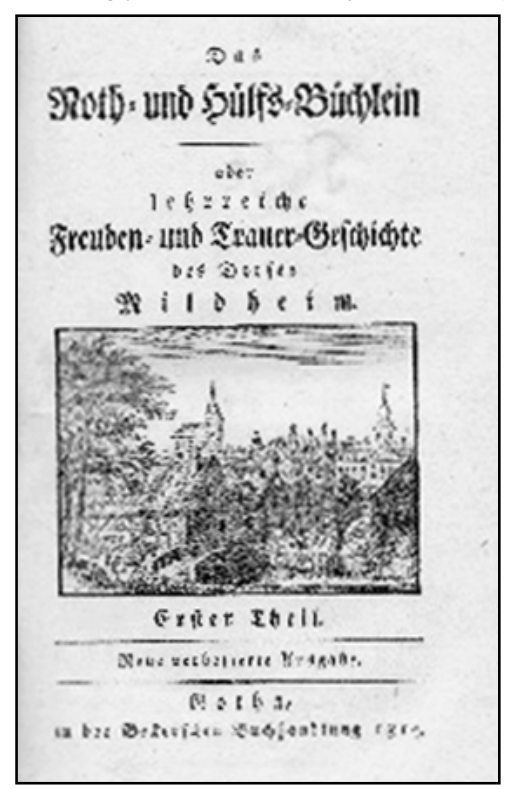

1802 wurde Becker zum fürstlich schwarzburg-sondershausischen Hofrat ernannt. Am 30. November 1811 wurde er durch die französische Gendarmerie wegen eines Aufsatzes in der National-Zeitung verhaftet und in die Feste Magdeburg gebracht, wo er bis zum April 1813 als Abschreckung für andere Aufklärer gefangen gehalten blieb, bis ihm die Verwendung des Herzogs August von Sachsen-Gotha-Altenburg, bei Napoléon Bonaparte als Gnade der Herrschenden wieder die Freiheit brachte. 1822 ist Becker in Gotha gestorben.

Spätestens die Karlsbader Beschlüsse 1819 und die beginnende »Demagogenverfolgung « zeigten, dass im 19. Jahrhundert, die Grenzen der Aufklärung sehr eng gezogen wurden. Die durch die Französische Revolution 1789 ausgelöste Freiheitshoffnung und die Aufbruchsstimmung der Volksaufklärung waren zunächst erstickt.

Die Schrift des evangelischen Generalsuperintendenten Heinrich Gottlieb Zerrenner (1750-1811) über »Volksaufklärung« stimmt das Programm auf die Institution Schule ab. Um die Anschaffungskosten zu mindern und zugleich an die auf dem Land vertrauteren Formen des Kalenders und der Erbauungsbüchlein anzuknüpfen, lag der Gedanke an ein periodisches Erscheinen nahe. Eines der beliebtesten Volksblätter war »Das räsonnirende Dorfkonvent für den Bürger und Landmann« (1786-1788).

Ergänzt wurden die Druckerzeugnisse durch »semiliterarische Prozesse«: Vorlesen, Predigten und Marktschauspiele. Vorgelesen wurde vor allem in den bäuerlichen Großfamilien an Sonntagen oder an Winterabenden, während dessen 
die Zuhörenden Handarbeiten machen. Die Predigten der Dorfpfarrer bezogen offizielle Proklamationen der Behörden mit ein und wurden ergänzt durch katechetischen Unterricht. Auf den Wochen- und Jahrmärkten traten Theaterensembles, Bänkelsänger und Rezitatoren auf.

Doch was bedeutet eigentlich Popularität?

Die am weitesten reichende Position vertrat Christian Garve (1742-1798), (s.o. Teil 2.2). Sein Ansatz zielt nicht auf eine Indoktrinierung und Disziplinierung der unteren Schichten, macht diese nicht zum Gegenstand der Politik und bürgerlicher Moral. Sondern sein Interesse galt zunächst dem Erfassen, Beschreiben und Analysieren sowie dem einfühlenden Verstehen der in sozialökonomischen Strukturen und historisch gewachsenen Gesellschaftsverhältnissen gegründeten (Garve 1790, 3).

Vom Titel her scheint Greilings »Theorie der Popularität« (1805) einschlägig zu sein. Johann Christoph Greiling (1765-1840), evangelischer Theologe und Oberhofprediger zu Aschersleben gehörte aber eher zur Gegenfraktion. Seine von philosophischem Jargon durchdrungene Theorie der Versinnlichung ist alles andere als populär: Der Kantianer Greiling, der auch im »Journal« von Niethammer und Fichte publizierte, vertrat die Position, Kants »Kritik der reinen Vernunft« dürfe niemals populär werden. Den Erfahrungsbezug, den Garve und andere stark machen, wendet Greiling geradezu als Argument gegen die Popularität. Er wollte verhindern, dass philosophisches Denken auf die »Vorstellungsart des gemeinen Verstandes« herabgewürdigt würde.

In Deutschland blieb Popularität im Spannungsverhältnis von Wissenschaftlichkeit und Allgemeinverständlichkeit, von Forschungsexponaten und Jahrmarktsattraktionen immer umstritten. Früh schon begann ein Kippen von Aufklärungsbestrebungen hin zu Dummheitssicherung.

Bereits in Zedlers Universal-Lexikon wurde vor der sich ausbreitenden Büchersucht gewarnt. Später gab es dann gezielte Versuche, die Lesewut zu bremsen. Sie halte von der Arbeit ab, führe zu Weichlichkeit und sei politisch gefährlich. Das Volk aber ist nicht dumm; es war immer schon gebildeter als es die Herrschenden haben wollten. In dem Band über »Volkskalender und Volksschriften überhaupt« erklärte Dohm deshalb 1796 in der »Deutschen Monatsschrift« $(185)$ beruhigend:

"Aber Lage und Bedürfnis werden hier schon immer ein gewisses Maß halten. Der gemeine Mann wird zu allen Zeiten nur wenig lesen und ich nehme keinen Anstand zu sagen - er muß auch wenig lesen."

Die Unterschiede im Leseverhalten der gesellschaftlichen Gruppen setzen sich bis heute fort. In den von der Gesellschaft für Konsumforschung (GfK) in Zusammenarbeit mit Sinus Sociovision für den Börsenverein für den Deutschen Buchhandel erstellten Untersuchungen wird auf das Milieu-Modell zurückge- 
griffen, um das größte Kundenpotenzial, seine Einstellungen und Werte, sowie Wünsche an Buch und Buchhandel zu identifizieren. Im Durchschnitt werden rund elf Bücher im Jahr gekauft. Legt man die Raster zur Kauf- bzw. Leseintensität an, schälen sich acht »Buchtypen« heraus:

- »Buchresistente«, die weder kaufen noch lesen; sie machen neun Prozent an der Bevölkerung aus.

- 36 Prozent sind der Gruppe der »Gelegenheitsleser« zuzuordnen. Sie kaufen keine Bücher.

- Buchkaufende »Nichtleser« hingegen kaufen Bücher, obwohl sie selbst nicht lesen. Sie machen zwei Prozent der Bevölkerung aus.

- »Wenignutzer« kaufen wenige Bücher und lesen aber auch wenig. Ihr Anteil liegt bei 16 Prozent.

- Drei Prozent der Bevölkerung sind der Gruppe der »Durchschnittsnutzer« zuzurechnen.

- Etwas mehr als ein Fünftel (21 Prozent) zählen zu den »ausleihenden Leseratten«: Sie lesen wesentlich mehr als sie selbst kaufen.

- »Kauffreudige Leseratten« sind die Wunschklientel der Branche - sie kaufen viel und lesen viel. Ihr Anteil an der Gesamtbevölkerung liegt bei fünf Prozent.

Die acht Buchtypen, also Personen mit unterschiedlich ausgeprägter Kauf- und Leseintensität, kommen in den sozialen Milieus unterschiedlich häufig vor. Kauffreudige Leseratten beispielsweise sind vor allem in den Sinus-Milieus der »Postmateriellen « und der »Konservativen « zu finden. Bücher sind Bestandteil ihrer Identität und gehören zum Alltag. In anderen Milieus hingegen ist die Lese- und Kaufaffinität geringer. Menschen, die diesen Lebenswelten angehören, greifen nur selten und bei spezifischen Themen zu Büchern. So bevorzugen beispielsweise »Konsum-Materialisten « leichte Unterhaltung, »Hedonisten« lesen dagegen gern Science-Fiction, Fantasy oder Bücher zur Subkultur (vor allem die Musik-Szene).

Bücherlesen wird ein abnehmender Anteil des Medienkonsums, der nach Daten des Statistischen Bundesamtes im Bundesdurchschnitt $2001 \mathrm{ca} .120 \mathrm{Mi}-$ nuten pro Tag betrug. Nach der Studie Massenkommunikation, im Auftrag von ARD und ZDF erstellt, stieg der Medienkonsum zwischen 2000 und 2005 um fast 90 Minuten auf zehn Stunden täglich. (Ridder/Engel 2005). Die hohen Zeiten sind nur erklärlich durch mitlaufenden Konsum, wenn z B. nebenbei der Radio dudelt. 
Abbildung 33: Medienkonsum in den alten Bundesländern 1977, 1992 und in Deutschland 2005. (Durchschnittliche Nutzungsdauer pro Tag in Minuten)

\begin{tabular}{|c|c|c|c|c|c|c|c|c|}
\hline Jahr & $\begin{array}{c}\text { Fern- } \\
\text { sehen }\end{array}$ & Hörfunk & $\begin{array}{c}\text { Tages- } \\
\text { zeitungen }\end{array}$ & Bücher & $\begin{array}{c}\text { Zeitschriften, } \\
\text { Illustrierte }\end{array}$ & $\begin{array}{c}\text { Schallplatten, } \\
\text { Tonband), } \\
\text { CD, MC } \\
\text { MP3-Player }\end{array}$ & $\begin{array}{c}\text { Wochen- } \\
\text { zeitung }\end{array}$ & Internet \\
\hline 1977 & 126 & 95 & 27 & 11 & 11 & 11 & & \\
\hline 1992 & 106 & 96 & 32 & 28 & 20 & 18 & 6 & \\
\hline 2005 & 220 & 221 & 28 & 25 & 12 & 45 & 15 & 44 \\
\hline
\end{tabular}

Die Ausweitung des Medienkonsums geht nach diesen Zahlen nicht auf Kosten der traditionellen Medien - Zeitungen und Bücher. Vielmehr findet insgesamt eine stärkere Verbreitung statt, bei der die »Neuen Medien« an Gewicht gewinnen. Aber nicht alle sind an dieser Expansion gleich beteiligt. Der Zugang ist sozial selektiv. Das Problem des »digital divide« taucht seit Mitte der 199oerJahre in der öffentlichen Diskussion auf. Dabei handelt es sich um eine Aktualisierung der Hypothese einer Wissenskluft. »Medienkompetenz« tritt an die Stelle von »Lesefähigkeit«. »Digital divide« steht für das Problem beziehungsweise die Befürchtung, dass die Chancen auf den Zugang zum Internet und anderen (digitalen) Informations- und Kommunikationstechniken ungleich verteilt und stark von sozialen Faktoren abhängig seien und dass diese Unterschiede ihrerseits gesellschaftliche Auswirkungen haben: Wer Zugang zu modernen Kommunikationstechniken hat, hat bessere soziale und wirtschaftliche Entwicklungschancen.

Die soziale Selektivität und Ambivalenz der »Volksaufklärung« bis hin zum Medienkonsum ermöglichte ihre Indienstnahme für politische und soziale Interessen. Zunächst war es das liberale Bürgertum, das sich der Volksbildung zur Integration der Arbeiterschaft in den aufstrebenden Kapitalismus bediente.

Ins Zynische und Absurde verkehrt wurde der Gedanke der Volksaufklärung durch das nationalsozialistische »Reichsministerium für Volksaufklärung und Propaganda«: Bereits am 25. März 1933 erläuterte Joseph Goebbels vor Intendanten und Direktoren der Rundfunkgesellschaften die zukünftige Funktion des Propagandaministeriums, das Ministerium habe die Aufgabe, in Deutschland eine geistige Mobilmachung $\mathrm{zu}$ vollziehen. Es sei auf dem Gebiet des Geistes dasselbe, was das Wehrministerium auf dem Gebiet der Wache ist. Ziel sei die Wehrhaftmachung des Volkes. Dies wird im Einrichtungserlass festgelegt:

"Der Reichsminister für Volksaufklärung und Propaganda ist zuständig für alle Aufgaben der geistigen Einwirkung auf die Nation, der Werbung für Staat, Kultur und Wirtschaft, der Unterrichtung der in- und ausländischen Öffentlichkeit über sie und der Verwaltung aller diesen Zwecken dienenden Einrichtungen." (Verordnung über die Auf- 
gaben des Reichsministeriums für Volksaufklärung und Propaganda (30.06.1933) In: documentArchiv.de [Hg.], URL: www.documentArchiv.de/ns/propaganda_vo.html Zugriff 1.10.2010)

Schon Goebbels als Reichsminister bediente sich des Rundfunks und des Films, um die nationalsozialistische Ideologie unters Volk zu bringen. Die Massenmedien tragen bis heute an dieser Schuld. Sie sind wie gemacht als Sprachrohr des Führers. Aufklärung schlägt unter dem Druck der Massenhaftigkeit um in Verdummung und Verblödung. Der bürgerliche Salon endet in der Öffentlichkeit des Containers der big-brother-show.

Da wo Wissenschaft mit ins Spiel kommt, wird die Information über Fakten zur televisionären Rate-Show. Zusammenhangslose Einzelkenntnis spiegeln Aufklärung nur vor und ersetzen wissenschaftliche Grundbildung. Diese wäre im Prinzip möglich und kann durch das Internet gestützt werden. Die Wissenschaftssendungen im Fernsehen, werden zwar oft in Kooperation mit Experten und Instituten erstellt. Aber: lohnt sich das und hilft es?

Abbildung 34: Wissenschaftssendungen im Fernsehen (Stand 8/2010)

\begin{tabular}{|c|c|}
\hline Nano (3sat) & $\begin{array}{l}\text { Online-Auftritt der täglichen Wissenschafts } \\
\text { sendung auf 3sat }\end{array}$ \\
\hline Quarks \& Co (WRD) & $\begin{array}{l}\text { Rangar Yogeshwars Wissenschaftssendung } \\
\text { Abenteuer Erde (HR) }\end{array}$ \\
\hline Abenteuer Forschung (ZDF) & Wissenschaftssendung mit Joachim Bublath \\
\hline Abenteuer Wissen (ZDF) & Magazin mit Wolf v. Lojewski \\
\hline Kulturzeit (3sat) & Täglich Neues aus Kultur, Kunst und Literatur \\
\hline BR alpha & $\begin{array}{l}\text { Online-Angebot des Bildungskanals } \\
\text { des Bayrischen Rundfunks }\end{array}$ \\
\hline W wie Wissen (ARD) & Das Wissenschaftsmagazin der ARD \\
\hline Die Sendung mit der Maus (WDR) & Kindersendung über "Alltagsrätsel" \\
\hline Discovery-Channel \& ZDF & $\begin{array}{l}\text { Dokumentationen aus der Welt der Tiere, } \\
\text { aus Natur, Geschichte und Forschung }\end{array}$ \\
\hline Abenteuer Leben (Kabel 1) & $\begin{array}{l}\text { Online-Präsentation des Kabel 1-Magazins } \\
\text { über Gesellschaft und Wissenschaft }\end{array}$ \\
\hline Galileo (Pro7) & \\
\hline
\end{tabular}

Die Dominanz der Zuschauer-, Hörer- oder Leserquote als Regulativ der Unterhaltungsindustrie entzieht den Formaten systematisch ihre Qualität. Es wird produziert und präsentiert, was konsumiert wird - und umgekehrt. Eine Wissensshow, in der Wissen nur interessiert, weil es einen Geldgewinn verspricht, aber ist vulgär, wenn sie nur mit Informationsbrocken um sich wirft. Die Quizsendung »Wer wird Millionär?« erhielt den Deutschen Fernsehpreis 2006 in 
der Kategorie »Beste Unterhaltungssendung«. Für die etabliert Talkshow am Sonntagabend um 21:45 Uhr im Ersten Programm der ARD wird ein Sendungspreis von mehr als 240.000 Euro pro Sendung bzw. ein Minutenpreis von 4.000 Euro geschätzt. Sie pflegt wie kaum eine andere Sendung das Prominentenunwesen, bei dem Wichtigkeit Personen zugesprochen wird, die das Verdienst haben häufig aufzutreten oder genannt zu werden. Moderatoren und Talkmaster behandeln sich selbst als Prominente, über die dann in den Medien ihrerseits wieder berichtet wird. Die Quote setzt an bei den Ressentiments des Publikums. Die Medien vertiefen die Vorurteile, die beseitigt werden müssen, wenn nicht Aufklärung der Öffentlichkeit in Sicherung bestehender Verhältnisse und fortbestehender Herrschaft kippen soll. Statt Aufklärung wird dann Verdummung und Verblödung vorangetrieben.

\subsection{AufkLärung Und Bildung}

Leitvorstellung der Aufklärung war die Überzeugung, dass die Menschen und also ihre Verhältnisse untereinander veränderbar und deshalb auch durch rationale Erkenntnis und zu moralischem Urteil bildbar seien. Die Umsetzung dieser Überzeugung verwies auf die »Erziehung des Menschengeschlechts« und unterstellt Erziehbarkeit und Erziehungsbedürftigkeit der Menschen. Historischer Fortschritt wurde gekoppelt an individuelle wie kollektive Lernprozesse. Basierend auf dieser Grundhaltung entwarfen die »Menschenfreunde« das Erziehungsprogramm des Philanthropismus und setzten es in vielfältigen Erziehungsprojekten in der zweiten Hälfte des 18. Jahrhunderts um.

Überzeugt waren die Protagonisten dieser Bewegung (Basedow, Rochow, Campe, Salzmann, Stuve, Trapp, Villaume) und viele andere (vgl. Schmitt 2003, 119ff.) von der Vernünftigkeit des Menschen. Nach ihrer Grundhaltung war Menschenliebe die wichtigste Voraussetzung gelingender Erziehung.

Johann Bernhard Basedow, geboren 1724 in Hamburg, nannte sein Hauptwerk »Vorstellung an Menschenfreunde und vermögende Männer über Schulen, Studien und ihren Einfluß auf die öffentliche Wohlfahrt, mit einem Plane des Elementarbuchs der menschlichen Erkenntnis« (1768). Diese Gedanken versuchte er im »Philanthropin« zu verwirklichen, das 1774 mit Unterstützung des Fürsten von Dessau als Musterschule errichtet wurde. Nicht durch Belehren, Befehlen, Warnen oder Strafen entstehen "gute Gewohnheiten«, sondern durch Üben, Rat und Hilfe. Die Erziehungsziele sind berufliche und gesellschaftliche Brauchbarkeit, sie werden verfolgt durch Abhärtung, Ertüchtigung und Entfaltung.

Die Schranken der ständischen Gesellschaft allerdings werden höchstens ansatzweise in Frage gestellt. An die Stelle der Geburtsstände treten die Berufsstände. Der Mensch als Rad in der großen Maschine der Gesellschaft soll nicht 
vollkommener gemacht werden, als sein Stand es erlaubt. Die Verbesserung der individuellen Lebensumstände durch Reform der Erziehung wird als ein Weg zur Modernisierung im Rahmen der gesellschaftlichen Situation des Spätabsolutismus beschritten. Es »wird die Schwäche des deutschen Bürgers erkennbar; er weicht der Konfrontation mit der Macht aus« (Heydorn 1970, 18). Der Versuch ist kennzeichnend, Macht durch Bildung zu unterlaufen.

"Die Macht soll schließlich domestiziert werden, ohne dass sie es selbst bemerkt hätte, auch wird versucht, sie zu überreden, günstig zu stimmen, sie mit ihren angeblich wahren Interessen bekannt zu machen, ihr zu versichern, dass niemand daran denkt, ihr ernsthaft zu Leibe zu rücken." (Ebd. 60)

So wird erstens die Fiktion entwickelt, die Obrigkeit werde in Erkenntnis, dass die Vernunft das Wirtschaftswachstum fördere, sich selbst verändern; und zweitens dass die lange Linie des historischen Fortschritts dies im Selbstlauf unterstütze.

Basedow, Campe, Trapp, Stuve, Villaume u.a. waren von der Notwendigkeit einer Reform der spätabsolutistischen Territorialstaaten überzeugt. Sie hielten es aber für eine »sehr alberne Furcht, wenn man sich einbildet, der große Haufe der Menschen würde durch vernünftige Belehrung über seine Rechte und Pflichten unvernünftiger, bösartiger rebellischer usw« (Stuve 1791, zit. In: Schmitt 2003, 138). Sie stellten es zumindest so dar. Die sozialintegrative Funktion von Bildung wurde als Vorteil angepriesen: Aufklärung und Steigerung der Intelligenz und Moral des Volkes durch fortgesetzten Unterricht wurde geradezu als Gegengift gegen revolutionäre Ausbrüche angepriesen.

Nichtsdestoweniger wurde der sich politisierende Philanthropismus von den konservativen Gegnern der französischen Revolution zum Feind der staatlichen Ordnung stilisiert. Der Vorwurf wurde immer lauter, dass seine Anhänger alles, was mit Ordnung und Anstrengung verbunden sei, ablehnen. Man zeige den jungen Leuten die Natur, mache Reisen, schwätze überflüssiges Zeug und vertändele die Zeit.

Diese Einschätzung wurde besonders nach 1789 opportun und auch Vertreter des Neuhumanismus schlossen sich ihr an. Diese Grundhaltung zieht sich durch die Kritik an der Reformpädagogik bis heute. Der »Mut zur Erziehung«, »Lob der Disziplin« und andere Kampfschriften der autoritären Konservativen schöpfen aus der gleichen Quelle. Ihre gegenaufklärerischen Ursprünge verbergen sie.

Die Aufklärung war besonders in Deutschland durchdrungen von pädagogischen Impulsen. Sie setzte sich zunächst ab gegenüber politischen Aktivitäten. Die Obrigkeit galt als Garant der Ordnung. So kam es darauf an, durch evolutionäre Pädagogik eine politische Revolution zu verhindern. Die Entwicklung von Mündigkeit sollte gestützt werden durch eine aufgeklärte Obrigkeit. 
Bestandteil dieser Haltung war nichtsdestoweniger eine eindeutige Kritik kommunaler, politischer, sozialer und gesellschaftlicher Zustände und der damit einhergehende Wille zu einer besseren Gestaltung der kritisierten Wirklichkeit bei gleichzeitiger Ablehnung revolutionärer Tendenzen.

Bei kaum einem der deutschen Aufklärer ist diese Ausgangslage als Spannungsverhältnis so deutlich wie bei Joachim Heinrich Campe (1746-1818), dessen politische Positionen weit fortgeschritten waren (s.o. Teil 2.1) und der für die Bildung ebenfalls progressive Positionen bezog.

\section{Abbildung 35: Joachim Heinrich Campe}

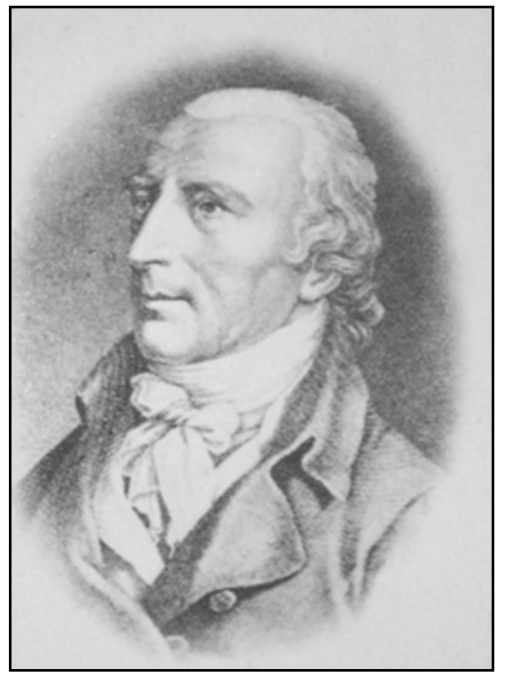

Geboren wurde Campe am 29.6.1746 in dem Dorf Deensen bei Holzminden/ Weser. Sein Vater war ein ortsansässiger Adliger, hatte jedoch auf seinen Titel verzichtet, als er eine bürgerliche Frau heiratete. Er bewirtschaftete einen Hof und betrieb gleichzeitig einen Handel mit Garn und Leinen. Johann Heinrich war das fünfte Kind von insgesamt acht Geschwistern.

Die Entfaltungsmöglichkeit aus der Familie war aufgrund von Geldmangel eingeschränkt. Nichtsdestoweniger wurde Johann Heinrich, besonders auf Drängen seiner Mutter Anna Margaretha, ein Studium ermöglicht.

Vierzehnjährig wurde er als Schüler auf das pietistische Gymnasium in Holzminden geschickt und wechselte 1765 zum Studium der evangelischen Theologie nach Helmstedt und weiter nach Halle. Während seiner Studienzeit setzt er sich mit dem Gedankengut der Aufklärungsepoche auseinander und wurde zu einem ihrer bedeutendsten Protagonisten und Kämpfer des aufgeklärten Bürgertums für Volksbildung.

Von 1769 bis 1776 war Campe Hauslehrer der Familie von Humboldt und übernahm die Erziehung von Alexander und Wilhelm. Er geriet in das Umfeld 
der Berliner Aufklärung und wurde zum Prediger an der Potsdamer Heiligen Geist Kirche. 1776 folgte er einem Ruf an das Philanthropin in Dessau als Lehrer und Leiter in der Nachfolge Basedows. Allerdings kündigte er nach kurzer Zeit auch dort und ging nach Hamburg.

Nach einem Intermezzo als leitender Lehrer am Philanthropin zu Dessau, der international gefeierten Modellschule der deutschen Aufklärung, gründete er ein eigenes Erziehungsinstitut in der Handels- und Hafenstadt Hamburg. Er knüpfte Kontakte zu den angesehenen und einflussreichen Hamburger Zirkeln der Aufklärungsgesellschaft. Mitte Oktober 1776 gelang ihm mit dem Jugendroman Robinson der Jüngere, 1779 im Selbstverlag veröffentlicht, der Durchbruch als pädagogischer Bestsellerautor. Der Selbstverlag legte die ökonomische Basis für einen beachtlichen Reichtum.

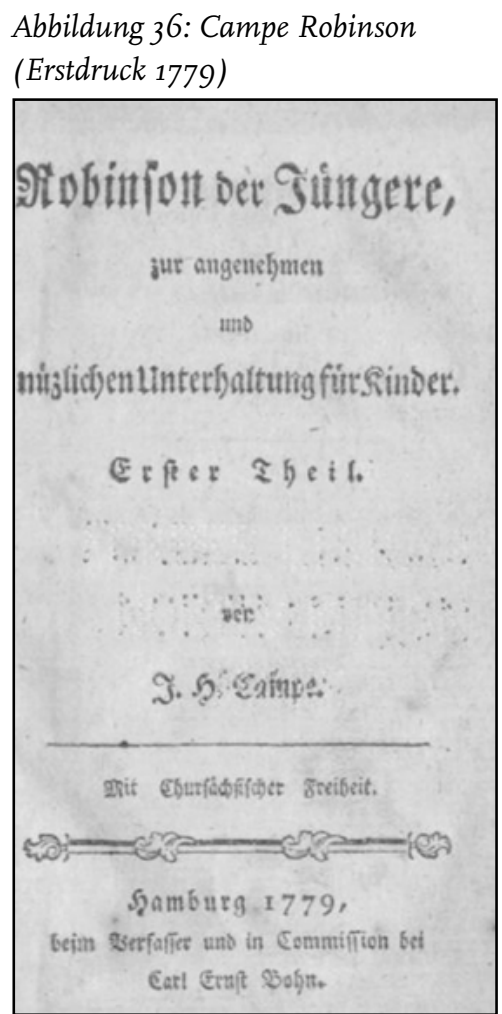

Im Frühjahr 1783 bezog Campe ein $20 \mathrm{~km}$ vor Hamburg gelegenes Landhaus. Dort entwickelte er den Plan einer »Allgemeinen Revision des gesamten Schulund Erziehungswesens«, dessen Beiträge zwischen 1785 und 1792 erschienen. Damit bekam er eine Schlüsselstellung in der spätaufklärerischen Erziehungsbewegung. Auf Einladung des Herzogs Karl Wilhelm Ferdinand von Braun- 
schweig-Wolfenbüttel erhielt er den Auftrag, dass theoretische Fundament für die Reform des Schulwesens im Herzogtum zu entwickeln. Noch im selben Jahr wechselte er in dessen Haupt- und Residenzstadt, um dort als »Edukationsrath « die Reform des Schulwesens voranzutreiben.

1786 verfasste er die pädagogisch-politische Streitschrift »Über einige verkannte, wenigstens ungenützte Mittel zur Beförderung der Industrie, der Bevölkerung und des öffentlichen Wohlstandes «. Diese Schrift enthielt eine umfassende Konzeption der Veränderung der Bildungswirklichkeit im Sinne der Aufklärung. Diese in Wolfenbüttel geschriebenen Fragmente entwickelten ein Programm zur »Umschaffung des Menschen« und somit der Gesellschaft im Ganzen.

Campe legte ein ganzes Strategiebündel vor, das von der Verwandlung der Volksschulen in Industrieschulen bis zur Erziehung der Töchter reichte:

Erstes Mittel: Verwandelung der Volksschulen in Industrieschulen

Zweites Mittel: Eine zweckmäßige Vorbereitung derer, welche bestimmt sind, Landprediger zu werden.

Drittes Mittel: Vollkommene und allgemeine Duldung.

Viertes Mittel: Kenntnis des menschlichen Herzens und Zuziehung solcher Personen, welche sich diese Kenntnis durch Philosophie und Menschenbeobachtung vorzüglich eigen gemacht haben.

Fünftes Mittel: Errichtung einer sich durchs ganze Land verbreitenden patriotischen Gesellschaft.

Sechstes Mittel: größere Sorgfalt von Seiten des Staats für die Erziehung der Töchter.

(Quelle: Campe, J. H.: Über einige verkannte wenigstens ungenützte Mittel Zur Beförderung der Indüstrie, der Bevölkerung und des öffentlichen Wohlstands. Wolfenbüttel 1786).

Campe setzte also auf eine Bildungsreform als Gesellschaftspolitik - allerdings unter der Obhut und Schirmherrschaft einer aufgeklärten Obrigkeit.

Die vorgeschlagenen Strategien zeigen aktuelle Tendenzen. Zum einen werden regionale Kooperationen als Grundlage wirtschaftlicher Entwicklung angesehen. Netzwerke von Unternehmen, Organisationen, Verbänden und staatlichen Einrichtungen sollen endogene Potentiale entfalten. So entstehen in den »Patriotischen Gesellschaften« »Lernende Regionen«, welche gemeinsame Initiativen entwickeln, um die Ökonomie voranzubringen.

Die Bildungsbemühungen Campes jedoch endeten zunächst in einer Niederlage. Er war der Bitte des Herzogs gefolgt und hatte die Leitung des Schuldirektoriums übernommen. Es wuchs allerdings der Widerstand der orthodoxen Geistlichkeit und der feudalen Stände. Durch seine Reise ins revolutionäre Paris und die auf großen Anklang stoßenden »Briefe aus Paris« wurde er zur Zielscheibe konservativer Kreise (s.o. Teil 2.1). Schon nach einem Jahr musste er die Tätigkeit im Schuldirektorium niederlegen und am 6. April 1790 erfolgte dessen Auflösung. 
Gleichzeitig wuchs Campes europaweiter Ruhm, weshalb er auch 1792 zum Ehrenbürger der französischen Republik ernannt wurde. Nach dem Scheitern seiner schulpolitischen Mission zog sich Campe auf seinen Landsitz nahe Braunschweig zurück, wo er am 22.10.1818 starb.

Der Umweg zur Befreiung über Bildung war ab 1789 blockiert. Die Gegenaufklärung konnte zurückgreifen auf die Ängste des Bürgertums und die Brutalität des wieder erstarkten Adels. Der Terror der Revolution wurde benutzt, um Unterdrückung neu zu rechtfertigen. Da wo Bildung sich anschickte, ihr Reservat zu verlassen, wurde sie instrumentalisiert und isoliert und zur Indoktrination gewendet. Vom Bildungsgedanken der Aufklärung blieb vor allem die Nützlichkeit, Mündigkeit wurde verschoben. In der Trennung zwischen allgemeiner und beruflicher Bildung hat der Neuhumanismus die Abspaltung curricular und institutionell befördert und verfestigt.

Damit generalisiert sich die Diskussion und bezieht sich auf die Frage nach der Tragfähigkeit des Begriffes Bildung überhaupt. Zuletzt ist auch der Bildungsbegriff immer wieder in Zweifel gezogen worden: Es handele sich um ein überhöhtes Postulat, welches die Lernwirklichkeit nicht erfasse; es handele sich um ein historisch überholtes Persönlichkeitsideal, das angesichts der gesellschaftlichen Strukturen obsolet sei.

Obwohl diese Kritik bedenkenswerte Momente enthält, rechtfertigt sie nicht den Verzicht auf den Bildungsbegriff als einer zentralen Kategorie, um sich angesichts der anstehenden Zukunftsaufgaben zu orientieren. Die Inhalte einer solchen Bildung bestimmen sich jedoch nicht aus einem zeitlosen Kanon, sondern historisch-konkret angesichts der sich gegenwärtig stellenden Probleme. Man kann - wie Wolfgang Klafki - die sich stellenden Perspektivfragen auch als »Schlüsselprobleme« von Bildung aufgliedern. Bildung heißt demnach, diejenige Kompetenz zu erwerben, um die Ursachen solcher für die weitere gesellschaftliche Entwicklung zentralen Probleme zu verstehen, die eigene Position dazu zu finden, entsprechende Entscheidungen treffen zu können und handelnd einwirken zu können. Bildung bleibt in diesem Sinn zentral als Selbstbestimmungs- und Mitbestimmungsfähigkeit. So ist Bildung immer Selbstentfaltung, aber immer auch schon in einer mit anderen geteilten Welt. »Aufklärung« und »Bildung« sind ein altes Ehepaar, die ohne einander nicht auskommen.

Die gemeinsame Vergangenheit wird aber immer wieder neu hinterfragt. Mit dem Stichwort »Lebenslanges Lernen« wird eine große Zukunft verkündet. Beim Nachdenken über die Diskrepanz zwischen Postulat und Realität stößt man auf einige immer wieder wiederholte Mythen - Wandelmetapher und Krisengerede, Wissensexplosion und Selbstorganisation, neue Lernkultur und Kompetenzentwicklung, Kooperationsverbünde und Kompetenznetze usw. - welche meist unbefragt als Hintergrundannahmen in die bildungspolitischen und wissenschaftlichen Diskussionen einfließen. Zwar werden »Weiter- 
bildung« und »Lebenslanges Lernen« hoch bewertet bei Jubiläen, Empfängen, Debatten, Diskussionen und in vielen Foren. Dabei klaffen aber Begründungslücken, wenn nach durch empirische Forschung erhärteten und durch theoretische Klärung fundierten Belegen gefragt wird.

Damit haben sich die Theorieprobleme jedoch eher noch potenziert. Die scheinbar neutrale, auf Kontinuität des Prozesses des Lernens während der gesamten individuellen Biographie betonenden Begrifflichkeit des »lebenslangen Lernens« erhält vielfältige Konnotationen.

Besonders Erwachsenenbildung erhält durch »lifelong learning « biographische Kontinuität über alle Phasen des Lebens und entgrenzt sich aus den traditionellen Institutionen. Schon der Begriff Weiterbildung, der in den 1970 er Jahren in Mode kam, deutete Unabgeschlossenheit in umfassenden Lernzusammenhängen an. Wenn es nicht um die Banalität gehen soll, dass wir nie auslernen, solange wir leben, ist ein Konzept der Aneignung und Vermittlung in intentionalen Lernprozessen verteilt über die Lebensphasen gemeint. »Lifelong learning « hat aber in der deutschen Fassung als »lebenslanges Lernen « einen negativen Mitklang - von »lebenslänglich « in einer Zwangsanstalt. Schon früh ist auf die Unentrinnbarkeit der »Lebenslänglichkeit«, aus der man nie entfliehen kann, und auf Anpassungstendenzen an eine unbegriffene Wandeldynamik hingewiesen worden. Und der Begriff Lernen bleibt inhaltsleer, wenn er sich der Tradition und Perspektive von »Bildung« verweigert. »Lebensbegleitend « klingt zu nebensächlich und könnte »sterbebegleitend « werden; »lebensumspannend « oder »lebensumfassend «, die ebenfalls als Stichwörter der Debatte auftauchen, haben fast totalitäre Konnotationen. Demgegenüber ist »lebensentfaltend « verbunden mit aktiver Gestaltung und Erweiterung der eigenen Horizonte und Handlungsmöglichkeiten. Vorzüge haben deshalb zum einen - weil aktiv - »lebensentfaltend «, zum anderen der zugegebenermaßen stark aufgeladene Begriff Bildung, So werden gegenüber ökonomischen und sozialen Anpassungszwängen personale Entfaltungsmöglichkeiten betont.

Der Begriff »Lebensentfaltende Bildung « liegt quer zum hegemonialen wissenschaftlichen und politischen Diskurs, in dem »Bildung « sowieso schlechte Karten hat und als überholtes und überzogenes Konzept dargestellt wird. Trotzdem erscheint eine solche Begriffsstrategie sinnvoll und begründbar, wenn sie die Konstitution ihrer Thematik interessenorientiert reflektiert.

Ausgehend von einer solchen Einordnung begründet Wissenschaft unterschiedliche Handlungsbezüge und Aufklärung gibt diesen ihre Begründung. Immer schon fließen in wissenschaftliche Gegenstandskonstitutionen Erkenntnisinteressen ein, welche ethisch reflektiert werden müssen, um standzuhalten. Dies erst liefert die moralische Legitimation unterschiedlicher Konzepte »lebenslangen Lernens «, die sich interessenbezogen unterscheiden im Spannungsfeld von Anpassung und Gestaltung als »lebensentfaltende Bildung «. 



\section{Perspektiven der Aufklärung}

Für die Zukunft von Wissen und Lernen wird es ausschlaggebend sein, ob Aufklärung als Prinzip reaktiviert und rehabilitiert und damit ein neuer Stellenwert von Wissenschaft initiiert werden kann. Dazu wird es nötig sein, Wissenschaft im »Lebenslangen Lernen« neu zu verankern, und Scheu vor »Popularität« ebenso aufzugeben wie destruktive Skepsis gegenüber »Bildung«. Dies wird ohne Beteiligung von Wissenschaft nicht möglich sein. Erst durch Konzepte und Strategien »öffentlicher Wissenschaft« kann die Selektivität der Bildungsteilhabe aufgehoben, und - wie einer demokratischen Gesellschaft angemessen - überwunden werden.

Das wissenschaftliche Wissen löst sich dann notwendig aus privater Vereinnahmung; es ist nicht mehr einzusperren in Eigentumsverhältnisse, welche kapitalistische Verwertung sichern.

Die Lesart der »Dialektik der Aufklärung«, welche die negative Seite des Umschlags in Unvernunft hervorhebt, muss gleichzeitig mit der positiven Möglichkeit des Progresses von Freiheit gesehen werden (3.1). Das Dreieck von Aufklärung, Bildung und Wissenschaft erhält dann eine neue, spannende, sicherlich auch weiterhin immer riskante Balance.

Immerhin gibt es Ansätze in der Diskussion um Erwachsenenbildung die fortgeführt werden können (3.2). Die ethische Dimension von Bildung als Urteilskraft setzt zugleich Kritik eines szientifischen Wissenschaftsverständnisses voraus. Dies problematisiert einen instrumentellen Begriff von Transfer, der auf einfache Weitergabe und Nützlichkeit abstellt. Reflexive Transferstrategien brauchen »Öffentliche Wissenschaft«, die ihre Konsequenzen mit bedenkt.

Erstaunlicherweise ist aller Schwarzseherei und Esoterik zum Trotz das Licht der Aufklärung nicht erloschen. Die Diskussion setzt sich fort (3.3).

\subsection{AufKLÄRUng Und Wissenschaft}

Widerstand gegen die zentralen Ideen der Aufklärung - Vernunft, Wahrheit und Öffentlichkeit - ist interessenpolitisch verständlich. Aufklärungsfeindschaft ist für die Herrschenden zugleich Verteidigung ihrer politischen, religiösen und 
ökonomischen Macht und damit ihrer Vorrechte. Gegen den Rationalismus der Aufklärung werden immer schon Irrationalismus, Hermetik, Obskurantismus bis zur Esoterik aktiviert.

Schon gegen Ende des 18. Jahrhunderts setzte der gegenaufklärerische Rückschlag mit aller Macht ein. Legitimationsquelle wurde der Schock durch die Erfahrung der französischen Umwälzung und besonders des terreurs in Paris sowie die Ausbreitung der Revolutionskriege auf deutschem Boden. Dies führte - bis auf wenige Ausnahmen wie z.B. Joachim Heinrich Campe und Georg Forster - zur Abwendung der deutschen Geistesgrößen der Klassik von Aufklärungsideen und Revolutionsneigungen - von Schillers Resignation und Rückzug in die Klassik bis zur Flucht in den Wahnsinn bei Friedrich Hölderlin. Angefangen mit den Romantikern begann eine kulturelle Reaktion, die bis heute fortdauert, in der Aufklärung schlecht gemacht, abgewertet und abgelehnt wird zugunsten einer gezielt gepflegten irrationalen Weltanschauung, die das Tiefe und Dunkle liebt. »Tief ist aber auch der Abgrund, in den man mangels Vernunft stürzt.« (Reed 2009, 17)

Francesco da Goya (1746-1828) hat in den Caprichios in Blatt 43 vor dem Schlaf der Vernunft gewarnt, der Ungeheuer gebiert. Der über seinem Arbeitstisch Eingeschlafene wird umkreist von den Geschöpfen der Dunkelheit: ein Luchs, Eulen, Vampire.

Abbildung 37: Francisco de Goya (1746-1828), Der Schlaf (Traum) der Vernunft bringt Ungeheuer hervor.

Aus: Los caprichos, Blatt 43, Radierung und Aquatinta

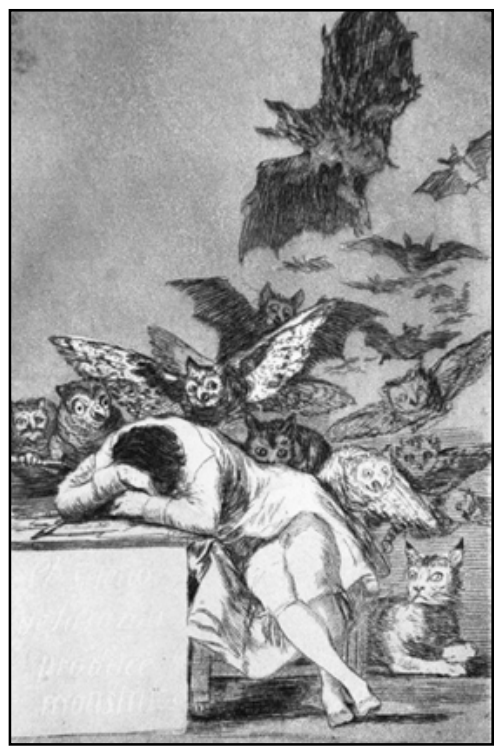


Vertreter eines reaktivierten orthodoxen Christentums übernahmen die führende Rolle. Besonders die Jesuiten standen zunächst an der Spitze einer religiös basierten Gegenaufklärung. In den in Augsburg ab 1787 erscheinenden »Gesammelten Schriften unserer Zeit zur Verteidigung der Religion und Wahrheit« (zit. Borgstedt 2004, 96) z.B. wurden den katholischen Geistlichen Predigtmaterialien zur Verfügung gestellt, die gegenaufklärerische Glaubenssätze aufbereiteten.

Halbierte Aufklärung, die zum Vernunftglauben sich übersteigerte, öffnete das Einfallstor für eine philosophische Aufklärungskritik, welche die Beschränkungen der Rationalitätsbewegung aufdeckte. Der Deutsche Idealismus überschritt, was Max Horkheimer später als »instrumentelle Vernunft« kritisierte (Horkheimer 1937), verlor aber zugleich seine gesellschaftliche Gründung.

Unbezweifelbar ist auch, dass im Kern der Aufklärung Wurzeln für Obskurantismus und Skurrilität mit angelegt waren. Die Geheimgesellschaften des 18. Jahrhundert von den Freimaurern bis zu den Rosenkreuzern pflegten Rituale und entwickelten Aktivitäten, welche gegenaufklärerischen Strategien und Positionen willkommenen Anlass zu Verleumdung und Verfolgung lieferten. Eine allzu platte Aufklärung und ihre Ordentlichkeit bis zur Dummheit trieben unruhige Geister immer wieder in eine Frontstellung, welche die scheinbare Klarheit und Vernünftigkeit ersetzte durch Idealismus und Romantik.

Ein Höhepunkt der Kritik ist zweifellos die »Dialektik der Aufklärung« (1944; deutsche Neuausgabe 1969). Im Exil - Los Angeles, California, Mai 1944 - haben Max Horkheimer und Theodor W. Adorno eine zutiefst pessimistische Perspektive der »Entwicklung zur totalen Integration« vorgelegt.

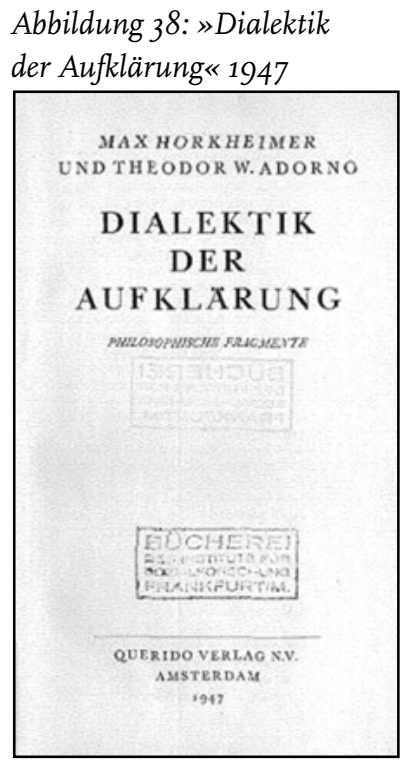


Jan Philipp Reemtsma sieht darin den zentralen verbindenden Text der »Kritischen Theorie«, der bei allen ihren Vertretern Zustimmung oder auch Ablehnung erzeugt hat (Reemtsma 2009). Die Verbindung von Wissenschafts- und Gesellschaftskritik wird zugespitzt nach der Erfahrung von Nationalsozialismus, Stalinismus und US-Kapitalismus. Kern der Reflexion ist eine »Kritik der instrumentellen Vernunft«, welche in der Geschichte immer nur beschränkten egoistischen Zwecken gedient hat. Technische Rationalität einer immer effizienteren Ausbeutung der Natur und des Menschen ist irrational bezogen auf die Gesamtheit von Natur und hat einen Grad erreicht, der das weitere Leben der Gattung selbst bedroht. Hauptproblem ist die »Selbstzerstörung der Aufklärung«.

"Was wir uns vorgesetzt hatten, war tatsächlich nicht weniger als die Erkenntnis, warum die Menschheit, anstatt in einen wahrhaft menschlichen Zustand einzutreten, in eine neue Art von Barbarei versinkt. [...] Hatten wir [...] seit vielen Jahren bemerkt, daß im modernen Wissenschaftsbetrieb die großen Erfindungen mit wachsendem Zerfall theoretischer Bildung bezahlt werden," indem "die Öffentlichkeit einen Zustand erreicht hat, in dem unentrinnbar der Gedanke zur Ware und die Sprache zur deren Anpreisung wird" in einer "selbstvergessenen Instrumentalisierung der Wissenschaft" (Horkheimer/Adorno 1969, 1-2).

Zwar wird der Stellenwert der Aufklärung als Grundlage der Befreiung aus Aberglaube und Herrschaft betont. Zugleich aber wird der Umschlag ins Negative von Unterdrückung und Entfremdung an die Wand gemalt:

"Wir hegen keinen Zweifel - und darin liegt unsere petitio principii -, daß die Freiheit in der Gesellschaft vom aufklärenden Denken unabtrennbar ist. Jedoch glauben wir, genauso deutlich erkannt zu haben, daß der Begriff eben dieses Denkens, nicht weniger als die konkreten historischen Formen, die Institutionen der Gesellschaft, in der es verflochten ist, schon den Keim zu jenem Rückschritt enthalten, der heute überall sich ereignet.." (Ebd. 1969, 3)

Und dann im ersten Satz des ersten Hauptteils:

"Seit je hat Aufklärung im umfassendsten Sinn fortschreitenden Denkens das Ziel verfolgt, von den Menschen die Furcht zu nehmen und sie als Herren einzusetzen. Aber die vollends aufgeklärte Erde strahlt im Zeichen triumphalen Unheils." (Ebd. 9)

Sie warnen eindringlich vor einer »Selbstzerstörung der Aufklärung«; unterhalb der kritischen Analyse herrscht unüberhörbar eine resignative Tendenz, indem die Möglichkeit totaler Manipulation durch die »Kulturindustrie« als real unterstellt wird. »Bildung « und »Wissenschaft« treten auseinander, der Instrumentalisierung von Wissenschaft entspricht der Zerfall von Bildung. 
"Auf dem Weg zur neuzeitlichen Wissenschaft leisten die Menschen auf Sinn Verzicht. Sie ersetzen den Begriff durch die Formel, Ursache durch Regel und Wahrscheinlichkeit." (Ebd. 11)

Eine so immens abstrakte Kritik entzieht sich der Auseinandersetzung mit den vielfältigen, widersprüchlichen konkreten Aspekten von Wissenschaftsentwicklung. Direkte Antworten auf Sinnfragen sind von Wissenschaft nicht zu erwarten, aber sie bleiben gefragt. Und auch Fragen, die unbeantwortbar sind, stellen sich trotzdem.

Was bei Horkheimer/Adorno unbefriedigt bleibt, ist die hartnäckige Suche nach Handlungsmöglichkeiten angesichts steigender Verwissenschaftlichung der Lebenswelt. Unbestreitbar gibt es eine Zurückdrängung der Erfahrung zugunsten wissenschaftlichen Wissens. Gesellschaftliche Praxis wird zunehmend in den Kategorien der institutionalisierten Wissenschaft perzipiert. Desto dringlicher stellt sich das Problem der Vermittlung.

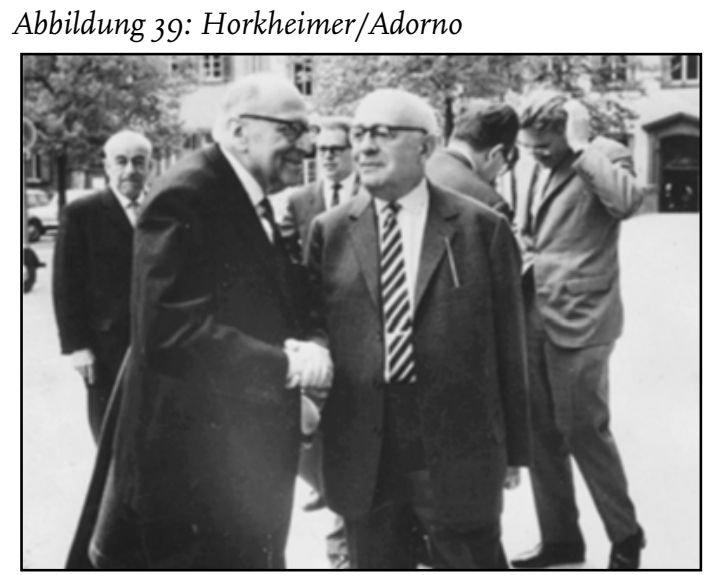

In seinem späten Aufsatz »Was ist Aufklärung?« (Foucault zuerst 1984, dt. 1990) nimmt Michel Foucault die Frage der »Berliner Monatschrift« nach 200 Jahren wieder auf. Er teilt mit Horkheimer/Adorno die Intention einer radikalen Kritik der Vernunft. Allerdings geht er noch weiter, indem er auch in deren Position die tendenziell totalitäre Macht der Kritik spürt. Das Umschlagen der Aufklärung in Verfinsterung bleibt immer noch in der Tradition der großen Erzählungen.

Demgegenüber plädiert Foucault dafür, die Genealogie des Wissens aus dem Kontext des Fortschrittsgedanken zu lösen und stattdessen ein antiteleologisches Denken zu aktivieren. Das Fortschreiten der Aufklärung von Unwissenheit zu Erkenntnis, vom Glauben zur Wissenschaft, vom Irrtum zur Vernunft erscheint ihm als einlinig. Stattdessen käme es darauf an, den vielfältigen 
und grenzenlosen Streit »der Wissen« untereinander wahrzunehmen und zuzulassen.

Zugleich optiert Foucault dafür, Aufklärung umfassender zu begreifen und sie abzulösen von angeblich ansteigendem Humanismus, da diese »Thematik in sich selbst zu elastisch, zu verschiedenartig und $\mathrm{zu}$ inkonsistent ist, um als Reflexionsachse dienen zu können« (ebd. 47). Allerdings geht es ihm nicht um ein »Verhalten der Ablehnung « (ebd. 48), sondern um ein geändertes philosophisches Ethos als »Grenzhaltung« (ebd.). Wenn »Kritik nicht länger als Suche nach formalen Strukturen mit universaler Geltung geübt wird, sondern eher als historische Untersuchung der Ereignisse « geht die historisch-kritische Haltung in eine »experimentelle« (ebd. 49) über. Foucault zieht »partielle Transformationen«, »die im Verhältnis von historischer Analyse und praktischer Haltung gemacht wurden, den Versprechungen eines neuen Menschen vor, die die schlechtesten politischen Systeme während des 20. Jahrhunderts wiederholt haben« (ebd. 50). Foucault holt dies aus Beliebigkeit zurück, weil sich die Perspektive nicht in Zufälligkeit und Unordnung verlaufen dürfe.

\section{Abbildung 40: Michel Foucault}

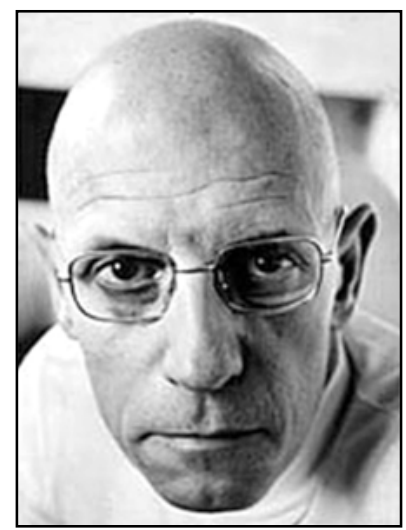

Damit sind wir aber wieder bei Kant, der den Prozessaspekt der Aufklärung betont hat. Foucault unterstreicht: »Ich weiß nicht, ob wir jemals mündig werden.« (Ebd. 52) Aufklärung bedeutet dann auch für ihn die kritische Befragung der Gegenwart.

"Ich weiß nicht, ob man heute sagen soll, dass die kritische Aufgabe immer noch den Glauben an die Aufklärung einschließt; ich denke jedenfalls, dass diese Aufgabe eine Arbeit an unseren Grenzen erfordert, das heißt eine geduldige Arbeit, die der Ungeduld der Freiheit Gestalt gibt.“ (Ebd. 53) 
Freiheit als Perspektive wissenschaftlicher Arbeit steht der Tendenz szientifischer Wissenschaft zur Instrumentalität für die Interessen von Herrschaft diametral entgegen. Wo Wissenschaft um ihr befreiendes Potential zu entfalten relative Autonomie braucht, erschwert dies den direkten Transfer in Technologie. Die negativen Konsequenzen instrumenteller Technologie für zukunftsfähige Ökologie und langfristig nachhaltige Ökonomie können an einer Vielzahl von Beispielen belegt werden. Wasserverschmutzung und Waldsterben, Vernichtungswaffen und Kriegsfolgen, Erwerbslosigkeit und Entfremdung usw. all dies kann einer entgrenzten unverantwortlichen Wissenschaft angelastet werden.

Es wäre aber fatal, das alles einer wissenschaftsethisch reflektierten Aufklärungsidee zu unterstellen. Schon beginnend bei Thomasius und entfaltet bei Kant haben die Philosophen der Aufklärung die moralische Verpflichtung wissenschaftlichen Forschens betont: bei Kant in der Formel geronnen, dass der Mensch der wichtigste Wert sei und durch keinen Preis zu bezahlen.

Gleichzeitig ist klar, dass viele der Lebensumstände - des Gesundheitswesens, des Wohnens, der Kommunikationschancen usw. -, die uns unverzichtbar erscheinen, nicht möglich wären ohne Wissenschaft. Besonders die Umsetzung der erfahrungsbezogenen Naturwissenschaften in technologisches Wissen hat dazu beigetragen. Ein gesellschaftlich reflektierter Wissenschaftstransfer bleibt daher unabdingbare Voraussetzung zivilisatorischen Fortschritts. Auch wenn uns das Wort Fortschritt manchmal im Hals stecken bleibt angesichts von nicht intendierten Konsequenzen und »Kollateralschäden«, leben wir doch angenehmer als alle Generationen zuvor - jedenfalls soweit es die materiellen Chancen betrifft. Und die sollte man nicht hochmütig zu gering schätzen.

\subsection{AufkLärung Und Erwachsenenbildung}

Aufklärung und Bildung haben es schwer: »Aufklärung« erhielt in Deutschland schnell einen Mitklang von Seichtheit, platter Verständlichkeit und billiger Volkstümlichkeit, also angeblich mangelnder Tiefe, Verlust von Dunkelheit und Verzicht auf Besonderheit. Die Gegenaufklärung hatte Erfolgt. Klassik und Romantik haben dazu beigetragen. Im 19. Jahrhundert setzte sich gegen die aufflammenden revolutionären Aktivitäten ein stark gewordener Konservatismus durch.

»Bildung« war dagegen lange der wichtigste Hochwertbegriff des deutschen Bürgertums. In der Gymnasiallehrerform des Neuhumanismus wurde »Bildung « zum Selbstverständniskern. Da man auf politische Partizipation verzichtete, rettete man sich ins exklusiv Private der Innerlichkeit.

Mittlerweile hat die Begriffszersetzung auch »Bildung« erreicht. Der Begriff Bildung scheint von Überalterung und Auszehrung bedroht, er wird nur noch als »Container-Wort« (Lenzen 1997) oder »Substrat-Kategorie« (Tenorth 
1997) angesehen. Es wird nahegelegt, auf den Bildungsbegriff in der wissenschaftlichen Diskussion zu verzichten. Darüber hinaus besteht der Verdacht, über die Möglichkeit von »Bildung « hartnäckig weiter nachzudenken, erzeuge Illusionen angesichts einer Lage, die gleichzeitig gekennzeichnet ist durch sich globalisierenden Kapitalismus, der regionale Kulturen aufsaugt, und sich fragmentierender Individualität, in der Identität zerstiebt. Damit würde das Dreiecksverhältnis von Aufklärung, Bildung und Wissenschaft aufgelöst.

Für die über Kinder- und Jugenderziehung hinausgehende lebensentfaltende Bildung gibt es keine umfassende Aufarbeitung ihres Verhältnisses zur Wissenschaft und zur Aufklärung. Walter Götze hat in seiner 1932 erschienen Schrift die »Wurzeln der Erwachsenenbildung in der Aufklärung« aufgespürt. Nach 1945 gibt es nur wenige Protagonisten der Ideen der Aufklärung in der Diskussion über Erwachsenenbildung und »Lebenslanges Lernen«. Zu ihnen gehören in der Bundesrepublik Deutschland Willy Strzelewicz und Kurt Meissner.

Einer, der sich lebenslänglich dem gegenaufklärerischen Trend entgegengestellt hat, war Willy Strzelewicz (23.10.1905-25.10.1986). Hans Tietgens hat seinen Festvortrag zum 8०. Geburtstag überschrieben: »Ein Leben für die Aufklärung.« Der wichtigste Beitrag von Willy Strzelewicz selbst zur wissenschaftlichen Diskussion war »Bildung und gesellschaftliches Bewusstsein « (zusammen mit Hans-Dietrich Raapke und Wolfgang Schulenberg 1966). Er hält fest an den Leitlinien: Aufklärung und Bildung.

Willy Strzelewicz war einer der Gründerväter der wissenschaftlichen Weiterbildung in der Bundesrepublik Deutschland und Beispielgeber sozialen Engagements in der Erwachsenenbildung (vgl. zum Folgenden: Faulstich/Zeuner 2001, 170-192). Orientiert an aufgeklärten und engagierten Positionen hat er in einem Interview kurz vor seinem Tod seine Geburt im Koordinatenkreuz des aktuellen Parteienspektrums verortet: »Ich bin 1905 in ein saftig grünes und purpurrotes Elternhaus hineingeboren.« (zit. in Hering 1992, 60)

Kern seiner politischen, beruflichen und persönlichen Identität sind die Forderungen der Menschenrechte und die Gedanken der Aufklärung. Diese liefern Leitlinien für seine Jugend, über die Flucht nach Schweden und die Emigration bis zu seinem Wirken in der Erwachsenenbildung in der Bundesrepublik Deutschland.

Geboren wurde Willy Strzelewicz am 23. Oktober 1905 in Berlin-Pankow. Noch als Gymnasiast wurde er Mitglied und Funktionär des kommunistischen Jugendverbandes. Er begann 1926 in Dresden Philosophie, Soziologie und Psychologie zu studieren u.a. bei Paul Tillich. Gleichzeitig war er Vorsitzender des sozialistischen Studentenbundes und gehörte zur Reichsleitung der kommunistischen Studentenfraktion. 1931 promovierte Strzelewicz bei Horkheimer und Tillich an der Frankfurter Universität mit einer Dissertation über »Die Grenzen der Wissenschaft bei Max Weber« (Strzelewicz 1931). Nach der Promotion ging 
er nach Berlin, wo er u.a. als wissenschaftlicher Mitarbeiter für das Frankfurter Institut für Sozialforschung an vorbereiteten Arbeiten für den später erschienenen Band »Autorität und Familie« beteiligt war. Vor den auf die Machtübergabe an Hitler folgenden Verfolgungen und Verhaftungen floh Strzelewicz im Mai 1933 als politischer Emigrant nach Prag. Unter dem Eindruck der von Stalin veranlassten Moskauer Schauprozesse veröffentlichte er eine kleine Schrift »Urrecht gegen Unrecht « (Prag 1937), in der er offen mit der kommunistischen Partei brach. So zwischen alle Stühle geraten flüchtete Strzelewicz weiter über Polen, Lettland, Estland, Island, Norwegen bis er im April 1940 nach Schweden kam. Dieses Land wurde in den nächsten 15 Jahren zu seiner zweiten Heimat. Er trat eine staatlich subventionierte Archivarbeitsstelle vom »Institut för Folklifsvorsknine« (Volkskundeinstitut) an. Ende 1943 veröffentlichte er das Werk »Kampf um die Menschenrechte«, das auf Vermittlung Herbert Wehners nach dem Krieg auch auf Deutsch erschien (Hamburg 1947). Es dauerte aber bis 1954, bis der Referent für Erwachsenenbildung im niedersächsischen Kultusministerium Heiner Lotze ihn fragte, ob er verantwortlich den Aufbau der universitären Weiterbildung an der Göttinger Universität übernehmen wolle.

Strzelewicz trat im Mai 1955 die Stelle als Leiter der »Arbeitsstelle für auswärtige Seminarkurse « an, die nach dem Vorbild der extra-mural-Aktivitäten englischer Universitäten aufgebaut wurde. Es entstand damit für die Bundesrepublik Deutschland die »Urform« der universitären Beteiligung an der Weiterbildung: die Seminarkurse. Diese Entwicklung blieb nachhaltig - auch nachdem Strzelewicz bereits im Jahr 1957 die Leitung der Pädagogischen Arbeitsstelle (PAS) des Deutschen Volkshochschulverbandes übernommen hatte. Auch dort hat er die grundlegenden Entwicklungslinien für die weitere Arbeit dieser Institution seit 1994 Deutsches Institut für Erwachsenenbildung (DIE) - gelegt. Dies blieb nur eine kurze Etappe, da Strzelewicz im Dezember 1960 eine Professur für Soziologie an der pädagogischen Hochschule Hannover erhielt.

Aus dieser Zeit stammt die mehrstufige soziologische Studie »Bildung und gesellschaftliches Bewußtsein«, die er gemeinsam mit Hans-Dietrich Raapke und Wolfgang Schulenberg erarbeitete. Die »Göttinger Studie« gilt immer noch als »Leitprojekt« der deutschen Erwachsenenbildung. Das Verständnis von Erwachsenenbildung, das Strzelewicz zunehmend für sich klärte, steht in der Spannung zwischen Industrialisierung und Demokratisierung. Die Erfahrungen im Exil haben ihn sensibilisiert für gegenaufklärerische, irrationalistische und romantisierende Strömungen. Aus diesen Herausforderungen folgen für Strzelewicz vier Aufgaben der Erwachsenenbildung - vorgetragen am 27. September 1986 zum 40 Jahrestag der Heimvolkshochschule Göhrde, wenige Tage vor seinem Tod: 
"1. Die Erwachsenenbildung ist ein Forum für alle, die Ängste, Sorgen und Nöte haben, die Einwände haben und Widersprüche, sich zu äußern und zu artikulieren. Denn ohne diese Artikulationsfreiheit würde es nie eine Verständigung unter den Menschen geben. Ich meine nicht unbedingt Einigung, aber Verständigung, was die Probleme bedeuten und wie man mit innen fertig wird.

2. Erwachsenenbildung ist ein Informationszentrum, aus dem die Menschen, die besorgt sind, ihre Ängste haben oder wissen möchten, was vor sich geht, Informationen abrufen können und erhalten.

3. Die Erwachsenenbildung ist eine Lerneinrichtung, um die Probleme verarbeiten zu können, um mit den Problemen der Orientierung individuell und sozial überhaupt fertig werden zu können.

4. Schließlich ist die Erwachsenenbildung auch in der Art ihrer Organisation eine Frühwarneinrichtung, wie ich es nennen möchte. Sie ist für alle Gruppen der Bevölkerung, die an sie herankommen können und ihre Sorgen und Nöte vortragen können, so etwas wie ein seismographisches Instrument, um beizeiten zu erfahren, was in der Bevölkerung vor sich geht, welche Sorgen sie hat, - rein persönlicher Art, aber auch in Verbindung mit sozialen, ökonomischen und industriellen technischen Vorgängen." (1986 (a) 12)

Es geht Strzelewicz um die Verwirklichung der Bedingungen eines hohen Anspruchs der Erwachsenenbildung, »nämlich im Lichte der Aufklärung, der Menschenrechtsidee mitzuhelfen, daß Verständigung unter den Menschen möglich wird und die Bewältigung der Probleme im Rahmen demokratischer Verhaltensweisen erhalten bleibt« (ebd. 17).

Am 25. Oktober 1986, zwei Tage nach seinem 81. Geburtstag, ist Willy Strzelewicz während einer Podiumsdiskussion über die Problematik der Menschenrechte in Hannover nach einer Reihe von Diskussionsimpulsen auf seinem Platz zusammengesunken und gestorben.

Strzelewicz nimmt in seiner Bildungskonzeption explizit Rückbezug auf die Aufklärungsidee:

"Einer der entscheidenden Ausgangspunkte für unsere Bildungsentwicklung und für die Erwachsenenbildung ist die Aufklärung. Die Aufklärung ist eine große und breite Strömung mit sehr verschiedenen Richtungen in verschiedenen Ländern und in verschiedene Schichten." (1986 (a), 7)

Zwar kann man heute viele der Fortschrittshoffnungen der Aufklärung nicht mehr ungebrochen festhalten, nichtsdestoweniger wirkt die Idee fort:

"Aber zwei Dinge sind noch heute lebendig, bis in unsere Tage hinein. Das sind spezifische Produkte der Aufklärung. Das eine geschichtsmächtigste Dokument ist die Erklärung der Menschenrechte von 1776." (Ebd.) 
Die Völkerrechts- und Menschenrechtsbewegungen in allen Kontinenten sieht Strzelewicz in der Tradition der Humanitätsidee als eine spezifische Leistung der Aufklärung.

"Die Idee der Menschenrechte steht im engsten Zusammenhang mit einem anderen Dokument, das von dem deutschen Philosophen Kant stammt. Aufklärung ist der Ausgang aus der selbstverschuldeten Unmündigkeit des Menschen. Und dieser Ausgang bedeutet, das jeder lerne, seinen Verstand ohne Anleitung anderer zu gebrauchen und Mut bekommt, sich seines Verstandes ohne Anleitung anderer Autoritäten zu bedienen." (Ebd. 8)

In der Verbindung von Aufklärungskonzeption und Menschenrechtscharta betont Strzelewicz ein Fortwirken einer Humanitätsidee, »die bis zum heutigen Tage gilt und für die Erwachsenenbildung maßgebend ist in dem Zusammenhang, in dem sie sich augenblicklich befindet« (ebd.).

Diese Resistenz ist keineswegs selbstverständlich. Die Vorstellung, die Aufklärung sei einseitig rationalistisch, abstrakt, ahistorisch und areligiös, der Staat dieser Zeit eine seelenlose Maschine, die Kirche erstarrt, die Dichtung bloß lehrhaft gewesen, ist lange vertreten worden und vorherrschend. Strzelewicz nennt dies die »deutsche Ambivalenz zwischen Aufklärung und Romantik « und kritisiert eine »verklärte, individuelle Innerlichkeit mit traumhaften Zügen frühkindlicher Glücksehnsüchte« (1986 (c) 22, 23). Ein revidiertes Verständnis der Aufklärung setzt also eine Kritik der Romantik und ihrer Folgen voraus.

Das »Eigentliche« der Erwachsenenbildung wurde im Konservativismus der »Neuen Richtung« jenseits von Aufklärung gesucht. Auch die »Alltagswende« betonte die lebensweltlichen und sinnlichen Seiten des Lernens. Aber erstaunlicherweise kommt spätestens mit der Diskussion um die »Wissensgesellschaft« das alte Problem des Umgangs der Erwachsenenbildung mit wissenschaftlichem Wissen wieder. Strzelewicz hat dies in seiner Tätigkeit als Leiter der Göttinger »Zentralstelle für auswärtige Seminarkurse« tatkräftig umgesetzt. Die Seminarkurse waren die erste Form des Wissenschaftstransfers. Allerdings sind »Aufklärung« und Transferstrategien wissenschaftlichen Wissens nicht mehr denkbar in einem Kaskadenmodell, in dem das Wissen herabfließt vom forschenden Experten zum staunenden Publikum. Vielmehr ist der Umgang mit wissenschaftlichem Wissen ein Prozess aktiver Aneignung.

Will man gegen eine fast schon hegemonial gewordene Destruktion des Bildungsdenkens den Mund aufmachen, ohne sofort als hoffnungslos antiquiert zu erscheinen, geht dies trotz alledem nur durch Rückbezug auf die historische Tradition des Begriffes Bildung und im Verhältnis zur Aufklärung. Dazu braucht man einige Hartnäckigkeit wie z.B. Willy Strzelewicz: 
"Aber etwas hat die Zeit überdauert und ragt in unsere Welt noch hinein. [...] in einer Nußschale das, was die Bildungskonzeption der Aufklärung war: Bildung und Lernen als Aufklärung, aber in Verbindung mit praktischer sozialer und politischer Reform." (Strzelewicz 1986 (a), 6/7)

Dies gilt auch nach dem Zerfall vielfältiger Illusionen. Gerade angesichts der drohenden Hegemonie neoliberalistischer Gesellschaftsvorstellungen steckt in der Tradition des Begriffs Bildung noch das kritische Potential im Sinne von Willy Strzelewicz, »nämlich im Lichte der Aufklärung, der Menschenrechtsidee mitzuhelfen, dass Verständigung unter den Menschen möglich wird und die Bewältigung der Probleme im Rahmen demokratischer Verhaltensweisen erhalten bleibt« (ebd. 17).

Ein weiterer der wenigen Protagonisten der Erwachsenenbildung, die nach 1945 an die Aufklärung anknüpften, war Kurt Meissner (1925-2003). Wenn man über Meissner spricht, redet man über weiterwirkende Impulse für die Erwachsenenbildung in einem Zeitraum von über 50 Jahren. Sowohl durch seine Funktionen in der Leitung von Einrichtungen der Erwachsenenbildung, beim Deutschen Volkshochschulverband, für Arbeit und Leben und im Zusammenhang des Adolf-Grimme-Instituts, als auch durch die permanente theoretische Reflexion der eigenen Tätigkeiten hat er immer wieder neue Anstöße gegeben, vielfältige institutionelle und politische Konsequenzen erzeugt und Diskussionen angeregt. Gerade durch seine über 22 Jahre dauernde Tätigkeit als Leiter der Hamburger Volkshochschule ist er nicht nur regional bedeutsam.

Kurt Meissner wurde 1925 in Kiel geboren. Dort lebte er 30 Jahre und sammelte erste Erfahrungen in der Erwachsenenbildung. Nach 1945 studierte er in Kiel unter anderem bei Fritz Blättner, der ihm riet, den Weg in die Erwachsenenbildung einzuschlagen. Kontakte ergaben sich über das Seminar für Erwachsenenbildung an der Universität Kiel, das 1949/50 eingerichtet worden war und später zu einer festen Einrichtung wurde. Neben Pädagogik, Philosophie und Psychologie studierte Meissner auch Soziologie und Kunstgeschichte. Man spürt die Breite des Engagements.

Der Kontakt zu Blättner, der bereits 1945 die Volkshochschule Kiel im Rathaussaal eröffnet und 1946 in Großbritannien Einrichtungen der Erwachsenenbildung kennen gelernt hatte, bestimmte zunächst Meissners beruflichen Weg. Er wurde Leiter der Laienspielgruppe an der Kieler Volkshochschule. Auch das Thema seiner Dissertation entwickelte er in diesem Zusammenhang. Die Arbeit beschäftigte sich mit dem Laienspiel, mit dessen Geschichte in der Jugendbewegung und mit seiner Theorie.

Seine erste feste Einstellung erhielt Meissner in der Erwachsenenbildung als Lehrer an der Heimvolkshochschule in Leck im Jahr 1950. Diese Heimvolkshochschule war eine typische ländliche und vom dänischen Modell beeinflusste Einrichtung. Meissner wurde Dozent in den Fächern Geschichte, Heimat- 
geschichte und deutsche Sprache. Teilnehmende waren hauptsächlich junge Männer im Alter von 18 bis 35 aus der Landbevölkerung. Beeinflusst wurde die Bildungsarbeit vor allem durch die Ideen Grundvigs.

1955 wechselte auf die Stelle des Leiters der Heimvolkshochschule Rendsburg, damals die größte und in vieler Hinsicht modellhafte Heimvolksschule in der Bundesrepublik Deutschland. Er führte diese Heimvolkshochschule von 1955 bis 1967, also zwölf Jahre lang. Dabei hat er die Entwicklung der Heimvolkshochschulen als Modell der Erwachsenenbildung wesentlich geprägt. In Rendsburg wurden Männer und Frauen in Sommer- und Winterlehrgängen zusammen unterrichtet. Im Zentrum standen Grundlehrgänge, welche Wissen über Zusammenhänge der Wirtschaft, Politik, Zeitgeschichte und Geschichte vermitteln sollten. Unterrichtet wurde auch Kunst und Literatur. Einbezogen waren musische Aktivitäten. Reflektiert hat Meissner diese Tätigkeit im »Versuch über die Heimvolkshochschule Rendsburg« (1967). Initiiert wurden auch zahlreiche Auslandskontakte, besonders zu den skandinavischen Ländern. Ausländische Teilnehmer der Kurse in Rendsburg kamen aus Schweden, Finnland, Dänemark, sowie aus England, Holland und Frankreich - früh also deutliche Bezüge zur Interkulturalität.

1967 übernahm Meissner zum 1. April die Leitung der Hamburger Volkshochschule. Dieser hat er ein neues und deutlich anderes Gesicht gegeben. Er hat in der damaligen Zeit wesentlich das Konzept einer integrativen Erwachsenenbildung geprägt und an der Hamburger Volkshochschule realisiert. Bereits vor seinem Amtsantritt in Hamburg hatte er 1961 den Aufsatz »Ausbildung und Bildung als Aufgabe der Volkshochschule« veröffentlicht, in dem er der berufsbezogenen Bildung einen wichtigen Stellenwert in der Volkshochschularbeit einräumte. »Berufsfördernde Erwachsenenbildung legt in der Dienstleistungsgesellschaft das Fundament für morgen.« $(1961,161)$

Dies entsprach damals keineswegs dem gängigen Selbstbild der deutschen Volkshochschulen, die zwar in der Realität der Berufsförderung bereits seit langem einen breiten Raum einräumten, aber dies mit deutlich »schlechtem Gewissen « $(1964,27)$ - wie Meissner formulierte. Er plädierte dafür diese Realität anzuerkennen und den Zusammenhang zwischen Berufs- und Lebenswelt als Aufgabe der Volkshochschule zu akzeptieren.

Meissner verdeutlichte seine Position in der »Denkschrift zur Situation und Entwicklung der Hamburger Volkshochschule«, die er anlässlich der Amtsübernahme am 1.4.1967 verfasste und im Februar 1968 dem Hamburger Senat und der Bürgerschaft vorlegte. Er schlägt eine weitgehende Neuordnung und Reorganisation der Volkshochschule vor, um den Ansprüchen, die in den kommenden Jahren an die Erwachsenenbildung gestellt würden, gerecht zu werden. Die Denkschrift bezieht ausdrücklich die wissenschaftliche und gesellschaftliche Diskussion um die Erwachsenenbildung Anfang bis Mitte der sechziger Jahre mit ein. Dies gilt für die »Empfehlungen des Gutachtens des deutschen Aus- 
schusses für das Erziehungs- und Bildungswesens« von 1960, das Gutachten des deutschen Volkshochschulverbandes zur »Stellung und Aufgabe der Volkshochschule im Bildungssystem « von 1966 sowie die Untersuchungen von Strzelewicz, Raapke und Schulenberg über »Bildung und gesellschaftliches Bewusstsein«. Kurt Meissner plädiert im Hinblick auf den gestiegenen gesellschaftlichen Stellenwert der Erwachsenenbildung für eine inhaltliche Erweiterung, die auch in einer höheren Professionalisierung des Personals ihren Niederschlag finden müsse. Die »Denkschrift« nimmt gesellschaftliche Modernisierungstendenzen und resultierende Anforderungen auf und übersetzt sie in Konzepte zum Aufbau der Volkshochschule, ihre organisatorische Differenzierung sowie ihre Professionalisierung. Während der Amtszeit Meissners erlebte die Hamburger Volkshochschule ihren größten Boom mit 94.00o Teilnehmern im Jahr 1975, was als Erfolg der von ihm eingeleiteten Entwicklung angesehen werden kann.

Parallel zu seiner Tätigkeit als Leiter der Hamburger Volkshochschule war Meissner immer auch auf überregionaler Ebene in Verbänden und im Wissenschaftsbereich tätig. Von 1963 bis 1979 fungierte er als geschäftsführender Vorsitzender des Deutschen Volkshochschulverbandes. In dieser Zeit vollzog sich die »realistische Wende« der Bildungsarbeit der Volkshochschulen. Wesentlich ist dies auf Anstöße Meissners zurückzuführen.

1969 wurde Kurt Meissner erstmalig zum zweiten Vorsitzenden des Bundesarbeitskreises »Arbeit und Leben«, einer gemeinschaftliche Organisation der Volkshochschulen und des Deutschen Gewerkschaftsbundes, gewählt. Während seiner Aktivitäten ist vor allem die Entwicklung des Bildungsurlaubs zu nennen, einem nach wie vor wichtigen, und heute unterbewerteten Instrument der Freistellung für Bildung. Wichtige Anstöße hat Meissner später auch gegeben für entsprechende Konzepte in den »neuen Bundesländern«, zum Beispiel in Brandenburg und Sachsen-Anhalt. Leitlinie dieser Arbeit ist die Ausgestaltung sozialer Demokratie, wobei ein Begriff von Politik unterlegt wird, der Konflikte, Auseinandersetzungen und Interessen akzeptiert.

Meissners praktische Wirksamkeit galt auch der Entwicklung und der Einsetzbarkeit von Medien in der Erwachsenenbildung. An der Gründung des Adolf-Grimme-Instituts war er wesentlich beteiligt. Dies ist heute das größte und wichtigste Zentrum der Diskussion um Medien in der Erwachsenenbildung.

Eine Besonderheit des Wirkens Meissners in der Erwachsenenbildung sind seine Beiträge zur Religiosität und zum interreligiösen Dialog. Er war über lange Zeit Synodaler der Nordelbischen evangelisch-lutherischen Kirche. Religiöse Bildung sieht Meissner als ein Umgreifendes bezogen auf die anderen Bereiche. Durch diesen Ansatz soll der Mensch befähigt werden, »sein Gewissen nicht nur als immerwährender Mahner zu befragen, sondern darin zugleich Maßstäbe für seine Entscheidung zu finden« $(1995,52)$.

Meissner hat immer wieder Beiträge zur Geschichte und Theorie der Er- 
wachsenenbildung geliefert. Zusammenfassend ist eine historische Aufarbeitung »75 Jahre Volkshochschule in Deutschland« (Meissner 1995). Dabei wird sowohl die eigene Arbeit als auch die institutionelle und politische Entwicklung der Erwachsenenbildung resümiert. Eindrucksvoll zu lesen ist auch die Autobiographie »Vom Menschen aus « (Meissner 1995) als die von einem Zeitzeugen beschriebene Entwicklung der Erwachsenenbildung nach 1945.

Meissner hat zunächst hauptsächlich über die Bildungsarbeit der Volkshochschulen und Heimvolkshochschulen geschrieben. Es geht dabei um das Verhältnis zur Tradition dänischer und deutscher Erwachsenenbildung sowie um die Besonderheiten der Erwachsenenbildungsarbeit durch interne Kooperation im Kollegium. Er resümiert:

"Eine Heimvolkshochschule ist das, was ihr Leiter an Teamwork, an Kooperationsbereitschaft in inr entfaltet. Das Kollegium einer Heimvolkshochschule muss das Modell einer demokratischen und pluralistischen Gesellschaft sein." (Ebd. 121)

Diese Kombination von Arbeit in der Heimvolkshochschule und wissenschaftlicher Interpretation des eigenen Handelns ist eine für Meissner typische Denkbewegung der Theorie-Praxis-Integration.

Sein besonderes Gespür für aktuelle Tendenzen und seine Fähigkeit, dies in große Linien einzuordnen, belegt Meissner in dem Buch »Die dritte Aufklärung « (1969). Er diskutiert drei Phasen der Aufklärung: Erstens die geistige Emanzipation des Bürgertums, zweitens Aufklärung als Volksbildung und drittens Erwachsenenbildung in einer »informierten Gesellschaft«. Erstaunlich ist, wie 1969 das Verhältnis von Information und Gesellschaft aufgegriffen wird. Es wird zu einem sehr frühen Zeitpunkt Bezug genommen auf Kybernetik und Medientheorie. Um die aktuellen Tendenzen zu begreifen, wird der historische Kontext hergestellt. Hintergrund ist eine Idee »öffentlicher Wissenschaft«, welche die Vermittlung wissenschaftlicher Arbeitsergebnisse für das Verständnis von Welt und angemessenes Handeln pointiert. Dies findet Kurt Meissner geschichtlich bereits in den Gedanken der Aufklärung. Wurzeln werden benannt in der »Deutschen Bewegung «, mit Herder und dem deutschen Idealismus, z.B. bei Kant, der Aufklärung im Salon bei Rachel Varnhagen, Boten und Hausfreunden bei Matthias Claudius, den patriotischen Gesellschaften und Justus Möser sowie im kritischen Engagement Lessings.

Hier wird die aufklärerische Traditionslinie aktiviert. Meissner übersieht nicht romantische oder konservative Tendenzen in der Tradition der Volksbildung. Auch hier bezieht er wieder eigene Erfahrungen aus Rendsburg ein und diskutiert Grundvig. Er pointiert die Unterschiedlichkeit proletarischer Bildungsarbeit und der Popularisierung des Wissens bei Johannes Tews und der »Gesellschaft für Verbreitung von Ausbildung«. Die Grundströmungen der »neuen Richtung« werden in ihrer Widersprüchlichkeit gekennzeichnet. Weg- 
weisend ist die Bezugnahme von Erwachsenenbildung und Wissenschaft. Dies wird in den Kontext »der dritten Aufklärung « gestellt.

Indem Meissner »Ausbildung und Bildung als Aufgabe der Volkshochschule« benennt, vollzieht er einen Bruch zu deren vorgängigem Bildungsverständnis. Er formuliert eine spezifische Form der Arbeitsorientierung. Dabei ist auch der Einbezug von Beruflichkeit als Bildungsaufgabe besonders betont.

"Immer aber ist eine breite Grundbildung dafür Voraussetzung und die dauernde Erneuerung der Bildung aus der Berufserfahrung ist die lebensbegleitende Dynamik [...]. Zugleich bietet ein solcher Beruf Elemente der Selbstbestätigung, der Steigerung des Selbstwertgefühls, ermöglicht Einordnung in die gesellschaftliche Prestigeskala." (Meissner 1969: 63)

Im Aufsatz »Prinzipien der Erwachsenenbildung« (1961) stellt Meissner zwei Bildungsbegriffe gegenüber. Auf der einen Seite steht eine Bildung, die auf Anpassung abzielt, auf der anderen Seite entwickelt er einen Bildungsbegriff, »in dem Bildung als ein Grundbestand des Daseins empfunden wird, der, indem er die gesellschaftliche Situation der Menschen erklärt, zugleich zur Veränderung der Gesellschaft beiträgt« (Ebd. 45).

Bei Meissner finden sich - wie angedeutet - auch Überlegungen zu einem Einbezug der Erwachsenenbildung in den Kontext »lebenslanges Lernen« - ein heute wieder neu aktuelles Thema und ein Gedanke, der bei Meissner in den frühen 1970er Jahren auftaucht. Obwohl heute anders konnotiert, ist eine Tendenz zur Verstärkung der Systematisierung, Curricularisierung und Professionalisierung zu sehen.

Damit werden Ansätze frühzeitig benannt, welche immer noch auf der Tagesordnung stehen. Auch finden sich frappierend aktuelle Bezüge:

"Im Selbstlernen und in der Entwicklung der Fähigkeit dazu ist dann womöglich die Integration von allgemeiner und beruflicher Bildung in der letzten Konsequenz erreicht." (Ebd. 172)

Während aber die Debatte um das »selbstorganisierte Lernen« merkwürdige Verwerfungen und antiinstitutionelle Affekte aufweist, hat Meissner die Notwendigkeit von Support und Institutionen immer unterstellt.

Ein Schwerpunkt der theoretischen wie praktischen Berührung Meissners in seiner Bildungsarbeit war bzw. ist immer auch die politische Bildung, wie er bereits in seinem Aufsatz »Politische Bewusstseinsbildung heute (1955) dargelegt hat. Es geht, eingebunden in die damals aktuelle Diskussion um das Buch von Borinski, um »Mitbürgerliche Bildungsarbeit«. Politisches Bewusstsein ist demnach Voraussetzung für begründete politische Meinungen und für vernünftiges politisches Handeln. Fortgesetzt wird dies in den $1960 e r$ Jahren unter dem 
Begriff »staatsbürgerliche Bildung«. Dabei nennt Meissner: »Staatsbürgerliche Bildung muss weltbezogen sein.« (In: 1985, 77)

»Weltbezug« bei Kurt Meissner und »Menschenrechte« bei Willy Strzelewicz sind die Stichwörter, die beide an die Tradition der Aufklärung rückbinden. Das heißt nicht, dass beide durch und durch Vertreter eine reflektierten Form waren. Je unterschiedliche Lebenserfahrungen brechen die Klarheit der Positionen. Bei Meissner finden wir in seinem Vorschlag der »Dritten Aufklärung« starke technologisch intendierte Bezüge und bei Strzelewicz ein ablehnendes Verhältnis zur kritischen Theorie. Nichtsdestoweniger gehören sie zu den wenigen, die die Entwicklungslinie der Aufklärung fortsetzen.

Auch in der gewerkschaftlichen Bildungsarbeit nach 1945 sind die Bezüge zur Aufklärung eher abstrakt und schwach geblieben. Das gilt sogar noch für die »Soziologische Phantasie« der Gruppe um Oskar Negt und die Vertreter der »Betriebsnahen Bildungsarbeit« (Adolf Brock, Wolfgang Hinrichs, Rainer Hoffmann, Willi Pöhler, Olaf Sund, Reinhard Weltecke).

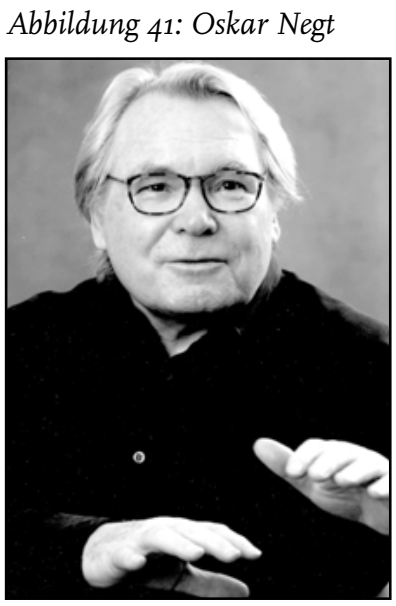

In seinen späteren Schriften hat Oskar Negt seinen Bezug zur Aufklärung deutlich gemacht. Er zeigt deren Unverzichtbarkeit für politische Bildung auf in seiner auf Kant zurück gehenden Vorstellung einer Kritik der Urteilskraft und versucht klarzumachen, dass legitime Kritik der Aufklärung ausschließlich im Sinne ihrer Erweiterung und Fortführung zu verstehen sei.

"Nicht ein Zuviel an Aufklärung, wie Wellen und Moden immer neuer Mythen und die archaisierende Gefühlsästhetik uns mit suggestivem Geschäftseifer nahelegen wollen, ist verantwortlich für die Misere des gesellschaftlichen Bewusstseins, mit dem wir es heute zu tun haben, sondern ein Zuwenig. Und wer sich entschlossen hat, vom Ende der Aufklärung als einem Tatbestand zu reden und vielleicht sogar das, was fällt, noch 
stoßen möchte, muss wissen, auf welche Abenteuer er sich einlässt. In einer auf sich selbst angewandten Aufklärung sehe ich dagegen das einzige Mittel, die Dunstschwaden der Gegenaufklärung zu vertreiben, die sich immer dann ausbreiten, wenn in gesellschaftlichen Krisenstimmungen ein starker Bedarf nach eindeutigen Schuldzuweisungen entsteht." (Negt 2010, 285)

Die Selbstaufklärung der Aufklärung hat - wie schon bei Jean Jacques Rousseau - den Zivilisationsprozess zum Thema, der zum Reichtum des Verstandes und zur Armut der Sinne geführt hat (ebd. 290). Bereits Georg Forster hatte deshalb die Utopie der Gemeinsamkeit der Bildung von »Vernunft, Gefühl und Phantasie im schönsten Tanze vereint« gemalt (s.o.). Kritische Reflexivität und praktische Konsequenz sind Leitlinien einer Idee von Aufklärung, die weiter Relevanz haben kann.

Für das Verhältnis zu Wissenschaft bedeutet das: nicht fertige Resultate sind Themen des Transfers; ohne Kreativität der Methoden bleibt das Wissen träge und Reflexivität für moralische Konsequenzen ist unabdingbar. Ein kritisch-pragmatischer Ansatz balanciert das Dreiecksverhältnis von Aufklärung, Bildung und Wissenschaft.

\subsection{Tendenzen und Perspektiven}

Die Diskussion bleibt offen. Angesichts der Destruktion des Begriffes der Aufklärung und der Erosion des Begriffes der Bildung stellt sich noch einmal die Frage: Ist es nicht überholt und damit überflüssig, sich mit Aufklärung, Bildung und Wissenschaft aufzuhalten? Der Mainstream geht in andere Richtung. Aber - so wenigstens der kräftige Spruch: Nur tote Fische schwimmen mit dem Strom. Der Gedanke der Aufklärung aber lebt noch, obwohl das ambitionierte Projekt gelaufen scheint; wir leben - so sieht es aus - nach der Aufklärung: Entweder weil sie sich durchgesetzt hat, oder weil sie von Anfang an unverwirklichbar war, oder aber weil die terroristischen Konsequenzen freigelassener Rationalität sie selbst zerstört haben. Ist das resignative Verdikt Horkheimers und Adornos berechtigt, dass die vollendete Aufklärung im Zeichen triumphalen Unheils leuchte (s.o. Teil 1.8).

Bei genauerem Hinsehen argumentiert die »Dialektik der Aufklärung« bemerkenswert und merkwürdig - bei Urvätern »Kritischer Theorie« - »undialektisch«. Sie betont die Seite des Untergangs und übergeht die orientierenden Wertsysteme der Menschenrechte, der Gerechtigkeit und der Freiheit - als weiter fließende Quellen. So ist es berechtigt, sich Sorge zu machen um die Tradition und die Perspektiven der Aufklärung.

Wir erleben eine tiefgreifende Verunsicherung über die »Nachhaltigkeit« und »Zukunftsfähigkeit« der Aufklärung und der Bildung. Angesichts zuneh- 
mendem Kulturkonservatismus, Postmodernismus, radikaler Rationalitätskritik, Antisubjektivismus und religiösem Fundamentalismus entstehen sich vertiefende Freund-Feindpolaritäten, zurückgewandter Nationalismus und ein konservativ-reaktionär dominiertes Diskussionsklima. Die Sorge um die Aufklärung ist begründet, weil nur noch wenige sich um sie sorgen, um die Prinzipien von Vernunft und Öffentlichkeit, die nicht naturgegeben sicher sind, sondern die auch verloren gehen können.

Die Wochenzeitschrift »Die Zeit« veröffentlichte Anfang 2010 unter dem Titel: »Das Ende der Aufklärung? Rein ins Handgemenge! « einen »Disput« zwischen dem Schriftsteller und Philosophen Rüdiger Safranski und dem Publizisten und Beiratsmitglied von Attac Mathias Greffrath (www.zeit.de/zeitgeschichte/ 2010/02/Streitgespraech-Safranski-Greffrath. Zugriff 1.8.2010). Allerdings ergänzen sich die Diskussionspartner mehr als dass sie streiten. Die Ausgangsfrage lautet: leben wir tatsächlich in einer so durch und durch aufgeklärten Zeit, wie oft behauptet wird?

\section{Mathias Greffrath antwortet:}

"Würde der Gott der Aufklärung ins Internet schauen, so würde er sehen, dass die Partie noch immer unentschieden ist. Einerseits zeigt sich dort sehr viel Vernunft - viele Pläne und Projekte, viel Welterklärung und Wissenschaft. Auf der anderen Seite blüht das Irrationale - Dogmen und Idole, dass es nur so kracht. Da ist unsere Epoche nicht viel anders als die Welt vor 200 oder 300 Jahren."

\section{Rüdiger Safranski korrigiert:}

"Mir scheint ein anderer Gegensatz wichtiger als der von Rationalität und Irrationalität. Gegenwärtig ist etwas aufgebrochen, was schon in der historischen Aufklärung angelegt war. Einerseits sollte sich der Mensch seines Verstandes bedienen, um mündig zu werden. Andererseits wurde die Rakete der exakten Wissenschaft gezündet, und die spezialisierten Disziplinen entstanden. Jetzt haben wir das Problem, dass die institutionalisierten, instrumentellen Wissenschaften den Allgemeinverstand überfordern. Außer auf dem kleinen Gebiet, auf dem wir uns spezialisiert haben, sind wir ja durchweg Laien und dadurch gläubige Mitwisser von Dingen, die wir nicht wirklich verstehen. Das erzeugt ein großes Spannungsverhältnis: Einerseits sind wir eine aufgeklärte Gesellschaft, andererseits eine Gesellschaft von Mitgläubigen, die an einem Wissen, das sie selbst nicht erarbeitet haben, partizipieren - und die von diesem Wissen auch beherrscht werden."

Mit der Aussage Safranskis wird das Auseinanderklaffen von technisch Machbarem und moralisch Beherrschbarem betont: Technikfeindlichkeit und Technikanbetung, die beide gleichzeitig sich ausbreiten, spiegeln ein mythisches, d.h. 
irrationales Verhältnis zu Wissenschaft und Technik, das entsteht, weil der wissenschaftliche Fortschritt der Erkenntnis mit Bildung und Urteilskraft des Allgemeinverstandes nicht mehr eingeholt wird. In der Formulierung eines neuen mythischen Verhältnisses wird die »Dialektik der Aufklärung « Horkheimers und Adornos aufgenommen und die düstere These, dass aufklärerische Vernunft Gefahr läuft, sich selbst zum Mythos zu machen und in neue Barbarei zu führen.

Greffrath hebt aber zu einer Kritik der Kritik an:

"Ich sehe da nicht so schwarz. Denn Horkheimer und Adorno haben die Aufklärung in unzulässiger Weise mit dem Gesamtprozess der Moderne identifiziert und dabei Wissenschaft und Kapitalismus, Waffentechnik, Warenfetischismus und Massenmedien in einem dunklen Topf verrührt. In einem aber haben sie zweifellos recht: dass dieser Prozess immense Gefahren mit sich bringt. Heute reichen sie vom Klimawandel bis hin zu einer rasant wachsenden sozialen Ungleichheit. Wir leben in einer Zeit voller Krisen. Genau an diesem Punkt aber kommen auch Irrationalitäten ins Spiel: Alte irrationale Erklärungsmuster haben in Krisenzeiten grundsätzlich Konjunktur. Da blüht die Astrologie, da blühen die Bachblüten, da kehren die alten Götter zurück."

Die Aufklärer des 18. Jahrhunderts, besonders die französischen, hatten einen starken polemischen Impuls gegen Religion und Kirche. Das waren die Gegenkräfte als Stützen der alten Herrschaft, die entlarvt werden sollten. Die Kritik der Religion war Voraussetzung des Kampfes gegen Aberglauben und Vorurteile. Wissen und Glauben traten auseinander.

Aber es bleibt anderes: Körperlichkeit, Sinnlichkeit, Gefühle, Ahnungen, Transzendenzerfahrungen. Das war Thema der Romantik. Sie konnte diese Lebenserfahrungen und Äußerungen besetzen, weil es der Gegenaufklärung gelungen war, die Vorwürfe der Vernünftelei und des Aufklärichts zu verbreiten.

Am Ende des 18. Jahrhunderts, 16 Jahre nach Kants »Was ist Aufklärung?«, trat Friedrich Schleiermacher auf und hielt die Religion wieder hoch - war dabei aber immer noch Aufklärer. Nicht neue Offenbarung, nicht reaktionäre Orthodoxie, nicht wieder erstarkte Fremdbestimmung wollte Schleiermacher begründen, sondern Autonomie im Glauben. Er warnte aber davor, auf ein reduziertes, rationalistisches Menschenbild zurückzugreifen.

Religion ist offenbar etwas, das auch in säkularisierten Gesellschaften nicht einfach verschwindet. Mehr als 200 Jahre später fällt die neue übersteigerte Religiosität des Fundamentalismus als Kreationimus, Moslemismus vs. Christlichem Fundamentalismus weit hinter die Möglichkeiten der Aufklärung zurück. Es bleiben Reservate des Unvernünftigen. Letztlich aber sagen Abwehrstrategien meist kaum mehr als der Deismus des 18. Jahrhunderts: Hinter der Endlichkeit liege immer noch eine Unendlichkeit; es gäbe etwas, das mit Vernunft und bloßem Denken nicht gefasst werden kann. Religiosität zieht sich daher zurück in eine Region des Übervernünftigen und beginnt aus dem 
Ghetto ihre beunruhigenden Ausfälle. Durch das Grenzen-Einziehen und die Selbstbeschränkung der Vernunft wird ein Reservat abgetrennt, das vom Strom der Wissenschaft unberührt bleibt und Verbotsschilder werden aufgestellt: Hier werden Gespenster gezeugt. Wenn man aber auf Spiritualitäten zurückgreift, kommt man wieder ins Reich der Geisterseher.

Nun war die Aufklärung aber nicht nur ein Wissensprojekt, sondern hatte zugleich einen normativen Anspruch. Ihr Ziel war Ausbreitung des Wissens und Befreiung von Herrschaft durch Nachfrage der Vernunft. Was aber, wenn das eine mit dem anderem in Konflikt gerät? Wenn Wissenschaft Herrschaft nicht mit bedenkt, ist das gefährlich und provoziert Illusionen.

Herrschaftskritik vollzieht sich in reflektierter Aufklärung nicht nur als moralisches Postulat. Sie liegt im Prozess des Aufklärens selbst begründet, denn dieser Prozess vollzieht sich in Gestalt des Meinungsstreits um Wissenschaft. Das Demokratische liegt also schon in der Form der Öffentlichkeit: Reflexive Kritik ist der Prozess, in dem sich Aufklärung selbst aufklärt.

Demokratischen Meinungsstreit muss man nun aber auch auf eine sich tendenziell dogmatisierende Wissenschaft anwenden. Im Streitfall müssen Experten ihre Resultate der Öffentlichkeit vorlegen, und die muss, ausgestattet mit ihrem unspezialisierten Normalverstand, entscheiden, welcher sie folgen will. Aufklärung als Institutionen- und Machtkritik kommt nicht umhin, zu erkennen, dass auch demokratische Institutionen machtdurchsetzt sind. Es droht eine Expertokratie, die nur durchbrochen werden kann, wenn Öffentlichkeit partizipiert.

Der unterstellte offene Meinungsaustausch wird nicht von Gebildeten geführt. Die Idee der Öffentlichkeit als einer Versammlung mündiger Bürger ist ein Konstrukt. Das wissen auch schon die Aufklärungsphilosophen. Aufklärungsprozesse sind nur möglich mit realen Menschen, die nicht alle erst mal vernünftig gemacht werden können, bevor das Risiko ihrer Entscheidungsbeteiligung eingegangen werden kann. Nur so kann Demokratie sich entwickeln. Selbstverständlich werden in jeder Debatte handfeste Interessen mit verhandelt. Das Risiko der Demokratie ist, dass sich auch irrationale und interessendominierte Positionen durchsetzen können, die vom wissenschaftlichen Standpunkt aus unvernünftig sind. Das gilt auch für den Prozess der Wissenschaftsentwicklung selbst.

In einer globalisierten Welt können solche Fragen nicht mehr nur unter den westlichen Staaten in europäischer Tradition diskutiert werden. Die anderen Kulturen der Völker der Welt melden sich an. Es gibt eine weltweite Herrschaftsdebatte, die sich vermengt mit einer Wissenschaftsdebatte darüber, was im Klimaschutz, in der Sperre der Atomwaffen, der Friedensicherung usw. notwendig ist.

Man stößt also auf das Problem der Universalisierung - wie es Safranski in die ZEIT-Debatte einbringt. Auch über dieses Problem haben die Aufklärer 
schon nachgedacht. Es kann nur universalisiert werden, was elementar ist etwas, auf das sich alles Mögliche noch draufsetzen kann an Varietät. Safranski fragt: »Und was ist dieses Elementare? Selbstbestimmung!«

Auch dazu sind selbstverständlich auch Gegenpositionen entwickelt worden: Nur höchste Formen der Individualität befähige überhaupt zu autonomem Handeln, der Normalmensch sei davon überfordert.

"Man kann also selbst noch den Universalismus der Selbstbestimmung bestreiten aber eben nur mit einem sehr dunklen Menschenbild, [...] das nicht mit der Aufklärung in Einklang zu bringen ist." (Ebd.)

Aufklärung meint zunächst immer ein optimistisches Projekt. Im Licht am Ende des Tunnels, da leuchtet Aufklärung. In diesem Bild schwingen alte Heilsvorstellungen mit - aus dem Dunkeln aufzusteigen ins Licht, die Höhle zu verlassen und die Wahrheit zu sehen.

Aber das ist nur eine von vielen Möglichkeiten. Eine andere Betrachtungsweise ist - so Safranski: Aufklären kann mit dem Entsetzen konfrontieren - wie Ödipus, der sich am Ende blendet.

"Da könnte man nun sagen: Besser wäre es gewesen, nicht aufgeklärt zu werden, besser und menschlicher ist es, den Menschen im Unklaren zu lassen. Aufklärung hat immer auch eine finstere Seite." (Ebd.)

Man kann die Tür zur Erkenntnis jedoch nicht öffnen und dann geschlossen halten, denn früher oder später wird jemand kommen und hindurchgehen. Das Wissen der Welt wächst und wuchert. Der Mensch, der begriffen hat, was Aufklärung sein kann, und der Aberglauben und Vorurteile hinter sich gelassen hat, kann nicht stillstehen und sich selbst eine Grenze setzten. Spannend bleibt immer, was hinter der Grenze liegt. Die Hoffnung auf lebensenfaltende Bildung trägt über selbstverschuldete Schranken hinaus. So bleibt Aufklärung am Ende ein ergebnisoffenes Verfahren.

\section{Greffrath ergänzt:}

"Wobei man sich gerade dabei heilsgeschichtlicher Ideen erwehren sollte. Dieser religiöse Rest der Aufklärung wird ja in mehrerer Hinsicht weitergetragen. Er hat mit der größten Kränkung zu tun, mit der wir Menschen fertig werden müssen - dass wir sterblich sind. Die Religion hat dieses Problem wunderbar gelöst. Die Wissenschaft hat mit der Utopie der Unsterblichkeit darauf geantwortet. Das finden wir heute noch bei manchen Pseudobiowissenschaftlern. Das ist natürlich idiotisch. Die Idee, die Endlichkeit zu überwinden, hat immer wieder in den Irrsinn geführt. Ein Irrsinn, wie inm auch die Ideologen unendlichen ökonomischen Wachstums aufsitzen. Die Idee unendlicher Be- 
dürfnisse und unendlicher Produktion - genau dieser fehlgeleitete Idealismus hat uns in die Finanzkrise geführt."

\section{Grundsätzlich ist nachzufragen:}

"Ein Versprechen der Aufklärung war es, den Menschen, wenn schon nicht unsterblich, so doch zu einem besseren Menschen zu machen. Gibt es das: moralischen Fortschritt? Hat es inn gegeben seit dem Zeitalter der Aufklärung? “

\section{Greffrath:}

"Ich glaube, wir haben in Europa seit 200, 300 Jahren große moralische Fortschritte gemacht. Die Menschen sind tatsächlich aufgeklärter. Vor 30 oder 50 Jahren haben Eltern ihre Kinder noch bedenkenlos mit Prügeln erzogen, heute werden Kinder nicht mehr so selbstverständlich geschlagen. Es gibt also Fortschritt. Wer das nicht sieht, ist blind."

\section{Safranski:}

"Man muss bei einer solchen Frage aber auch an die entsetzlichen moralischen Katastrophen des 20. Jahrhunderts denken, an den Holocaust und an die Verbrechen, die im Namen des Kommunismus verübt worden sind. Aber es stimmt: Man darf aus der Kritik am Fortschritt nicht wiederum eine Ideologie machen. Vielleicht kann man sich darauf einigen, dass es Fortschritte gegeben hat, im Plural. Die Aufklärung hat ja diese eigenartige Singularisierung betrieben. Der Fortschritt - dieses Bild, dass die Menschen den Auszug aus der Wüste ins Gelobte Land antreten. So würden wir das heute nicht mehr betrachten. Die Geschichte - auch eine Idee der Aufklärung: dass Geschichte ein Zug ist, den man verpassen oder auf den man aufsteigen kann. Sich von solchen Bildern zu lösen heißt, den Prozess der Aufklärung weiterzuführen."

\section{Safranski spitzt zu:}

"Sogar die Menschenrechte kann man infrage stellen. Und dies macht deutlich: All diese Dinge gehen auf Entscheidungen zurück. Noch hinter dem Elementarsten steht eine Entscheidung. Aber wir alle haben natürlich die große Sehnsucht, dass die Entscheidungen irgendwo einmal aufhören und die Wahrheit beginnt, eine Sehnsucht danach, dass es endlich einmal Ruhe gibt."

\section{Greffrath präzisiert:}

"Aber wenn Menschenrechte verletzt werden - bei Gewalt in der Ehe oder Misshandlung von Kindern -, dann ist das keine Privatangelegenheit mehr, sondern ein Verstoß 
gegen geltendes Recht. Mit einem forcierten Begriff von Republikanismus kommt man da weiter als mit philosophischen Argumenten."

Letztlich geht es um Fragen des Zusammenlebens. Aufklärung, das sagen Horkheimer und Adorno ebenfalls, heißt auch, die Menschen heimisch auf der Erde zu machen. Aufklärung ist auch und vor allem eine Form des Handelns. Sie beruht wesentlich auf der Entfaltung der Einzelnen, auf ihrer Bildung. In einer wissenschaftlich basierten Zivilisation ist die nur möglich durch Partizipation an Wissenschaft.

Eine solche Perspektive kommt nicht aus ohne den Begriff Bildung. Safranski resümiert in der ZEIT-Diskussion:

"Aber lassen Sie mich hier wenigstens auf einen zentralen Begriff hinweisen: Bildung! Schon den Aufklärern des 18. Jahrhunderts war ja nicht ganz wohl dabei, dass man bei Aufklärung sofort ein Sender-und-Empfänger-Modell vor Augen hat. Da ist dann der Adressat der Aufklärung, und der andere klärt auf. Die Karriere des Begriffes Bildung setzt genau an diesem Punkt an: In einem jeden von uns will etwas werden und wachsen. Wir müssen daher Milieus und Kontexte schaffen, in denen dieses Etwas aufgehen kann wie eine Blüte. Man wird, was man sein möchte, und nicht, was andere aus einem machen wollen - das ist eine der ganz kostbaren Wendungen der Aufklärung: Hilfe zur Selbsthilfe geben. Aufklärung heißt schließlich nichts anderes als Ermöglichung des Menschen durch den Menschen."

Die Debatte endet also vorläufig in einer Apologie der Aufklärung. Es geht um eine Weiterführung der Aufklärung. Erstaunlich unterbelichtet bleibt der Stellenwert der Wissenschaft in diesem Prozess. Matthias Greffrath deutet sein Unbehagen mit der modischen Wissenschaftsschelte zumindest an, indem er Erkenntnisfortschritte der Naturwissenschaften - der Molekularbiologie, der Gehirnforschung, der Astrophysik - hervorhebt. Allerdings haben solche Einsichten nicht dazu geführt, Wissenschaft, ihre Produktions-, Distributions- und Transferaktivitäten genauer in den Blick zu nehmen. Die Diskussion um »öffentliche Wissenschaft« hat sich wieder beruhigt - um nicht zu sagen: sie ist eingeschlafen.

Die Debatte setzt sich aber noch fort. Die Beunruhigung durch die Aufklärung dauert an. Wenn Michel Foucault 1984 - kurz vor seinem Tod - die Frage aufgreift »Was ist Aufklärung? «, dann setzt er damit einerseits eine lebenslange Beschäftigung mit Kant fort. Andererseits macht er deutlich, dass dieses Problem gegenwärtig nur reflexiv - und das bedeutet für ihn zugleich ironisch - behandelt werden kann.

"Vielleicht können wir im Echo antworten: moderne Philosophie ist die Philosophie, die versucht, die vor zwei Jahrhunderten so unvorsichtig aufgeworfene Frage zu beantworten: Was ist Aufklärung?« $(1986,35)$ 
Foucault sieht in der Frage »den Umriß dessen, was man die Haltung der Moderne nennen könnte« (ebd. 41).

Deshalb kann er »deutlich machen, daß nicht die Treue zu doktrinären Elementen der Faden ist, der uns mit der Aufklärung verbinden kann, sondern die ständige Reaktivierung einer Haltung - das heißt eines philosophischen Ethos, das als permanente Kritik unseres historischen Seins beschreiben werden könne« (ebd. 45).

Die »Problematisierungsweisen« der Kritik erhalten eine historische Form.

Wenn Pierre Bourdieu 2002 - veröffentlicht im Jahr seines Todes - für eine neue europäische Aufklärung eintritt, dann ist ihm bewusst, dass die wirtschaftliche und soziale Welt immense Veränderungen erfahren hat. Der Gegner kritischer Aufklärung ist unsichtbar und unfassbar geworden.

\section{Abbildung 42: Pierre Bourdieu}

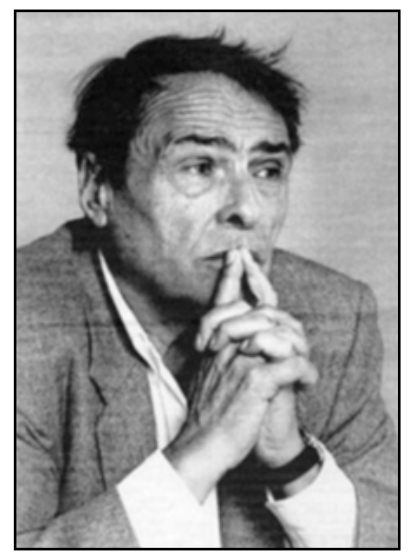

"Heute wird die Wirtschaft von der blinden Logik des ökonomischen Feldes, oder genauer gesagt, des Feldes des Finanzkapitals beherrscht, das nur seinem Selbstzweck folgt, dem Streben nach maximalem Profit." (Bourdieu 2002, 390)

Nichtsdestoweniger haben sich besonders im Feld der Wissenschaft - so glaubt Bourdieu - »soziale Universen« heraus gebildet die »zu einem echten Interesse an der Uneigennützigkeit, einer Leidenschaft für die Vernunft und einer Liebe zur Wahrheit geführt haben« (ebd. 395).

Er plädiert dafür, dass es möglich ist

"eine Realpolitik der Vernunft zu entwickeln und durchzusetzen, eine Politik, die in der Lage ist, in der sozialen Welt zu intervenieren und die, soweit es möglich ist, den im wissenschaftlichen Feld geltenden Regeln gehorcht; eine Politik die dazu in der Lage 
ist, den letzten Stand der Wissenschaft in den öfentlichen Diskurs einzubringen, wo er tragischer weise noch nicht wahrgenommen wurde, und die es möglich macht, die geschwätzigen und inkompetenten Feuilletonisten zur Zurückhaltung oder zum Schweigen zu bewegen, die sich ununterbrochen in Presse, Rundfunk und Fernsehen äußern; eine Politik, die es ermöglicht, die Gesamtheit der kritischen Energie zu befreien, die hinter den Mauern des akademischen Dorfes eingeschlossen ist: Einerseits aufgrund falsch verstandener wissenschaftlicher Tugend, die es dem homo academicus verbietet sich in die plebejischen Debatten der Welt der Journalisten und Politiker einzumischen, anderseits aufgrund der Denk- und Schreibgewohnheiten, die dazu führen, dass die Spezialisten es einfacher und, im Hinblick auf akademische Profite, Iohnenswerter finden, die Produkte ihrer Arbeit wissenschaftlichen Publikationen vorzubehalten, die ausschließlich von ihresgleichen zur Kenntnis genommen werden." (Bourdieu 2002, 396)

Damit verweist Bourdieu auf immanente Defizite des Wissenschaftsbetriebs: die Dominanz interner Mechanismen der Anerkennung zum einen und der Verzicht auf Bemühungen zur Popularisierung zum anderen. Solche Transferaktivitäten wären aber Voraussetzung, dass »eine neue europäische Aufklärung entstehen kann, die sich in allen Belangen gegen das neue ökonomische und soziale Modell richtet, das uns heute angeboten wird und das deshalb so schwer zu bekämpfen ist, da es in Gestalt eines aufgeklärten Obskurantismus erscheint« (ebd. 397).

Durchgehalten über 200 Jahre hat sich in diesen Postulaten der Kampf gegen Verdunkelung und die Hochschätzung von Wissenschaft als Weg zur Aufklärung. Sie wird nach wie vor trotz vielfältiger Irritationen zur Beschaffung von Legitimation hochgehalten. Eine solche Funktion kann sie aber nur erfüllen, wenn ihre Leistungen über die Bereitstellung technischer und ökonomischer Innovationen hinausgehen.

Insofern bleibt sie einem Anspruch auf Wahrheit verpflichtet, den sie nur in kritischer Reflexion gewinnen kann. Kritische Wissenschaft erhält aber ihre eigene Rechtfertigung nicht aus der Bestätigung des Bestehenden, sondern aus der Eröffnung des Möglichen, das falsche Verhältnisse aufdeckt und veränderbar macht. Öffnung des Wissenschaftsbetriebs und -transfers seiner immer wieder neu weiter zu entwickelnder und in Frage zu stellender Resultate werden für die Entwicklung zukunftsfähiger Gesellschaftsordnungen unverzichtbar. 


\section{Personenindex}

Addison 132

Adorno 19, 56, 153, 154, 155, 168, 170, 174

Aristoteles 20, 21, 107, 109

Arnauld 88, 89

Bach 99

Bacon 57, 62, 88

Basedow 40, 136, 143, 144, 146

Becker 135, 136, 137, 138

Biester 36

Black, Adam 92

Black, Charles 92

Blättner 162

Bloch 12

Bonaparte 138

Borges 93

Borinski 166

Bougainville 113

Bourdieu 94, 105, 106, 128, 175, 176

Braunschweig-Wolfenbüttel, Herzog

Karl Wilhelm Ferdinand von 146

Brecht 62, 111, 112

Brock 167

Brun 119

Buffon 24, 89

Campe, Anna Margaretha 145

Campe, Joachim Heinrich 40, 69, 70,

$71,72,73,74,75,143,144,145,146$,

$$
147,148,152
$$

Campe, Lotte 70

Caritat 79
Chodowiecki 17, 18

Claudius 165

Condorcet 23, 62, 79, 80

Cook 113, 114, 115, 120

Corneille 109

Cuvier 24

Dalberg, Karl Theodor von 135

Danton 62

Delacroix 65, 66

Deleuze 62, 94

Descartes 26

Diderot 18, 24, 27, 40, 62, 67, 89, 90, 91, 92

Diterich 35

Dohm 35, 139

Ekhof 50, 98, 111

Engel 35

Erxleben 29

Ewald 98, 125, 126

Faßmann 132

Feller 98

Fleischbein 51

Forster, Georg 19, 26, 27, 37, 40, 69, $75,76,77,78,79,98,113,114,115$, $116,117,118,119,120,121,123,152$, 168

Forster, Johann Reinhold 113, 114

Foucault 62, 88, 93, 94, 155, 156, 174, 175

Francke 40

Freeman 124 
Friedrich II. 23, 42, 49, 50, 59, 66, 135

Frisch 132

Galilei 24

Garve 9, 40, 84, 85, 139

Gedike 36

Gleim 98, 131

Goebbels 141, 142

Goethe 9, 23, 65, 107, 131

Goeze 99

Gottsched 108, 132, 133

Götze 125, 158

Goya 152

Goya 43, 44

Greffrath 169, 170, 172, 173, 174

Greiling 139, 186

Guattari 62, 94, 184

Gutenberg ${ }_{3}$

Habermas 80, 81, 186

Hagenbeck 122

Haller 23, 40

Heller 10

Herder 113, 165

Herz, Dr. Markus 36

Herz, Henriette 36

Heyne, Christian Gottlob 118

Heyne, Therese 118

Hinrichs 167, 187

Hobbes 67

Hoffmann 167

Hogarth 18

Hölderlin 55, 65, 152

Horkheimer 19, 56, 153, 154, 155, 158 , $168,170,174,187$

Humboldt, Alexander von 36, 117, 145

Humboldt, Wilhelm von 36, 55, 56, $70,74,145$

Hume 26, 46

Irving 36

Joseph II. 43

Jung-Stilling 131

Kant 9, 10, 16, 17, 18, 20, 26, 36, 40, 41, $42,44,46,47,48,49,50,56,66$,
$67,84,112,119,120,121,125,139$, $156,157,161,165,167,170,174,187$

Katharina II. 114

Kepler 20, 24, 25

Klafki 761, 148

Klein 35

Kleist 98

Klopstock 75, 98, 131

König 99

Kopernikus 20, 24, 25

La Roche 40, 133

Lamarck 24, 120

Lavater 131

Lavoisier 28

Le Breton 90

Leibniz 10, 23, 26, 45, 46

Leopold 99

Lessing, Gotthold Ephraim 37, 38, 39, 40, 50, 62, 97, 98, 99, 100, 101, $102,103,104,105,107,108,109,112$, $113,118,131,165,187$

Lessing, Johann Gottfried 98

Lichtenberg 19, 23, 40, 118, 131

Liebknecht 58, 59, 62, 187

Linné 24, 40, 88, 89, 119

Locke 46, 67

Lotze 159

Löwen 99

Ludwig XV. 75

Madame de Pompadour 90

Malthus 31

Mann 97

Marat 69

Maria Theresia 43

Mattheson 132, 133

Mead 123, 124

Mehring 50, 87, 104, 188

Meissner 10, 19, 57, 158, 162, 163, 164, $165,166,167,188$

Mendelssohn 20, 33, 36, 40, 56, 82, $84,98,125,188$

Merck 131 
Meyers 131

Mirabeau 72

Möhsen 35

Montaigne 113

Moritz 50, 51, 52, 54, 62, 109, 110, 111, 112

Möser 165

Motte-Fouqué 36

Negt $167,168,188$

Newton 7, 18, 23, 24, 25, 40

Nicolai 39, 40, 98, 130

Orlov 114

Papst Clemens XIII. 90

Paul 36

Pestalozzi 131

Petty 88, 89

Pfuel 36

Plato 23

Pöhler 167

Pope 25

Priestley 28

Raapke 158, 159, 164

Reemtsma 154, 188

Reimarus 99, 100

Robespierre 62, 69, 79, 119

Rochow 40, 130, 143

Rousseau 40, 62, 66, 67, 68, 69, 80, $113,117,136,168$

Safranski 169, 171, 172, 173, 174

Saint-Just 62, 69

Salome 98

Salzmann 131, 143

Sanger 95

Schelling 36, 69

Schiller 9, 65, 75, 79, 107

Schlegel 36

Schleiermacher 170

Schlosser 131

Schubart 64, 65

Schulenberg 158, 159, 164

Selle 36

Seume 131
Smith 18

Sömmering 118

Stahl 27, 28

Steele 132

Strzelewicz 10, 158, 159, 160, 161, 162, $164,167,190,191$

Sturm 132

Stuve 143,144

Sulzer 98

Sund 167

Swedenborg 46

Teller 35

Tews 165

Thomasius 9, 18, 20, 21, 22, 26, 29, $40,56,83,84,132,157$

Tieck 36

Tietgens 158, 191

Tillich 158

Tippelt 128, 183

Trapp 33, 40, 73, 143, 144

Vester 128

Villaume 40, 143, 144

Voltaire 18, 40, 66, 70, 90, 98

Voss 40

Wales 95

Weber 158, 190

Wehner 159

Weishaupt 38

Weltecke 167

Wiesel 36

Winkler 98

Wolff 22, 23, 29, 40, 46, 131

Zedler 92, 97, 139

Zerrenner 125, 138, 191

Zöllner 36 



\section{Abbildungsverzeichnis}

Abbildung 1: Chodowiecki, Daniel: Aufklärung 1791 17 www.flickr.com/photos/14868225@No4/3360260861

Abbildung 2: Einige Daten zum Umfeld der Aufklärung | 18 Eigene Zusammenstellung

Abbildung 3: Hexenverbrennung $\mid 22$ www.pictokon.net/bilder/2007-10-bilder

Abbildung 4: Vorbereiter der Aufklärung in der Naturwissenschaft | 24 Eigene Zusammenstellung

Abbildung 5: Isaak Newton bei einem Experiment mit Sonnenlicht | 25 http://wwwo.artflakes.com/artwork/products/248943/poster/ 248943.jpg? 1296481478

Abbildung 6: Antoine Lavoisier und seine Frau $\mid 28$ http://www.fiebich-frankfurt.de/lavoisier.jpg

Abbildung 7: Stände im 18. Jahrhundert (um 1790) | 31 http://germanhistorydocs.ghi-dc.org/images/30028945_Symbo lische\%2oDarstellung\%2oSt\%C3\%A4nde.jpg

Abbildung 8: Wappen der Patriotischen Gesellschaft Hamburg 1765 | 35 http://www.hamburg-for-free.de/bild/l/umwelthauptstadt-hamburg -eine-nachhaltige-zukunft-460428018.jpg

Abbildung 9: Symbol der Freimaurerei $\mid 37$ http://www.verschwoerungen.info/images/7/72/Zirkel_und_ Winkel.jpg

Abbildung 10: Geheime Figur der Rosenkreuzer $\mid 38$ http://upload.wikimedia.org/wikipedia/commons/c/c6/Extrait_ Altona_1785_v3.jpg

Abbildung 11: Pyramide der Illuminaten 39 www.verschwoerung-von-illuminaten-bis-wtc.de/

Abbildung 12: Goya »Auf dir, dem Schwachen« Caprichos 42 | 43 http://www.franciscodegoya.net/Caprichos-Plate-42-They-whoCannot.jpg 
Abbildung 13: Immanuel Kant $\mid 48$ commons.wikimedia.org/wiki/File:Hagemann-Kant.

Abbildung 14: Karl Philipp Moritz | 51 www.zeno.org/Philosophie/I/mori_ooo

Abbildung 15: Wolken vor der Sonne (Zeitgenössischer Druck) | 57 11fs309.blogspot.com/2010_01_01_archive.htm

Abbildung 16: Wilhelm Liebknecht (Photographie aus den 187oer Jahren) | 59 www.marxists.org/.../liebknechtw/index.htm

Abbildung 17: Delacroix: Die Freiheit auf den Barrikaden 1830 65 http://www.muenster.org/abendgymnasium/faecherprojekte/ projekte/delacroix/bild_freiheit.htm

Abbildung 18: Frontispiz zu Jean-Jacques Rousseau: Emile ou de l'éducation.

Den Haag, Amsterdam 1762 68 lettres.lem.online.fr/premiere/ombres_lumiere.

Abbildung 19: Guillotine: Exekution Robespierres |69 http://upload.wikimedia.org/wikipedia/commons/2/21/Execut ion_robespierre\%2C_saint_just....jpg

Abbildung 20: Georg Forster $1785 \mid 75$ http://de.wikipedia.org/wiki/Image:Georg_Forster.jpg

Abbildung 21: Erstürmung der Bastille $\mid 78$ http://www.welt.de/multimedia/archive/00363/Bastilleı_BM_ Berlin_36361og.jpg

Abbildung 22: Der Denkerclub. Karikatur von 1820 | 80 http://germanhistorydocs.ghi-dc.org/images/30011250-r\%20 copy1.jpg

Abbildung 23: Enzyklopädie | 91

http://upload.wikimedia.org/wikipedia/commons/8/8e/ENC _1-NA5_6oopx.jpeg

Abbildung 24: Vergleich einiger Enzyklopädien und Lexika | 97

Eigene Zusammenstellung

Abbildung 25: Aufführung des »Nathan« $\mid 103$

http://www.dhm.de/magazine/plakate/theater/theater_bilder_ gross/nathan.htm

Abbildung 26: Gotthold Ephraim Lessing 1729-1781 | 104

http://www.spotlightstranscom.de/images/lessing_gotthold_ ephraim-1.jpg

Abbildung 27: Lessing Denkmal auf dem Hamburger Gänsemarkt.

Enthüllung $1881 \mid 109$

http://sv.wikipedia.org/wiki/Fil:Pincerno_-_Lessing_1881.jpg

Abbildung 28: Georg und Reinhold Forster | 114 http://projects.prm.ox.ac.uk/forster/images/med/Forster_105. jpg 
Abbildung 29: Georg Forster $1784 \mid 118$

http://www.humboldt-portal.de/mediaarchiv/grab_pic_chris. php?id=9727

Abbildung 30: Menschenrassen | 123

http://www.presse.uni-wuerzburg.de/uploads/RTEmagicC -41schulwandbild.jpg.jpg

Abbildung 31: Der Patriot 1737 | 133

http://www.kettererkunst.de/kunst/kd/details.php?obnr $=410$ 706585\&anummer $=340$

Abbildung 32: Noth und Hilfsbüchlein $1788 \mid 138$

http://www.buchfreund.de/covers/13203/9511.jpg

Abbildung 33: Medienkonsum in den alten Bundesländern 1977, 1992 und in Deutschland 2005 | 141

http://de.wikipedia.org/wiki/Mediennutzung

Abbildung 34: Wissenschaftssendungen im Fernsehen (Stand 8/2010) | 142 eigene Zusammenstellung

Abbildung 35: Johann Heinrich Campe | 145

http://www.rousseau-emile.wg.am/JH-Campe.JPG

Abbildung 36: Campe Robinson (Erstdruck 1779) | 146

http://www.ub.tu-dortmund.de/images/Campe-Titel.jpg

Abbildung 37: Francisco de Goya (1746-1828), Der Schlaf (Traum) der Vernunft bringt Ungeheuer hervor $\mid 152$

http://www.wesleyan.edu/dac/imag/1946/ooD1/o040/1946-

D1-40-0043-mo1.jpg

Abbildung 38: Dialektik der Aufklärung« 1947 | 153

http://www.ifs.uni-frankfurt.de/image/dialektik_d_a.jpg

Abbildung 39: Horkheimer/Adorno | 155

http://upload.wikimedia.org/wikipedia/commons/c/c3/Adorno HorkheimerHabermasbyJeremyJShapiro2.png

Abbildung 40: Michel Foucault $\mid 156$

http://info.kopp-verlag.de/data/image/Wang_Xin_Long/2010o6/Gender\%2oMainstreaming\%2oWoher\%2okommt\%2o eigentlich\%2oder\%2oWahnsinn/Gender-foucault.jpg

Abbildung 41: Oskar Negt | 167

http://www.philosophietage.ch/_upl/files/Negt.jpg

Abbildung 42: Pierre Bourdieu | 175

http://www.balam-ix.com/wp-content/uploads/2009/11/bour dieu1.jpg 



\section{Literaturverzeichnis}

Baasner, Rainer: Einführung in die Literatur der Aufklärung. Darmstadt 2006

Bahr, Ehrhard (Hg.): Was ist Aufklärung? Thesen und Definitionen. Stuttgart 2004

Barz, Heiner/Tippelt, Rudolf: Weiterbildung und soziale Milieus in Deutschland. 2 Bde. Bielefeld 2004

Becker, Rudolf Zacharias: Beantwortung der Frage: »Kann irgend eine Art von Täuschung dem Volke zuträglich sein, sie bestehe nun darinn, dass man es zu neuen Irrthümern verleitet, oder die alten eingewurzelten fortdauern läßt?« Leipzig 1781

Becker, Rudolf Zacharias: Versuch über die Aufklärung des Landmannes. Dessau/Leipzig 1785

Becker, Rudolph Zacharias: Noth- und Hülfsbüchlein für Bauersleute. Nachdruck der Erstausgabe von 1788 Dortmund 1980

Behringer, Wolfgang: Wissenschaft im Kampf gegen den Aberglauben. In: Dülmen, R. van/Rauschenbach 2004. 365-389

Bödecker, Hans Erich/Herrmann, Ulrich: Über den Prozess der Aufklärung in Deutschland. Göttingen 1987

Bödeker, Hans Erich/Herrmann, Ulrich: Aufklärung als Politisierung - Politisierung der Aufklärung. Hamburg 1987

Böning, Holger: Der »gemeine Mann« als Adressat aufklärerischen Gedankengutes. Ein Forschungsbericht zur Volksaufklärung. In: Das Achtzehnte Jahrhundert 1988. 52-88

Böning, Holger: Bibliographie zur Volksaufklärung. In: Das Achtzehnte Jahrhundert. Mitteilungen der Deutschen Gesellschaft für die Erforschung des 18. Jahrhunderts. Wolfenbüttel 1989. H. 1. 67-80

Böning, Holger: Volksaufklärung. In: Lexikon der Aufklärung. Deutschland und Europa. Hg. v. Werner Schneiders. München 1995, 434-437

Böning, Holger: Aufklärung auch für das Volk? Oldenburg 1998

Böning, Holger: Pressewesen und Aufklärung - Intelligenzblätter und Volksaufklärung. In: Döring-Manteufel, S. u.a. (Hg.): Pressewesen der Aufklärung. Berlin 2001. 69-119 
Böning, Holger: Popularaufklärung - Volksaufklärung. In: Dülmen, R. van/ Rauschenbach 2004. 563-581

Böning, Holger: Entgrenzte Aufklärung - Die Entwicklung der Volksaufklärung von der ökonomischen- zur Emanzipationsbewegung. In: Ders./Schmitt, H./Siegert, R. (Hg.): Volksaufklärung. Eine praktische Reformbewegung des 18. und 19. Jahrhunderts. Bremen 2007. 13-50

Böning, Holger/Siegert Reinhart (Hg.): Volksaufklärung. Ausgewählte Schriften. Bd. 1-13. Stuttgart-Bad Cannstatt 1990 ff.

Böning, Holger/Siegert, Reinhart: Volksaufklärung. Biobibliographisches Handbuch zur Popularisierung aufklärerischen Denkens im deutschen Sprachraum von den Anfängen bis 1850. Bd. 1, Bd. 2. Stuttgart/Bad Cannstatt 1990. 2001

Böning, Holger/Schmitt, Hanno/Siegert, Reinhart (Hg.), Volksaufklärung. Eine praktische Reformbewegung des 18. und 19. Jahrhunderts. Bremen 2007

Borgstedt, Angela: Das Zeitalter der Aufklärung. Darmstadt 2004

Bourdieu, Pierre: Die feinen Unterschiede. Frankfurt a.M. 1982

Bourdieu, Pierre: Praktische Vernunft: Zur Theorie des Handelns. Frankfurt a.M. 1998

Bourdieu, Pierre: Für eine neue europäische Aufklärung. In: Utopie konkret (2002) 389-397

Brecht, Bertold: >Kleines Organon für das Theater<., In: Gesammelte Werke 16. Frankfurt a.M. 661-700

Campe, Joachim Heinrich: Über einige verkannte wenigstens ungenützte Mittel Zur Beförderung der Indüstrie, der Bevölkerung und des öffentlichen Wohlstands. Wolfenbüttel 1786

Campe, Joachim Heinrich: Briefe aus Paris zur Zeit der Revolution geschrieben, Braunschweig 1790 In: Historikum-Net www.revolution.historicum. net/quellen/campe/brief_1.html

Campe, Joachim Heinrich: Briefe aus Paris. Berlin 1961

Cassirer, Ernst: Die Philosophie der Aufklärung. Hamburg 1998 (1932)

Conein, Stephanie/Schrader, Josef (Hg.): Erwachsenenbildung und die Popularisierung von Wissenschaft. Bielefeld 2004

Conrad, Anne: Aufgeklärte Elite und aufzuklärendes Volk. In: Dies./Herzig, A./ Kopitzsch, F. (Hg.): Das Volk im Visier der Aufklärung. Studien zur Popularisierung der Aufklärung im späten 18. Jahrhundert. Hamburg 1998. 1-15

Daum, Andreas: Wissenschaftspopularisierung im 19. Jahrhundert. München 2002

Deleuze, Giles/Guattari, Felix: Rhizom. Berlin 1977

Diderot, Denis: Enzyklopädie. Eine Auswahl. Leipzig 1972

Diderot, Denis: Ausgewählte Werke. Berlin 1984 
Diderot, Denis: Philosophische Schriften. Wahrendorf 2003 Dräger, Horst (Hg.): Volksbildung in Deutschland im 19. Jahrhundert. Bd.1. Braunschweig 1979

Drews, Wolfgang: Lessing. Reinbek 1962

Dülmen, Richard van/Rauschenbach, Sina (Hg.): Macht des Wissens. Köln 2004

Dülmen, Richard van: Die Aufklärungsgesellschaften in Deutschland als Forschungsproblem In: Francia (1977) München 1978. 251-275

Dülmen, Richard van: Die Gesellschaft der Aufklärer. Zur bürgerlichen Emanzipation und aufklärerischen Kultur in Deutschland. Frankfurt a.M. 1986

Engelsing, Rolf: Kleine Wirtschafts- und Sozialgeschichte Deutschlands. Hannover 1968

Engelsing, Rolf: Analphabetentum und Lektüre. Stuttgart 1973

Engelsing, Rolf: Der Bürger als Leser, Lesergeschichte in Deutschland 15001800. Stuttgart 1974

Enskat, Rainer: Bedingungen der Aufklärung. Philosophische Untersuchungen zu einer Aufgabe der Urteilskraft. Weilerswist 2008

Enzensberger, Ulrich: Georg Forster. Weltumsegler und Revolutionär. Berlin 1979

Ewald, Johann Ludwig: Über Volksaufklärung, ihre Grenzen und Vorteile. Berlin 1790

Faulstich, Peter: Erwachsenenbildung und Hochschule. München 1982

Faulstich, Peter: »Vielfältiger Gewinn. (Plädoyer für einen konzeptionell geklärten Pragmatismus beim Wissenschaftstransfer.)«. In: Deutsche Universitätszeitschrift (1995) H. 11, E1-E4

Faulstich, Peter: Vermittler wissenschaftlichen Wissens. Biographien von Pionieren öffentlicher Wissenschaft. Bielefeld 2008

Faulstich, Peter (Hg.): Öffentliche Wissenschaft - Neue Perspektiven der Vermittlung in der wissenschaftlichen Weiterbildung. Bielefeld 2006

Faulstich, Peter/Zeuner, Christine: Erwachsenenbildung und soziales Engagement. Bielefeld 2001

Faulstich, Peter/Zeuner, Christine: Erwachsenenbildung - Resultate der Forschung. Weinheim 2010

Forster Georg: Reise um die Welt. Frankfurt a.M. 1784. 2007

Forster, Georg: Werke in zwei Bänden. Berlin 1968

Forster, Georg: Werke in vier Bänden, hg. von Gerhard Steiner. Leipzig 19671971

Forster, Georg: Parisische Umrisse. www.zeno.org/Literatur/M/Forster,+Georg/ Essays+und+Reden/Parisische+Umrisse, Zugriff 20.4.2011

Foucault, Michel: Die Ordnung der Dinge. Frankfurt a.M. 1971

Foucault, Michel: Archäologie des Wissens. Frankfurt a.M. 1981 
Foucault, Michel: Was ist Aufklärung? In: Erdmann, E.: u.a. (Hg.): Ethos der Moderne. Frankfurt a.M. 35-54

Götze, Walter: Die Begründung der Volksbildung in der Aufklärung. Langensalza 1932

Garve, Christian: Über den Charakter des Bauern und ihr Verhältniß gegen die Gutsherrn und gegen die Regierung. Frankfurt und Leipzig 1790

Garve, Christian: Von der Popularität des Vortrages. In: Vermischte Aufsätze, welche einzeln oder in Zeitschriften erschienen sind. Neuherausgegeben und verbessert von Christian Garve. Erster Theil. Breslau 1796. 331-358. Repr. Nachdr. Wölfel, K. (Hg.): Christian Garve, Gesammelte Werke. Erste Abteilung: Die Aufsatzsammlungen, Bd. IV, Teil 1 und 2, Hildesheim/Zürich/New York 1985

Gerhards, Jürgen/Neidhardt, Friedhelm: »Strukturen und Funktionen moderner Öffentlichkeit« . In: Müller-Doohn, S./Neumann-Braun, K. (Hg.): Öffentlichkeit, Kultur, Massenkommunikation, Oldenburg 1991, 31-89

Greif, Stefan: Georg Forsters >revolutionäre< Bildungstheorie. In: Aufenanger u.a. (Hg.): Bildung in der Demokratie. Opladen 2010. 39-53

Greiling, Johann Christoph: Theorie der Popularität. Neudruck der Ausgabe Magdeburg: Georg Christian Keil 185 mit einem Nachwort von Holger Böning. Stuttgart-Bad Cannstatt 2001

Habel, Thomas: Gelehrte Journale und Zeitungen der Aufklärung: Zur Entstehung, Entwicklung und Erschliessung deutschsprachiger Rezensionszeitschriften des 18. Jahrhunderts. Bremen 2007

Habermas, Jürgen: Strukturwandel der Öffentlichkeit. Neuwied 1962

Hammerstein, Notker: Die deutschen Universitäten im Zeitalter der Aufklärung. In: ZHF (1983) 73-89

Harpprecht, Klaus: Georg Forster oder Die Liebe zur Welt. Eine Biographie. Reinbek 1987

Harpprecht, Klaus: Ein Fremder namens Forster. In: Die Zeit 7.2.1994. 38

Heine, Heinrich: Sämtliche Schriften. Bd. 5. Frankfurt a.M. 1981

Henning, Friedrich-Wilhelm: Das vorindustrielle Deutschland 800-1800. Paderborn 1974

Hering, Sabine u.a. (Hg.): Wegweiser. Die politische Erwachsenenbildung nach dem Kriege. Bonn 1992

Herrmann, Ulrich (Hg.): »Das pädagogische Jahrhundert« Weinheim und Basel 1981

Herrmann, Ulrich (Hg.): Über den Prozeß der Aufklärung in Deutschland im 18. Jahrhundert. Göttingen 1987

Heydorn, Heinz H.: Über den Widerspruch von Bildung und Herrschaft. Frankfurt a.M. 1970

Hildebrandt, Dieter: Lessing. Biographie einer Emanzipation. Frankfurt a.M. 1982 
Hinrichs, Ernst: Zur Erforschung der Alphabetisierung in Nordwestdeutschland in der Frühen Neuzeit. In: Das Volk im Visier der Aufklärung. Studien zur Popularisierung der Aufklärung im späten 18. Jahrhundert. Hg. v. Anne Conrad, Arno Herzig und Franklin Kopitzsch. Hamburg 1998 (= Veröffentlichungen des Hamburger Arbeitskreises für Regionalgeschichte 1) 35-56.

Hinske, Norbert/Specht, Rainer (Hg.): Die Philosophie der deutschen Aufklärung. Stuttgart 1990

Horkheimer, Max: Traditionelle und Kritische Theorie. In: ZfS (1937) 245-294

Horkheimer, Max/Adorno, Theodor W.: Die Dialektik der Aufklärung. Frankfurt a.M. 1969

Jens, Walter: In Sachen Lessing. Vorträge und Essays. Stuttgart 1983

Kant, Immanuel: Theorie-Werkausgabe. Werke in zwölf Bänden. Frankfurt a.M. 1969

Kelchner, Ernst: Becker. In: Allgemeine Deutsche Biographie (ADB). Band 2. Leipzig 1875. 228.

Knopf, Jan: Kalender. In: Fischer, E./Haefs, W./Mix, Y.-G. (Hg.): Von Almanach bis Zeitung. Ein Handbuch der Medien in Deutschland 1700-1800. München 1999. 121-136

Kohlfeldt, Christian: Die gemeinnützig-ökonomische Aufklärung als Wegbereiterin für die Volksaufklärung. In: Volksaufklärung. Eine praktische Reformbewegung des 18. und 19. Jahrhunderts. Hg. v. Holger Böning, Hanno Schmitt und Reinhart Siegert. Bremen 2007 (= Presse und Geschichte Neue Beiträge 27) 127-139

Körber, Esther-Beate: Die Zeit der Aufklärung. Stuttgart 2006

Koselleck, Reinhart: Kritik und Krise- Frankfurt a.M. 1973

Kraus, Werner: Über die Konstellation der Aufklärung in Deutschland. In: Sinn und Form (1961) 65-100

Krockow, Christian Graf von: Der große Traum von Bildung. Auf den Spuren der großen Entdeckungsreisenden James Cook und Georg Forster. Berlin 2005

Lenzen, Dieter: Lösen die Begriffe Selbstorganisation, Autopoiesis und Emergenz den Bildungsbegriff ab? In: Zeitschrift für Pädagogik (1997) 949-967

Lessing, Gotthold Ephrahim: Werke in sechs Bänden. Leipzig o.J.

Liebknecht, Wilhelm: Wissen ist Macht - Macht ist Wissen. Berlin 1968

Lohmann, Ingrid: Über die Anfänge bürgerlicher Gesprächskultur. Moses Mendelssohn (1729-1786) und die Berliner Aufklärung. In: Pädagogische Rundschau (1992) H. 1, 35-49

Lorenzen, Arnold D.: Philosophie in der Erwachsenenbildung. Göttingen 1986 Ludewig, Johann: Der Gelehrte Bauer. Mit D. Christian Gotthold Hoffmanns Vorbericht. Neudruck der ersten Ausgabe Dresden 1756. Mit einem Nachwort von Holger Böning. Stuttgart-Bad Cannstatt 1992 
Mahlerwein, Gunter: Wandlungen dörflicher Kommunikation im späten 18. und in der ersten Hälfte des 19. Jahrhunderts. In: Kommunikation in der ländlichen Gesellschaft vom Mittelalter bis zur Moderne. Hg. v. Werner Rösener. Göttingen 2000 (= Veröffentlichungen des Max-Planck-Instituts für Geschichte 156), 345-364

Mann, Thomas: Reden über Lessing 1929. In: Appell an die Vernunft. Frankfurt a.M. 1994

Mehring, Franz: Die Lessing Legende. GX 9. Berlin 1983

Meissner, Kurt: Die dritte Aufklärung. Braunschweig 1969

Meissner, Kurt: Bildung als permanente Aktualität. Bad Heilbrunn 1985

Meissner, Kurt: Vom Menschen aus. Frankfurt a.M. 1995

Mendelssohn, Moses: Über die Frage: Was heißt Aufklären? In: Bahr 2004. 3-8 Möller, Horst: Vernunft und Kritik. Deutsche Aufklärung im 17. und 18. Jahrhundert. Frankfurt a.M. 1986

Moritz, Karl Philipp: Anton Reiser. Frankfurt a.M. 1979 (1775-1790)

Müller, Winfried: Die Aufklärung. München 2002

Negt, Oskar: Der politische Mensch. Demokratie als Lebensform. Göttingen 2010

Niemeyer, Beatrix: Ausschluss oder Aufklärung? Frauen im Umkreis der Universitäten im 18. Jahrhundert. In: Kleinau, E./Opitz, C. (Hg.): Geschichte der Mädchen und Frauenbildung. Bd.1. Frankfurt a.M. 1996. 275-294

Nisbet, Hugh Barr: Lessing. Eine Biographie. München 2008

Overhoff, Jürgen: Die Trümmer der Bastille. Zeuge des historischen Augenblicks: Wie der deutsche Pädagoge und Verleger Joachim Heinrich Campe das Paris der Revolution erlebte. Zeit-Online: http://www.zeit.de/2008/29/ A-Campe?page=all\&print=true, Zugriff 20.4.11.

Porter, Roy: Kleine Geschichte der Aufklärung. Berlin 1991

Prange, Hans-Werner: Sozialgeschichte des Hochschulwesens. München 1979. Prinz, Alois: Die Lebensgeschichte des Georg Forster. Frankfurt a.M./Leipzig. 2008

Pütz, Peter: Die deutsche Aufklärung. Darmstadt 1991

Reed, Terence J.: Mehr Licht in Deutschland. Eine kleine Geschichte der Aufklärung. München 2009

Reemtsma, Jan Philipp: Widerspruch und Fortsetzung. In: Basaure, M./Reemtsma, J. P./Willig; R. (Hg.) Erneuerung der Kritik. Frankfurt a.M. 209. 11-18

Ridder, Christa-Maria/Engel, Bernhard: Massenkommunikation 2005: Images und Funktionen der Massenmedien im Vergleich. In: media perspektiven 9/2000, 422-448

Rousseau, Jean-Jaques: Emile. Düsseldorf 1997

Schalk, F.: Aufklärung. In: Ritter, J. (Hg.): Historisches Wörterbuch der Philosophie. Basel/Stuttgart Bd 1. 1971. 620-634 
Schenda, Rudolf: Alphabetisierung und Literarisierungsprozesse in Westeuropa im 18. und 19. Jahrhundert. In: Herrmann 1981. 154-167

Schenda, Rudolf: Volk ohne Buch. Studien zur Sozialgeschichte der populären Lesestoffe 1770-1910. Frankfurt a.M. 1970. (auch: München: dtv 1977).

Schindling, Anton: Bildung und Wissenschaft in der frühen Neuzeit 1650-1800. München 1999

Schmale, Wolfgang/Dodde, Nan L. (Hg.): Revolution des Wissens? Europa und seine Schulen im Zeitalter der Aufklärung (1750-1825). Bochum 1991

Schmied-Kowarzik, Wolfdietrich: Georg Forster. Kasseler Universitätsreden. Kassel: Gesamthochschul-Bibliothek 1988

Schmitt, Hanno (Hg.): Briefe von und an Joachim Heinrich Campe. Bd. 1: Briefe von 1766-1788. Wiesbaden 1996

Schmitt, Hanno (Hg.): Visionäre Lebensklugheit: Joachim Heinrich Campe in seiner Zeit (1746-1818). (Ausstellung des Braunschweigischen Landesmuseums und der Herzog August Bibliothek Wolfenbüttel vom 29. Juni bis 13. Oktober 1996) Wiesbaden 1996

Schmitt, Hanno: Joachim Heinrich Campes Reise ins revolutionäre Paris (1789). In: Die Deutsche Schule (1989) 90-102

Schmitt, Hanno: Der andere Campe. In: Die Deutsche Schule (1997) 25-35

Schmitt, Hanno (Hg.): Vernunft fürs Volk. Friedrich Eberhard von Rochow 17341805 im Aufbruch Preußens. Berlin 2001

Schmitt, H./Lindemann-Stark, A./Losfeld, Chr. (Hg.): Briefe von und an Joachim Heinrich Campe. Bd. 2: Briefe von 1789-1814. Wiesbaden 2007

Schneider, Ulrich Johannes: Foucault und die Aufklärung. In: Das 18. Jahrhundert (1999) 13-25

Schneiders, Werner: Die wahre Aufklärung. Frankfurt a.M. 1974

Schneiders, Werner: Das Zeitalter der Aufklärung. München 1997

Schneiders, Werner: Einleitung. Das Zeitalter der Aufklärung. In: Schneiders, W. (Hg.): Lexikon der Aufklärung. Deutschland und Europa. München 1995. 9-23

Siegert, Reinhard: Aufklärung und Volkslektüre. Exemplarisch dargestellt an Rudolph Zacharias Becker und seinem »Noth- und Hülfsbüchlein«. Mit einer Bibliographie zum Gesamtthema. Buchhändlervereinigung. Frankfurt a.M. 1978

Siegert, Reinhart: Der »gemeine Mann« und die Welt der Bücher um 180o. In: Jahrbuch für Kommunikationsgeschichte (JbKG), Bd.4. Wiesbaden 2002. 32-51

Siegert, Reinhart: Die Lesegewohnheiten des »gemeinen Mannes« um 1800 und die Anfänge von Volksbibliotheken. In: Internationales Archiv für Sozialgeschichte der deutschen Literatur (IASL). Sonderheft 8: Literatur, Politik und soziale Prozesse. Studien zur deutschen Literatur von der Aufklärung bis zur Weimarer Republik. Tübingen 1997. 40-61 
Siegert, Reinhart: Medien der Volksaufklärung. In: Von Almanach bis Zeitung. Ein Handbuch der Medien in Deutschland 1700-1800. Hg. v. Ernst Fischer, Wilhelm Haefs und York-Gothart Mix. München 1999. 374-387

Siegert, Reinhart: Nachwort. In: Rudolph Zacharias Becker: Noth- und Hülfsbüchlein für Bauersleute. Nachdruck der Erstausgabe von 1788. Herausgegeben und mit einem Nachwort versehen von Reinhart Siegert. Dortmund 1980. 461-499

Siegert, Reinhart: Rudolph Zacharias Becker - Der »Erfinder der Publizität« und sein Einsatz für die Volksaufklärung. In: Volksaufklärung. Eine praktische Reformbewegung des 18. und 19. Jahrhunderts. Hg. v. Holger Böning, Hanno Schmitt und Reinhart Siegert. Bremen 2007 (= Presse und Geschichte - Neue Beiträge 27) 141-161

Siegert, Reinhart: Volk/Gemeiner Mann/Pöbel. In: Lexikon der Aufklärung. Deutschland und Europa. Hg. v. Werner Schneiders. München 1995. 432434

Siegert, Reinhart: Volksbildung im 18. Jahrhundert. In: Hammerstein, N./Hermann. U. (Hg.): Handbuch der deutschen Bildungsgeschichte II: 18. Jahrhundert. München 2005. 443-483

Siegert, Reinhart: Zum Stellenwert der Alphabetisierung in der deutschen Volksaufklärung. In: Goetsch, Paul (Hg.): Lesen und Schreiben im 17. und 18. Jahrhundert. Tübingen 1994. 109-124

Stegbauer, Christian: Wikipedia: Das Rätsel der Kooperation. Wiesbaden 2009 Stollberg-Rilinger, Barbara: Europa im Jahrhundert der Aufklärung. Stuttgart 2000

Strzelewicz, Willy: Die Grenzen der Wissenschaft bei Max Weber, Frankfurt a.M. 1931. Teildruck Frankfurt a.M. 1934

Strzelewicz, Willy: Der Kampf um die Menschenrechte. Hamburg 1947, 1948 Frankfurt a.M. 1968

Strzelewicz, Willy: Hochschulen des Volkes. Der Göttinger Versuch. In: Offene Welt 1956, 457-459

Strzelewicz, Willy: Industrialisierung und Demokratisierung in der modernen Gesellschaft. Hannover 1958 a

Strzelewicz, Willy: Die Göttinger Seminarkurse. In: Volkshochschule im Westen (1958) 162-164 b

Strzelewicz, Willy: Seminarkurse. Die Mitarbeit der Universität an der Erwachsenenbildung. Göttingen 1959

Strzelewicz, Willy: Demokratisierung und Erwachsenenbildung. Braunschweig 1973

Strzelewicz, Willy u.a.: Aufklärung in der Demokratie. 30 Jahre Seminarkurse. Göttingen 1986 a 
Strzelewicz, Willy: Popularisierung in der Erwachsenenbildung als soziokulturelles Problem. In: Ruprecht, H./Sitzmann, G.-H. (Hg.): Erwachsenenbildung als Wissenschaft. Weltenburg 1986 b

Strzelewicz, Wily: Erwachsenenbildung und ihre sozialhistorische Bedeutung. In: Bildungszentrum Jagdschloss Göhrde (Hg.) 40 Jahre Göhrde. Göhrde $1986 \mathrm{c}$

Stucke, Horst: Aufklärung. In: Brunner, O. u.a. (Hg.): Geschichtliche Grundbegriffe. Stuttgart 1972. 243-342

Tenorth, Heinz-Elmar: »Bildung « - Thematisierungsformen und Bedeutung in der Erziehungswissenschaft. In: Zeitschrift für Pädagogik (1997) 969-984

Tietgens, Hans: Ein Leben für die Aufklärung. pas-arbeitspapier 105-12.86. Frankfurt a.M. 1986

Tölle, Ursula: Rudolf Zacharias Becker. Münster 1994

Trossbach, Werner: Bauern 1648-1806. München 1993

Ulbricht, Otto: Englische Landwirtschaft in Kurhannover in der zweiten Hälfte des 18. Jahrhunderts. Ansätze zu historischer Diffusionsforschung. Berlin 1980 (= Schriften zur Wirtschafts- und Sozialgeschichte 32)

Vierhaus, Rudolf (Hg.): Wissenschaften im Zeitalter der Aufklärung. Göttingen 1985

Vierhaus, Rudolf: Deutschland im 18.Jahrhundert: soziales Gefüge, politische Verfassung, geistige Bewegung. In: Herrmann 1981. 15-28

Vierhaus, Rudolf: Die Erforschung des 18. Jahrhunderts. Aktivitäten - Desiderate - Defizite. In: Das 18. Jahrhundert (1995) 158-162

Wehrmann, Volker: Volksaufklärung. In: Herrmann 1981. 143-153

Weingart, Peter: Wissenschaftssoziologie. Bielefeld 2003

Wittmann, Reinhart: Buchmarkt und Lektüre im 18. und 19. Jahrhundert. Beiträge zum literarischen Leben 1750-1880. Tübingen 1982 Zentralstelle für Weiterbildung der Georg-August-Universität: 30 Jahre Zentralstelle für Weiterbildung: Professor Willy Strzelewicz zum 8o. Geburtstag. Göttingen 1985

Zerrenner, Heinrich Gottlieb: Volksaufklärung. Uebersicht und freimüthige Darstellung ihrer Hindernisse nebst einigen Vorschlägen denselben wirksam abzuhelfen. Neudruck mit einem Nachwort von Reinhart Siegert. Stuttgart-Bad Cannstatt 2001 


\section{Theorie Bilden}

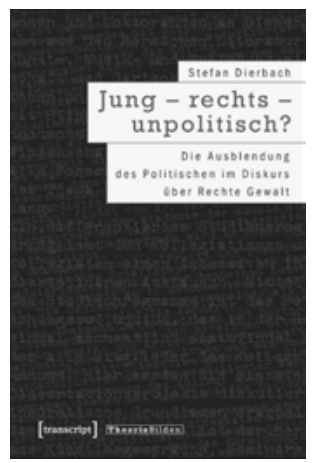

Stefan Dierbach

Jung - rechts - unpolitisch?

Die Ausblendung des Politischen im Diskurs

über Rechte Gewalt

20I0, 298 Seiten, kart., $29,80 €$,

ISBN 978-3-8376-I468-8

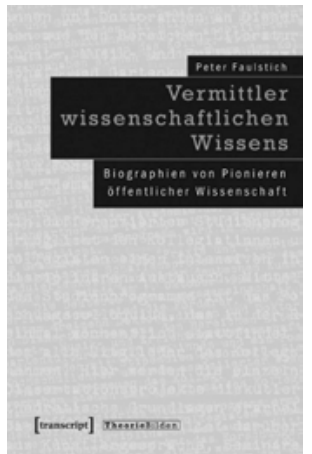

Peter Faulstich

Vermittler wissenschaftlichen Wissens

Biographien von Pionieren öffentlicher

Wissenschaft

2008, I96 Seiten, kart., 19,80€,

ISBN 978-3-89942-878-0

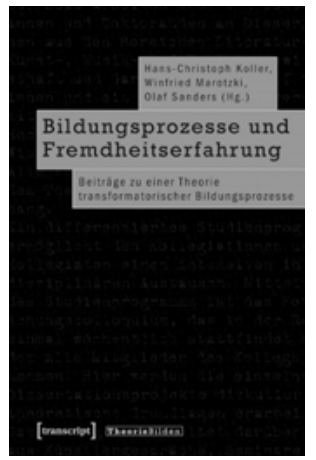

Hans-Christoph Koller, Winfried Marotzki, Olaf SAnders (Hg.)

Bildungsprozesse und Fremdheitserfahrung Beiträge zu einer Theorie transformatorischer Bildungsprozesse

2007, 260 Seiten, kart., 25,80€, ISBN 978-3-89942-588-8 


\section{Theorie Bilden}

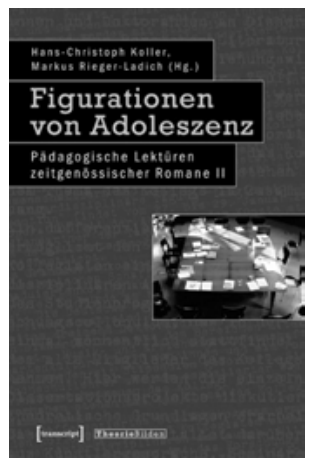

HANS-Christoph Koller, Markus Rieger-Ladich (Hg.)

Figurationen von Adoleszenz

Pädagogische Lektüren zeitgenössischer Romane II

2009, 216 Seiten, kart., 25,80€,

ISBN 978-3-8376--1025-3

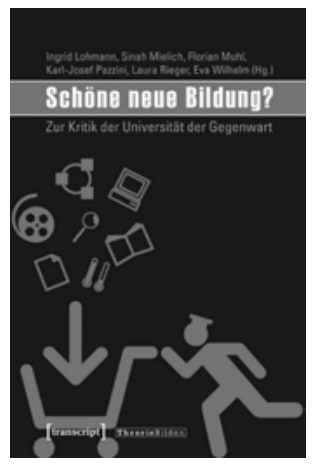

Ingrid Lohmann, Sinah Mielich, Florian Muhl, Karl-Josef PaZzini, Laura Rieger, Eva Wilhelm (Hg.)

Schöne neue Bildung?

Zur Kritik der Universität der Gegenwart

Mai 20II, 242 Seiten, kart., zahlr. Abb., 25,80€, ISBN 978-3-8376-I75I-I

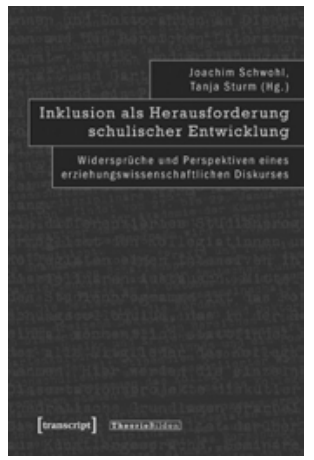

Joachim Schwohl, Tanja Sturm (Hg.) Inklusion als Herausforderung schulischer Entwicklung

Widersprüche und Perspektiven eines erziehungswissenschaftlichen Diskurses

20Io, 364 Seiten, kart., zahlr. z.T. farb. Abb., $32,80 €$, ISBN 978-3-8376-I490-9 


\section{Theorie Bilden}

Sönke Ahrens

Experiment und Exploration

Bildung als experimentelle Form

der Welterschließung

20I0, 330 Seiten, kart., 29,80€,

ISBN 978-3-8376-1654-5

\section{FRANK ELSTER}

Der Arbeitskraftunternehmer und seine Bildung

Zur (berufs-)pädagogischen Sicht auf die Paradoxien subjektivierter Arbeit 2007, 362 Seiten, kart., 31, $80 €$,

ISBN 978-3-89942-79I-2

Werner Friedrichs

Passagen der Pädagogik

Zur Fassung des pädagogischen

Moments im Anschluss an

Niklas Luhmann und Gilles Deleuze

2008, 306 Seiten, kart., 32,80€,

ISBN 978-3-89942-846-9

KATHRIN HaHN

Alter, Migration und Soziale Arbeit

Zur Bedeutung von Ethnizität in

Beratungsgesprächen der Altenhilfe

Juli 201 I, ca. 342 Seiten, kart., ca. $33,80 €$,

ISBN 978-3-8376-1680-4

JENNY LÜDERS

Ambivalente Selbstpraktiken

Eine Foucault'sche Perspektive auf Bildungsprozesse in Weblogs

2007, 280 Seiten, kart., $28,80 €$,

ISBN 978-3-89942-599-4

Stephanie Maxim

Wissen und Geschlecht

Zur Problematik der Reifizierung

der Zweigeschlechtlichkeit in der

feministischen Schulkritik

2009, 306 Seiten, kart., 29,80€,

ISBN 978-3-8376-I030-7
Torsten Meyer,

Andrea Sabisch (Hg.)

Kunst Pädagogik Forschung

Aktuelle Zugänge und Perspektiven

2009, 276 Seiten, kart., zahlr. Abb., 28,80€,

ISBN 978-3-8376-1058-I

Karl-Josef Pazzini,

Marianne SCHUller,

Michael Wimmer (Hg.)

Lehren bildet?

Vom Rätsel unserer Lehranstalten 20Iо, 338 Seiten, kart., 29,80€,

ISBN 978-3-8376-II76-2

FLORIAN VON ROSENBERG

Bildung und Habitustransformation

Empirische Rekonstruktionen und

bildungstheoretische Reflexionen

Juni 20II, 352 Seiten, kart., $34,80 €$,

ISBN 978-3-8376-I6I9-4

AndRea SABISCH

Inszenierung der Suche

Vom Sichtbarwerden ästhetischer

Erfahrung im Tagebuch. Entwurf

einer wissenschaftskritischen

Grafieforschung

2007, 290 Seiten, kart., 31,80€,

ISBN 978-3-89942-656-4

Simone Tosana

Bildungsgang, Habitus und Feld

Eine Untersuchung zu den

Statuspassagen Erwachsener

mit Hauptschulabschluss

am Abendgymnasium

2008, 276 Seiten, kart., $27,80 €$,

ISBN 978-3-89942-798-I

Katharina Willems

Schulische Fachkulturen

und Geschlecht

Physik und Deutsch -

natürliche Gegenpole?

2007, 314 Seiten, kart., 30,80€,

ISBN 978-3-89942-688-5 